\title{
Photocatalytic Oxidation and Reduction Chemistry and a New Process for Treatment of Pink Water and Related Contaminated Water
}

\author{
Daniel M. Blake \\ Edward Wolfrum \\ James Boulter \\ National Renewable Energy Laboratory \\ Golden, Colorado \\ Michael Prairie \\ Steven Showalter \\ Philip Rodacy \\ Pam Leslie \\ Bertha Stange \\ Sandia National Laboratories \\ Albuquerque, New Mexico

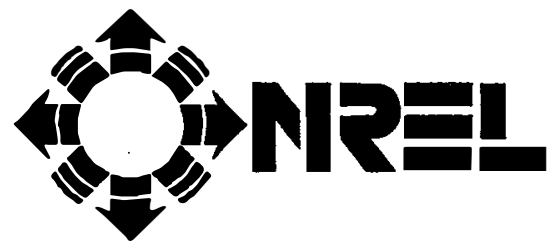 \\ National Renewable Energy Laboratory \\ 1617 Cole Boulevard \\ Golden, Colorado 80401-3393 \\ A national laboratory of the U.S. Department of Energy \\ Managed by Midwest Research Institute \\ for the U.S. Department of Energy \\ under Contract No. DE-AC36-83CH10093
}




\section{Photocatalytic Oxidation and Reduction Chemistry and a New Process for Treatment of Pink Water and Related Contaminated Wâter}

Daniel M. Blake

Edward Wolfrum

James Boulter

National Renewable Energy Laboratory

Golden, Colorado

Michael Prairie

Steven Showalter

Philip Rodacy

Pam Leslie

Bertha Stange

Sandia National Laboratories

Albuquerque, New Mexico

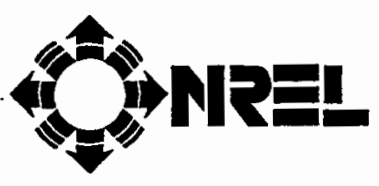

National Renewable Energy Laboratory 1617 Cole Boulevard Golden, Colorado 80401-3393

A national laboratory of the U.S. Department of Energy Managed by Midwest Research Institute for the U.S. Department of Energy under Contract No. DE-AC36-83CH10093

Prepared under Task No. SI613610

October 1996 


\section{NOTICE}

This report was prepared as an account of work sponsored by an agency of the United States government. Neither the United States govermment nor any agency thereof, nor any of their employees, makes any warranty, express or implied, or assumes any legal liability or responsibility for the accuracy, completeness, or usefulness of any information, apparatus, product, or process disclosed, or represents that its use would not infringe privately owned rights. Reference herein to any specific commercial product, process, or service by trade name, trademark, manufacturer, or otherwise does not necessarily constitute or imply its endorsement, recommendation, or favoring by the United States govemment or any agency thereof. The views and opinions of authors expressed herein do not necessarily state or reflect those of the United States government or any agency thereof.

Available to DOE and DOE contractors from:

Office of Scientific and Technical Information (OSTI)

P.O. Box 62

Oak Ridge, TN 37831

Prices available by calling (423) 576-8401

Available to the public from:

National Technical Information Service (NTIS)

U.S. Department of Commerce

5285 Port Royal Road

Springfield, VA 22161

(703) $487-4650$ 


\section{TABLE OF CONTENTS}

Page

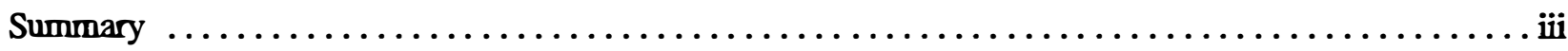

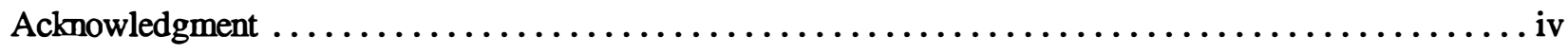

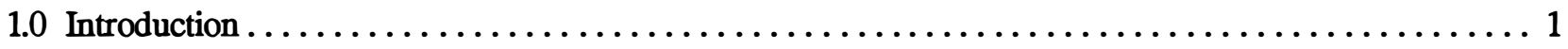

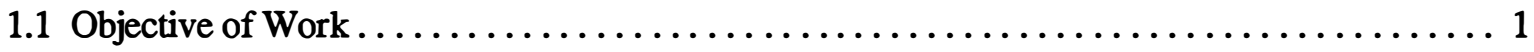

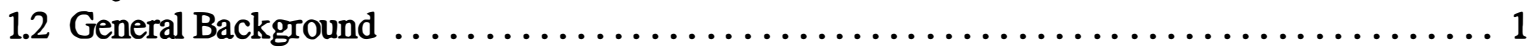

2.0 Photocatalytic Oxidation and Reduction Processes and the Combination of Photocatalytic Reduction with Biological Treatment $\ldots \ldots \ldots \ldots \ldots \ldots \ldots \ldots \ldots \ldots \ldots$

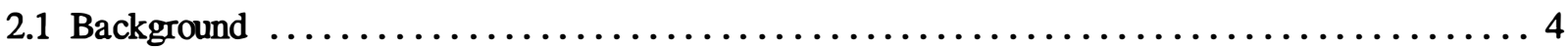

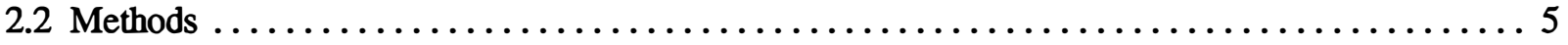

2.2.1 Photocatalytic Process Under Oxidative Conditions ..................... 6

2.2.2 Photocatalytic Chemistry Under Reductive Conditions $\ldots \ldots \ldots \ldots \ldots \ldots \ldots \ldots \ldots$

2.3 Biotreatment after Pretreatment by Photocatalytic Reduction . . . . . . . . . . . . . . . . 14

2.4 Estimated Electrical Power Requirements for Photocatalytic Oxidation or Reduction of TNT ... 15

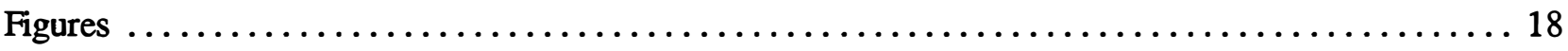

3.0 New Process Chemistry for Removal of TNT and Other HE Compounds from Water ........ 36

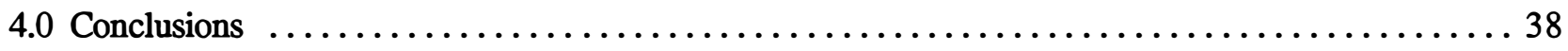

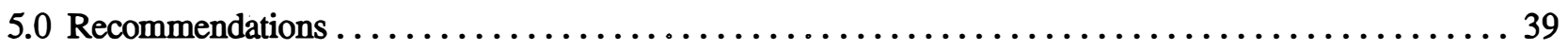

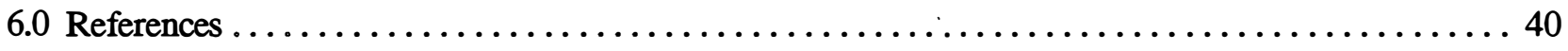

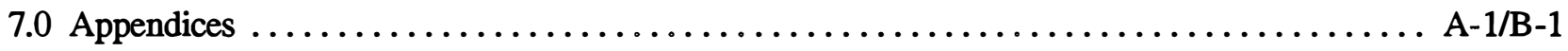

A. Report on Subcontract No. XCK-5-15163-01, "Combined Photocatalytic and Biological Treatment of Pink Water," University of Idaho, Moscow, ID, July 1996. . . . . . . . . . . . A-1

B. Bibliography of work on treatment of pink water and related water contamination. ......... B-1 


\section{Acknowledgment}

Funding for this project, No. 93-349-DOE, was provided by the Strategic Environmental Research and Develop Program (SERDP). 


\section{Summary}

This project was carried out at the National Renewable Energy Laboratory (NREL), Sandia National Laboratory (SNL), and by a group at the University of Idaho (UI) working under subcontract to NREL. Project staff met with engineering and environmental compliance staff at Longhom and Iowa Army Ammunition Plants to become familiar with current pink water treatment technology and requirements. The initial focus was on photocatalytic oxidation and reduction chemistry that could use sunlight as the photon source. This work demonstrated the technical feasibility of the photocatalytic processes; however, the process removed the hazardous components of pink water at such low efficiency that it would be expensive to operate lamps in a treatment system. Technical success in removing trinitrotoluene (TNT) from water by photocatalytic reduction chemistry led us to test that as a pretreatment step for a biological treatment process. The photocatalytic reduction of TNT did render the simulated pink water more amenable to mineralization by Phanerochaete chrysosporium. This result led us to explore other chemistry for removal of TNT and related explosives from water.

The new process that was investigated in this project very effectively removed TNT from pink water. The operating cost is estimated to be about half that of conventional treatment using granular activated carbon (GAC). The capital costs are estimated to be about the same for the new process and GAC treatment. The new process is sufficiently novel to warrant initiating steps that would lead to a patent. Reporting in an open literature document constitutes disclosure. For this reason the details of the new process are being withheld until the novelty and potential for a patent application are determined. Patents resulting from this work will be submitted to the Strategic Environmental Research and Development Program (SERDP) personnel when issued. In this report a general description of the results of work on the new process are presented. The details will be made available to parties willing to sign a non-disclosure agreement with NREL. 


\subsection{Introduction}

\subsection{Objective of Work}

The objective of this project was to develop new photocatalytic or other innovative process chemistry for the treatment of pink water and related contaminated water.

\subsection{General Background}

Pink water is the term applied to waste water from Load, Assemble, and Pack (LAP) operations at Army Ammumition Plants (AAPs) where 2,4,6-trinitrotoluene (TNT) in combination with other explosives is loaded into various munitions. 1,3,5-Trinitro-1,3,5-triazacyclohexane (RDX) and 1,3,5,7-tetranitro-1,3,5,7-tetrazacycloctane ( $\mathrm{HMX}$ ) are used with TNT in the composite explosives.

The abreviation HE will be used to designate high explosives individually or collectively. ${ }^{1}$ The chemical structures of the compounds of interest in this work are shown in Figure 1.1. Water from washing and condensed steam used to melt composite explosives contain low levels of TNT (about $100 \mathrm{ppm}$ ), HMX (about $10 \mathrm{ppm}$ ) and RDX (about $25 \mathrm{ppm}$ ). When exposed to sunlight the water becomes colored owing to the formation of a number of products of photochemical

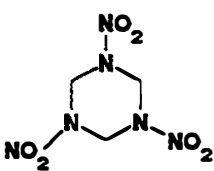

RDX

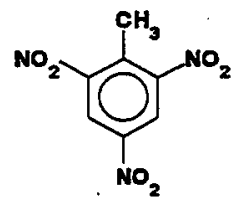

TNT<smiles></smiles>

HMX reactions of TNT. The photochemistry of TNT in water has been elucidated by a number of workers. $23,4,5$

Pink water also arises from cutting and milling operations and during demilitarization of munitions being

Figure 1.1. Structure of HE Compounds Most Commonly Found in Pink Water.

taken out of service, in which the explosive is melted using steam. Contaminated ground water with components like those in pink water is found at AAPs where soil has been contaminated owing to past disposal practices or where waste disposal ponds have leaked into aquifers. Environmental contamination by these compounds is also found at depots and bases within the Department of Defense complex and at some Defense Program sites operated by the Department of Energy. Pink water is considered hazardous because of the toxicity of the original explosive compounds or the presence of other compounds that were by-products of the production process. Dinitrotoluene and trinitrobenzene are examples of such compounds.

The location of AAPs in the United States are shown on the map in Figure 1.2. ${ }^{1}$ Most of the AAPs are in various stages of shut down and environmental clean up activities. Pink water is produced at Iowa, Longhom, and Holston.

The current state of the art for treating pink water at AAPs is adsorption on granulated activated carbon (GAC). The flow diagram for the treatment system in use at Iowa AAP is shown in Figure 1.3. The system as operated meets current discharge standards for TNT, HMX, and RDX of $<1,<5$, and $<5 \mathrm{ppm}$, respectively. Iowa AAP currently produces about 18,000 gal/day of pink water and would produce about 100,000 gal/day at full mobilization. The spent carbon is sent for regeneration and can be recycled about four times before it becomes unusable due to particle size reduction and fragility. ${ }^{6}$ Experience with GAC regeneration and disposal at AAPs was surveyed by A. D. Little, Inc. for the Army. ${ }^{7}$ There is concern that the system at Iowa AAP will not be able to meet lower discharge standards currently under discussion. The new limits would be $600 \mathrm{ppb}$ TNT and $1 \mathrm{ppm}$ for HMX and RDX. 


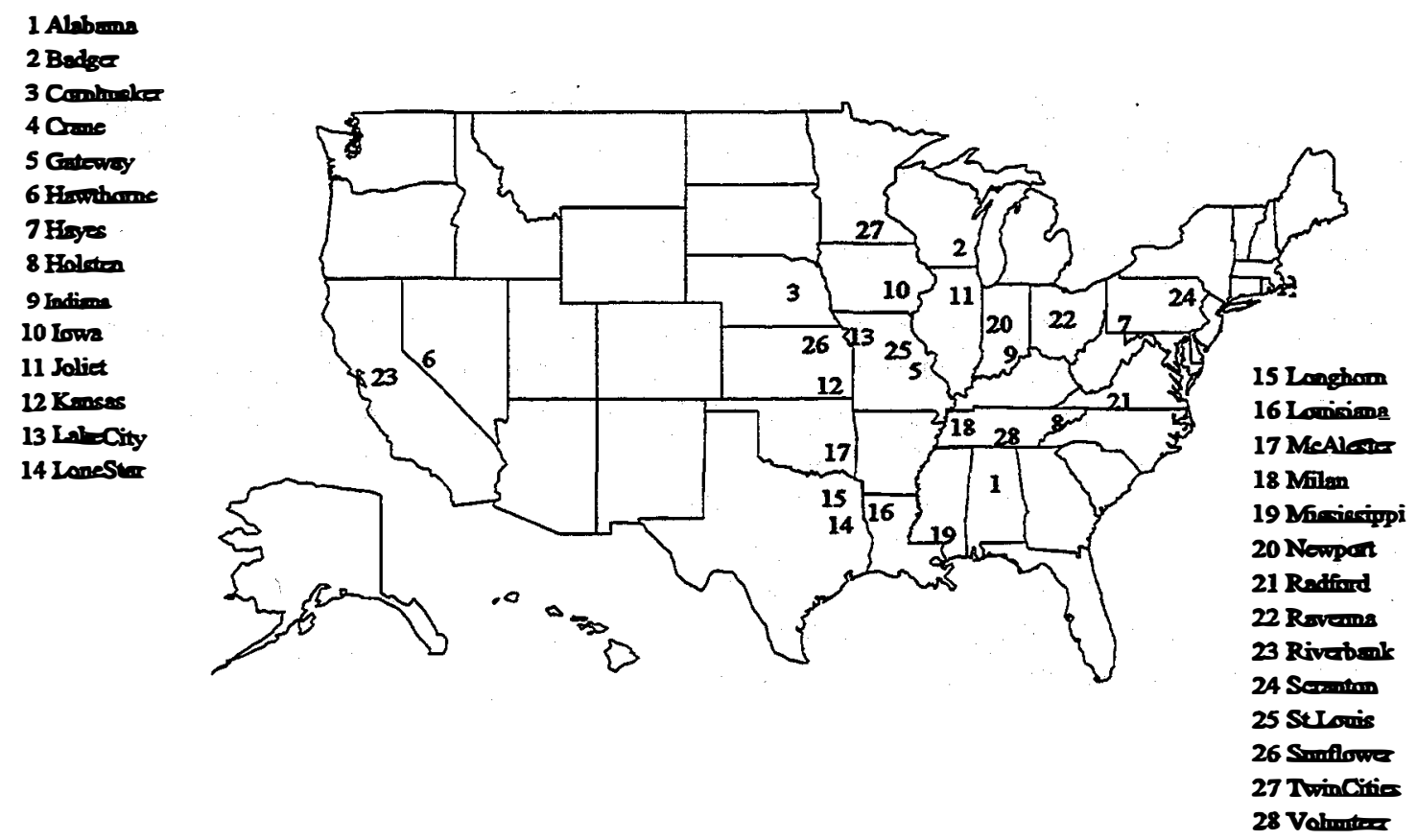

Figure 1.2. Location of Army Ammunition Plants

The ability of GAC treatment to meet proposed or potential discharge standards having lower levels of contaminants has been investigated for the Amny at a bench and pilot scale. The work concluded that GAC would have a problem meeting new discharge standards if they were to be set as low as $300 \mathrm{ppb}$ for TNT and 30 ppb for HMX and RDX as was being discussed for some locations. ${ }^{8}$

The requirement for regeneration and ulimate disposal of contaminated GAC, the associated costs, and potential that the carbon adsorption process might not treat pink water to meet future standards has resulted in a continuing search for new treatment processes.

Advanced oxidation processes have received the most attention among the chemical treatment methods. The common feature of these processes is the involvement of hydroxyl radicals in oxidation. Ultraviolet (UV) light in combination with ozone, $\mathrm{UV}-\mathrm{O}_{3},{ }^{9,10,11}$ and hydrogen peroxide, $\mathrm{UV}-\mathrm{H}_{2} \mathrm{O}_{2},{ }^{12,13,14,15}$ have been studied at laboratory and pilot plant scale. The Fenton reaction $\left(\mathrm{Fe}^{+2} / \mathrm{H}_{2} \mathrm{O}_{2}\right)$ has also been investigated. ${ }^{16,17}$ Heterogeneous photocatalytic oxidation has received some attention and will be discussed in Section 3 in connection with the description of one of the processes being investigated in this project. Other physical or chemical processes that have been studied include use of advanced adsorption materials, ${ }^{18,19}$ surfactant precipitation, ${ }^{20}$ and photosensitized reactions. ${ }^{21}$

Biological treatment of pink water and water having related contaminants has been investigated by number of groups. ${ }^{222324,25}$ Anaerobic biodegradation has been studied at both laboratory and pilot scale. Of concem in the biotreatment processes is the general observation that only a small fraction of carbon-14 labeling incorporated 


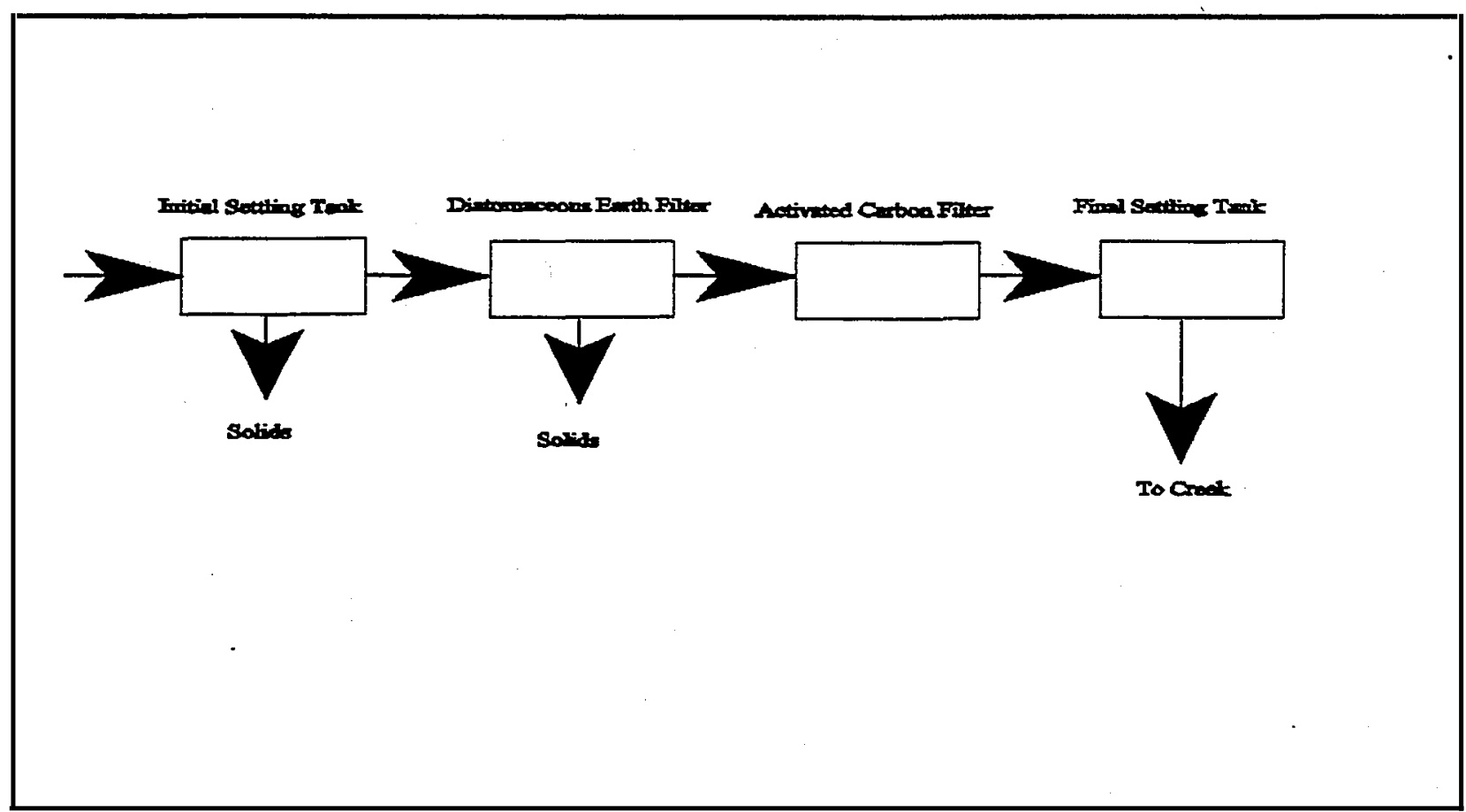

Figure 1.3. Overall Process Flow Diagram for Pink Water Treatment Unit at lowa AAP

into TNT is released as carbon dioxide. This indicates that TNT is converted to other compounds that remain in the water or soil being treated Failure to achieve mineralization and the potential that some of the by-products of biological treatment may be hazardous has been a barrier to adoption of the technology. ${ }^{25}$

Recuction chemisty for purposes of treating pink water has been investigated mainly in the context of biological treatment under anaerobic conditions. However, there is an extensive body of work on reduction of nitro groups in organic compounds for synthetic purposes. ${ }^{25}$ Denitrificarion (removal of nitro groups) of unsymetrical isomers of TNT by reaction with sodium borohydride was investigated as a means of purifying or recycling waste material. ${ }^{27}$ A study of photochemical reactions of sodium borohydride with dinitrotoluenes and related compounds was recently reported. ${ }^{28}$ 


\subsection{Photocatalytic Oxidation and Reduction Processes and the Combination of Photocatalytic Reduction with Biological Treatment}

\subsection{Background}

Heterogeneous photocatalytic chemistry as applied to oxidation is considered to be an advanced oxidation process because as usually applied under aerobic conditions, hydroxyl radicals are believed to be formed. The general reaction scheme for action of a photocatalyst in water is as follows:

Semiconductor $\longrightarrow$ Light, E>Band Gap

The valence band hole functions as an oxidizing agent and the conduction band electron as a reducing agent. The semiconductor absorbs light at all wavelengths having energy greater than the band gap, which is $3.2 \mathrm{eV}(\lambda<$ $385 \mathrm{~nm}$ ) for anatase. This is shown pictorially in Figure 2.1. The reduction potentials of valence and conduction bands depend on the particular semiconductor. Most work done on the application of this chemistry to environmental problems to date is based on titanium dioxide in the anatase form as the photocatalyst. The oxidizing power of the electron hole in $\mathrm{TiO}_{2}$ is sufficient to oxidize water to hydroxyl radical, $\mathrm{OH}$, which then initiates the oxidation of the organic compound. ${ }^{29,30}$ The conduction band electron must be transferred to an oxidizing agent to maintain electroneutrality. The oxidizing agent is usually molecular oxygen or hydrogen peroxide. The net chemical reaction is the oxidation of the target compound by oxygen or hydrogen peroxide. A lesser amount of work has been done in which a sacrificial reducing agent, usually an organic compound, is used as a hole (or $\mathrm{OH}$ ) acceptor and the conduction band Figure 2.1. Oxidation and Reduction on $\mathrm{TiO}_{2}$. electron is used to reduce metal ions for the purpose of

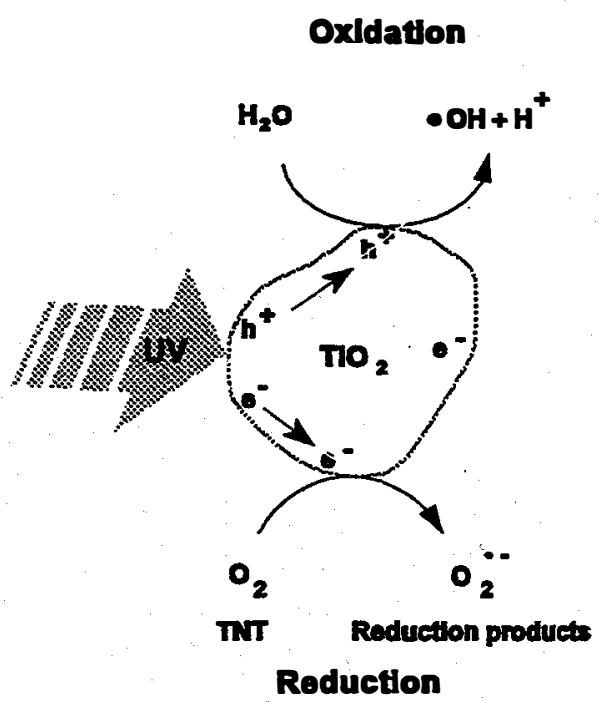

removing them in the elemental form or as a reduced hydroxide precipitate. ${ }^{31}$ Some studies have demonstrated electron transfer from the excited semiconductor particles to dye molecules. The process has been suggested as a method to decolor water contaminated with dyes. ${ }^{32}$

Some work on photocatalytic oxidation of TNT had previously been carried out under aerobic conditions. ${ }^{33,34,35,36,37}$ Other related compounds such as nitrophenols and nitrobenzenes have also been studied. ${ }^{3839}$ This and other work on photocatalytic processes suggested that the process has potential for treating pink water and that there is opportunity for innovation.

TNT and other explosives are based on chemical structures which contain both oxidizing and reducing sites. This presents the possibility that they might be amenable to a photocatalytic destruction process under conditions where no added oxidant or reductant is required. A second possibility is that the oxidizing nature of the substances may make them amemable to photocatalytic reduction chemistry. Reaction with a sacrificial reductant may be a means to convert them to harmless substances or forms that can be readily be treated by another process step. These innovative chemical approaches have been investigated in this work. A further consideration in this 
project is that a combination of a photocatalytic treatment operation with a biological treatment process might be more effective than either alone.

To these ends, the research reported here was done. Characterization of the photocatalytic chemistry under aerobic and anaerobic conditions and with various oxidizing and reducing agents and semiconductors was carried out at NREL and SNL. Work on the combination of photocatalytic reduction chemistry and biotreatment was done under subcontract by a group at the University of Idaho that has extensive experience with biotreatment of soil and water contaminated with TNT and herbicides based on nitroaromatic compounds.

\subsection{Methods}

General methods and reagents. Synthetic pink water was prepared in the laboratory from deionized water and the appropriate high explosive. It was prepared by dissolving the explosive material(s) in $18 \mathrm{M} \Omega$ water with stirring over a period of days. The stock solutions were colorless and stored in amber glass bottles which were kept in dark cabinets until used. The concentrations of the high explosives approached their saturation limits in water (1ppm = lmg/L): TNT (90 ppm), RDX (40 ppm) and HMX (4 ppm). Actual pinkwater was obtained from the Louisiana Army Ammunition Plant (LAAP), Thiokol Corporation, Shreveport, LA and from the Iowa AAP (IAAP), Mason and Hanger-Silas Mason Co., Inc., Middletown, $\mathrm{OH}$ The sample from the LAAP contained $63 \mathrm{ppm}$ of TNT, $52 \mathrm{ppm}$ RDX and a number of other components that may have resulted from photo-reactions of TNT. The color of this solution is deep pink or orange. The IAAP sample contained approximately $45 \mathrm{ppm} \mathrm{C}$ of dissolved organic carbon and approximately $210 \mathrm{ppm} \mathrm{C}$ of dissolved inorganic carbon. Three organic species were identified and quantitfied as HMX ( 10 ppm), RDX ( $\sim 30 \mathrm{ppm})$ and TNT ( $80 \mathrm{ppm})$, which accounts for about $32 \mathrm{ppm} \mathrm{C}$ of the dissolved organic carbon. Additionally, 2-amino-4,6-dinitrotoluene was detected in the sample but was not quantified. Degussa P25 and anatase from Tioxide were used in the photocatalysts.

Batch reactor. Most experiments performed at Sandia National Laboratories were performed in a $1.5 \mathrm{~L}$ batch photocatalytic reactor assembly, shown schematically in Figure 2-2. In each experiment, $400 \mathrm{~mL}$ of the high explosive (HE) mixtures were placed in the glass pot reactor and illuminated with an Oriel $1000 \mathrm{Watt} \mathrm{Hg}-\mathrm{Xe}$ ozone-free arc lamp. The pot was maintained at $20^{\circ}-25^{\circ} \mathrm{C}$ through the use of a cooling jacket. All external optics employed were constructed of quartz (however, the lamp bulb is composed of Pyrex to forestall ozone generation) to maximize transmittance. A Spectronics Spectroline band pass filter, 300-420 nm, was used to restrict the wavelengths passed to the near UV region. Actinometry measurements showed that about 5.2 watts of incident light that is available for $\mathrm{TiO}_{2}$ photocatalysis $(300-400 \mathrm{~nm})$. The pot reactor was sealed gas-tight with a quartz lid and a Viton O-ring. Anaerobic reactions were carried out by vigorously sparging the reactor with nitrogen gas for $30 \mathrm{~min}$ before the reaction and then slowly during the reaction though a fritted glass tube. A similar procecture was employed for aerobic reactions using zero-air. All reactions were stirred using a magnetic stirrer. In some experiments the initial $\mathrm{pH}$ was adjusted by addition of nitric acid or sodium hydroxide solutions.

A typical nn was performed for 4-5 $\mathrm{h}$ and had samples removed for total organic carbon (TOC) (5mL), (HPLC) $(2 \mathrm{~mL})$ and UV-Vis $(2 \mathrm{~mL})$ analyses at predetermined times. TOC samples were covered with Parafilm and refrigerated until analyzed. HPLC samples were sealed and refrigerated until analyzed. In order to maintain the UV-Vis spectra within the linear range of the spectrophotometer ( 2.0 absorbance units), all UV samples were either analyzed with a 1-mm-pathlength cell or diluted by a factor of four with deionized water. All of the samples were withdrawn through a sealable sampling port. Each of the samples was filtered prior to analysis through a $0.2 \mu \mathrm{m}$ Teflon syringe filter. Catalyst was recovered for analysis by filtration using nylon filters and was allowed to air dry prior to solid state analysis.

Experiments requiring concentrated light were done using the Oriel 1000 watt lamp fitted with a 4" convex, quartz focussing lens and appropriate neutral density filters. 
Recirculating reactor. A schematic diagram of the recirculating, batch, annular photoreactor reactor assembly, showing the major components, is presented in Figure 2-3. The assembly consists of three main components: a jacketed water-cooled reservoir, a magnetic-drive centrifugal pump, and an annular photoreactor. The three parts are connected by $3 / 8$ " comugated flexible Teflon tubing. The reservoir is a $1 \mathrm{~L}$, water-jacketed, roundbottomed flask, modified to contain three ground-glass fittings at the top and one 1/2" (OD) glass tube protruding from the bottom. The centrifugal pump has a magnetic drive with a plastic impeller. Two different pump models were used in the various reactor assemblies. Both had maximum flowrates of approximately $10 \mathrm{~L}$ per minute. This flow rate provides a residence time of approximately $1.5 \mathrm{~s}$ per pass in the annular reactor.

The annular reactor design is similar in size and design to those used by Turchi ${ }^{40}$ and consists of six parts: two identical endpieces, machined out of Teflon by technicians at NREL, two glass pipes which constituted the inner and outer walls of the reactor, and two Teflon flow dispersion disks. The outer glass pipe is constructed from $54 \mathrm{~mm}$ standard-wall Pyrex tubing. The inner glass pipe is constructed of $35 \mathrm{~mm}$ standard-wall Pyrex tubing. The dispersion disks are used to initiate turbulent flow and decrease any dead space of the reaction mixture and to guarantee a well-distributed flow through the reactor. A satisfactory design of the distributor holes was determined by trial and error. Several different designs were tested and the flow distribution was visually examined using a methylene blue solution in the reactor to improve contrast.

The reactor assembly is illuminated by placing a 1" diameter, 18" long fluorescent lamp (NEC 15W F15T8-BLB "Blacklight Blue") in the center of the annulus. Actinometry measurements on this lamp yielded 1.7 watts of light available for photocatalysis $(300-400 \mathrm{~nm})$. The temperature was controlled at $25 \pm 1^{\circ} \mathrm{C}$ by the circulation of water through the reservoir water jacket from a controlled temperature water bath (VWR scientific).

Samples were taken at intervals throughout the experiment. Each sample ( $5.0 \mathrm{~mL}$ in volume) was drawn from the reactor reservoir and filtered through a $0.2-\mu \mathrm{m}$-pore-size nylon syringe filter. The first $2 \mathrm{~mL}$ of filrate were discarded and the remainder was split into two amber HPLC vials and sealed with a crimped aluminum cap and septum. Following the experiment, the catalyst was recovered by filtration using a $0.2-\mu \mathrm{m}$-pore-size Nalgene cellulose acetate filter for eventual analysis to determine the amount of carbon and nitrogen adsorbed on the used catalyst. A fraction of the supernatant was also kept for use in other analyses, if required.

\subsubsection{Analytical methods}

Spectrophotometric methods. Ultraviolet-Visible spectroscopy (UV-Vis) was performed using an HP8452A photodiode array spectrometer. Scans were made between 190 and $820 \mathrm{~nm}$ using a1-mm-path-length cell digitally zeroed against $18 \mathrm{M} \Omega$ deionized water.

High performance liquid chromatography (HPLC). At NREL, analyses for parent HE compounds and detection of intermediates were performed using a Hewlett Packard 1050 HPLC system with an online vacuum degasser and gradient pump, autosampler, and single wavelength $240 \mathrm{~nm}$ detector, which was interfaced to a PCbased data collection system sampling at $5 \mathrm{~Hz}$. The system was calibrated through a range of two orders of magnitude with six calibration standards analyzed in triplicate. A quantitaion limit for TNT in water was established to be below $20 \mathrm{ppb}$. The chromatography was performed on a 250-x 4-mm column packed with 5 $\mu \mathrm{m}$ C18 Spherisorb ODS2 stationary phase. The mobile phase was a water/methanol $\left(\mathrm{H}_{2} \mathrm{O} / \mathrm{MeOH}\right)$ gradient from $5 \%$ methanol (0 to $3 \mathrm{~min}$ ) to $100 \% \mathrm{MeOH}$ from 3 to $10 \mathrm{~min}$ and held at the final level for the final $10 \mathrm{~min}$ of elapsed time. Between each chromatographic nn, the column was equilibrated with $\mathrm{MeOH}$ for $5 \mathrm{~min}$. The flow rate was $0.75 \mathrm{~mL} / \mathrm{min}$, the column was maintained at $27.5^{\circ} \mathrm{C}$, and the sample volume was $25.0 \mu \mathrm{L}$. All intermediates were reported in units of UV-Vis response unless they were specifically identified and could be quantitated. 
At SNL, a Waters HPLC system with an online helium degasser, Waters 600E gradient pump, WISP 715 autosampler, and a Waters UV-Vis 486 detector was interfaced with a PC data collection and control system rmning Water's Millennium 2010 software, sampling at $80 \mathrm{~Hz}$ and data averaging to manageable data files of $5 \mathrm{~Hz}$. The system was maintained at $1 \mathrm{~mL}$ min and ambient temperature. It was calibrated with multiple volume injections of two standards for each HE compoumd. The chromatography was performed on a 25-cm by 3.9-mm column packed with $5 \mu \mathrm{m}$ reverse-phase Spherisorb stationary phase. The mobile phase was a water/methanol gradient from $90 / 10 \%$ to $30 / 70 \%$ during $40 \mathrm{~min}$. The typical sample volume was $40 \mu \mathrm{L}$ and the detector was set at $231 \mathrm{~nm}$. The detection limit was $150 \mathrm{ppb}$ with no change in sensitivity range and $10 \mathrm{ppb}$ with a change in sensitivity range.

Total organic carbon (TOC) analysis. At NREL, a Dohrmann DC-180 TOC analyzer measured total dissolved organic carbon using the UV/persulfate method. The instrument was calibrated as per manufacturer specifications at $100 \mathrm{ppm} \mathrm{C}$ using sodium bicarbonate, $\mathrm{NaHCO}_{3}$, for inorganic carbon (IC) and potasium hydrogen phthalate, KHP, for organic carbon (OC). The calibration was verified and corrected daily with a two point curve (plus a blank) analyzed in triplicate. The total dissolved organic carbon (TDOC) was determined by analyzing the total IC and the total dissolved carbon in a $150 \mu \mathrm{L}$ sample and taking the difference.

At SNL, TOC was performed using a Shimadzu TOC-5000 with an ASI-5000 autosampler. The instrument measures total carbon by passing the sample through a platinum oxidation catalyst and detection of resultant $\mathrm{CO}_{2}$ with an infrared analyzer. The inorganic carbon was measured by the outgassing of an acidified solution. The instrument was calibrated as per manufacturer's instructions with three points and 1 blank of $18 \mathrm{M} \Omega$ Millipore Ultrapure water. The ranges were two organic carbon ranges (10-50 ppm and 1-10 ppm) using the compounds as above. The instrument was also calibrated for two inorganic carbon ranges (0-1 ppm and 1-10 ppm). All of these calibrations can be stored within the instrument. The instrument was calibrated a minimum of once a month and standards were performed alongside experimental samples to ensure that the calibration was still valid.

Carbon, hydrogen, and nitrogen (CHN) analysis. CHN analysis of solid samples was performed on a PerkinElmer $2400 \mathrm{CHN}$ Elemental Analyzer. Oxidative combustion is performed at $925^{\circ} \mathrm{C}$ with a mixture of catalysts including silver tungstate on magnesium oxide, silver vanadate as well as chromium and nickel oxides. The reduction analysis is performed at $640^{\circ} \mathrm{C}$ and employs a mix of Cuprox and a copper catalyst. The samples are placed in a crimped foil holder and can be varied from $2.5 \mathrm{mg}$ to $7.5 \mathrm{mg}$ in size. Standards are performed prior to each analysis and use high-carbon-iron alloy for carbon standardization, sucrose for hydrogen and carbon calibration and acetoaniline for nitrogen calibration. All samples were performed as triplicates and amounts were reported as percentages.

Ion Chromatography. Data were collected using a Dionex 2000i/SP ion chromatography system fitted with a Dionex autosampler and attached through a Dionex Advanced Computer Interface to an IBM 386 PC running Dionex AI-450 Acquisition Software (rev. 3.32). Anions were eluted in an aqueous $1.8 \mathrm{mM} \mathrm{Na} \mathrm{CO}_{3} / 1.7 \mathrm{mM}$ $\mathrm{NaHCO}_{3}$ solution through a Dionex AS4A 4-mm column. Cations were eluted in an aqueous $20 \mathrm{mM}$ methane sulfonic acid solution through a Dionex CS 12 4-mm column. Both solutions were He degassed and suppressed inline for complementary ions. A $0.5 \mathrm{~mL}$ sample was injected into the system and known standard solutions were used to calibrate the instrument.

Carbon Dioxide Analysis. Off-gassing of carbon dioxide was measured via a $\mathrm{Ba}(\mathrm{OH})_{2}$ solution connected to the outlet purge line of the pot reactor. This solution contained a two times excess of reagent based on the total carbon in the reaction system. Background checks showed no appreciable $\mathrm{CO}_{2}$ in the zero-air over the time period of the pot reactions. Pot reactions were taken "off-lamp" and allowed to stir and purge for $30 \mathrm{~min}$ after the end of the reaction to fully sweep out the solution and head space. The barium carbonate precipitate was recovered on ashless filtered paper and then washed with degassed deionized water. The sample was allowed to air dry for 
a minimum of two days and ashed in a $500^{\circ} \mathrm{C}$ muffle furnace. The crucibles used were first zeroed at $500^{\circ} \mathrm{C}$. The samples were ignited for four hours total. They were removed and weighed after $2 \mathrm{~h}$ of heating and $4 \mathrm{~h}$ (cooling in a desiccator) with no significant difference in the two weights. This analysis was not performed for HMX reactions owing to the low level of carbon in the samples.

\subsubsection{Photocatalytic Process Under Oxidative Conditions}

\subsubsection{Results}

It is well known that TNT is light sensitive. Photochemistry may be initiated by irradiation with light that has an overlap with the absorption spectrum shown in Figure 2.4. Photochemical degradation of TNT in water is illustrated in Figure 2.5 for a solution of $90 \mathrm{ppm}$ TNT that was illuminated in a batch reactor in the absence of any photocatalyst. Two types of data are shown in the figure. The left ordinate with the bottom abscissa corresponds to UV-Vis difference spectra obtained by subtracting the initial spectrum $(t=0)$ from the spectra taken at later imes. The dashed spectrum shows what the difference spectrum would look like if all of the TNT initially present were destroyed, and the horizontal line at zero absorbance units is the difference spectrum for $t=0$. The spectra between these two extremes show the progress of the reaction. Difference spectra were used because they highlight the formation of light-absorbing reaction intermediates. Any part of the spectrum that is greater than zero results from these intermediates. As shown in Figure 2.5, the conversion of TNT is slow in the absence of catalyst and significant intermediates was formed. This result was confirmed by the TOC data which are plotted against the right ordinate and the top abscissa. There is some scatter in the TOC data but it is evident that the extent of mineralization (conversion of carbon content to $\mathrm{CO}_{2}$ ) is very low during the five hours of light exposure.

Photocatalytic destruction of TNT, HMX, and RDX individually and as components in actual pink water were carried out in both the batch and recirculating reactor systems. Aerobic reactions were performed by sparging with compressed air. A representative example of the photocatalytic oxidation of TNT in the batch reactor is shown in Figure 2.6. Complete destruction of TNT was achieved in five hours of inadiation in the batch reactor system. The TOC was reduced by only about $50 \%-60 \%$ under these conditions. A similar experiment was done in the recirculating reactor, Figure 2.7, with comparable results. Because $\mathrm{pH}$ can have a significant effect on TNT chemistry, experiments were done to test the effect of initial $\mathrm{pH}$ on photocatalytic oxidation. These results are shown in Figure 2.8. The final $\mathrm{pH}$ was usually in the range of three to four independent of the initial $\mathrm{pH}$. When the $\mathrm{pH}$ was held constant at nine by the periodic addition of base there was a smaller decrease in the TOC and a larger number of detectable by-products were formed. Figure 2.9 provides information on the fate of the nitrogen under aerobic and anaerobic photocatalytic conditions. Nitrate, nitrite, and ammonium ion were found.

Analytical work was done on the aqueous, solid, and gas phases in order to identify the fate of the carbon and nitrogen in these reactions. This is summanized in Table 2-1. In this set of experiments about $40 \%$ of the carbon from the explosive TNT was converted to $\mathrm{CO}_{2}$ (i.e., mineralized) from solutions by oxidative photocatalysis. Oxidation of TNT resulted in a number of organic intermediates remaining in the solution after the $5 \mathrm{~h}$ reaction time (about $38 \%$ of carbon by TOC analysis and seven intermediates as determined from HPLC analysis). The catalyst recovered from the aerobic reaction with TNT contains detectable amounts of carbon and nitrogen (about $15 \%$ and $2 \%$ of the total material introduced, respectively). However, no color is evident by visual inspection on the surface of the used catalyst. Intermediate products were not in general identified. An exception is trinitrobenzene which was identified by comparison of HPLC retention times and UV-Vis spectra with those of authentic samples.

Similar data were obtained for HMX and RDX which are also shown in Table 2-1. The destruction of RDX, about $75 \%$ conversion, yielded predominantly $\mathrm{CO}_{2}$ and material adsorbed on the catalyst surface. In the case of $\mathrm{HMX}$, the extent of destruction was about $80 \%$ in a $5 \mathrm{~h}$ experiment. 
Table 2-1. Mole Balance Data for Carbon and Nitrogen Under Aerobic Conditions.

\begin{tabular}{|c|c|c|c|}
\hline & $\begin{array}{c}\text { TNT } \\
\mathrm{O}_{2} \\
\end{array}$ & $\begin{array}{c}\mathrm{RDX} \\
\mathrm{O}_{2} \\
\end{array}$ & $\begin{array}{c}\mathrm{HMX} \\
\mathrm{O}_{2} \\
\end{array}$ \\
\hline \multicolumn{4}{|l|}{ Type of Carbon } \\
\hline \multicolumn{4}{|l|}{ Solution Carbon } \\
\hline HE Carbon & $0 \%$ & $30.6 \%$ & $0 \%$ \\
\hline Carbonate & $<1$ & $<1$ & 0 \\
\hline By-product(s) & 37.8 & 0 & 17.8 \\
\hline Carbon on $\mathrm{TiO}_{2}$ & 14.8 & 27.2 & 1.5 \\
\hline Carbon Dioxide & 40.1 & 44.1 & ND* \\
\hline Recovered Carbon & 92.7 & 101.9 & 19.3 \\
\hline \multicolumn{4}{|l|}{ Type of Nitrogen } \\
\hline \multicolumn{4}{|l|}{ Solution Nitrogen } \\
\hline HE Nitrogen & $<1 \%$ & $30.6 \%$ & $0 \%$ \\
\hline Ammonium & 15.8 & 14.8 & 19.8 \\
\hline Nitrite & $<1$ & $<1$ & 0 \\
\hline Nitrate & 12.4 & 14.1 & 16.3 \\
\hline By-product Nitrogen ${ }^{\star \star}$ & 37.8 & 0 & 17.8 \\
\hline Nitrogen on $\mathrm{TiO}_{2}$ & 2 & 0 & 0 \\
\hline Recovered Nitrogen & 68.2 & 59.7 & 53.9 \\
\hline
\end{tabular}

A number of experiments with mixtures of TNT and RDX were performed in the recirculating reactor assembly using a hard quartz annulus and a lamp which emitted short wavelength $U V$ ( $\lambda \sim 185$ to 254nm) illumination. In this configuration the reaction mixture, with $\mathrm{TiO}_{2}$ photocatalyst, was illuminated by the full lamp output spectrum. Passing air through the space between the lamp and the inner reactor wall generates ozone. The mixture of oxygen and ozone was then bubbled through the reactor reservoir. The results of these experiments are presented in Figure 2.10 for TNT, HMX, and RDX. TOC analyses of these experiments are shown in Figure 2.11. In all three compounds the removal of TOC was significantly slower than the disappearance of the explosive.

The use of short-wavelength UV illumination with no catalyst and an air atmosphere results in loss of the reactants at a rate comparable to that found with the use of photocatalyst. Data on removal of the explosives and the corresponding TOC analysis is shown in Figures 2.12 and 2.13, respectively. The catalyst was found to have little effect and may have slightly reduced the rate of reaction by blocking the light available for direct photolysis. It is likely that the use of short-wavelength illumination results in direct photolysis not possible with near-UV light. $^{3}$ 


\subsubsection{Discussion}

The photocatalytic oxidation of TNT, HMX, and RDX in both synthetic samples and in the form of pink water from AAPs has been studied under a wide range of conditions. The results generally agree with those reported by Schmelling and Gray, ${ }^{33}$ and Schmelling et al., ${ }^{33,34} \mathrm{Kang}$ and Kutal, ${ }^{36}$ and Diller, et al ${ }^{37}$ However, Schmelling and Gray report significantly more rapid mineralization of TNT than we have been able to achieve. They report $>90 \%$ mineralization of TNT within $120 \mathrm{~min}$ whereas the best we have been able to achieve is about $50 \%$ conversion to $\mathrm{CO}_{2}$ within $300 \mathrm{~min}$.

We carried out experiments under conditions that attempted to reproduce some of the earlier work. Analytical methods were chosen which allowed us to follow the disappearance of the parent HE compound, track the appearance of intermediate oxidation products and in some cases identify them, to follow total organic carbon content of the aqueous phase, to analyze the titanium dioxide photocatalyst for adsorbed carbon and nitrogen, and to determine the amount of evolved carbon dioxide. This allowed mole balances to be determined, Table 2-1.

In general, under conditions in which the aqueous phase was saturated with oxygen by sparging with air during the experiment, the photocatalytic oxidation of TNT proceeds with formation of a number of intermediates. These were not identified but were followed by HPLC analysis and reported as total counts by the UV detector of the HPLC unit. Depending on $\mathrm{pH}$, the number of detactable major intermediates ranged from four to seven; the fewest were observed at the lowest $\mathrm{pH}$. After four hours of irradiation the conversion of TNT was in the range $50 \%-60 \%$ and the TOC in solution remained at about $40 \%-50 \%$ of the initial level. There was about a $40 \%$ yield of carbon dioxide. This is consistent with the existence of intermediate products that are not mineralized.

Our results are in reasonable agreement with the work of Wang and Kutal who reported about $60 \%$ mineralization of TNT during a $4 \mathrm{~h}$ reaction. ${ }^{36}$ Their experimental system is similar to ours; they used a purged batch reactor and light of wavelength above $290 \mathrm{~nm}$. They used oxygen instead of air, $0.1 \mathrm{wt} \%$ of catalyst, and used the DegussaP25 form of $\mathrm{TiO}_{2}$ rather than that from Tioxide, Ltd. We tested the effects of these three variables and have observed no significant differences in either the rate of reaction, nor in the final TOC concentration. It is difficult to make more detailed comparisons because of the lack of details of the lamp and reactor geometries.

Comparison with the results of Schmelling and $\mathrm{Gray}^{33}$ and Schnelling et al.,34,35 is less direct. They report about 90\% mineralization within about 120 min under the following conditions. They used a closed batch reactor system, saturated with oxygen, 0.025 wt \% P25 catalyst, and irradiation with a $450 \mathrm{~W}$ medium pressure mercury arc lamp with the output filtered to remove all but light between 340 and $390 \mathrm{~nm}$.

In an attermt to duplicate the work of Schmelling and Gray, we experimented with other variables: a saturated oxygen atmosphere, the use of tap water for the HE solutions, lowered concentrations of TNT in solution (40$50 \mathrm{ppm}$ ), higher than normal incident light concentrations (use of a focusing lens and a small reactor), the use of P25 as the catalyst, and a band pass light filter. The results of these experiments were similar to results of our previous work. One observable difference was the appearance of a red color in the reaction solution that used a tap water/HE mixture. This red solution is reported at the beginning (after exposure to the lamp) of all of the reactions reported by Schmelling and Gray; however, we do not observe color in the solution until 2-3 $\mathrm{h}$ into the reaction. Although TOC dropped during the reaction to one third to half of the initial concentration, Carbon in our solutions did not disappear to the degree achieved by Schmelling and Gray. We attempted to increase the TOC removal by varying other reaction conditions. In all of our reactions the $\mathrm{pH}$ started out slightly acidic (ca. $\mathrm{pH}$ 6.5) and became more strongly acidic (ca. pH 3.5) at the end of the reaction. Experiments tested how the initial or reaction $\mathrm{pH}$ affected the final TOC concentrations. The reactions were started following adjustment to a pH value of $9,7,5$, or 3 by addition of sodium hydroxide or nitric acid solution, Figure 2-8. In another test, the solution was held in the range of $8-10$ by perodic addition of base throughout the. Color change in these 
reactions evident only towards the 3-4 h mark. We can generate this color by artificially raising the $\mathrm{pH}$ at the begiming of the reaction ( $>8 \mathrm{pH}$ ). Therefore there could be an effect of the initial $\mathrm{pH}$. We have also performed experiments where the $\mathrm{pH}$ is varied (to address this problem) and this has no major effect on the final TOC results, but it does significantly influence the type and number of intermediates formed. In all experiments, there was no significant impact on the TOC compared with our earlier results.

\subsubsection{Photocatalytic Chemistry Under Reductive Conditions}

\subsubsection{Results}

Reducing conditions have also been tested in order to evaluate the full range of photocatalytic capability of irradiated $\mathrm{TiO}_{2}$. When a photocatalytic system is nu under anaerobic conditions electron transfer from the conduction band of the irradiated semiconductor to a target compound can be enhanced since there is no oxygen to scavenge electrons. ${ }^{31.32}$ Under these conditions electrons and holes must both be consumed by the HE compound(s) in order for a sustained reaction to occur. Reduction of the HE can be forced by added reducing agents that would consume holes so that only electrons would be available to react with the HE compound(s). Because light absorption by the $\mathrm{TiO}_{2}$ photocatalyst generates both a hole and an electron, it was postulated that if we could prevent electron scavenging by oxygen (by keeping a strictly anaerobic system), or by adding a sacrificial reductants (to scavenge the photo-generated holes), we could direct the chemistry toward photoreduction of the explosive compounds. Organic and inorganic reducing agents were screened for activity.

Organic reductants that prior work ${ }^{31}$ found to be effective in the photocatalytic reduction of metal ions were tested on TNT degredation in a batch reactor. Organic reductant ( $0.72 \mathrm{mM}$ concentration, 2:1 molar ratio of added organic to TNT) was added to a nitrogen-purged TNT solution containing suspended $\mathrm{TiO}_{2}$. The results are summarized in Figure 2.14, which also includes the case of the self-redox reaction (no added organic). Citric acid and disodium ethylenediaminetetraacetic acid ( $\left.\mathrm{Na}_{2} \mathrm{EDTA}\right)$ produce the greatest increase in the rate; $\mathrm{RDX}$ and hydrogen have no effect; and salicylic acid inhibits the reductive photocatalysis.

Mass balances were determined for the reactions of TNT, HMX and RDX under anaerobic conditions with no added reducing agent. The results are summarized in Table 2-2. At the end of the anaerobic reaction of TNT the catalyst was coated with a brown substance (60\% deposited carbon and $45 \%$ nitrogen, where percentages refer to the fraction of the element initially present as TNT) or a $4 / 1$ by mass ratio of carbon to nitrogen. This result, when compared to a 2.3/1 ratio of carbon to nitrogen in the parent compound, suggests that this is not simply adsorbed TNT, but rather some decomposition product. Analytical techniques have yet to positively determine the nature of this coating, but early results point towards a polyaniline analogue produced through the reduction of nitro-groups to amines or diazo linkages. ${ }^{41}$ We have also found that the surface of this coating, as observed with X-ray photoelectron spectroscopy (XPS), differs from the bulk, indicating that there is a change in the deposited species during the course of the reaction. The results for HMX and RDX also reveal that there is little mineralization and significant depostion of material on the catalyst under anaerobic conditions when there is no added reducing agent. Soluble nitrogen species were identified by ion chromatographic analysis, (Figure 2.9b).

The reduction with EDTA was investigated in more detail in a recirculating reactor. Reaction at an initial $\mathrm{pH}=6.85$ ("natural" $\mathrm{pH}$ of TNT solution) resulted in about $65 \%$ destruction of TNT and formation of four major intermediates or by-products. The latter are identified by HPLC retention time in Figure 2.15. Buffering with sodium bicarbonate to a $\mathrm{pH}=7.0$ decreases the rate of disappearance of TNT and resulted in different intermediates (Figure 2.16). Reaction at initial pH $=5.15$ resulted in more rapid TNT destruction (Figure 2.17). At still lower $\mathrm{pH}, 3.05$, removal of TNT was achieved within $40 \mathrm{~min}$ with the lowest concentration of intermediates (Figure 2.18). HPLC data showed three major reduction products in these experiments. 
Table 2-2. Mole Balance Data Under Anaerobic

Conditions With No Added Reductant

\begin{tabular}{|c|c|c|c|}
\hline & $\begin{array}{l}\text { TNT } \\
\mathrm{N}_{2} \\
\end{array}$ & $\begin{array}{c}\mathrm{RDX} \\
\mathrm{N}_{2}\end{array}$ & $\begin{array}{c}\mathrm{HMX} \\
\mathrm{N}_{2}\end{array}$ \\
\hline \multicolumn{4}{|l|}{ Type of Carbon } \\
\hline \multicolumn{4}{|l|}{ Solution Carbon } \\
\hline HE Carbon & $<1 \%$ & $44.5 \%$ & $\begin{array}{c}17.7 \\
\%\end{array}$ \\
\hline Carbonate & $<1$ & $<1$ & $<1$ \\
\hline By-product(s) & 32.9 & 45.3 & 28.0 \\
\hline Carbon on $\mathrm{TiO}_{2}$ & 62.0 & 2.4 & 1.9 \\
\hline Carbon Dioxide & 4.0 & 10.2 & $N^{*}$ \\
\hline Recovered Carbon & 98.9 & 102.8 & 47.6 \\
\hline \multicolumn{4}{|l|}{ Type of Nitrogen } \\
\hline \multicolumn{4}{|l|}{ Solution Nitrogen } \\
\hline HE Nitrogen & $<1$ & 44.5 & 17.7 \\
\hline Ammonium & 15.1 & 3.8 & 1.4 \\
\hline Nitrite & 2.2 & $<1$ & 0 \\
\hline Nitrate & $<1$ & $<1$ & $<1$ \\
\hline $\begin{array}{l}\text { By-product } \\
\text { nitrogen }{ }^{\star \star}\end{array}$ & 32.9 & 45.3 & 28 \\
\hline Nitrogen on $\mathrm{TiO}_{2}$ & 42.7 & 0 & $<1$ \\
\hline Recovered N & 94.2 & 93.9 & 47.1 \\
\hline
\end{tabular}

${ }^{\star} \mathrm{ND}=$ not done

* The numbers for by-product nitrogen are assumed from the percentage of by-product carbon. All other values are experimentally determined.

experiments. These were identified by matching HPLC retention imes, UV-Vis spectra, and HPLC-MS analyses. The three products were 2,4-dihydroxylamino-6-nitrotoluene, 2-hydroxylamino-4-amino-6-nitrotoluene, and 2,4-diamino-6-nitrotoluene. ${ }^{42}$

Mass balance studies with carbon-14 labeled TNT, [U-ring, ${ }^{14} \mathrm{C}$ ]-TNT, were done on EDTA experiments to determine how well transformation products could be recovered and detected. Results showed that most of the products were soluble but a significant amount remained on the reactor and had to be washed off with $\mathrm{NaOH}$ or water (Figure 2.19). The solubility of reaction products when EDTA is used is in contrast to the degree to which insoluble material is deposited on the $\mathrm{TiO}_{2}$ when no reducing agent is present in the reaction mixture, which was described above. HPLC analysis of the soluble radioactivity showed the three products mentioned above accounted for the majority of eluted radioactivity (Figure 2.20) but only about 55\% of the injected radioactivity was recovered in eluent. The hydroxylamine products, if formed, apparently have a propensity to bind to the 
HPLC column, or other products were formed which are not amenable to this type of analysis. Silylation and (GCMS) did not reveal any other products and in fact was not succesful in determining the hydroxylamines. The amount of soluble radioactivity decreased during the time of incubation in air (Figure 2.21) indicating polymerization or other reaction that produces insoluble products. ${ }^{14} \mathrm{C}$-labeled TNT was used to confirm that at acidic $\mathrm{pH}$ conditions most of the carbon was present as soluble compounds. At basic $\mathrm{pH}$, azoxy coupling to give dimers ocarred to a greater extent. The reaction of 4-amino-2,6-dinitrotoluene under photocatalytic conditions was tested. This compound was reduced to 2,4-diamino-6-nitrotoluene, which was stable under the reaction conditions indicating that it is a practical end point of reduction (Figure 2.22). ${ }^{41}$

Inorganic reductants and additional organic reductants were investigated in experiments at NREL in the recirculating annular reactor. The results of these tests are shown in Figure 2.23a. The data for EDTA under these conditions is also included as a reference point for comparison with the results described above. The rate of TNT removal with formate was nearly the same as for EDTA. Glucose removed TNT at a rate similar to that of the inorganic reductants. Sulfite and hypophosphite were active only when light and catalyst were present and dramatically increased the reductive degradation rate of TNT (Figure 2.23b). The experiment with sodium borohydride $\left(\mathrm{NaBH}_{4}\right)$, a strong reducing agent, is notable. TNT was rapidly removed upon addition of $\mathrm{NaBH}_{4}$, before the lamp was turned on (Figure 223a). Subsequent illumination decreased TNT concentration only very slight further, and did not discemibly decrease TOC.

Other experiments examined the light intensity dependence of the rate of photocatalytic conversion of TNT. The pot reactor described above was used, and neutral density filters were inserted between the reactor and the light source to attenuate the incident light. In the absence of any organic reductant, the photocatalytic conversion rate of TNT shows linear behavior with respect to incident light intensity under both aerobic and anaerobic conditions (Figure 2.24a). When the hole scavenger EDTA is added under anaerobic conditions, not only does the rate increase dramatically, but it exhibits half-order dependence on light intensity (Figure 2.24b). We believe this may indicate that when the rate of the chemical reactions are slow, photo-generated holes and electrons are consumed by chemical reactions in proportion to their concentration, and that physical processes within the catalyst that govern the rate of recombination are not factors. When the chemistry is accelerated by adding hole scavengers, the competitive effect of exciton recombination becomes evident.

Experiments using an initial anaerobic photocatalytic step followed by oxidative conditions in TNT wastewater show this to be an effective way to clean the catalyst that has been coated in the reductive reaction, while producing fewer intermediate species than direct oxidation of TNT, Figure 2.25. This procedure does have the drawback of increasing the reaction time, but it may prove useful in decreasing the overall toxicity of the treated water.

\subsubsection{Discussion}

The initial rationale for testing the photocatalytic reaction of TNT under anaerobic conditions was based on the knowledge that the molecular structures of $\mathrm{HE}$ compounds are designed to include both oxidizing and reducing functionalities. HE compounds are designed to self destruct and the challenge is to bring this about under mild conditions. TNT is reactive under conditions in which no other oxidizer or reducing agent is present as shown in Figure 2.14 (curve for no added electron scavenger). Unfortunately, very little of the carbon content is converted to $\mathrm{CO}_{2}$ under these conditions. The majority, about $62 \%$, of the TNT is converted to forms which are deposited on the catalyst surface and most of the balance is in the form of soluble by-products (Table 2-2). Subsequent photocatalytic reaction of the mixture under aerobic conditions can accomplish some cleaning of the catalyst. 
Added reducing agents can dramatically increase the rate of photocatalytic removal of TNT compared to anaerobic conditions with only HE present. This is particularly true when EDTA, citrate, or formate are added as reducing agents, but inorganic reductants such as sulfite or hypophosphite are also effective. Sodium borohydride rapidly reduces TNT by a dark reaction. The few products that have been identified indicates that it is possible to reduce up to two of the nitro groups in TNT to amine groups. The introduction of nitroso, hydroxylamine, and amine groups provides new chemical pathways for formation of by-products. This is shown in simplified form in Figure 2.26. Because TNT has multiple nitro groups the coupling reactions that are illustrated in the figure can lead to polymeric materials which may account for the insoluble products observed under some conditions.

The results achieved demonstrate the ability to partially reduce nitro groups in TNT to amine, nitroso, hydroxylamine, azoxy, or other less-oxidized function groups. This process might be a useful pretreatment step to prepare pink water for further biological treatment.

\subsection{Biotreatment after Pretreatment by Photocatalytic Reduction}

\subsubsection{Background}

The concept of using a photocatalytic process to treat a waste stream before it enters a biological treatment process has received little attention. Biological transformation processes as stand-alone operations have been described but most give poor mineralization, which is a common measure of the extent of degradation. The best mineralizer described so far is Phanerochaete chrysosporium but a fairly low level of TNT is toxic to this organism. Biochemistry of toxicity to lignin peroxidase has been ascribed to hydroxylaminodinitrotoluene. Once TNT is reduced to aminodinitrotoluene, toxicity is reduced. ${ }^{22,23,24,25}$

The results described in the previous section suggested a new approach: first reduce TNT then feed it into a Phanerochaete chrysosporium system. The rationale was the pretreatment that would reduce the toxicity of components of the waste stream to the organisms used in the biological step, or that it would reduce the time required by the biotreatment. A subcontract was awarded to the University of Idaho to explore the combination of anaerobic photocatalytic reduction of TNT with EDTA followed by treatment with Phanerochaete chrysosporium. The decision to use Phanerochaete chrysosporium as a likely biological agent for follow-on photoreactor product degradation was based on the assumption that reaction intermediates from the above photocatalytic reduction degradation experiments were possibly dimers or polymeric compounds. The full report ${ }^{42}$ covering this work is included as Appendix A of this report so only a summary of the results is included here.

\subsubsection{Results}

The combined photocatalytic and biological degradation experiments comprised two parts: i) preliminary experiments to idenlify a likely biological treatment organism and qualitative aspects of photoreactor treatment product degradation and ii) quantitative experiments using ${ }^{14} \mathrm{C}$-TNT in a precedent photocatalytic degradation step with follow-on biological treatment of the photodegradation products. The ${ }^{14} \mathrm{C}$-radiotracer experiments allowed quantitation of ulimate TNT mineralization in addition to an overall carbon balance in the system.

Initial experiments were conducted to observe the presence or absence of biological activity as seen by decoloration of the compounds adsorbed on the $\mathrm{TiO}_{2}$ and in solution after the photocatalytic step. Anaerobic photocatalytic treatment with no added EDTA was used to produce the feed mixture for the biological step.

Fresh hyphae, harvested from Phanerochaete c. previously grown up on a glucose/dimethyl succinic acid media, were added to varying amounts of the photocatalytic reaction mixture. The first biological experiment used a 
ratio of hyphae:fluid of 5:1, on a volume-to-volume basis. The fluid was decolored, or bleached white (the $\mathrm{TiO}_{2}$ showed white) within 3 days. The second biological experiment used a hyphae:fluid ratio of 1:5. A color change from reddish-brown to light brown was observed at 3 days with no further decoloration up to 10 days. No analyses of the Phanerochaete-amended fluid was done at this time, although it is possible that this first biological experiment was successful in degrading the polymeric materials left from anaerobic chemical photocatalysis.

Experiments compared biological reament of ${ }^{14} \mathrm{C}$-TNT solutions that had undergone $2 \mathrm{~h}$ and $6 \mathrm{~h}$ photocatalytic pretreatment under anaerobic conditions with added EDTA. These mixtres were treated using Phanerochaete crysosporium. The photocatalytic portion of the experiment was identical to previous experiments. The biological portion of the experiment followed a protocol similar to that of 40 CFR 796.310 Aerobic Aquatic Biodegradation Shake Flask Protocol. Replicate $50 \mathrm{ml}$ quantities of mixed reactor contents from photocatalysis of ${ }^{14} \mathrm{C}$-TNT for $2 \mathrm{~h}$ and $6 \mathrm{~h}$ and a blank with $100 \mathrm{mg} /{ }^{14} \mathrm{C}$-TNT (no photocatalytic treatment) were inoculated with Phanerochaete crysosporium and incubated on a shake table. An abiotic control was also run on the reactor contents. Removal and counting of the base solution contained within the flasks was done every two days for the 27-day experiment, to quantitate the ${ }^{14} \mathrm{C}-\mathrm{CO}_{2}$ evolved. Final results from the experiment showing accumulated percent ${ }^{14} \mathrm{C}-\mathrm{CO}_{2}$ released are presented in Figure 2.27 . Ultimately more ${ }^{14} \mathrm{C}_{-} \mathrm{CO}_{2}$ was released from the solution that had received phocatalytic treament for $6 \mathrm{~h}$ than from that treated for $2 \mathrm{~h}$, and both released more ${ }^{14} \mathrm{C}-\mathrm{CO}_{2}$ than the untreated TNT. This probably indicates that either longer reductive photocatalytic treatment is necessary for follow-on oxidative biological treatment or the destruction of a biologically toxic intermediate occurs after two or more hours of photocatalytic treatment. Chromatograms showing TNT reduction products, before and after biological treatment, with overlain radioactive counts for the 2-h and 6-h samples are shown in Figures 2.28 and 2.29. Distribution of photocatalytic products in both the 2- and 6-hour-treatment solutions were similar, except that two peaks between 20 and 25 minute retention were at higher concentration in the 2-htreatment solution. This peak probably represented the toxic fraction of photoproducts that inhibited mineralization in the $2 \mathrm{~h}$ samples. Distribution of radiolabel was similar in both the 2- and 6-hr-treatments solutions after fungal treatment.

The overall carbon mass balances ranged from about $93 \pm 2 \%$ to $101 \pm 11 \%$. The data are included in Appendix A. All recoveries of radio-tracer were good and in all cases were greater than $92 \%$. As can be seen in the lower portion of the Table, almost twice as much radio-labeled material was associated with the biomass of the fungi (numbers in the rows named $\mathrm{HCl}$ digest and tissue solubilizer rows) in the 2-h-treatment solution as with the biomass in the 6-h-treament solution. This data agreed with the hypothesis that longer photocatalytic treatment produced more polar products having less tendency to adsorb.

\subsubsection{Discussion}

Partial mineralization of TNT was achieved by the combination of photocatalytic reduction with EDTA and treatment with Phanerochaete crysosporium. The maximum observed was $32 \%$ conversion of the original carbon content to $\mathrm{CO}_{2}$. The length of time used in the photocatalytic step was a significant factor in determining the extent of mineralization by the combined processes. Two hours in the photocatalytic step resulted in $23 \%$ mineralization and six hours in the photo step allowed $32 \%$ mineralization by the two-step process.

\subsection{Estimated Electrical Power Requirements for Photocatalytic Oxidation or Reduction of TNT}

The results of the experiments described above allow a rough estimate of the energy requirements for the photocatalytic treatment of pink water under aerobic conditions. The calculation is based on the following assumptions and methodology. The destruction of TNT is assumed to follow first order kinetics and the energy 
Table 2-3. Electrical power requirements for photocatalytic oxidation and reduction processes estimated from the results obtained in this project.

\begin{tabular}{lccc}
\hline & \multicolumn{2}{c}{$\begin{array}{c}\text { Time and power needed to reduce TNT } \\
\text { by one decade }\end{array}$} & $\begin{array}{c}\text { kWh/1000 gal of } \\
\text { pink water }\end{array}$ \\
\cline { 2 - 4 } Reactor and Conditions & min & Wh/L & \\
\hline Batch (1000 W; 0.4 L) & 10 & 113 & 428 \\
Reduction-EDTA & 230 & 417 & 1578 \\
Reduction & 145 & 6014 & 22,868 \\
Oxidation & & & \\
Recirculating (15 W; 1 L) & 50 & 12.5 & 47 \\
Reduction-EDTA & 600 & 150 & 568 \\
Reduction & 453 & 9583 & 36.276 \\
Oxidation & & & \\
\hline
\end{tabular}

Equation = (Electral Power)*(Time to destroy one decade of TNT in hrs)/(Volnme of reaction solution, in liters), this is then converted to $\mathrm{kWh} / 1000 \mathrm{gal}$. A cost can be calculated by assnming a cost for electricity.

Table 2-4. Apparent Photoefficiency (mole TNT eliminated/mole photons supplied) for photocatalytic oxidation and reduction processes

\begin{tabular}{lccc}
\hline & $\begin{array}{c}\text { Time needed to } \\
\text { reduce TNT } \\
\text { bamp and Conditions }\end{array}$ & $\begin{array}{c}\text { UV photons available } \\
\text { (Ei) }\end{array}$ & $\begin{array}{c}\text { Mol of TNT/ } \\
\text { Mol of photons }\end{array}$ \\
\hline $\begin{array}{c}\text { Oriel (9.5098E-04 Ei/min; } \\
\text { 1.43E-04 mol TNT) }\end{array}$ & & & \\
Reduction-EDTA & & 0.00950 & 0.01503 \\
Reduction & 10 & 0.21872 & 0.00065 \\
Oxidation & 230 & 0.13789 & 0.00103 \\
$\begin{array}{l}\text { Black (2.7441E-04 Ei/min; } \\
\text { 3.56E-04 mol TNT) }\end{array}$ & 145 & & \\
Reduction-EDTA & & 0.01372 & 0.02594 \\
Reduction & 50 & 0.16464 & 0.00216 \\
NREL (2.7441E-04 Ei/min; & 600 & & \\
3.56E-04 mol TNT) & & & 0.00288 \\
\hline Oxidation & 450 & 0.12348 & \\
\hline
\end{tabular}

Equation $=(\text { Flux in Ej/min from actinometry })^{*}$ (Time to degrade unit amount, $81 \mathrm{ppm}$, in minutes)/(Moles of TNT in unit amount, $81 \mathrm{ppm} *$ volume of reactor) 
requirements are based on the use of fluorescent black lamps that have the same electrical to near-UV light output as the lamps used in this study (15:1.1 W) or on the Hg-Xe arc lamp (1000:4 W). Each decade of destruction; 100 to $10 \mathrm{ppm}, 10$ to $1 \mathrm{ppm}$, etc., would require the same amount of time to achieve under conditions which fit the assumptions. There are a number of variables that are included to determine the power requirements for photocatalysis. One method is to detenmine the electrical power required to create one decade of reduction (from 100\%-10\%) in the target contaminant in one liter. This methodology provides the results summarized in Table 2-3.

A second method is to determine the efficiency of the reaction by measuring the UV photons available expressed in Einsteins (Ei), from actinometry measurements, per molecule of compound degraded, and comparing this with the concentration decrease of the target species per unit time (100-10\% is 90 ppm-9 ppm, or 81 ppm of TNT destroyed). This generates a unit-less efficiency, Table $2-4$. 


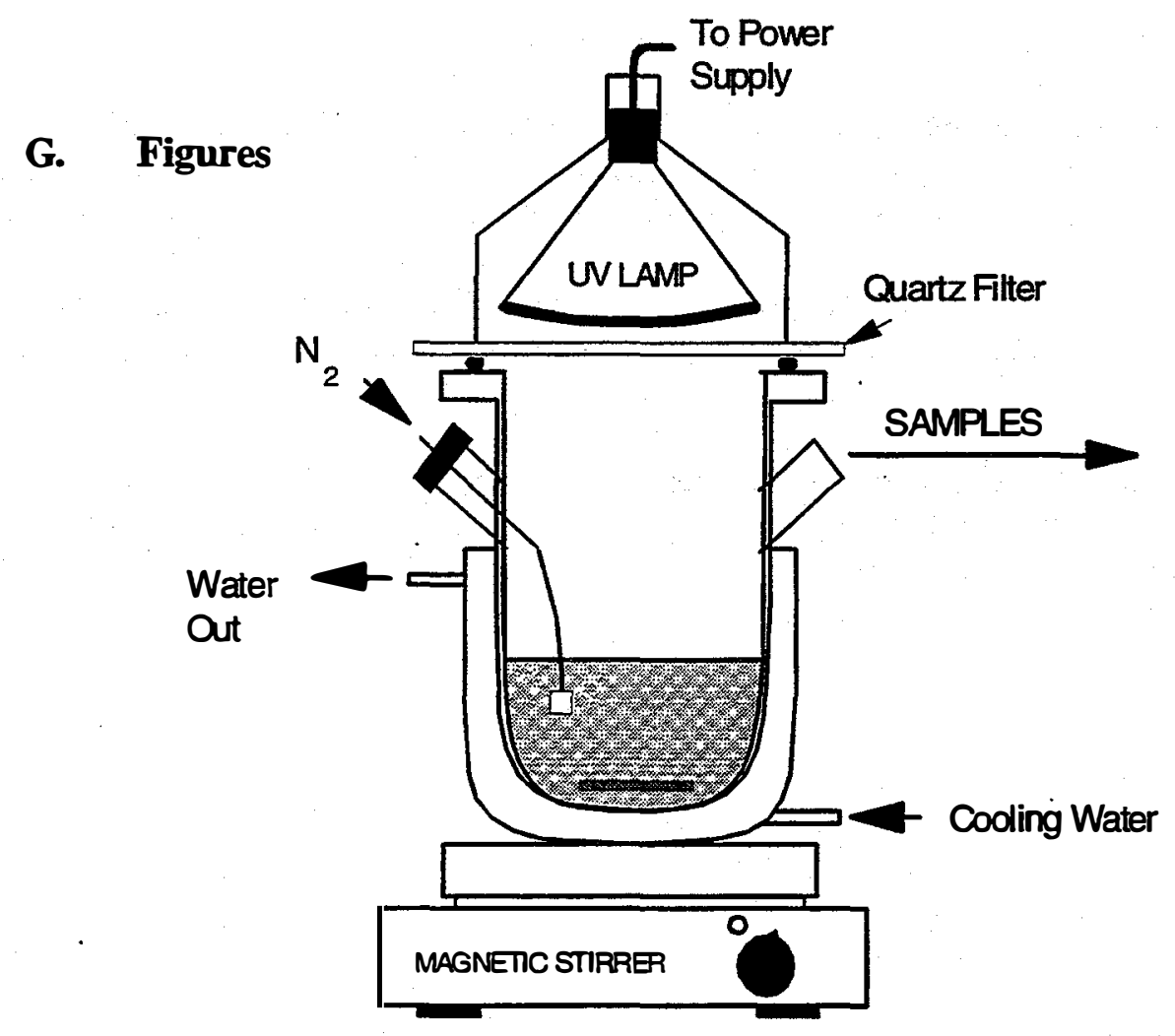

Figure 2.2. Batch photocatalytic reactor system.

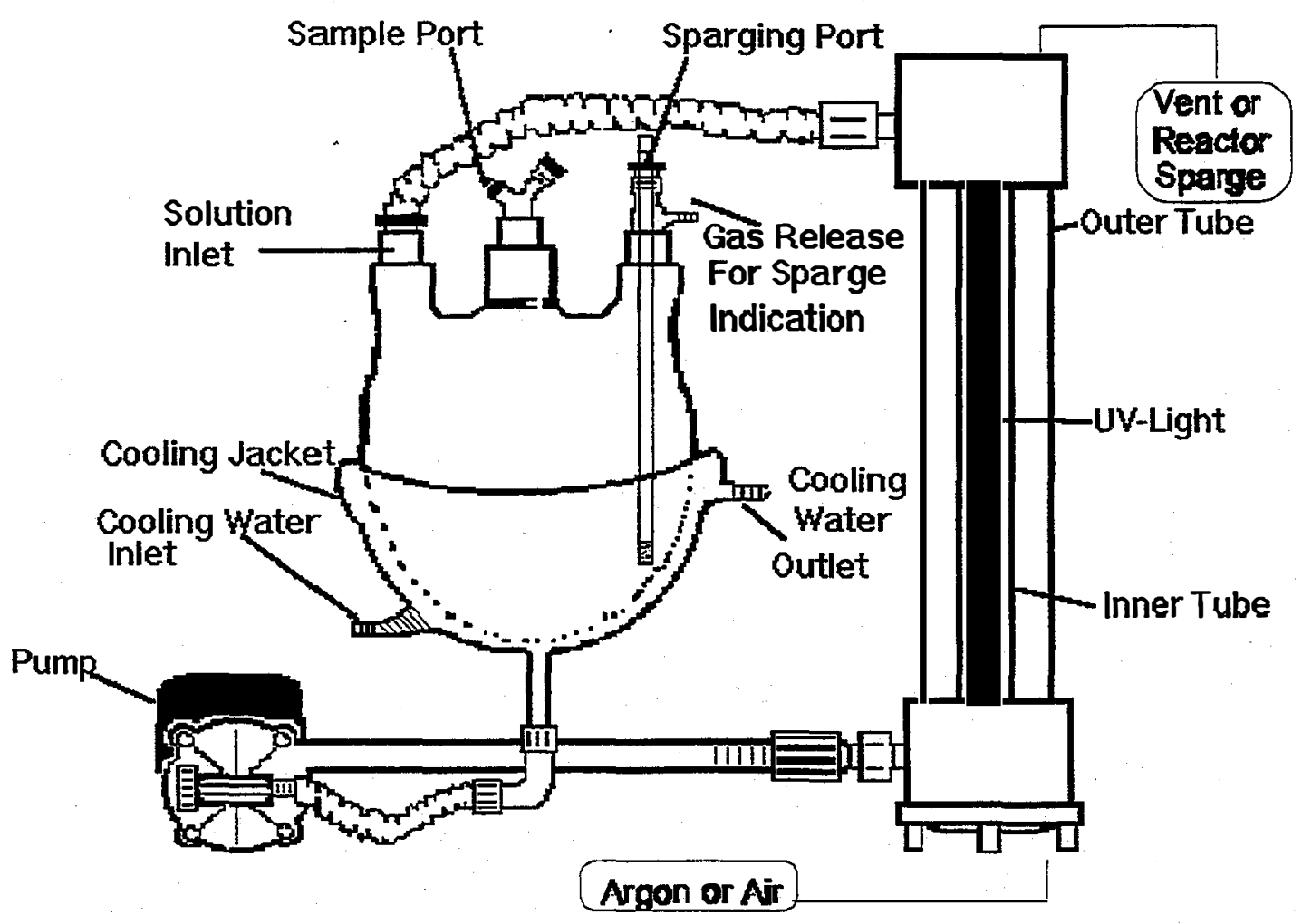

Figure 2.3. Recirculating photochemical reactor system. 


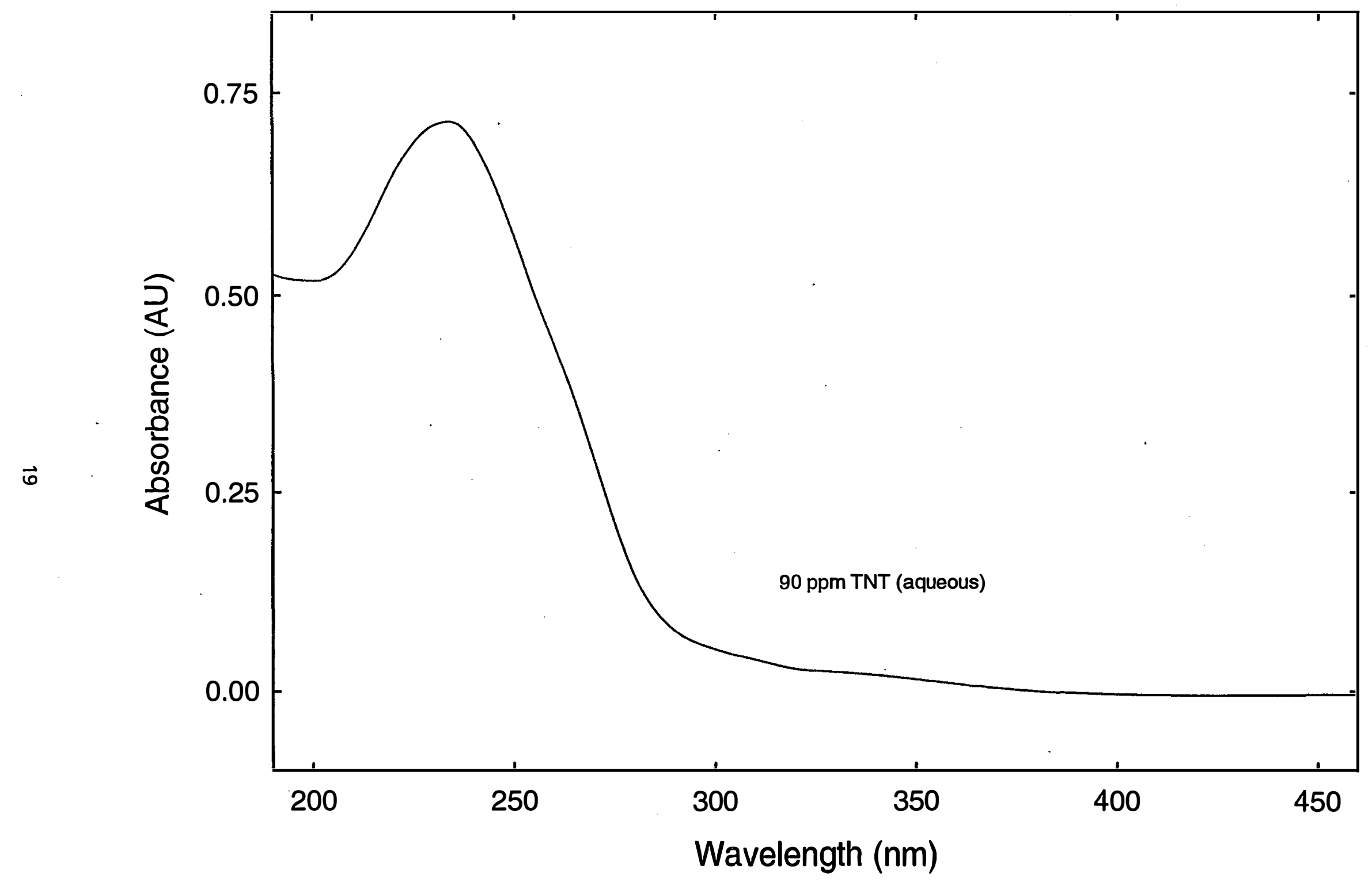

Figure 2.4. UV-Visible absorption spectrum of TNT. 
Time (min)

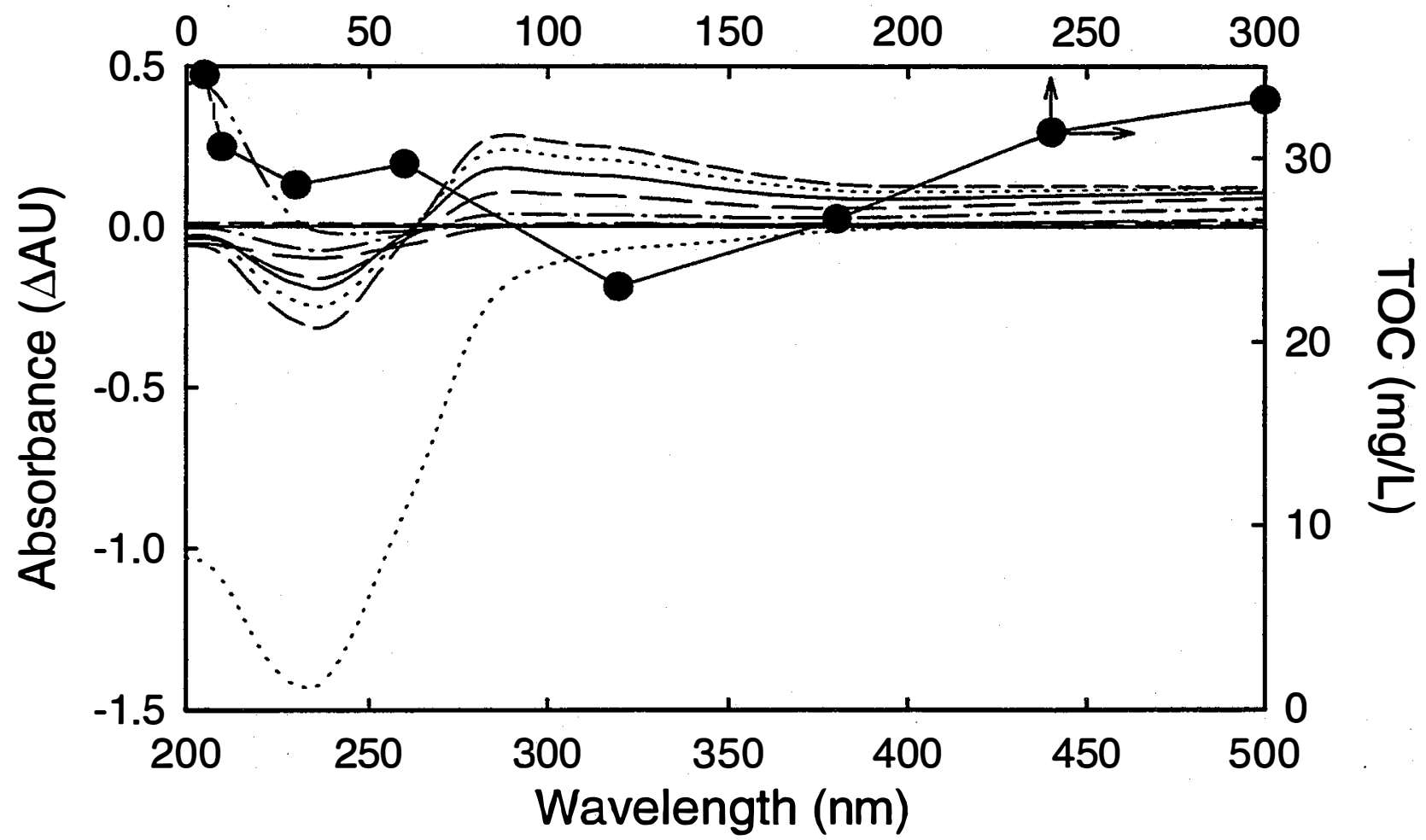

2.5. Photocatalytic oxidation of TNT in the batch reactor with no $\mathrm{TiO}_{2}$ showing difference UV-Vis spectra and TOC vs. time.

Time (min)

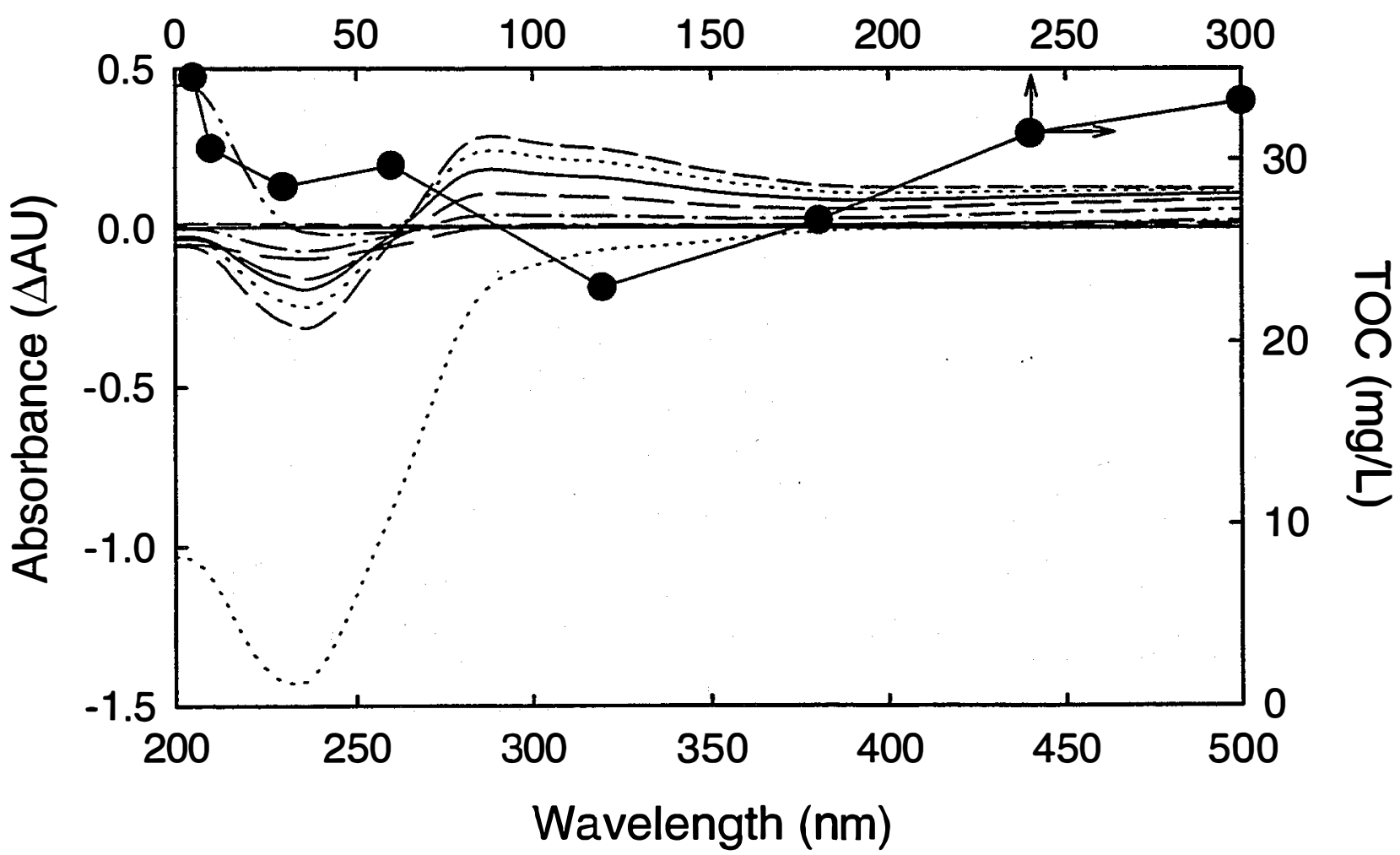

2.6. Photocatalytic oxidation of TNT in the batch reactor with $\mathrm{TiO}_{2}$ showing difference UV-Vis spectra and TOC vs. time. 


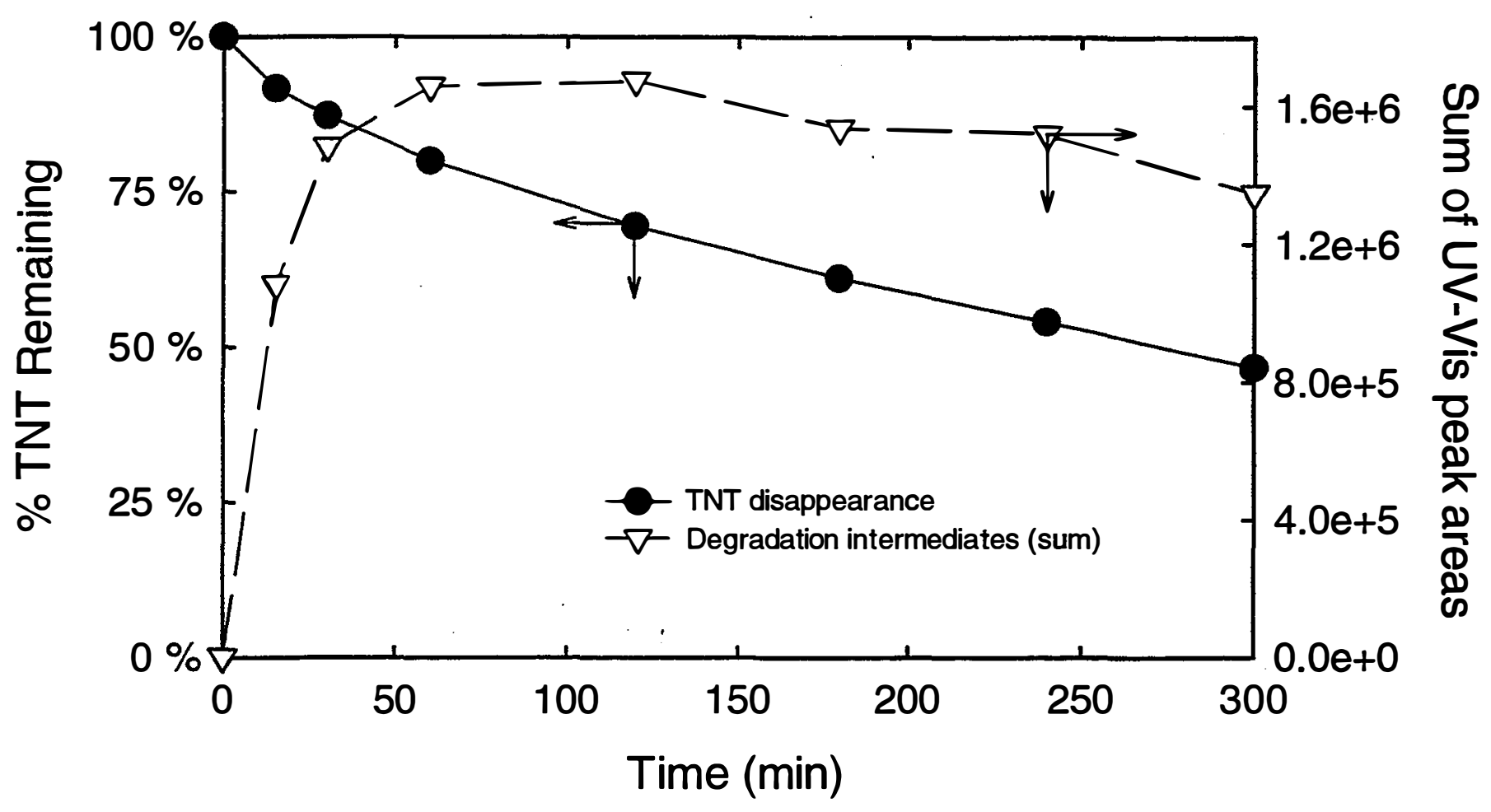

Figure 2. 7. Photocatalytic oxidation of $90 \mathrm{ppm}$ TNT in the recirculating reactor; $1.0 \mathrm{~g} / \mathrm{L} \mathrm{TiO}{ }_{2}$, air purge, UV illumination.

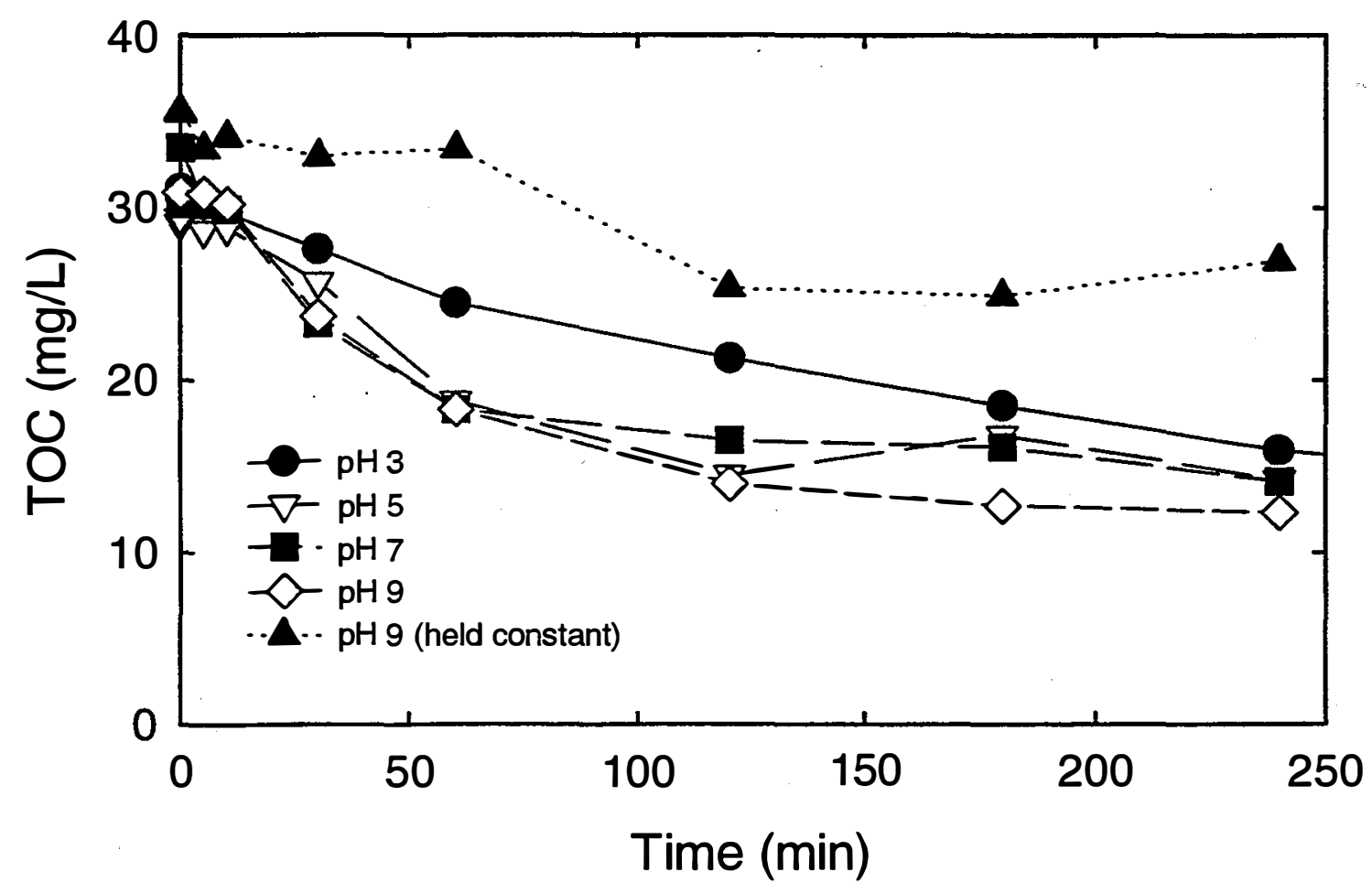

Figure 2.8 Effect of $\mathrm{pH}$ on the removal of TOC during photocatalytic oxidation of TNT in the batch reactor. 


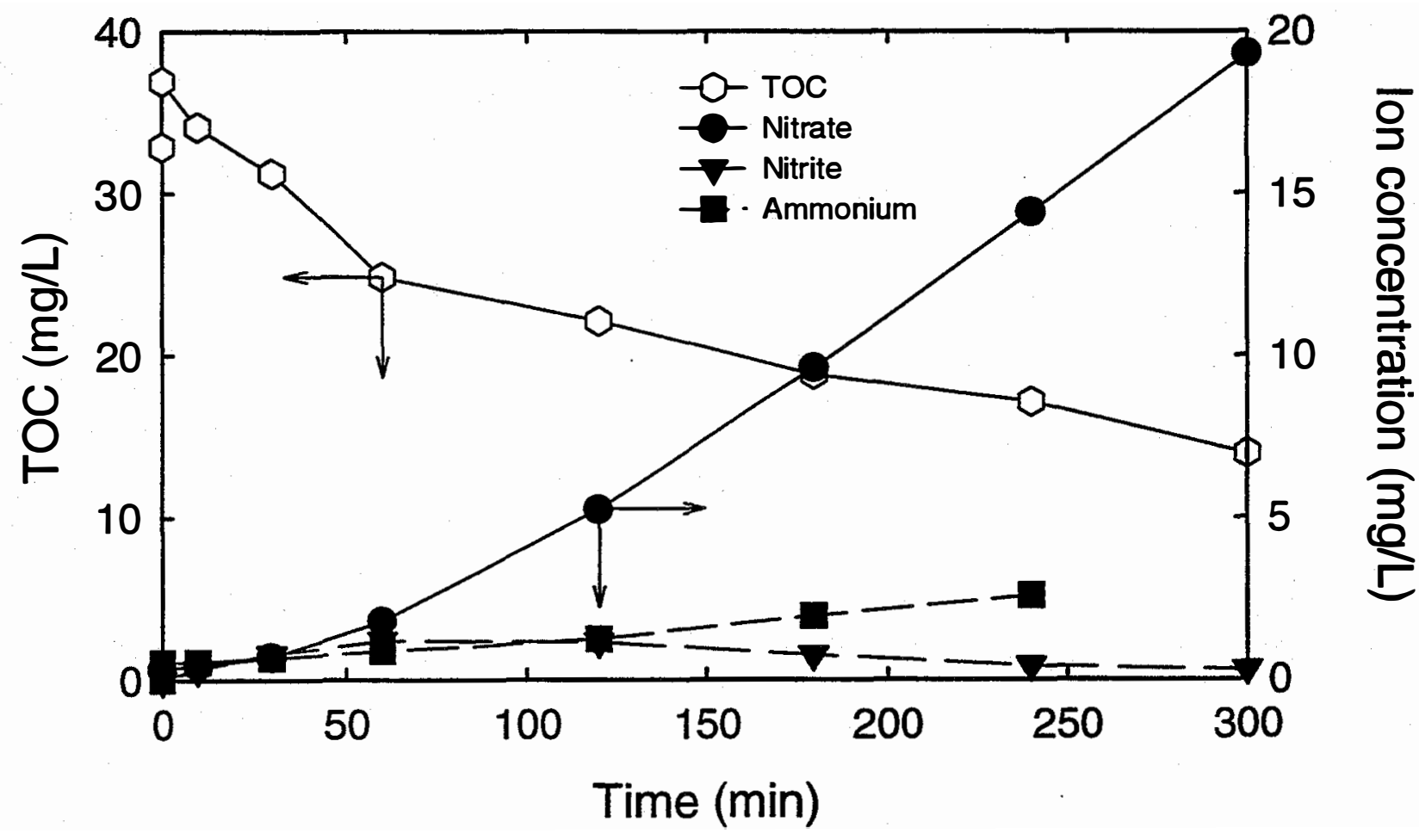

Figure 2.9a. TOC and inorganic nitrogen species formed during oxidative destruction of TNT in the batch reactor.

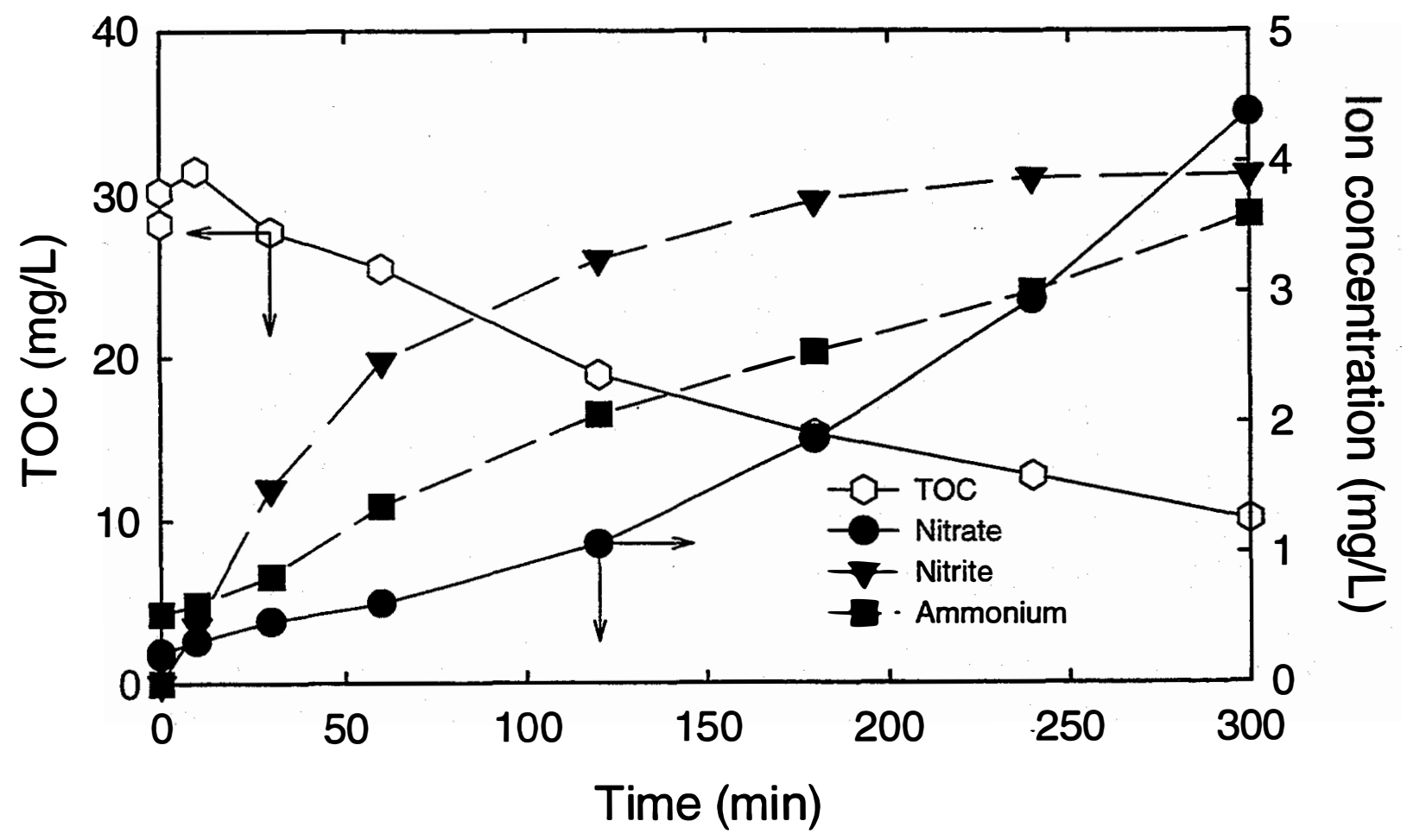

Figure 2.9b. TOC and inorganic nitrogen species formed during reductive destruction of TNT in the batch reactor. 


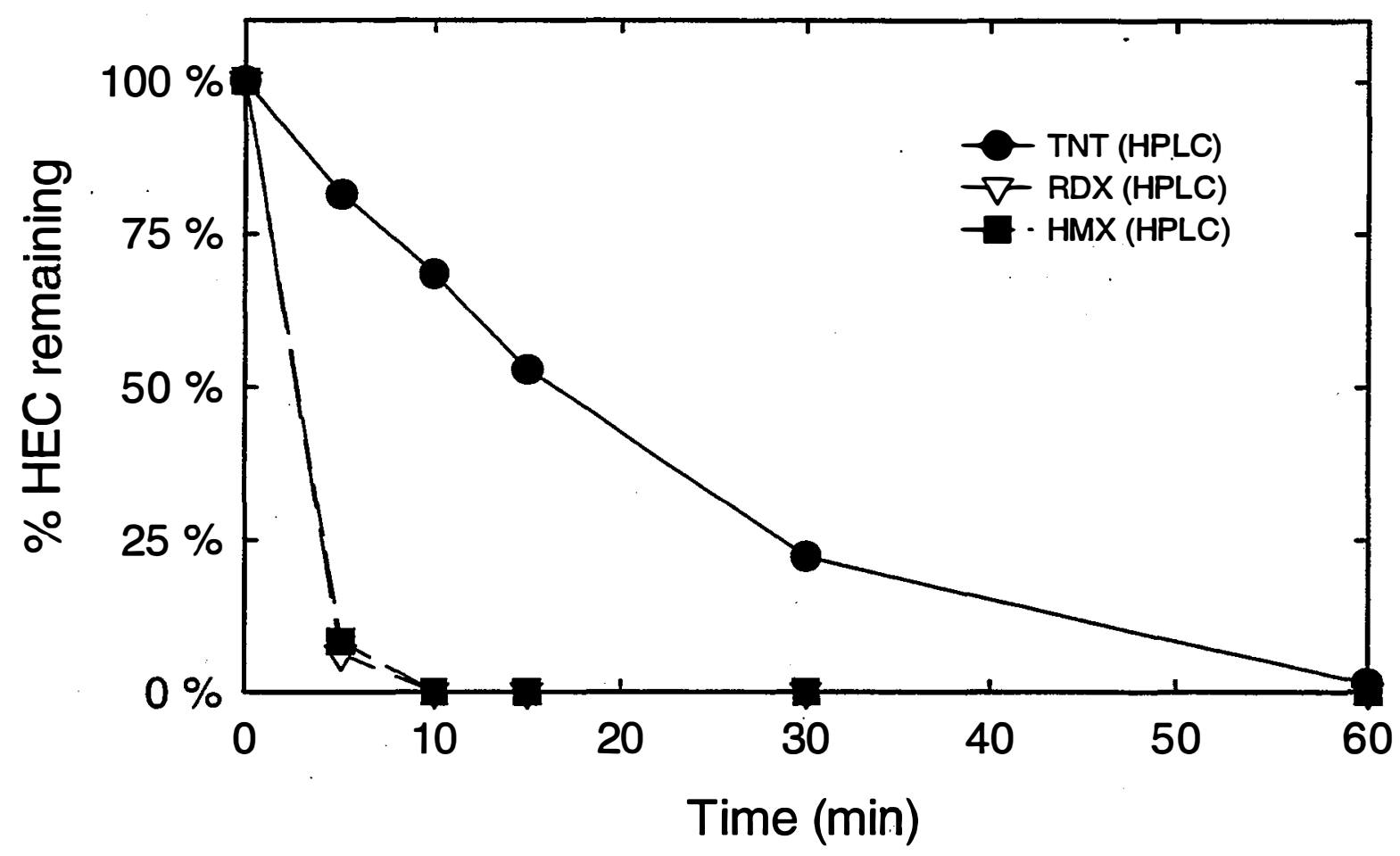

Figure 2.10 HPLC of HE destruction using 180-254 $\mathrm{nm}$ ozone generating spa lamp with $\mathrm{TiO}_{2}$ in the recirculating reactor.

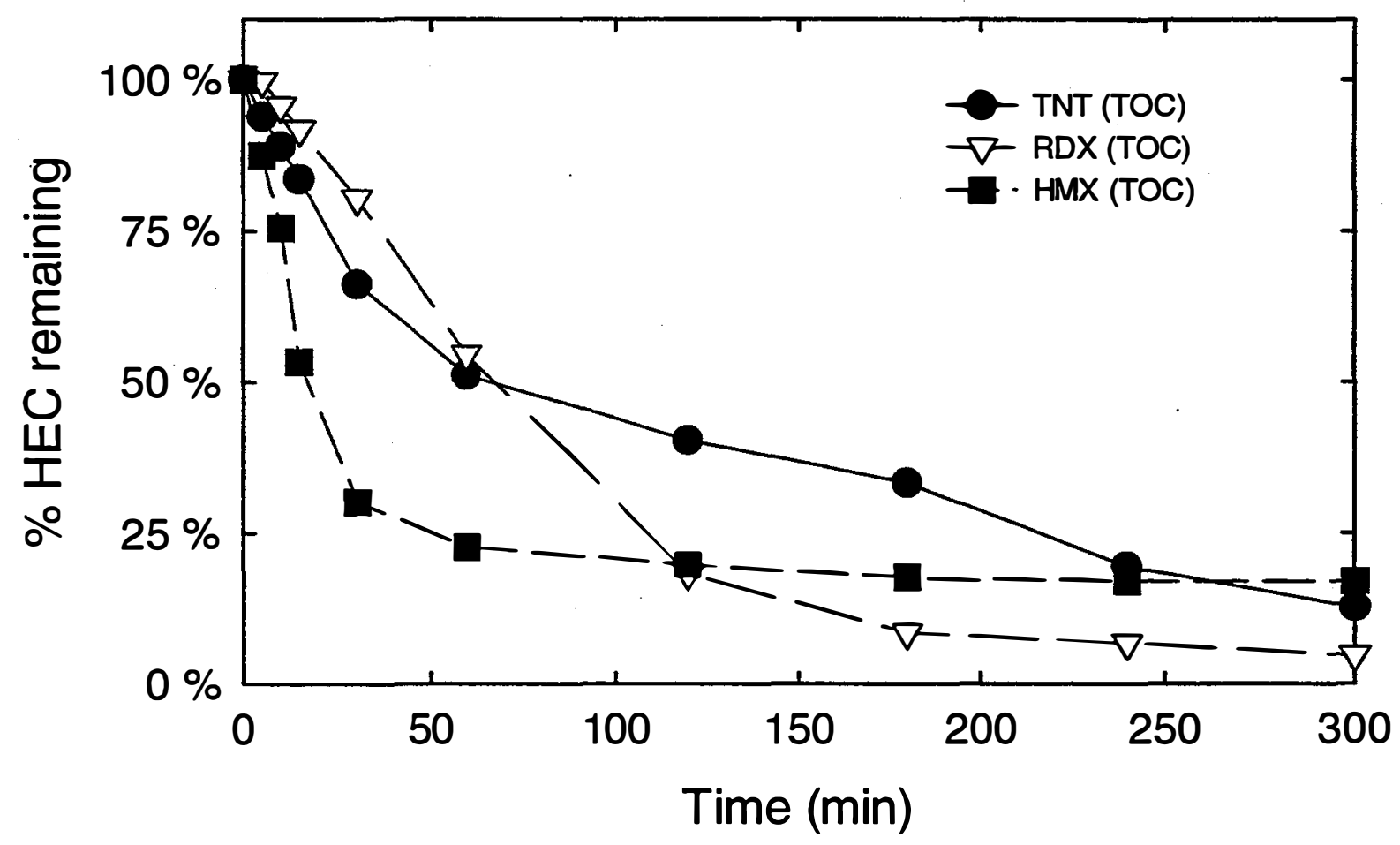

Figure 2.11 TOC of HE destruction using 180-254 nm ozone generating spa lamp with $\mathrm{TiO}_{2}$ in the recirculating reactor. 


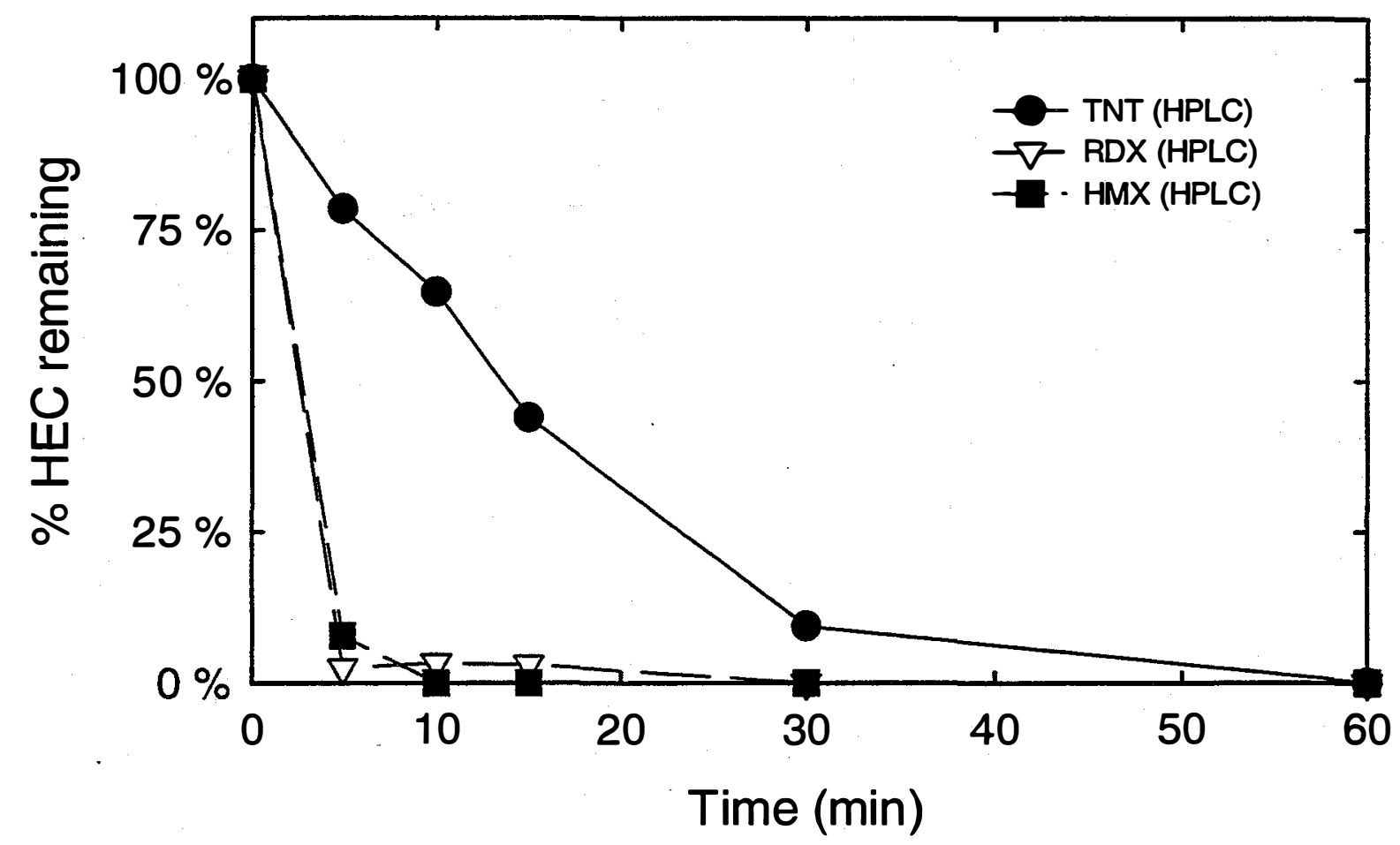

Figure 2.12 HPLC of HE destruction using 180-254 nm ozone generating spa lamp without $\mathrm{TiO}_{2}$ in the recirculating reactor.

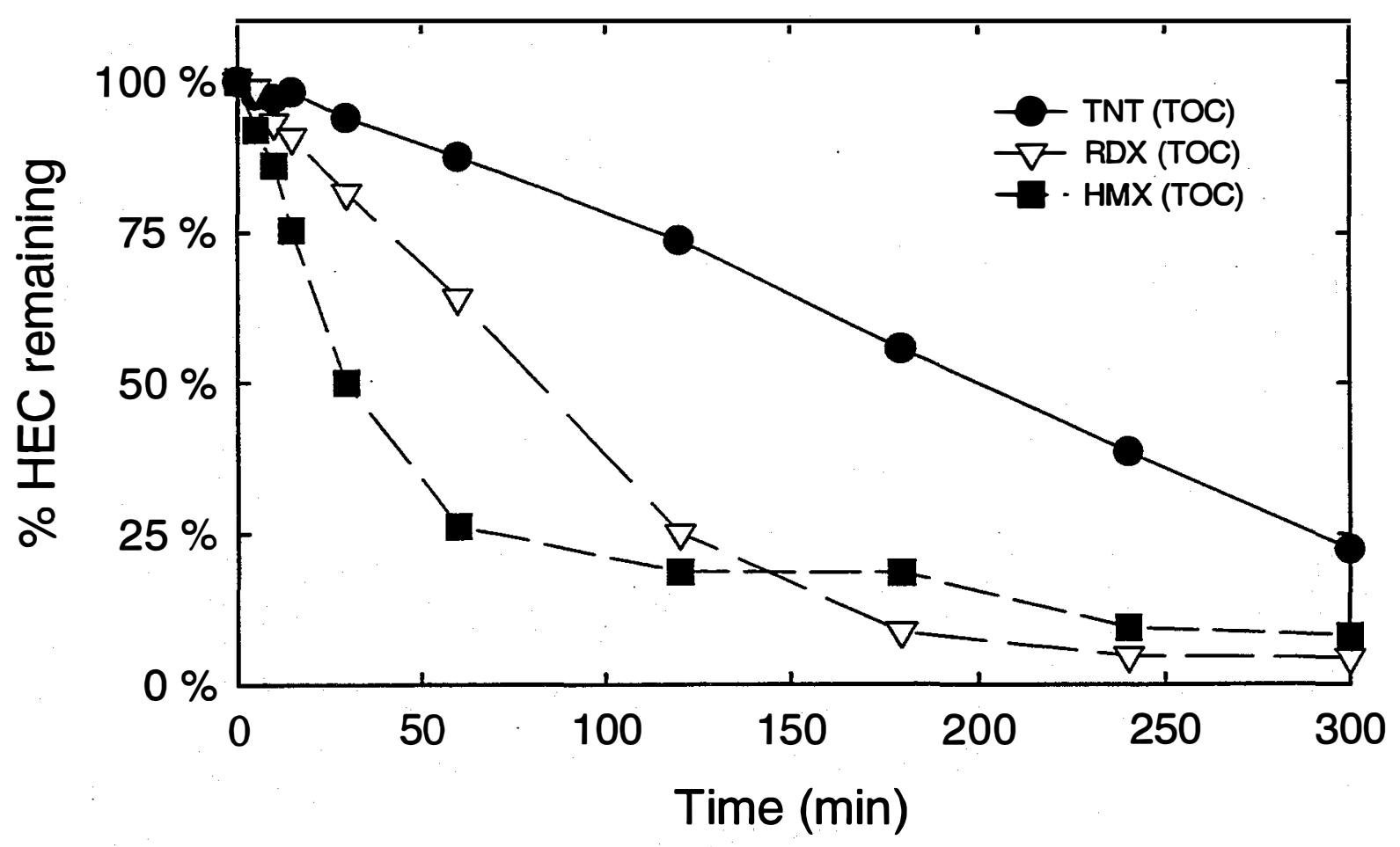

Figure 2.13 TOC of HE destruction using 180-254 nm ozone generating spa lamp without $\mathrm{TiO}_{2}$ in the recirculating reactor. 


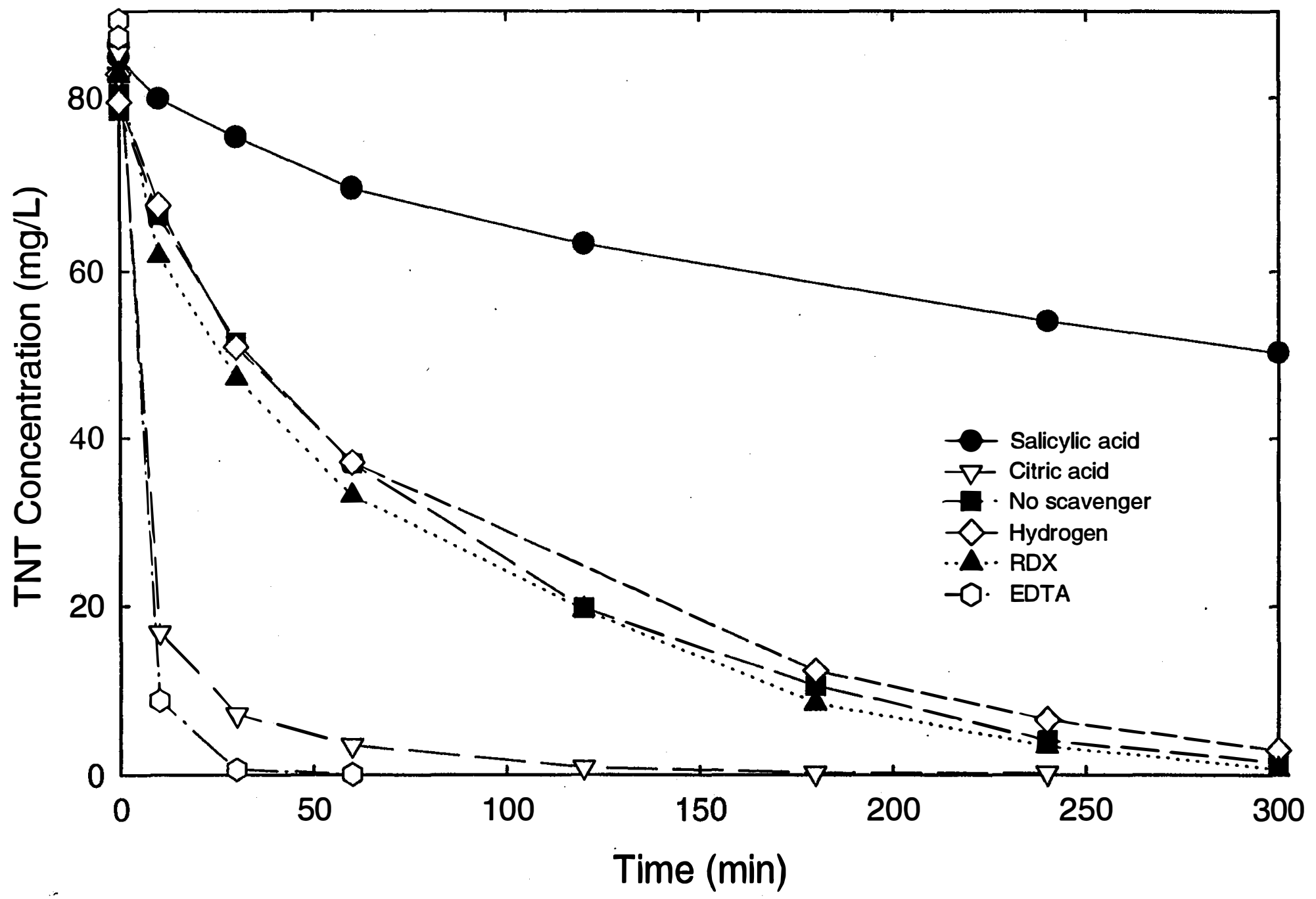

Figure 2.14. Reduction of TNT in the batch reactor with various added hole scavengers. 


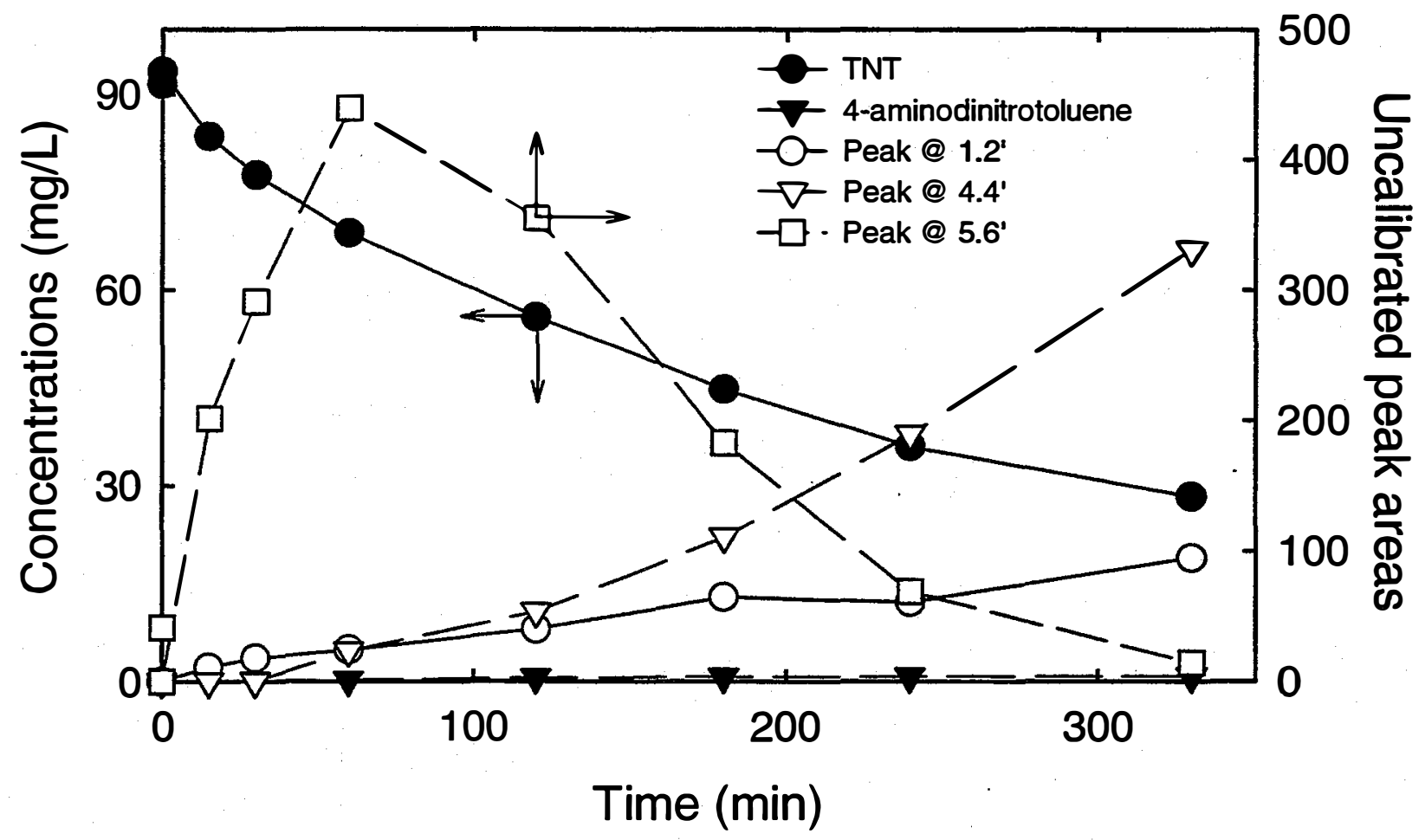

Figure 2.15. Intermediates and by-products detected in the photocatalytic reduction of TNT with EDTA at initial $\mathrm{pH}=6.85$.

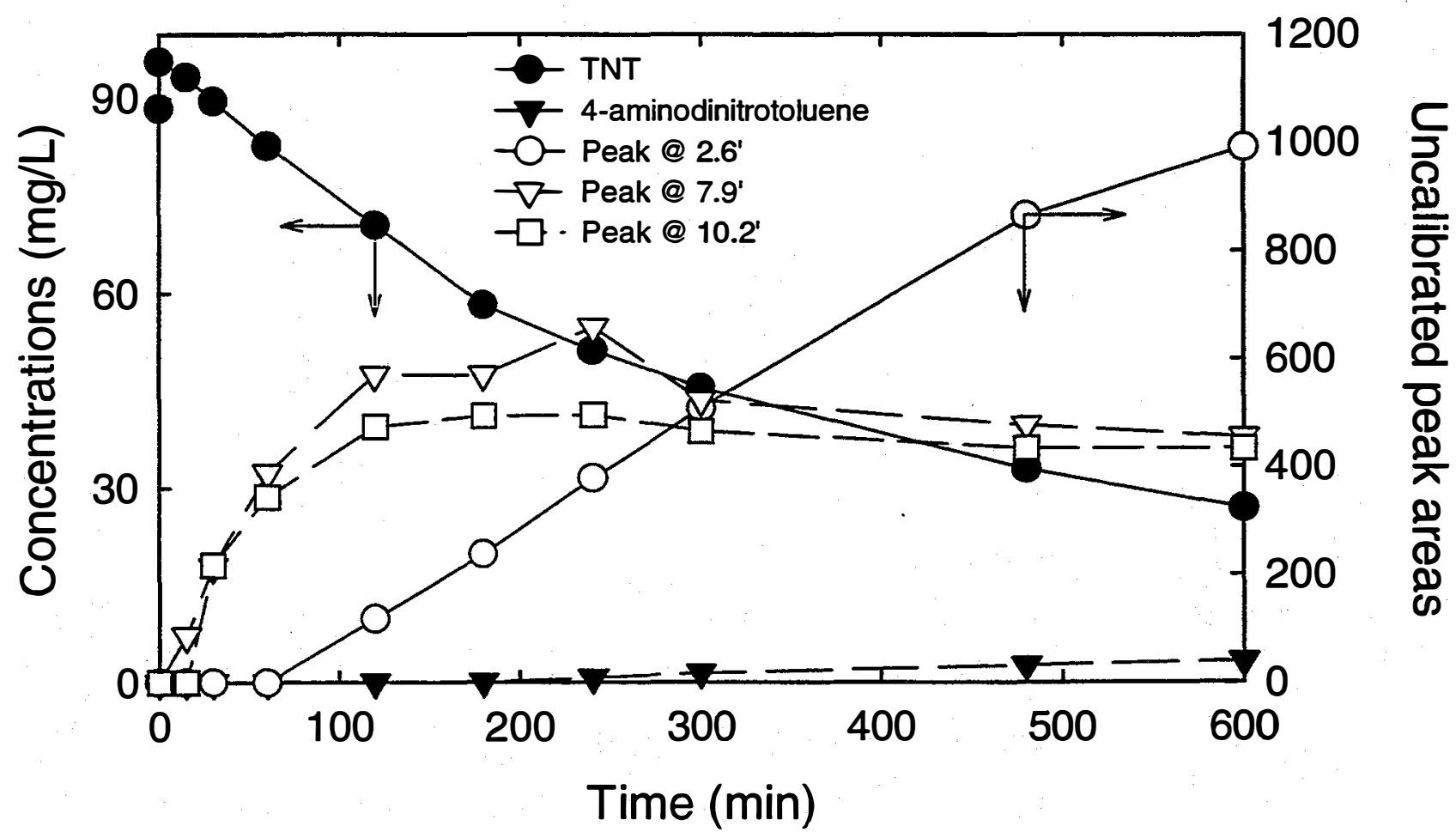

Figure 2.16. Intermediates and by-products detected in the photocatalytic reduction of TNT with EDTA held at $\mathrm{pH}=7.0$, using a bicarbonate buffer. 


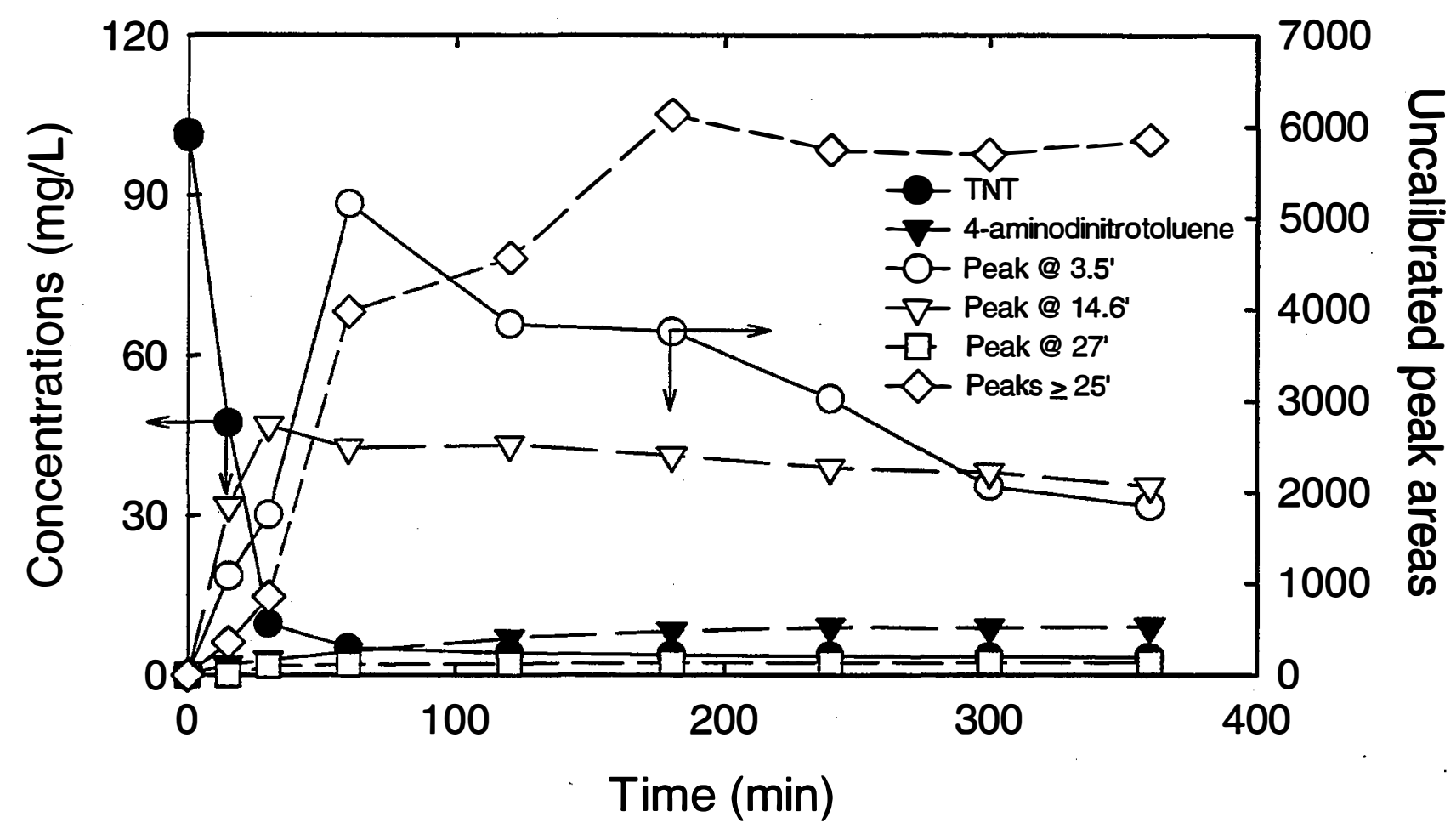

Figure 2.17. Intermediates and by-products detected in the photocatalytic reduction of TNT with EDTA at an initial $\mathrm{pH}=5.15$.

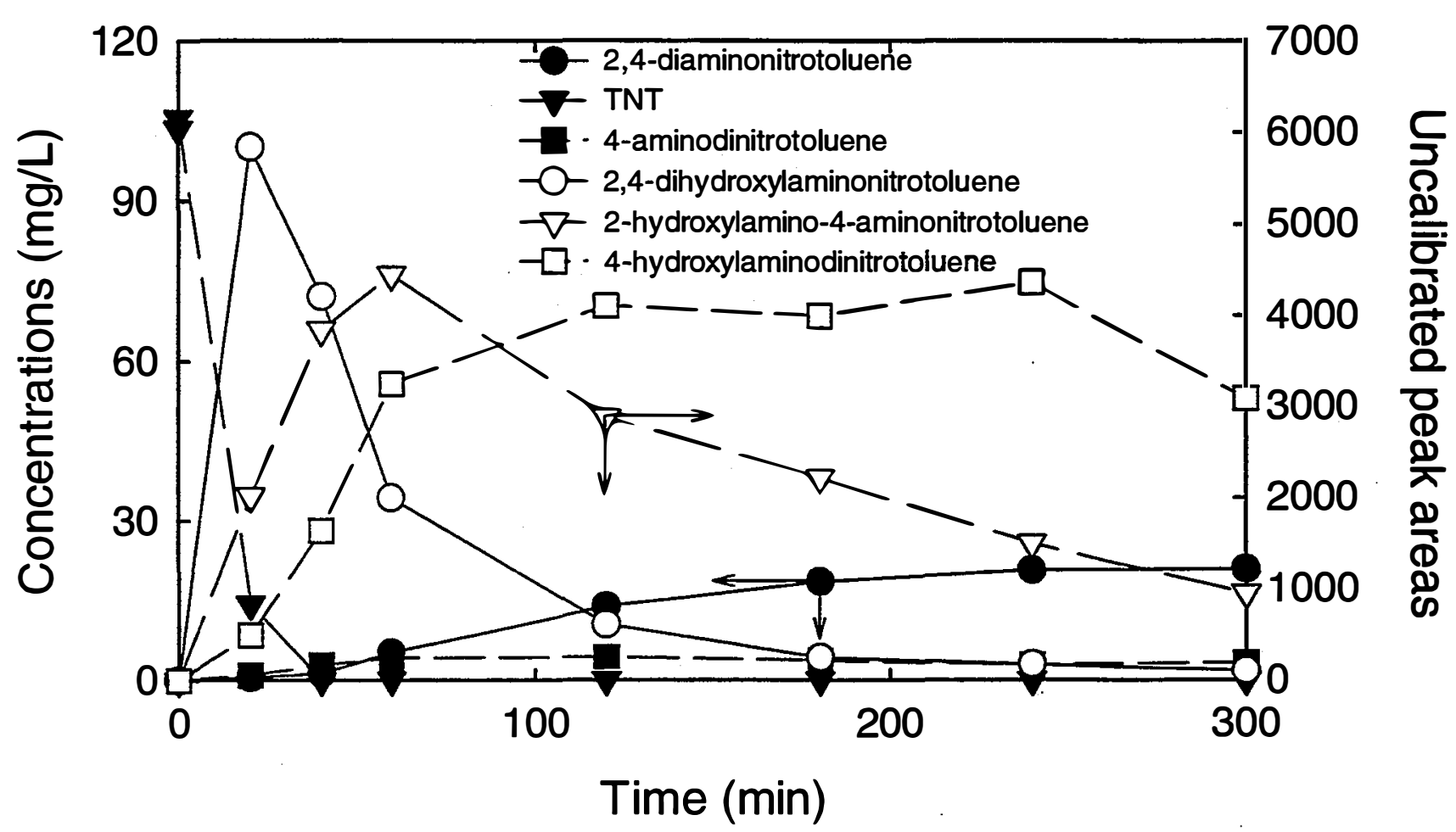

Figure 2.18. Intermediates and by-products detected in the photocatalytic reduction of TNT with EDTA at initial $\mathrm{pH}=3.05$. 


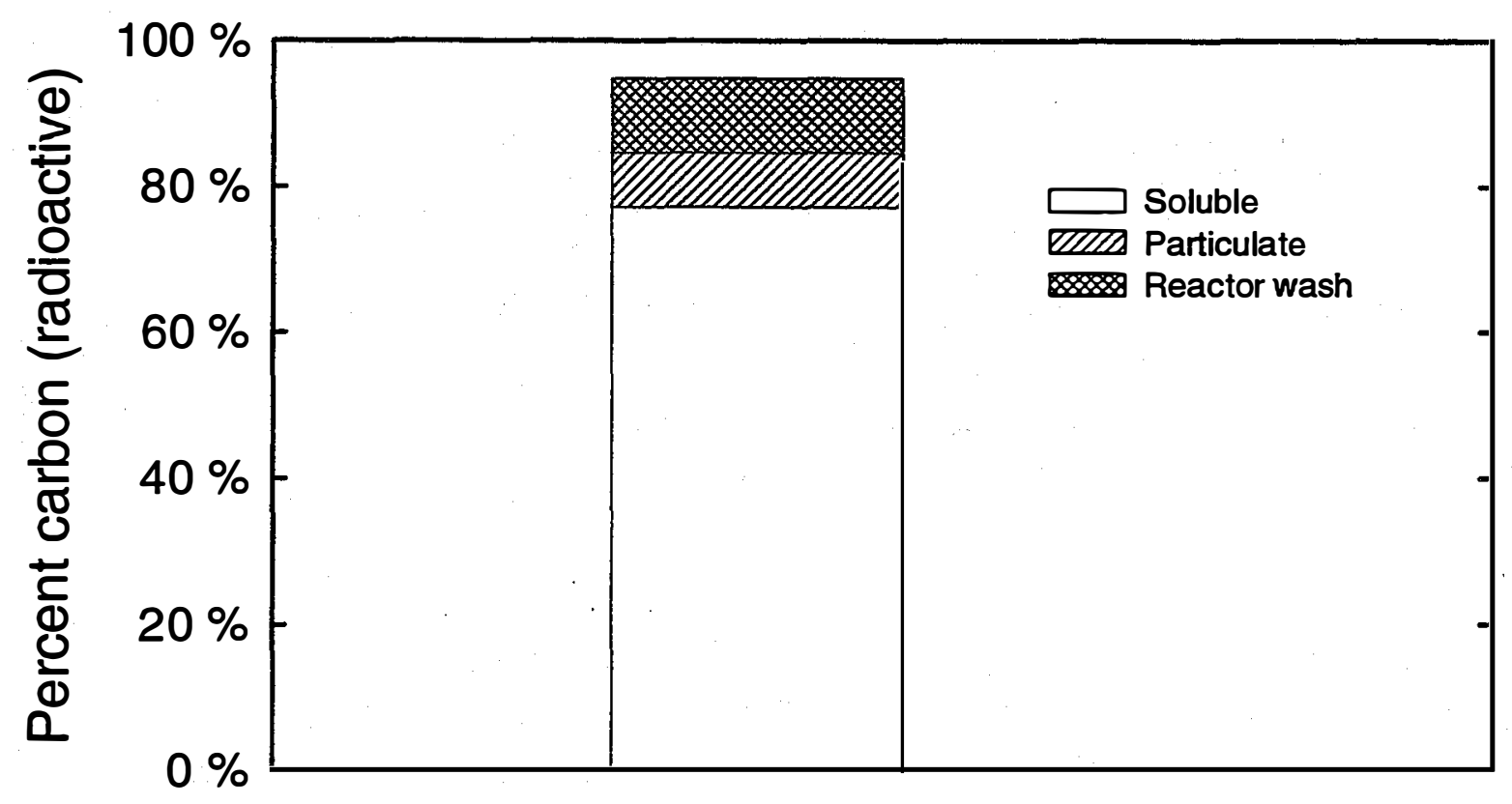

Figure 2.19. Recovery of ${ }^{14} \mathrm{C}$ labeled products from the photocatalytic reduction of ${ }^{14} \mathrm{C}$-labeled TNT with EDTA.

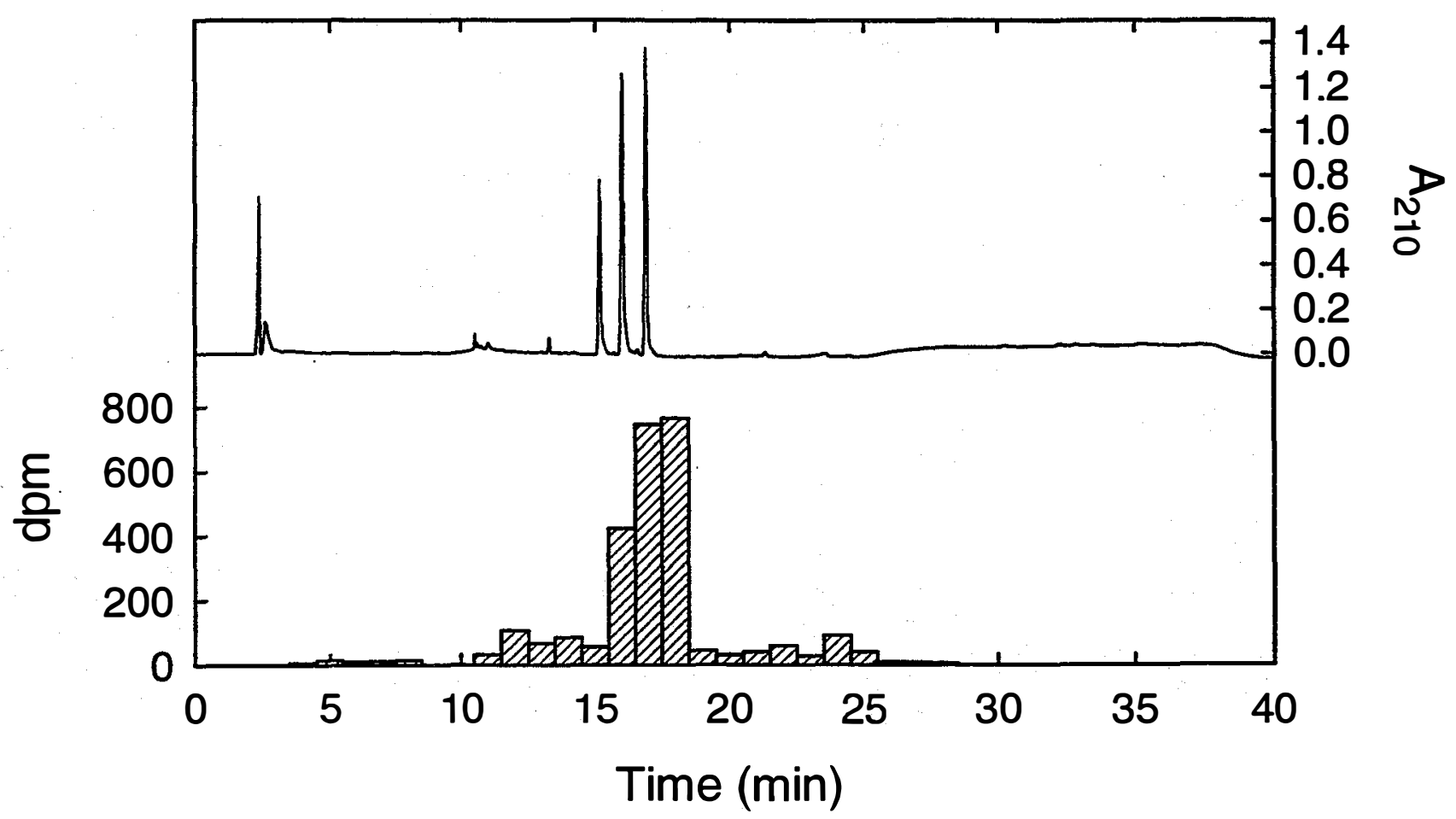

Figure 2.20. HPLC analysis of soluble intermediates and by-products from the photocatalytic reduction of ${ }^{14} \mathrm{C}$-labeled TNT with EDTA (chromatographic peaks: $\mathrm{A}_{210}$ and ${ }^{14} \mathrm{C}$ fraction: $\mathrm{dpm}$ ). 


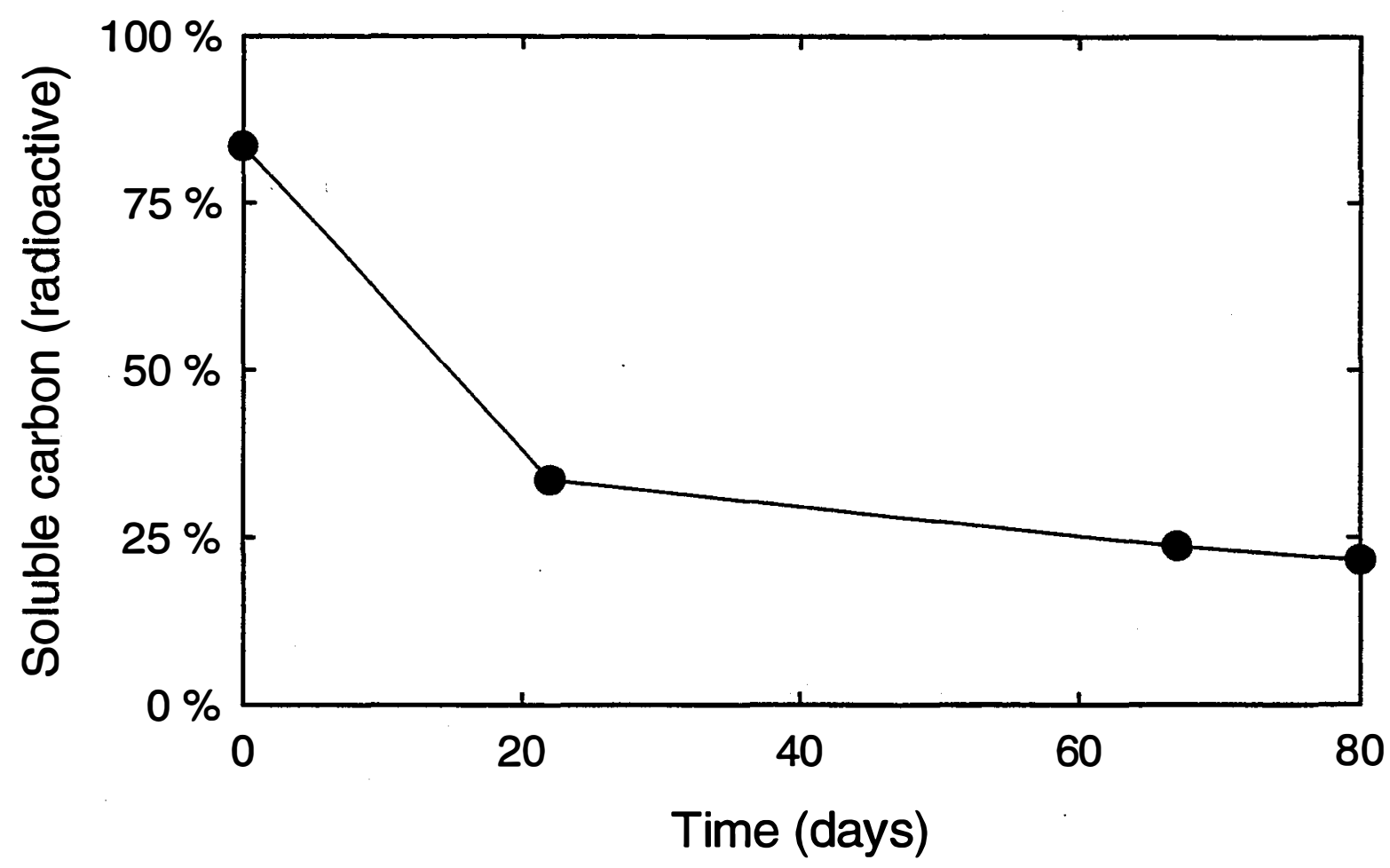

Figure 2.21. Effect of incubation time on the soluble radioactivity in the reaction mixture formed by the photocatalytic reduction of TNT with EDTA.

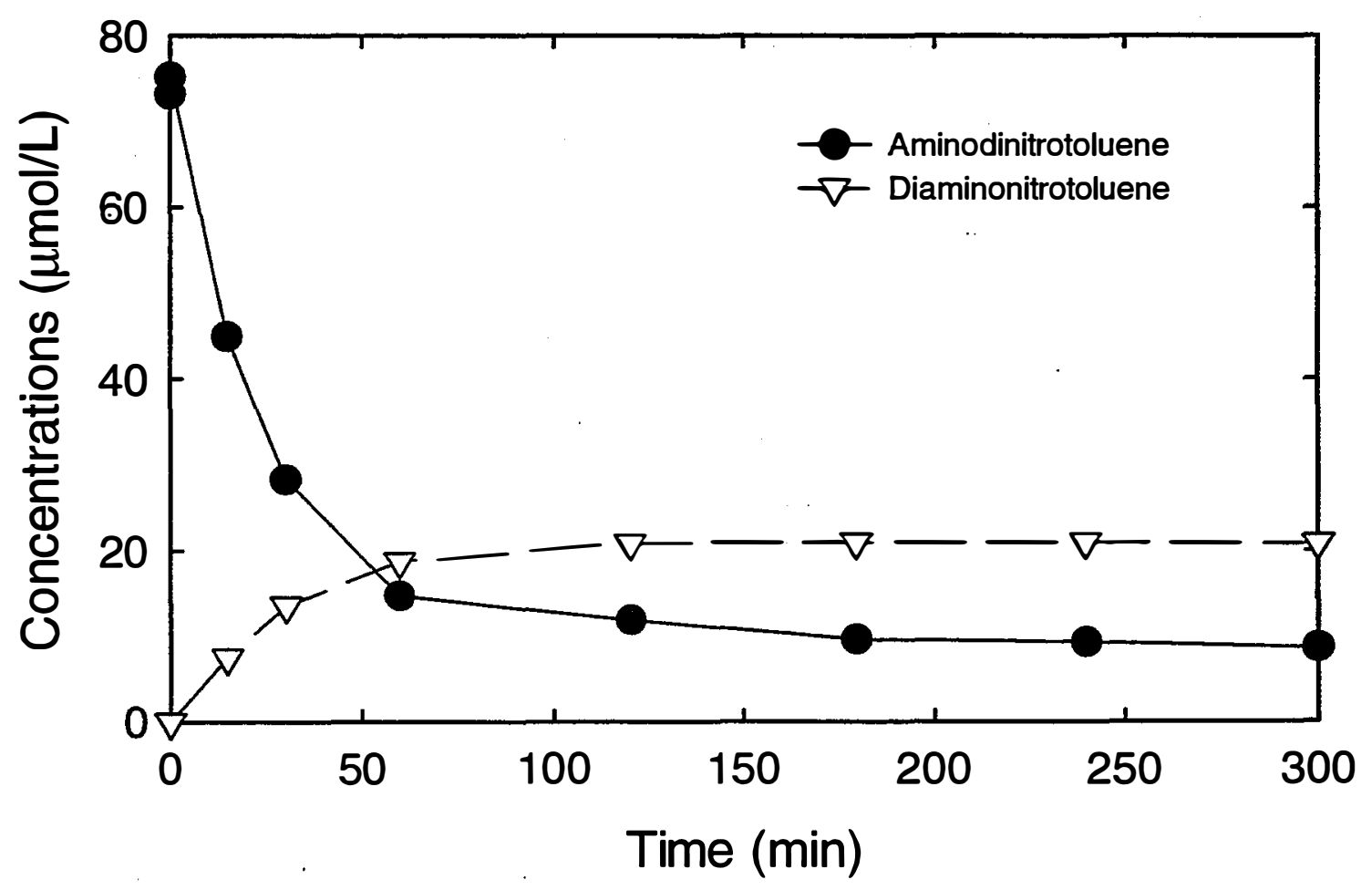

Figure 2.22. Photocatalytic reduction of 4-amino-2,6-dinitrotoluene with EDTA. 


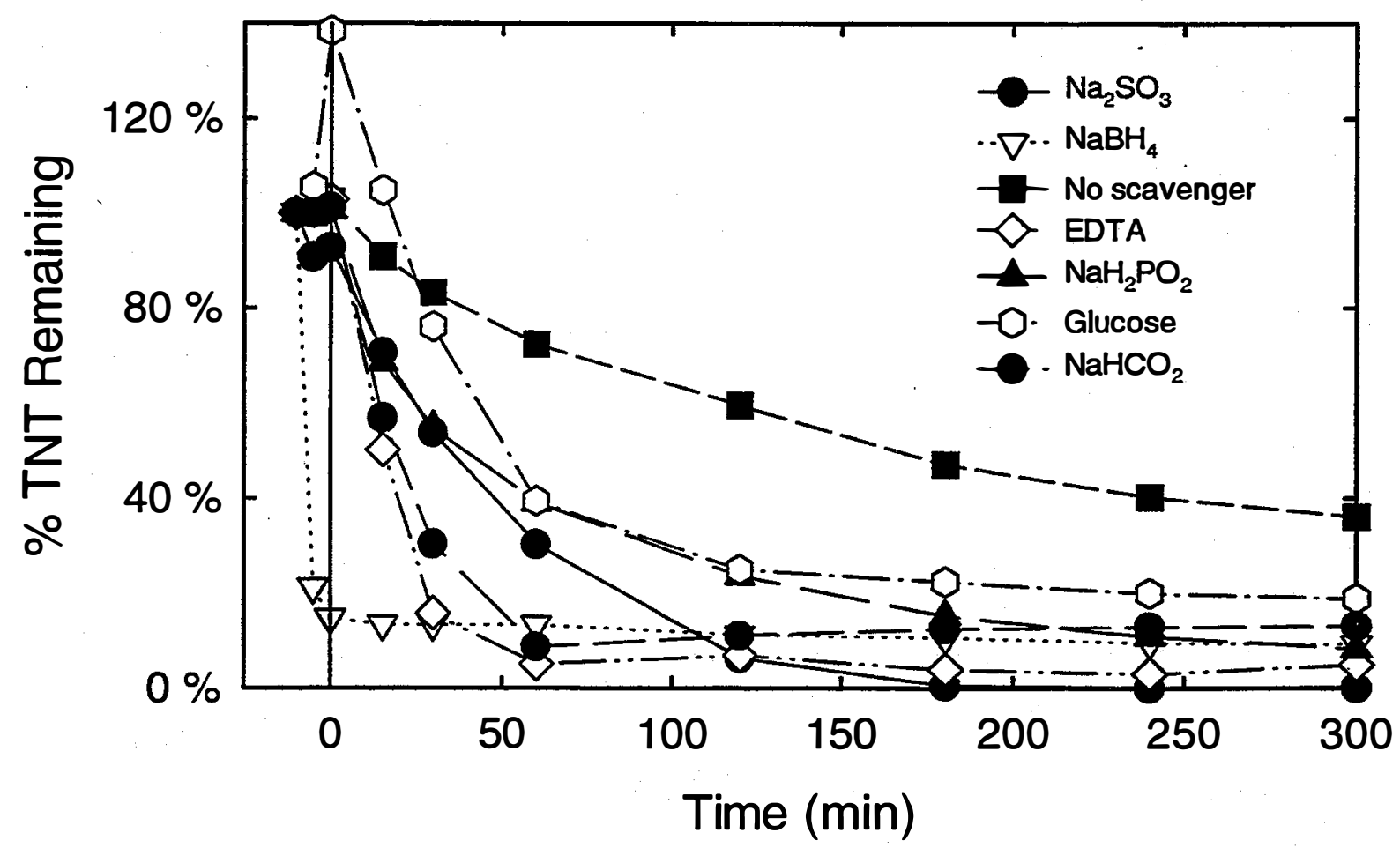

Figure 2.23a. Effect of hole scavengers upon the photocatalytic reduction of TNT in the recirculating reactor.

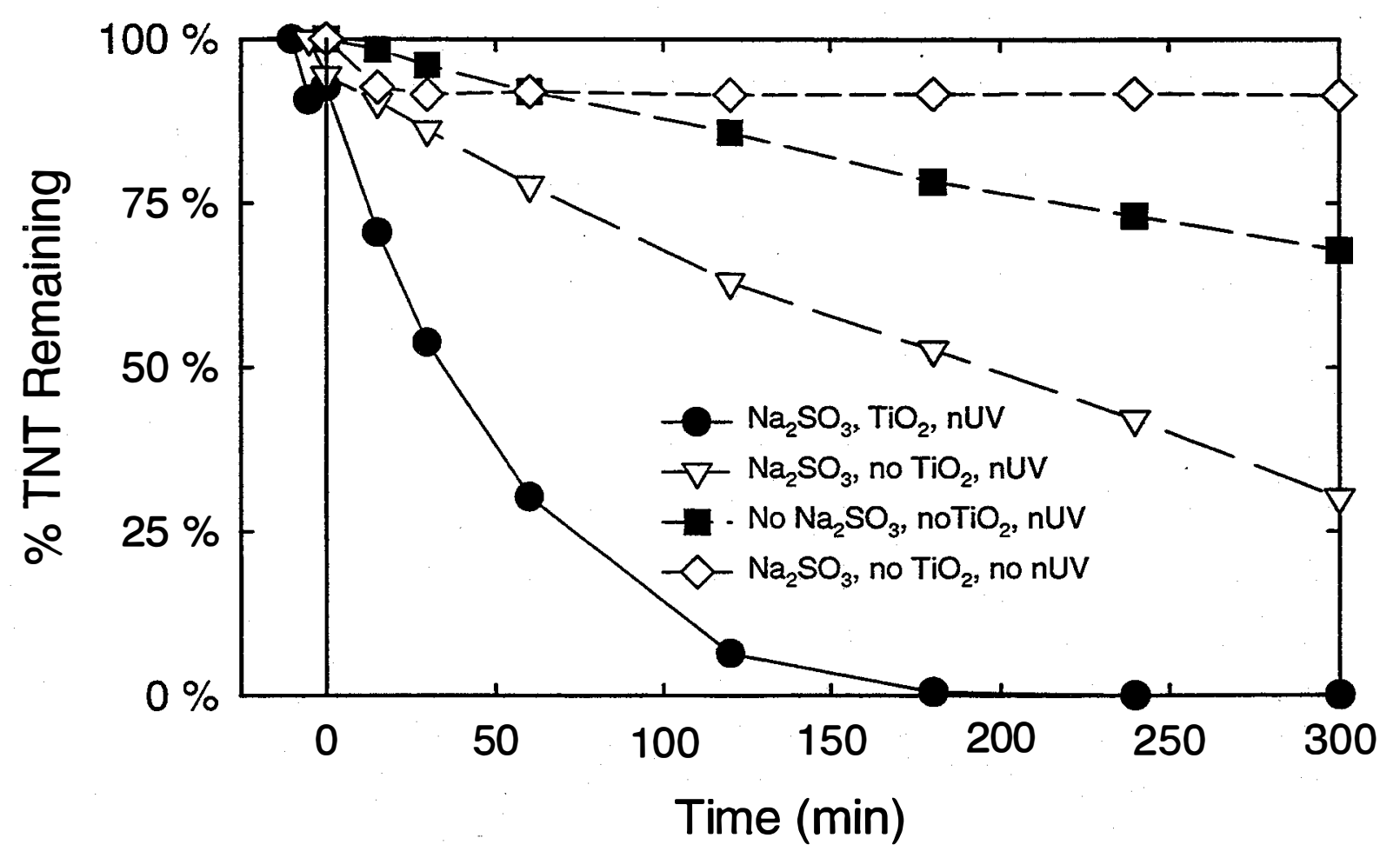

Figure 2.23b. Combined effects of sodium sulfite, $\mathrm{TiO}_{2}$, and $\mathrm{UV}$ illumination on the photocatalytic reduction of TNT in the recirculating reactor. 


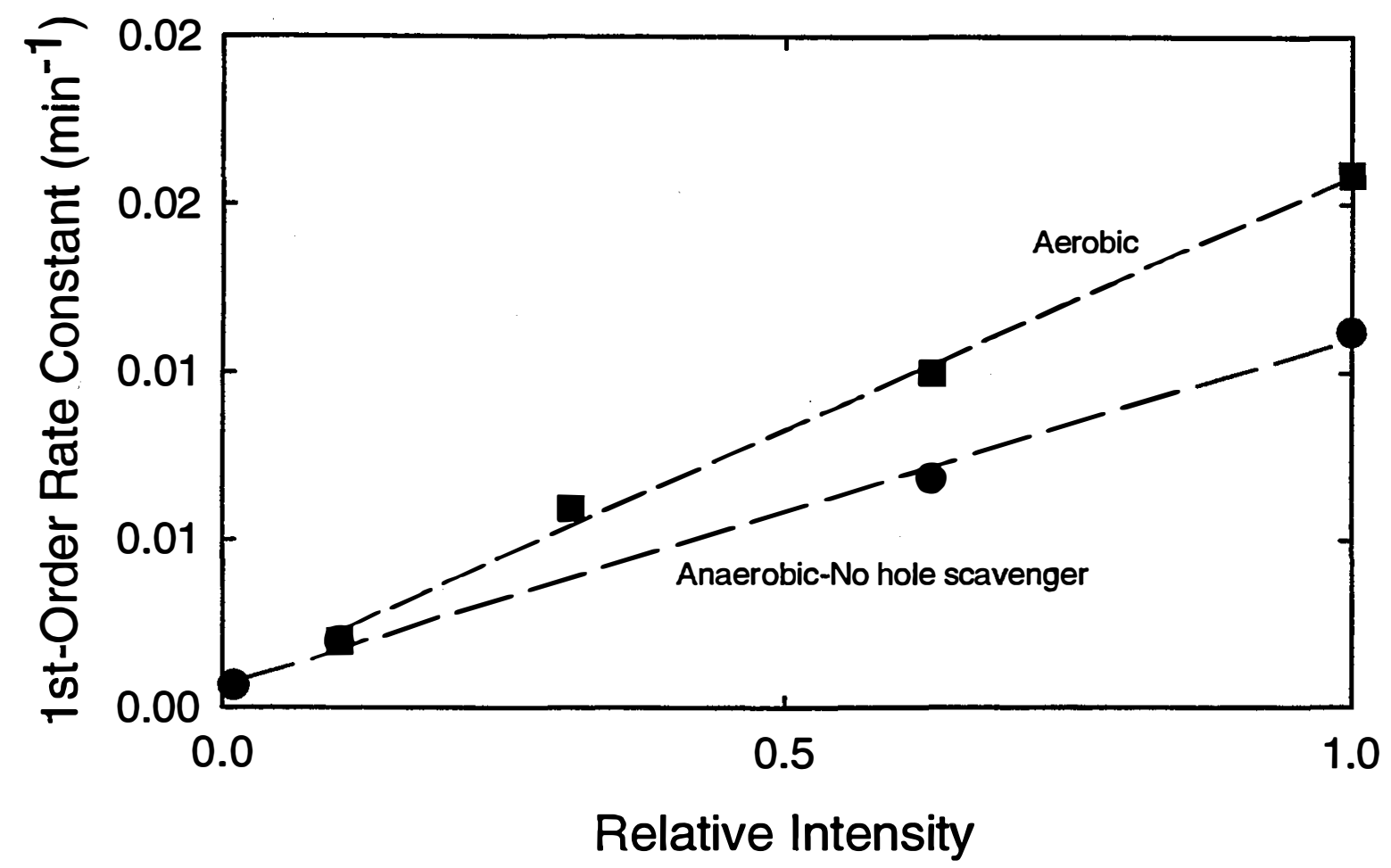

Figure 2.24a. First Order Rate Constant vs Relative Intensity for Anerobic and Aerobic TNT Degradation (Rate constant from $\ln (c)=k t+b$ )

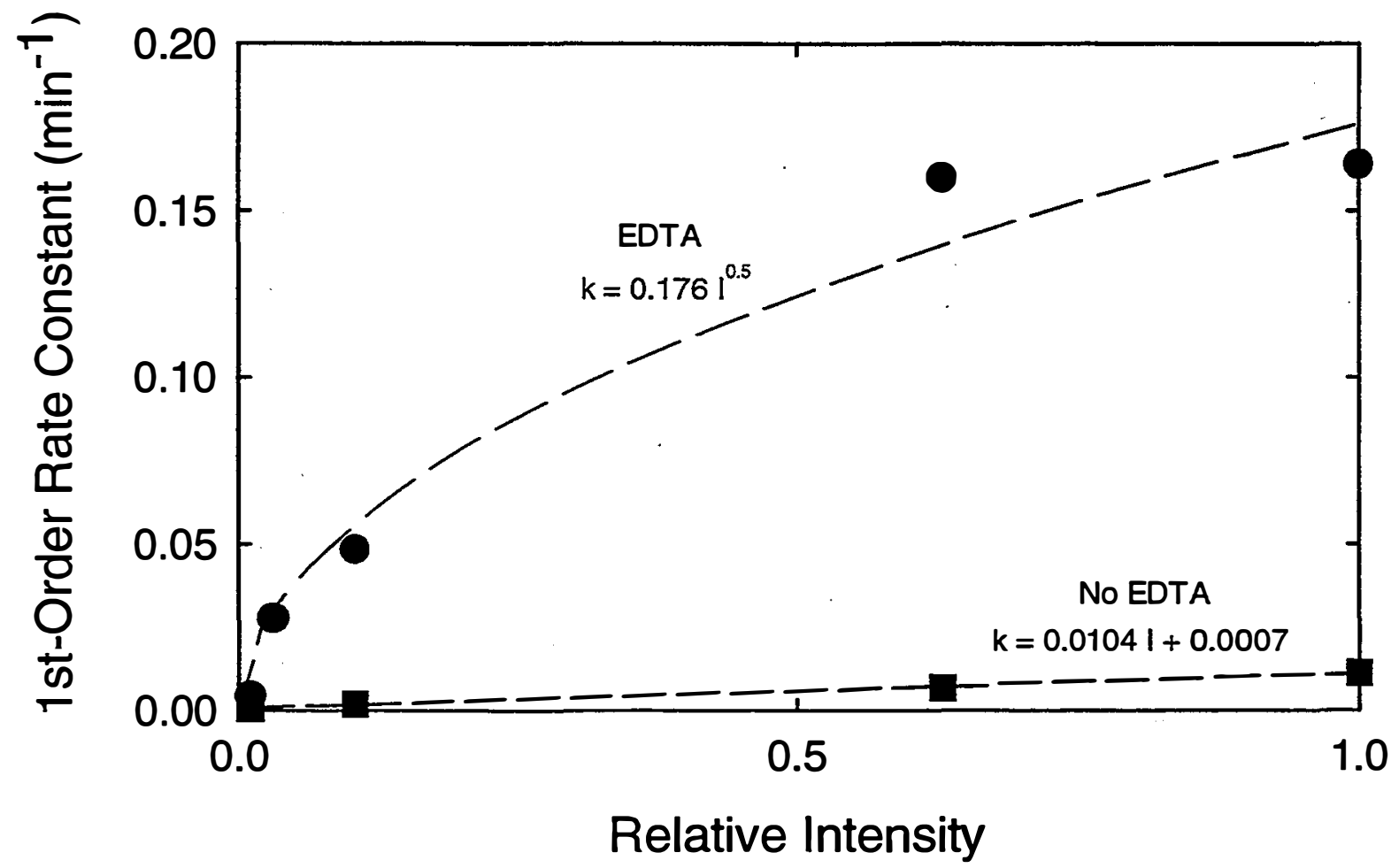

Figure 2.24b. First Order Rate Constant vs Relative Light Intensity for Anerobic TNT Degradation with and without EDTA Present (Rate constant from $\ln (c)=k t+b$ ) 


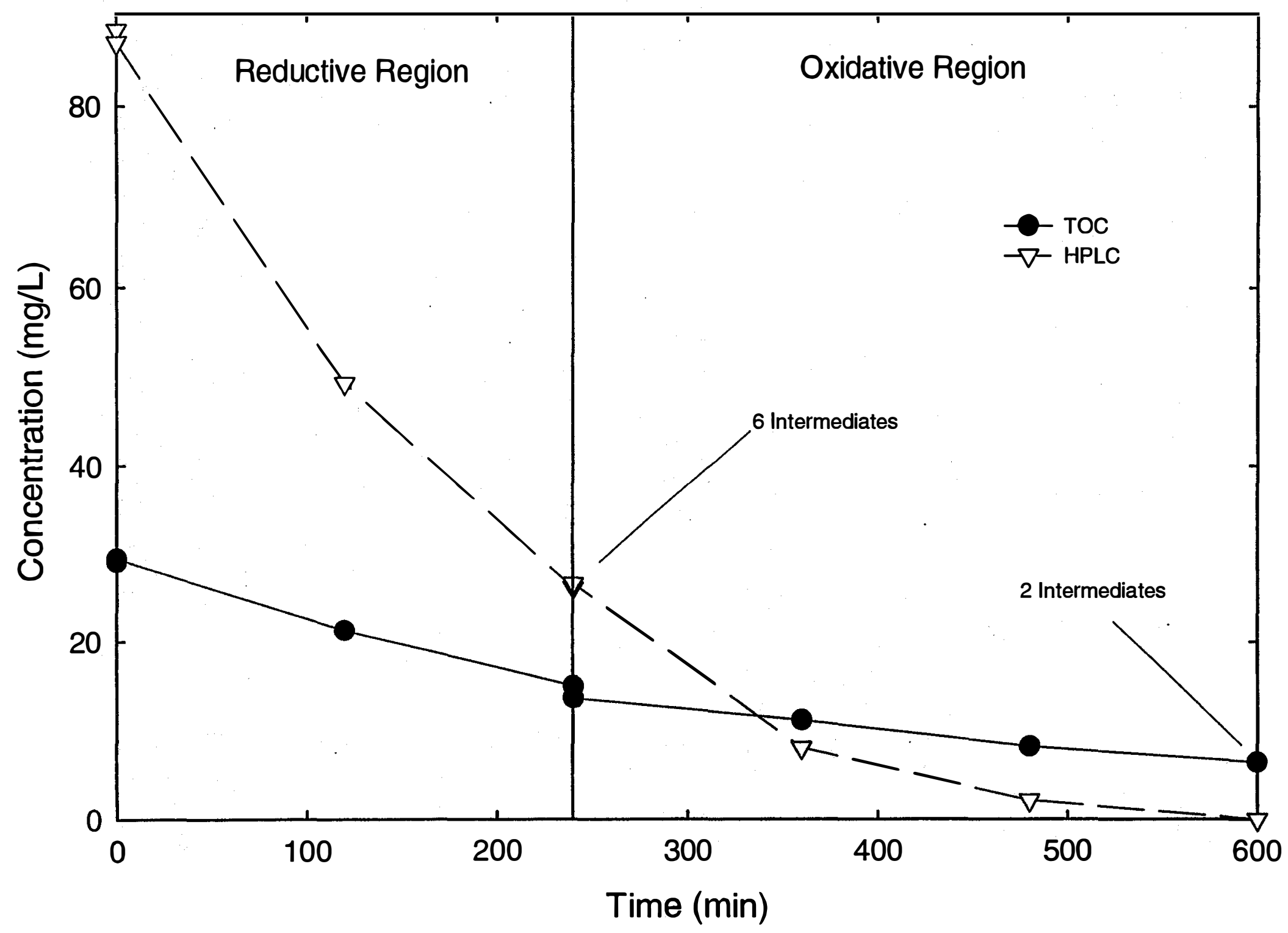

Figure 2.25. Plot of TOC and HPLC Results for Cycling of Oxidative and Reductive Conditions of TNT Degradation to Clean Catalyst Surface. 


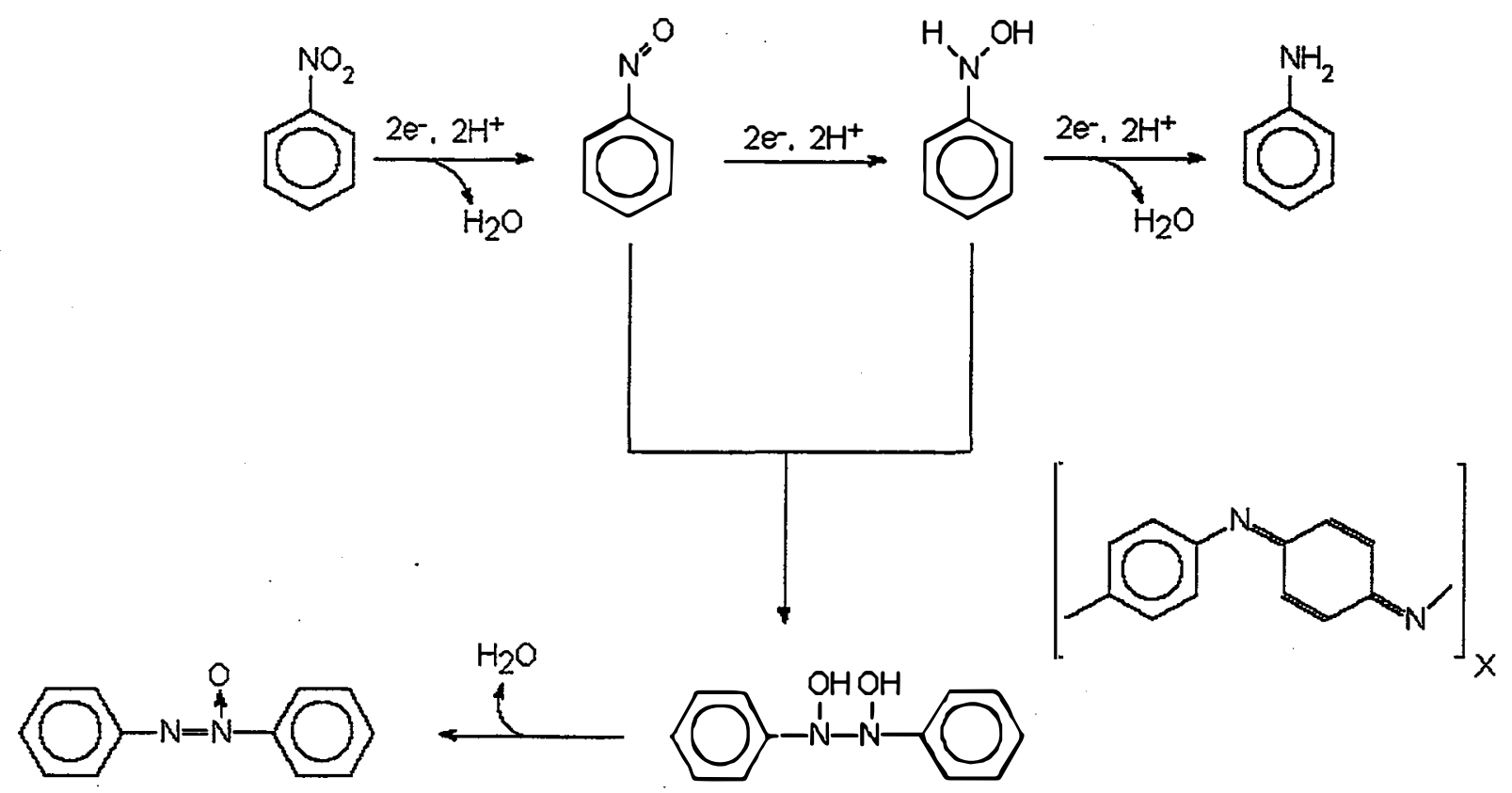

Figure 2.26. Simplified reaction scheme for reduction and coupling of the nitrogen functionality in nitroaromatic compounds.

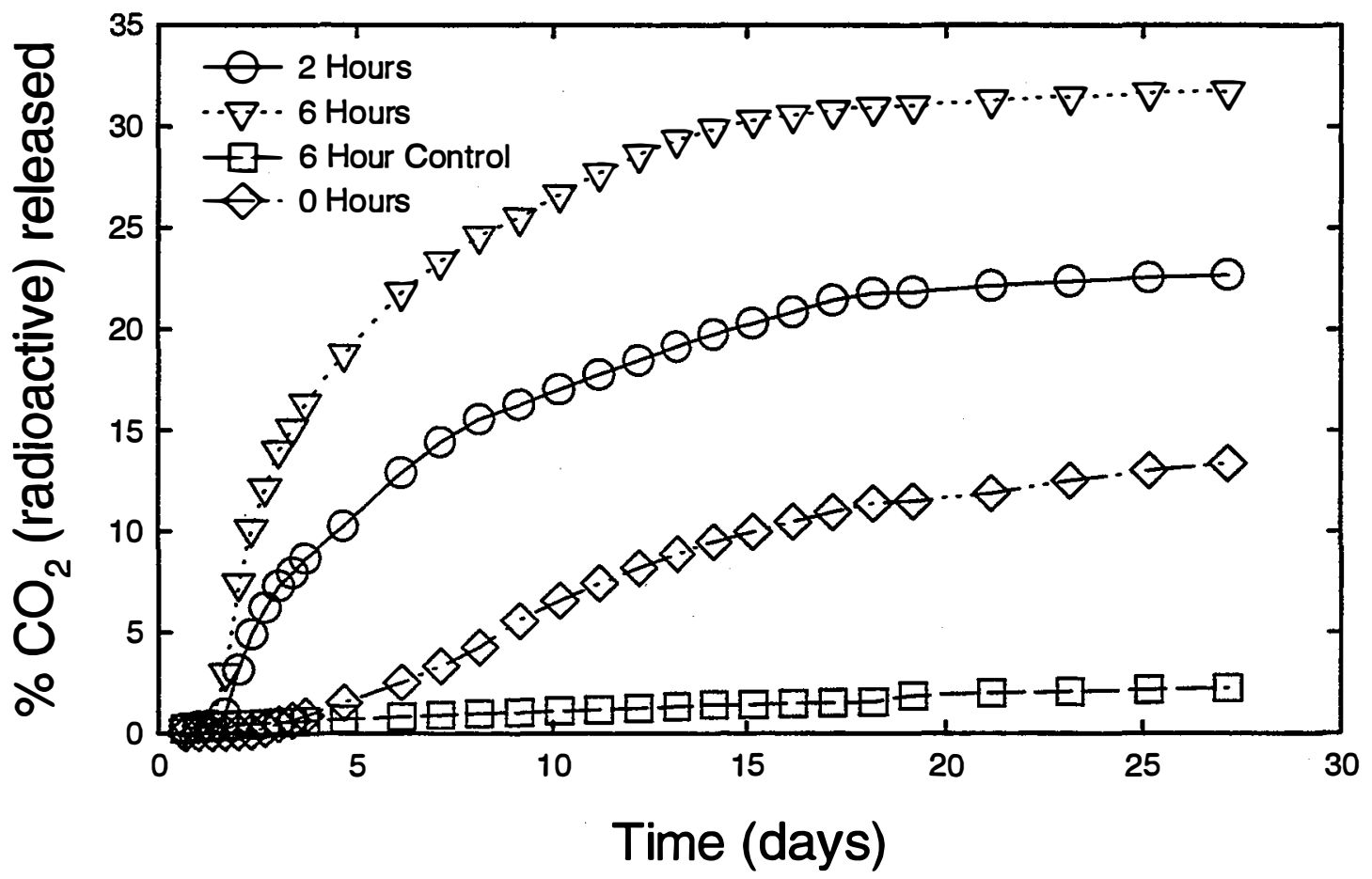

Figure 2.27. Evolution of ${ }^{14} \mathrm{C}-\mathrm{CO}_{2}$ over time from aerobic biological degradation of photocatalytic TNT degradation products by $P$. crysosporium. Graph shows four treatments: a non-inoculated control, no photocatalytic treatment (0 hours), and 2 and 6 hours of photocatalysis. 


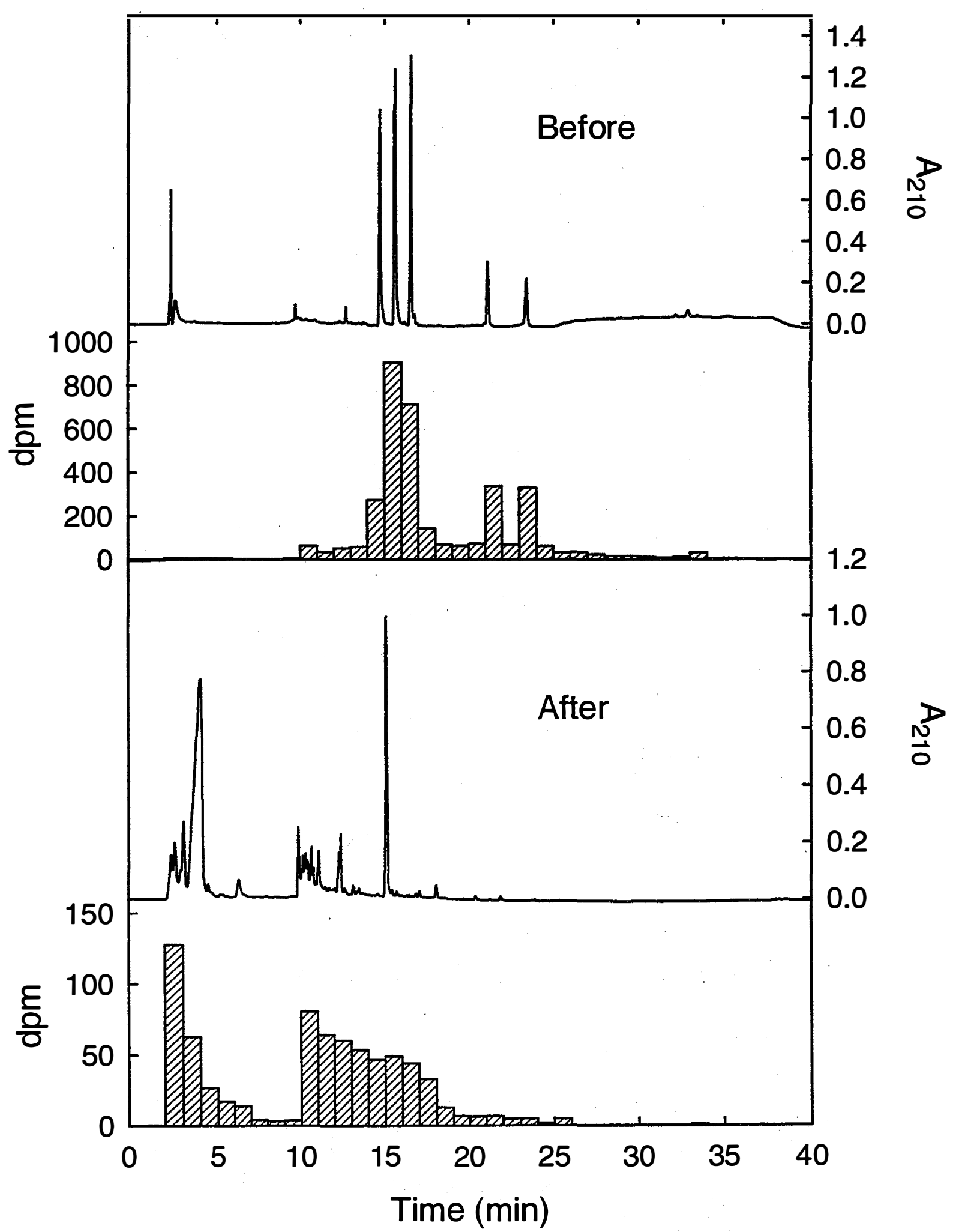

Figure 2.28. Chromatographic peaks $\left(\mathrm{A}_{210}\right)$ with associated ${ }^{14} \mathrm{C}$ fractionation (dpm) of photoreactor products from 2 hours of photocatalytic treatment of TNT before (top graph) and after (bottom graph) aerobic biological treatment by $P$. crysosporium. 


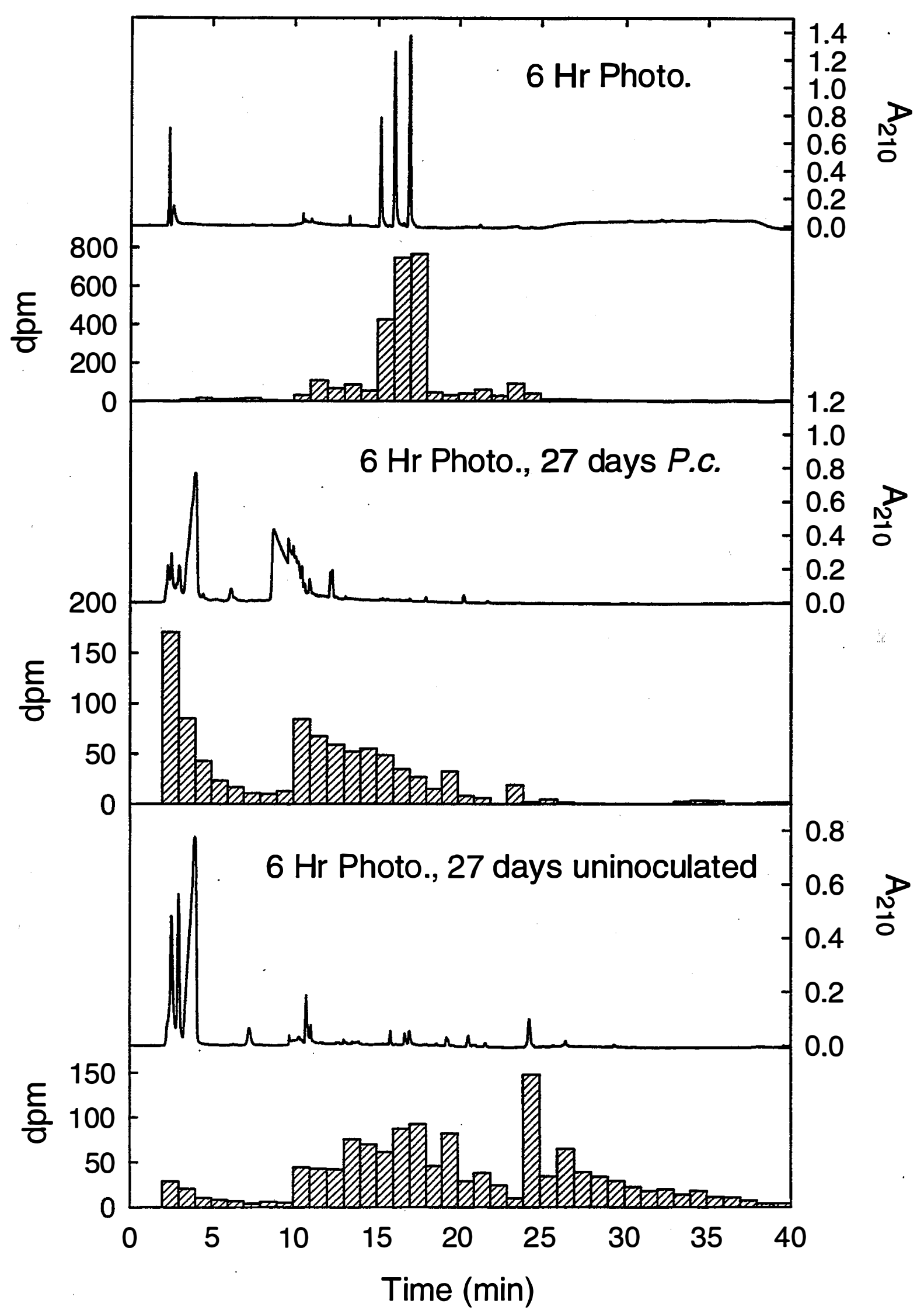

Figure 2.29. Chromatographic peaks $\left(\mathrm{A}_{210}\right)$ with associated ${ }^{14} \mathrm{C}$ fractionation (dpm) of photoreactor products from 6 hours of photocatalytic treatment of TNT before (top graph) and after (middle graph) aerobic biological treament by $P$. chrysosporium. An abiotic control (bottom graph) is included for comparison. 


\subsection{New Process Chemistry for Removal of TNT and Other HE Compounds from. Water}

A new process for the removal of TNT and other HE compounds from process water or contaminated groundwater has been identified in this project. The process is based on the use of novel reduction chemistry that does not require light or other unusual conditions. The chemistry has been characterized sufficiently to bring the process to the proof-of-concept level of development. The process is sufficiently innovative to warrant maintaining it as NREL Protected Information to allow for prosecution of patent. Therefore only a general description of the performance of this process is included here.

Figure 3.1 shows the removal of TNT from water by the process as a function of time using four variations of the reagents appropriate to the process. These reagents are indentified in the figure as R1 through R4. The TNT content is reduced below the detection limit, $20 \mathrm{ppb}$, by the process. The performance of the process is relatively insensitive to the $\mathrm{pH}$ and presence of ambient air but is accelerated by increasing temperature. Not all intermediates and by-products of the reaction chemistry have been identified. For this reason it is not known with certainty if the treated water will be without hazard. Additional work will determine if hazardous products remain in the water. If so, there are a number of options for removing them with little alteration of the process.

An economic analysis based on the carrent level of understanding indicates that the process will be less expensive to operate than the GAC systems now used to treat pink water at AAPs. The reductant is readily available in bulk quantities at low cost and neither it nor its reaction products are hazardous. The capital cost is expected to be similar to that for those systems. This new process has the potential to be a major improvement over the GAC system and will not require significant changes in process operations. 


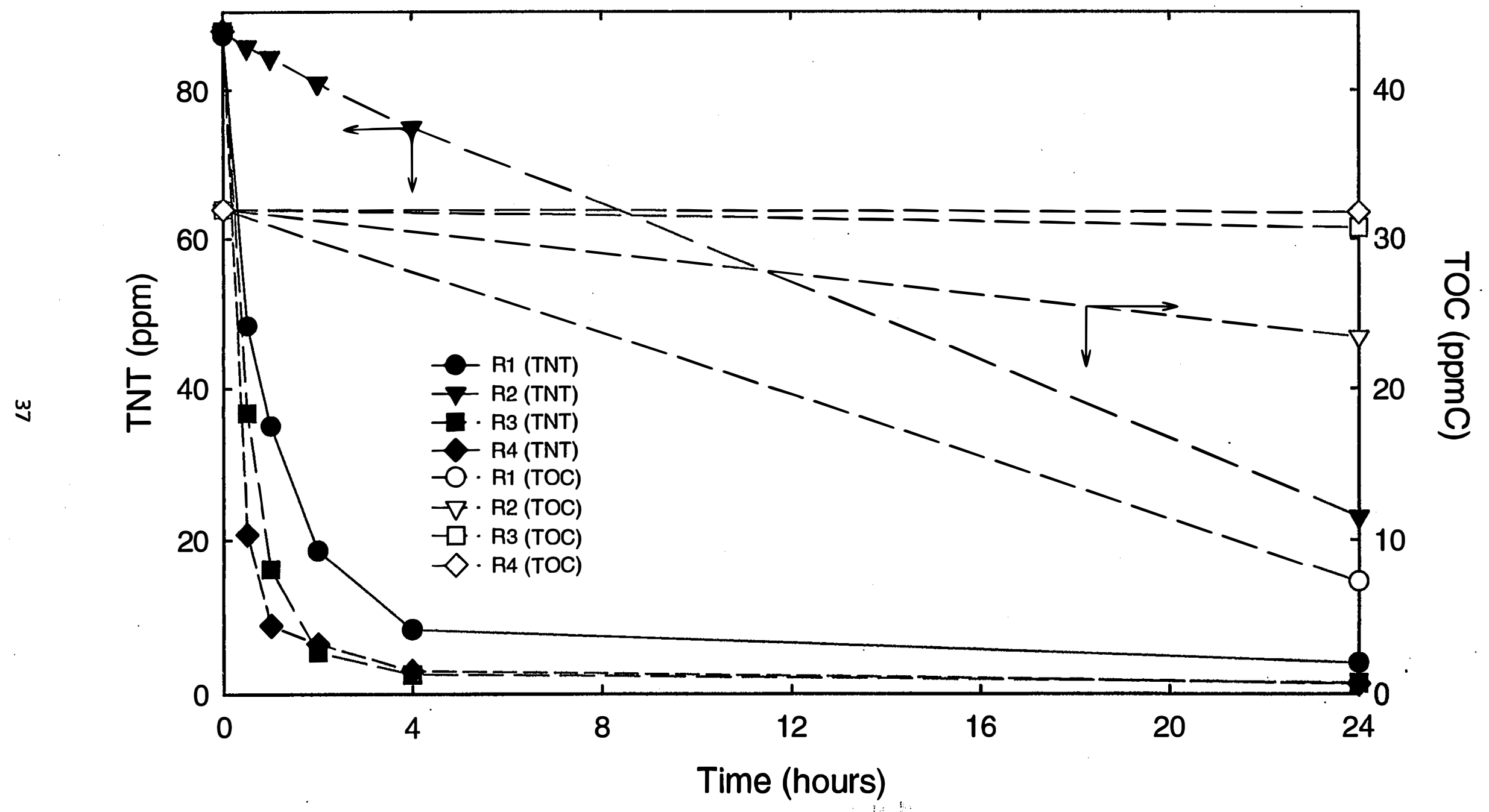

Figure 3.1. Effect of reagent type on the removal of TNT and TOC. 


\subsection{Conclusions}

Photocatalytic treatment of pink water under oxidative conditions can mineralize TNT, HMX, and RDX but requires long residence times which translates to large power consumption by the process.

Photocatalytic trearment of pink water under reducing conditions will convert TNT to other substances. The most effective reducing agents are organic compounds such as EDTA, citric acid, glucose, and sodium formate. The power requirement and the reducing agent would contribute significantly to the process cost. However, the power required for the photocatalytic reduction process is significantly less than that for the oxidative process.

Biological trearment using Phonerochaete crysosporium following reductive treatment of pink water with EDTA resulted in partial mineralization of TNT. The degree of conversion of carbon content to $\mathrm{CO}_{2}$ in the biological treatment step was dependent on the length of the photocatalytic pretreatment. The maximum extent was $32 \%$ which was achieved using a feed solution that had been exposed to $6 \mathrm{~h}$ of photocatalytic pretreatment.

This innovative new process for treating pink water is an effective method to reduce the level of TNT in pink water to below the detection limit (20 ppb). The rates of removal of HMX and RDX are lower than that for TNT under the treatment conditions that have been developed to date. It is possible that different treatment conditions will improve the rate of destruction of $\mathrm{HMX}$ and RDX. Parties interested in learning more about this process may contact the authors of this report at NREL.

The annual operating costs determined at this early stage of development for the new process process is $\$ 179,000$ for a $150 \mathrm{gpm}$ flow of pink water. This is very favorable when compared to $\$ 323,500$ estimated for the carbon adsorption process. The capital costs are believed to be similar for the two processes. 


\subsection{Recommendations}

The new process developed in this project has the potential to be a simple and low-cost method of treating pink water from LAP and demilitarization operations or for treatment of contaminated ground water. In order to develop this potential it is necessary to address gaps in the current understanding of the process. The following are recommended to provide a complete basis for assessing the process:

The nature and toxicity of the products from treatment of TNT in the new process must be determined.

The distribution of the organic and inorganic content of the treated water between solid and aqueous phases must be determined.

The amount of reagents assumed to be required, in order to estimate the cost of the process, was very conservative. Actual reagent consumption must be determined for the optimum process.

The reactivity of HMX and RDX must be improved for the process to be practical for pink water treatment. This may not be critical in the groundwater treatment application where HMX and RDX are not key factors. 


\subsection{References}

1. Pal, Bimal C.; Ryon, Michael G. Database Assessment of Pollution Control in the Military Explosives and Propellants Production Industry, Oak Ridge, TN: Oak Ridge National Laboratory, February 1986. AD-A165 853.

2. Burlinson, N.E.; Sitzmann, M.E.; Kaplan, L.A.; Kayser, E. "Photochemical Generation of the 2,4,6-Trinitrobenzyl Anion." J. Org. Chem.; Vol. 44, No. 21, 1979, pp. 3695-3698.

3. Burlinson, Nicholas E.; Kaplan, Lloyd A.; Adams, Charles E. Photochemistry of TNT: Investigation of the "Pink Water" Problem. White Oak, Silver Spring, MD: Naval Ordnance Laboratory. 3 October 1973. AD 769670.

4. Kaplan, Lloyd A.; Burlinson, Nicholas E.; Sitzmann, M.E. Photochemistry of TNT: Investigation of the Pink Water Problem, Part II. Silver Spring, MD: Naval Surface Weapons Center. 21 November 1975.

5. Mabey, W.R; Tse, D.; Baraze, A.; Mill, T. "Photolysis of Nitroaromatics in Aquatic Systems. I. 2,4,6Trinitrotoluene." Chemosphere, Vol. 12, No. 1, 1983, pp. 3-16.

6. Crowley, John, Iowa Army Ammunition Plant, Information Exchange Meeting, 27 September 1994.

7. Mahannah, J.L. Survey of Generation and Management of Explosive-Laden Spent Carbon. Cambridge, MA: Arthur D. Little, Inc. November 1992. AD Little, Inc.

8. Hinshaw, Gary D.; Fanska, Cindy B.; Fiscus, Douglas E.; Sorensen, Scot A. Granular Activated Carbon (GAC) System Performance Capabilities and Optimization. Kansas City, MO: Midwest Research Institute, 27 February 1987. MRI.

9. Andrews, Catherine C. Photooxidative Treatment of TNT Contaminated Wastewaters. Crane, IN: Naval Weapons Support Center. December 1979. ADA 084684.

10. Bowen, Richard C.; Balasco, Ammand A.; Bryant, Michael; Cahill, Kevin; Marando, Michael. Final Feasibility Study for Ground Water at Explosive Washout Lagoons (OU-3) at the Umatilla Depot Activity (UMDA). Aberdeen Proving Ground, MD 21010: US Army Environmental Center. 10 December 1993. USAEC.

11. Layne, William S.; Nicholson, Richard A.; Wahl, Richard M.; O'Brian, Patrick M. Ultraviolet-Ozone Treatment of Pink Water - A Pilot Plant Study. Middletown, Iowa: Mason \& Hanger - Silas Mason Co., Inc. 15 September 1980. Mason \& Hanger - Silas Mason Co., Inc.

12. Ho, Patience C. "Photooxidation of 2,4- Dinitrotoluene in Aqueous Solution in the Presence of Hydrogen Peroxide." Environ. Sci. Technol.; Vol. 20, No. 3, 1986, pp. 260-267.

13. McCormick, N.G.; Peltonen, T.D.; Kaplan, A.M. Development of Design Parameters for an Explosive Contaminated Wastewater Treatment System. Crane, IN: Naval Weapons Support Cente. June 1985. AD-A159 416.

14. Noss, Charles I.; Chyrek, Ralph H. Tertiary Treatment of Effluent from Holston AAP Industrial Liquid Waste Treatment Facility IV. Ultraviolet Radiation and Hydrogen Peroxide Studies: TNT, RDX, HMX, TAX, and SEX. Frederick, MD: Fort Detrick. March 1984. AD-A141 135. 
15. Roth, Milton;.Murphy, Jr., Joseph M. Ultraviolet-Ozone and Ultraviolet-Oxidant Treatment of Pink Water. Dover, NJ: US Army Ammament Research and Development Command, Large Caliber Weapon Systems Laboratory. November 1978. AD-E400 263.

16. DeBerry, David W.; Viehbeck Alfred; Meldrum, Dean. A Literature Survey: Basic Mechanisms of Explosive Compounds in Wastewater. Aberdeen Proving Ground, MD: USATHAMA May 1984.

AD-A141 703.

17. Lipczynska-Kochany, Eva. "Novel Method for a Photocatalytic Degradation of 4-Nitrophenol in Homogeneous Aqueous Solution." Environmental Technology; Vol. 12, 1991, pp. 87-92.

18. Jain, Kamlesh K.; Bryce, Armond J. "Feasibility of Munitions Wastewater Treatment by AdsorptionOxidation." Carbon Adsorption Handbook. Edited by Paul N. Chesemisinoff and Fred Ellerbush. Ann Arbor, MI: Ann Arbor Science Publisher, 1978, pp. 661-85.

19. Kulkami, Ramchandra K. Pollutant Adsorbent Systems for TNT, RDX, and HMX in Wastewater, Frederick, MD: US Army Medical Research and Development Command. October 1986. AD-A188 407.

20. Freeman, Donald J.; Colitti, Olin A. Removal of Explosives from LAP Wastewater (Pink Water) Using Surfactant Technology. Dover, NJ: ARRADCOM, TSD. May 1982. AD A115086.

21. Simmons, Milagros S.; Zepp, Richard G. "Influence of Humic Substances on Photolysis of Nitroaromatic Compounds in Aqueous Systems." Water Res.; Vol. 20, No. 7, 1986, pp. 899-904.

22. Hoffsommer, J.C.; Kaplan, L.A.; Glover, D.J.; Kubose, D.A.; Dickinson, C.; Goya, H.; Kayser, E.G.; Groves, C.L.; Sitzmann, M.E. Biodegradability of TNT: A Three-Year Pilot Plant Study. Silver Spring, MD: Naval Surface Weapons Center. 13 February 1978. AD A061 144.

23. McCormick, N.G.; Comell, J.H.; Kaplan, A.M. "Biodegradation of hexahydro-1,3,5-Trinitro1,3,5-Triazine." Applied and Environmental Microbiology; Vol. 42, No. 5, 1981, pp. 817-823.

24. Mondecar, M.; Bender, J.; Ross, J.; George, W.; Preslan, J. "Removal of 2,4,6-Trinitrotoluene from Contaminated Water with Microbial Mats." Applied Biotechnology for Site Remediation. Edited by Robert E. Hinchee, Daniel B. Anderson, and Gregory D. Sayles. Boca Raton, FL: Lewis Publishers, 1994, pp. 342-9.

25. Walker, John E.; Kaplan, David L: "Biological Degradation of Explosives and Chemical Agents." Biodegradation; Vol. 3, 1992, pp. 369-385.

26. Wade, Robert C. "Catalyzed Reductions of Organofunctional Groups With Sodium Borohydride." J. Mol. Catal.; Vol. 18, 1983, pp. 273-297.

27. Lamson, Davis W.; Ulrich, Peter; Hutchins, Robert O. "Aromatic Denitration With Borohydride. Nucleophilic Displacement of Nitrite by Hydride." J. Org. Chem.; Vol. 38, No. 17, 1973, pp. 2928-2930.

28. Larson, Richard A.; Miller, Penney L.; Crowley, Thomas O. "Borohydride Photoreduction of Nitroaromatic Compounds Related to Military Ordnance Constituents." Environ. Sci. Technol.; Vol. 30, No. 4, 1996, pp. 1192-1197.

29. Webb, John D.; Blake, Daniel M.; Turchi, Craig C.; Magrini, Kimberly. "Kinetic and Mechanistic Overview of $\mathrm{TiO}_{2}$-Photocatalyzed Oxidation Reactions in Aqueous Solutions." Solar Energy Mat.; Vol. 24, 1991, pp. 584-93. 
30. Fox, Marye Anne; Dulay, Marla T. "Heterogeneous Photocatalysis." Chem. Rev.; Vol. 93, 1993, pp. 341-357.

31. Prairie, Michael R; Evans, Lindsey R.; Stange, Bertha M.; Martinez, Sheryl L. "An Investigation of the $\mathrm{TiO}_{2}$ Photocatalysis for the Treatment of Water Contaminated with Metals and Organic Chemicals." Environ. Sci. Technol.; Vol. 27, 1993, pp. 1776-1782.

32. Vinodgopal, K.; Bedja, Idriss; Hotchandani, Surat; Kamat, Prashant V. "A Photocatalytic Approach for the Reductive Decolorization of Textile Azo Dyes in Colloidal Semiconductor Suspensions." Langmuir; Vol. 10, 1994, pp. 1767-1771.

33. Schmelling, D.C.; Gray, K.A. "Feasibility of Photocatalytic Degradation of TNT as a Single or Integrated Treatment Process." Trace Metals in the Environment, Vol. 3, Photocatalytic Purification and Treatment of Woter and Air, edited by David F. Ollis and H. Al-Ekabi. New York, NY: Elsevier, 1993, pp. 625-631.

34. Schmelling, Daniel C.; Gray, Kimberly A. "Photocatalytic Transformation an d Mineralization of 2,4,6Trinitrotoluene (TNT) in $\mathrm{TiO}_{2}$ Slurries." Water Res. Vol. 29, No. 12, 1995, pp. 2651-2662.

35. Schmelling, Daniel C.; Gray, Kimberly A. "Photocatalytic Transformations and Degradation of 2,4,6Trinitrotoluene (TNT) in $\mathrm{TiO}_{2}$ Slurries." Crit. Issues Water Wastewater Treat., Proc. Natl. Conf. Environ. Eng. Edited by Joseph N. Ryan and Marc Edwards. New York, NY: American Society of Civil Engineers, 1994, pp. 751-755.

36. Wang, Zhikai; Kutal, Charles. "Photocatalytic Mineralization of 2,4,6-Trinitrotoluene in Aqueous Suspensions of Titanium Dioxide." Chemosphere ; Vol. 30, No. 6, (1995, pp. 1125-1136.

37. Diller, Ralf; Brandt, Matthias; Fornefett, Iris; Siebers, Ulrike; Bahnemann, Detlef. "Photocatalytic Degradation of Trinitrotoluene and Other Nitroaromatic Compounds." Chemosphere; Vol. 30, No. 12, 1995, pp. 2333-2341.

38. Augugliaro, Vincenzo; Palmisano, Leonardo; Schiavello, Mario; Sclafani, Antonino; Marchese, Leonardo; Martra, Gianmario; Miano, Fausto. "Photocatalytic Degradation of Nitrophenols in Aqueous Titanium Dioxide Dispersion." Appl. Catal.; Vol. 69, No. 2, 1991, pp. 323-340.

39. Dieckmann, M.S.; Gray, K.A.; Kamat, P.V. "Photocatalyzed Degradation of Adsorbed Nitrophenolic Compounds on Semiconductor Surfaces." Water Sci. Technol; Vol. 25, No. 3, 1992, pp. 277-279.

40. Turchi, Craig S. "Heterogeneous Photocatalytic Degradation of Organic Water Contaminants: Kinetics and Hydroxyl Radical Mechanisms," Ph.D. Thesis, Raleigh, NC: North Carolina State University, February 1990.

41. Lund, Henning. "Cathodic Reduction of Nitro and Related Compounds," Organic Electrochemistry, edited by Henning Lund and Manuel Baizer. New York, NY: Marcel Dekker, Inc. 1991, pp. 401-432.

42. Hess, Thomas; Crawford, Ronald L.; Lewis, Thomas. "Combined Photocatalytic and Biological Treatment of Pink Water." Subcontract No. XCK-5-15163-01 Final Report. CITY, STATE: University of Idaho, July 1996 (Included as Appendix A of this report). 


\title{
7.0 Appendices
}

A. Report on Subcontract No. XCK-5-15163-01, "Combined Photocatalytic and Biological Treatment of Pink Water," University of Idaho, Moscow, ID, July 1996.

FINAL REPORT

SUBCONTRACT NO. XCK-5-15163-01

Combined Photocatalytic and Biological Treatment of Pinkwater

\author{
Principal Investigator \\ Thomas F. Hess, PhD \\ Department of Biological \& Agricultural Engineering \\ University of Idaho \\ Moscow, ID \\ Tom Lewis, PhD; Ron Crawford, $\mathrm{PhD}$ \\ Center for Hazardous Waste Research and Remediation \\ University of Idaho \\ Moscow, ID
}

\section{Acknowledgment}

Funding for this project was provided by the Strategic Environmental Research and Develop Program (SERDP). 


\begin{abstract}
A recirculating batch, annular photoreactor in combination with cultures of the ligninolytic fungus, $P$. chrysosporium, was used to investigate degradation and ultimate mineralization of aqueous solutions of 2,4,6-trinitrotoluene (TNT), a "pink water" constituent. The photocatalytic pretreatments of TNT were performed under anaerobic conditions with the addition of EDTA as a reducing agent to promote TNT reduction. Follow-on biological treatment of the photoreactor degradation products was performed under aerobic conditions using mycelial preparations of $P$. chrysosporium. Radiotracer experiments showed up to 32 percent mineralization of the parent CTNT, depending on length of phototreatment. Longer photocatalytic treatment of the TNT resulted in a greater extent of mineraliztion. An early reduction intermediate in the TNT degradation pathway was shown to be inhibitory to the fungal mineralization of the photoproducts, as shown by the radiotracer studies. The combined processes of $\mathrm{TiO}_{2}$ assisted photocatalysis and follow-on biological mineralization have the potential for being an effective technology for the remediation of pink water constituents.
\end{abstract}

\title{
INTRODUCTION
}

This report summarizes experimental work on Subcontract No. XCK-5-15163-01 "Combined Photocatalytic and Biological Treatment of Pinkwater" related to photocatalysis and biological treatment of 2,4,6-trinitrotoluene (TNT), a constituent of pinkwater.

\section{METHODS AND MATERIALS}

I. Photocatalytic Reactor System Description: All photocatalysis experiments for TNT degradation were performed in a batch, recirculating annular photoreactor, similar in design to reactors used by NREL scientists in their research (Blake et al., 1995). A schematic of the photocatalytic reactor system is shown in Figure 1. The reactor system consisted of a reservoir with temperature-control bath, a magnetic-drive centrifugal pump, and an annular photoreactor. The three parts were connected with $3 / 8$ " corrugated flexible Teflon tubing.

Reservoir: The reservoir was a IL round-bottomed flask with three 24/40 ground glass-fittings at the top and one 1/2" (OD) glass tube protruding from the bottom. One of the ground-glass fittings served as the return line from the annular reactor, one held a nitrogen sparging assembly, and the third held a sample-port/thermocouple assembly. The ground-glass fitting used ACETHRED adapters for the inlet tube, gas sparger, and thermocouple.

Centrifugal Pump: The centrifugal pump was variable speed with magnetic drive and plastic impeller. The pump had a maximum flow rate of $10 \mathrm{lpm}$ providing a residence time of approximately 1.5 seconds per pass in the annular reactor.

Annular Reactor: The annular reactor design was similar in size to a reactor used by the group at NREL in their research (Blake et al., 1995). The reactor consisted of six parts. Two identical end pieces, machined out of Teflon, two glass pipes which constituted the inner and outer walls of the reactor, and two flow dispersion disks, also made out of Teflon. The two end pieces and two glass tubes were held together by compression of the O-rings. The outer glass pipe was constructed from $54 \mathrm{~mm}$ standard-wall Pyrex tubing. Each pipe was 10-1/2" in length and the ends lightly fire-polished. The inner glass pipe was constructed of $35 \mathrm{~mm}$ standard wall Pyrex or Quartz tubing 14" in length and lightly fire-polished. The choice of Pyrex or Quartz tubing was dictated by the light source. A quartz tube is necessary only when using a UV (germicidal) lamp, since Pyrex is not transparent to UV light. The Pyrex sleeve was used with the near UV (blacklight) lamp since Pyrex is transparent to these wavelengths. 
The Teflon dispersion disks were used to prevent any "short-circuiting" of the reaction mixture and to guarantee a well-distributed flow through the reactor. The dispersion disks had an outer diameter of $48 \mathrm{~mm}$ and an inner diameter of $35 \mathrm{~mm}$. The inlet disk had 24, $2.25 \mathrm{~mm}$ diameter holes evenly distributed around the disk (on $15^{\circ}$ centers) providing an evenly distributed stream flow. The outlet disk had $8,3 \mathrm{~mm}$ diameter holes evenly distributed around the disk (on $45^{\circ}$ centers). The disks were held by compression between the inner and outer glass tubes of the reactor.

Light Source: The reactor assembly was illuminated by placing a 1" diameter, 18" long lowpressure mercury arc lamp in the center of the annulus. The UV lamp (General Electric 15W G15T8-BLB) emitted in a band between $300 \mathrm{~nm}$ and $400 \mathrm{~nm}$, with a maximum wavelength of approximately $346 \mathrm{~nm}$.

II. Sampling method for the reactor: Solutions were mixed and stirred in the anaerobic chamber overnight prior to placement in the photoreactor. TNT, EDTA powder, and $\mathrm{Na}_{2}$ EDTA $2 \mathrm{H}_{2} \mathrm{O}$ were all mixed and stirred thoroughly. The reactor system was assembled and checked for any leaks by running water through it. $\mathrm{TiO}_{2}$ was added just before the reactor run. The light was allowed to warm up and the reaction samples were collected at periodic intervals of time. A circulating bath was used to monitor any change in the reaction temperature (maintained at $25^{\circ} \mathrm{C}$ ) and a $\mathrm{pH}$ probe was used to check the drop in $\mathrm{pH}$ with reaction time.

In all the experiments, a standard procedure was followed for collecting the reactor samples through the length of the photocatalytic reaction. All samples for HPLC analysis were collected in duplicate. The samples for each time period were taken using a $5 \mathrm{ml}$-syringe out of which $2 \mathrm{ml}$ of the sample was wasted, the next $2 \mathrm{ml}$ collected in two different HPLC vials with the final $1 \mathrm{ml}$ again wasted. The samples were immediately taken for HPLC analysis avoiding instantaneous reaction within the vials leading to enors in analysis and compound identification.

III. Analytical techniques: The primary analytical techniques used in the experiments were High Performance Liquid Chromatography (HPLC), Mass Spectrometry (MS), and the scintillation spectroscopy for the radiolabeled TNT experiments.

HPLC: The concentrations of TNT and its reduction products were determined by HPLC with a Phenomenex (Torrance, Calif.) Spherex 5-m C 18 reverse-phase column $(250 \times 2 \mathrm{~mm})$ and a $5 \mathrm{~cm}$ x $2 \mathrm{~mm}$ guard column. A Hewlett-Packard model 1090A instrument equipped with a diode array UV/VIS detector and a computerized data system was used for the analyses. The column was run with a number of mobile phase programs based on the desired chromatographic separation of degradation intermediates. For example, the program employed early in the experimentation used $10 \%$ acetonitrile and $90 \% 41 \mathrm{M} \mathrm{LiOH}$ phosphate buffer ( $\mathrm{pH} 4.0$ ) for $2 \mathrm{~min}$, and then the acetonitrile was increased to $70 \%$ over the next $15 \mathrm{~min}$. The acetonitrile was then increased to $100 \%$ over $1 \mathrm{~min}$ and maintained at that level for $2 \mathrm{~min}$. The acetonitrile was then decreased back to $10 \%$ over $2 \mathrm{~min}$. The solvent flow rate was $0.25 \mathrm{ml} / \mathrm{min}$, and the column temperature was $42^{\circ}$ C. Subsequent programs decreased the percent acetonitrile and increased the overall run length (see Conclusions and Discussion section). TNT and possible transformation products were detected by use of the diode array UV/VIS detector, recording the A210 with continuous scanning of the absorption spectrum of each peak from 190 to $600 \mathrm{~nm}$. Samples for HPLC were filtered through 0.2-m-pore-size syringe filters (diameter, $25 \mathrm{~mm}$; Supor, Gelman Sciences, Ann Arbor, Mich.) before analysis by HPLC.

Mass Spectrometry: Mass spectrometry was performed with a Hewlett Packard model 1050 HPLC with a $2.0 \times 25 \mathrm{~cm} \mathrm{C} 18$ column (Spherex) and a $2.0 \times 5 \mathrm{~cm}$ guard column (Phenomenex, Torrance, Calif.). Acetonitrile (A) and $15 \mathrm{mM}$ ammonium acetate, $\mathrm{pH} 7.1$, (B) were used as 
solvents used as solvents with a flow rate of $0.3 \mathrm{mV} / \mathrm{min}$. The gradient program was $99 \% \mathrm{~B}(0-5$ $\mathrm{min})$ to $90 \% \mathrm{~B}(5-7 \mathrm{~min})$ to $55 \% \mathrm{~B}(7-27 \mathrm{~min}$, held $3 \mathrm{~min})$, followed by retum to starting conditions (32 min). Absorbance at $220 \mathrm{~nm}$ as well as scanning ion monitoring with a model 5989A quadrupole mass spectrometer equipped with a model 59980B particle beam interface allowed detection of reduction compounds of interest. An injection volume of $50 \mu \mathrm{l}$ was used in order to direct enough material to the mass spectrometer for these analyses.

IV. Sample holding for the HPLC measurements: Early in the experimentation it was observed that spontaneous reaction and precipitation of contents was occurring in HPLC sample vials when held overnight or under refrigeration. A procedure was developed where the HPLC system was coordinated with sampling such that samples were collected and analyzed within 30 minutes.

V. Fungal growth media composition: Spores of $P$. chrysosporium were cultivated from $3 \%$ malt extract, $0.3 \%$ yeast extract, $1.5 \%$ agar medium in tissue culture flasks incubated for approximately 30 days. Suspensions of spores were made using sterile $0.2 \%$ Tween 80 and filtered through sterile glass wool. Spore suspensions were stored at $4^{\circ} \mathrm{C}$. Composition of one liter of media for cultivating the mycelia of $P$. chrysosporium (modified from Bonnarme et al., 1991) was the following:

$$
\begin{aligned}
& \text { Mineral salts - } 100 \mathrm{ml} \\
& \text { Mn }(0.1 \mathrm{M} \text { ) solution }-1.8 \mathrm{ml} \\
& \text { Glucose }-50 \mathrm{ml} \\
& \text { DMS (pH } 4.55)-10 \mathrm{ml} \\
& \text { Diammonia Tartarate }-5 \mathrm{ml} \text {. }
\end{aligned}
$$

These ingredients were added to $830 \mathrm{ml}$ of sterile water and inoculated using $3 \mathrm{ml}$ of spore suspension. The inoculated solution was placed in a shake flask and maintained in an incubator at $150 \mathrm{rpm}$ at $37^{\circ} \mathrm{C}$.

VI. Fungal growth methods: A $500-\mathrm{ml}$ portion of the above mentioned growth media was placed in a 2L shake flask and $1.5 \mathrm{ml}$ of the fungal culture was aseptically added. The flask contents, with sterile cotton stopper, were maintained in an incubator at $37^{\circ} \mathrm{C}$ and $150 \mathrm{rpm}$. The culture flasks were ready to be used as mycelia inoculatants 2-3 days after placement in the incubator.

VII. Fungal inoculation into photoreactor products: Fungal cultures retrieved from the incubator were allowed to cool for $30 \mathrm{~min}$ before inoculation into the photodegradation products solutions. Equal numbers of fungal mycelial masses were added to each flask of photoreactor degradation products using a sterile pipette in a laminar flow hood. Inoculation occurred immediately after opening the photoreactor, thus providing little time for any dissolved nitrogen to exchange to the atmosphere.

VII. ${ }^{14} \mathrm{C}$ experiments- 40 CFR 796.310 Procedure: This experimental procedure was used to quantitate ${ }^{14} \mathrm{C}-\mathrm{CO}_{2}$ evolution and a ${ }^{14} \mathrm{C}$ balance during mineralization of ${ }^{14} \mathrm{C}$-TNT by $P$. chrysosporium. All fungal cultures were made according to methods described above.

The $\mathrm{CO}_{2}$ evolution shake flask apparatus consisted of $1 \mathrm{ml}$ of $1 \mathrm{~N} \mathrm{NaOH}$ in an open container $\left(\mathrm{CO}_{2}\right.$ trap) suspended over $100 \mathrm{ml}$ of culture medium in a $250 \mathrm{ml}$ Erlenmeyer flask. The $\mathrm{NaOH}$ container was a $10 \mathrm{ml}$ glass tube suspended by means of a hole in the rubber stopper with the glass support rod attached to the container. The $\mathrm{NaOH}$ (with captured ${ }^{14} \mathrm{CO}_{2}$ ) was removed from the tube at least daily and placed in scintillation vial for radioactivity counting. The tube was then rinsed twice with $2 \mathrm{ml}$ of deionized water and refilled with fresh base. The wash solution was also transferred to scintillation vials and $15 \mathrm{ml}$ of the scintillation cocktail was added to these samples. All samples were quenched in the dark ovemight before being counted. The fungal cultures were 
sparged with 10 psi oxygen (for 1-2 minutes) at each time period after the samples were collected. All flasks were maintained at $37^{\circ} \mathrm{C}$ in an incubator between sampling periods.

In order to perform the final carbon balance on the inoculated photoproduct solutions, the flask contents were first filtered through a glass fritted filter. One ml each of the samples before and after filtration were collected for radioactivity counts. The filtrate volume was noted in each case and the remaining filtrate was then collected in a scintillation vial which was used for the fraction collector for HPLC analysis. Duplicate wash samples were then collected for the counts after washes with $10 \mathrm{ml}$ of $\mathrm{M9}$ salts, $10 \mathrm{ml}$ of cold trichloroacetic acid (TCA), and $10 \mathrm{ml}$ of ethanol/ether mixture (1:1). Ten ml of hot TCA (brought to $70^{\circ} \mathrm{C}$ using a water bath) was then used for washing in a similar manner. The cells were then digested with $5 \mathrm{ml} \mathrm{HCl}$ and maintained at $50^{\circ} \mathrm{C}$ oven in centrifuge tubes. The digested cells were centrifuged at $7000 \mathrm{rpm}$ at $4^{\circ} \mathrm{C}$ for 15 min and then decanted and centrifuged again. The final step involved the use of the tissue solubilizer and was repeated until all brownish color was removed from the fungal mycelium.

IX. Chemicals: Standards of 2,4-diamino-6-nitrotoluene (DANT) and 4-amino-2,6dinitrotoluene (ADNT) were purchased from SRI International (Menlo Park, Calif.). 2,4,6trinitrotoluene (TNT) was prepared from 2,4-dinitrotoluene (Eastman Organic Chemicals, Rochester, N.Y.) by nitration according to the procedure of Heertjes (1958)with slight modification. [Phenyl-U- ${ }^{14} \mathrm{C}$ ] labeled TNT was prepared by two-step nitration from toluene and [ring-UL- ${ }^{14}$ C]toluene (Sigma Chemical Company, St. Louis, Mo.). The low-temperature nitration was performed in acetonitrile solution using silver nitrate and fluorosulfonic acid, followed by a high temperature step with mixed acids (nitric acid-sulfuric acid-sulfur trioxide) under optimized time and temperature conditions. The specific activity was $58.9 \mathrm{Cj} / \mathrm{mmol}$ and the radiochemical purity was $>99 \%$ as verified by HPLC. All ${ }^{14} \mathrm{C}-\mathrm{TNT}$ and unlabeled TNT solutions were made up and stirred in an anaerobic atmosphere overmight and added to the photoreactor the next day.

X. ${ }^{14} \mathrm{C}$ - fractionation from HPLC: The system used was a Beckman model 338 with 110B pumps, 406 analog interface with pump control, 507 autosampler with a 100-1 sample loop, and a 167 detector with data analysis and system control provided by an IBM PS/2 with System Gold software (Beckman Instruments, Inc., San Ramon, Calif.). This method was also used with a Hewlett Packard model 1090 equipped with a diode-array detector and ChemStation software (Hewlett Packard Co., Avondale, Penn.). Radioactivity in the eluent fractions was quantified by collecting fractions on a Frac 100 fraction collector (Pharmacia, Uppsala, Sweden) loaded with vials containing $10 \mathrm{ml}$ of Bio Safe II scintillation cocktail (Research Products Intemational, Mount Prospect, Ill.), mixing, and counting in a Beckman LS 7000 scintillation counter. Disintegrations per minute (dpm) were calculated from counts per minute using an efficiency correction curve made by counting a set of quenched standards and plotting efficiency versus $H$ numbers (Beckman). In cases where a Packard scintillation counter was used, this curve was generated by counting a different set of standards and plotting efficiency versus SIS numbers.

\section{RESULTS}

\section{ANALYTICAL METHODOLOGY DEVELOPMENT}

Three experiments were conducted for analytical methodology development and achievement of baseline conditions for photocatalytic degradation of TNT similar to NREL experimentation. Experiments 1 and 2 tested two HPLC mobile phase systems while experiment 3 tested TNT photocatalysis under anaerobic conditions. 
Experiment 1 - The intent of this experiment was to test the experimental apparatus and compare two HPLC analysis methodologies, a methanol-water solvent system and an acetonitrile solvent system. Analyses were carried out on a HP-1050 HPLC system with a $25 \mathrm{~cm} \times 2 \mathrm{~mm}$ Spherex $\mathrm{C}_{18}$ column (Phenomenex) with a $5 \mathrm{~cm} \times 2 \mathrm{~mm}$ guard column.

A one-liter quantity of $100 \mathrm{ppm}$ TNT solution was treated in the photoreactor using anaerobic conditions ( $\mathrm{N}_{2}$ purge) and in the presence of $0.3 \mathrm{~g} \mathrm{TiO}_{2}$. Reactor startup and sampling was identical to the methodology outlined in the NREL Six Month Progress Report (Blake et al., 1995). Initial solution $\mathrm{pH}$ was 6.4 and initial temperature was $29^{\circ} \mathrm{C}$. Approximately 10 minutes after lamp ignition and startup of the reactor, a slight reddish-brown color to the reactor contents was noted, similar to previous NREL results. Sampling continued, as outlined in the NREL report, for five hours. Final solution $\mathrm{pH}$ was 4.95 and final temperature was $27^{\circ} \mathrm{C}$.

Analyses of the samples were conducted using two different solvent systems, a methanol-water solvent method (NREL method) and an acetonitrile-buffer solvent method (ACN method). Representative chromatograms from the NREL and ACN methods are shown in Figures 2 and 3, respectively. Both methods used a Spherex $\mathrm{C}_{18}$ column and $7 \mu \mathrm{l}$ injection volumes. As shown by the enclosed chromatograms of both methods, the separation of reaction products was superior with the acetonitrile solvent system.

Overall TNT degradation in this first experiment was similar to that seen in NREL experiments, approximately 81 percent. (Based on peak areas from representative chromatograms, data not shown). Formation of reaction intermediates occurred, however mass spectrometry on the compounds was successful in identifying only one of the reduction compounds, an aminonitrotoluene. The spectral analyses of two of the intermediates are shown in Figures 4 and 5 . Both of these compounds were identified as amino-dinitrotoluene isomers with a mw of 197 . An injection volume of $50 \mu \mathrm{l}$ was used in order to direct enough material to the mass spectrometer for these analyses. Even with such a high injection volume, other intermediates, at retention times of 2.63 and 29.27 minutes, could not be identified due to low recovery amounts sent to the particle beam.

Experiment 2. This experiment was conducted to quantitate TNT degradation and intermediate production. The HPLC analyses were done with a HP 1090 system, a Spherex $\mathrm{C}_{18}$ column and a solvent delivery methodology specific for TNT and amino-nitrotoluene quantitation (Table 1). The HPLC method in Table 1 was used for the remainder of experimentation on the projects with only minor changes depending on run length and type of column used.

Initial and operating conditions for the experiment were similar to those of experiment 1 . Sampling was conducted for five hours during which the reactor contents remained at $23.5^{\circ} \mathrm{C}$. Initial and final reaction $\mathrm{pH}$ were 6.85 and 4.42 , respectively. Similar to the previous experiment, a reddishbrown product was formed that remained in solution at the end of the experiment after five hours of phototreatment.

Overall TNT degradation was approximately 65 percent as shown in Figure 6. Four intermediates were produced, only one of which was positively identified as 4-amino, 2,6-dinitrotoluene (ADNT). The other three intermediates were not identified, similar to the results in experiment 1.

Experiment 3 - The intent of this experiment was to create a totally anaerobic environment for the photocatalytic reaction using a nitrogen gas purge and quenching of hydroxyl formation from the valence band hole reaction using bicarbonate ion. A one-liter quantity of $100 \mathrm{ppm}$ TNT solution was treated in the photoreactor in the presence of $0.3 \mathrm{~g} \mathrm{TiO}_{2}$, phosphate buffer at $\mathrm{pH} 7$ and the addition of enough $\mathrm{Na}_{2} \mathrm{CO}_{3}$ to produce $1 \mathrm{mM} \mathrm{HCO}_{3}^{-}$at $\mathrm{pH}$. Reactor startup and sampling was identical to the methodology outlined in the NREL Six Month Progress Report (Blake et al., 
1995). Initial solution $\mathrm{pH}$ was 7.04 and initial temperature was $27^{\circ} \mathrm{C}$. After lamp ignition and startup of the reactor, a pink color of the reactor contents was noted, similar to previous Experiments 1 and 2 results, only more intense. Sampling continued as per the previous experiments except for a total of ten hours. Final solution $\mathrm{pH}$ was 6.98 and final temperature was $24^{\circ} \mathrm{C}$.

Overall TNT destruction in this third experiment was approximately 70 percent after ten hours of treatment, as shown in Figure 7. Four reaction intermediates were formed and quantified one of which, eluting near TNT, was identified as ADNT (similar to Experiment 2). The remaining intermediates were not identified from this analysis. A chromatogram from HPLC analysis of the last sample of experiment 3 (data which went to form Figure 7) is shown in Figure 8. In comparison to a chromatogram from the last sample of experiment 2 (not buffered, no hydroxyl radical quench) the experiment 3 chromatogram shows additional intermediate compound production during photocatalysis. These differences were hypothesized to be do either to the anaerobic, buffered environment and/or the difference in reaction times between the two experiments, 5 and 10 hours for experiments 2 and 3, respectively.

\section{PHOTOCATALYSIS OF TNT AND AMINO-DINITROTOLUENE (ADNT) AND QUALITATIVE PHOTOCATALYTIC PRODUCT IDENTIFICATION EXPERIMENTS}

Eight experiments were conducted in this section of research devoted to either quantitating photocatalysis of TNT and ADNT or qualitative breakdown product identification. Experiments 4, $5,10,11$ and 16 were conducted on photocatalytic TNT destruction in the presence of ethylenediaminetetraacetic acid (EDTA) as a catalyst hole scavenger. Experiments 6 and 7. were conducted on photocatalytic ADNT destruction to imitate potential precedent biological degradation products that could be sent to a photocatalytic reactor in a combined biological/photocatalytic degradation sequence. Experiment 17 was a repeat of experiments 10 and 11 examining photodestruction products from a longer ten-hour photocatalytic treatment:

\section{TNT Photocatalysis Degradation Product Identification Experiments}

Experiment 4 - The intent of this experiment was to create a totally anaerobic environment for the photocatalytic reaction requiring nitrogen gas purge and quenching of hydroxyl formation from the valence band hole reaction. A one-liter quantity of $100 \mathrm{ppm}$ TNT solution was treated in the photoreactor in the presence of $0.3 \mathrm{~g} \mathrm{TiO}_{2}$, phosphate buffer at $\mathrm{pH} 7,107 \mathrm{mg} \mathrm{Na}_{2} \mathrm{CO}_{3}$ to produce $1 \mathrm{mM} \mathrm{HCO}_{3}{ }^{-}$at $\mathrm{pH} 7$ and $0.72 \mathrm{mM}$ disodium EDTA. Reactor startup and sampling was identical to the methodology outlined in the NREL Six Month Progress Report (Blake et al., 1995). Initial solution $\mathrm{pH}$ was 7.26 and initial temperature was approximately $24^{\circ} \mathrm{C}$. After lamp ignition and startup of the reactor, a slight orange color of the reactor contents was noted. Sampling continued as per the previous experiments for a total of five hours. Final solution $\mathrm{pH}$ was 7.28 and final temperature was approximately $23^{\circ} \mathrm{C}$.

Overall TNT destruction in this third experiment was approximately 96 percent after five hours of treatment, as shown in Figure 9. Four reaction intermediates were formed and quantified. Two of the intermediates, eluting at approximately 20 and 27 minutes, were identified as 4-amino,2,6dinitrotoluene (ADNT) and 2,2',6,6'-tetranitro-4,4'azoxytoluene (TNAzT), respectively, based on UV-vis spectral analysis from the diode array. Spectral analyses and library match confirmation are shown in Figures 10 and 11. The remaining intermediates were not identified from this analysis, however spectral analysis of the intermediate eluting at 14.6 minutes was similar to ADNT and the compound eluting at 3.5 minutes appeared to be a mixture of compounds. 
Experiment 5 - Experiment 5 was to designed observe the "fast" anaerobic photocatalytic reaction at uncontrolled $\mathrm{pH}$ as compared to experiment 4, at $\mathrm{pH} \mathrm{7.} \mathrm{A} \mathrm{one-liter} \mathrm{quantity} \mathrm{of} 100 \mathrm{ppm}$ TNT solution was treated in the photoreactor in the presence of $0.3 \mathrm{~g} \mathrm{TiO}_{2}$ and $0.72 \mathrm{mM}$ disodium EDTA . Reactor startup and sampling was identical to the methodology outlined in the NREL Six Month Progress Report (Blake et al., 1995). Initial solution pH was 5.15 and initial temperature was approximately $22^{\circ} \mathrm{C}$. Sampling continued as per the previous experiments for a total of five hours. Final solution $\mathrm{pH}$ was 8.02 and final temperature was approximately $21^{\circ} \mathrm{C}$. Reactor contents ultimately tumed to a brown color, but at a slower rate than coloration during experiment 4.

Overall TNT destruction in this experiment was approximately 97 percent after five hours of treatment, as shown in Figure 12. At this $\mathrm{pH}$ regime, 90 percent TNT destruction was seen within 30 minutes of lamp ignition. Similar to experiment 4, four major reaction intermediates were formed and quantified, also shown in Figure 12. Two of the intermediates were identified, similar to experiment 4, as 4-amino,2,6-dinitrotoluene (ADNT) and 2,2',6,6'-tetranitro-4,4'azoxytoluene (TNAzT), eluting at 20 and 27 minutes, respectively. Spectral matches were conclusive for ADNT and inconclusive for TNAzT, due to noise. Additional intermediates formed, eluting near the previously identified TNAzT peak at $27.16 \mathrm{~min}$., were lumped together and listed as compounds with elution times $>25$ minutes (Figures 12 and 13). These compounds were thought to be azoxyisomers, although their identification was not confirmed. The remaining intermediates were not identified from this analysis, however spectral analysis of the intermediate eluting at 14.6 minutes was similar to ADNT and the compound eluting at 3.5 minutes appeared to be a mixture of compounds. Additionally, the compounds eluting at 2.37 and $3.5 \mathrm{~min}$. may have been EDTA and its reduction product, but were not confirmed.

Experiment 10. Because the acid-form of EDTA was used in experiment 9, $\mathrm{pH}$ values were lower than when using disodium EDTA. This presumably avoided the formation of azoxy compounds. Experiment 10 was a repeat of experiment 9 to further quanify the effects of acidform EDTA use. A one-liter quantity of $100 \mathrm{ppm}$ TNT solution was treated in the photoreactor in the presence of $0.3 \mathrm{~g} \mathrm{TiO}_{2}$ and $0.4 \mathrm{mM}$ acid-form EDTA and $0.43 \mathrm{mM}$ disodium EDTA. Reactor startup and sampling was identical to the methodology outlined in the NREL Six Month Progress Report (Blake et al., 1995). Initial solution pH was 3.2 and initial temperature was approximately $27^{\circ} \mathrm{C}$. Sampling continued as per the previous experiments for a total of five hours. Final solution pH was 6.7 and final temperature was approximately $26^{\circ} \mathrm{C}$.

Results of experiment 10 are shown in Figure 14 Upon lamp ignition, TNT disappeared at a fast rate with no detectable concentration af ter 60 minutes. Both ADNT and 2,4-diamono-6nitrotoluene (DANT) were detected as TNT degradation products, in addition to TNAzT. The azoxytoluene did disappear by the end of the experiment, while the amino-compounds continued to increase in peak size.

Problems with this experiment indicated that there may have been compounds precipitating out of sample solution prior to analysis. Problems also arose with one of the HPLCs used for analysis.

Experiment 11. Experiment 11 was a repeat of experiment 10, to quanify the effects of acidform EDTA use and correct sample holding time that gave problems in experiment 10. A one-liter quantity of $100 \mathrm{ppm}$ TNT solution was treated in the photoreactor in the presence of $0.3 \mathrm{~g} \mathrm{TiO}_{2}$ and $0.4 \mathrm{mM}$ acid-form EDTA and $0.43 \mathrm{mM}$ disodium EDTA. Reactor startup and sampling was identical to the methodology outlined in the NREL Six Month Progress Report (Blake et al., 1995). Initial solution $\mathrm{pH}$ was 3.05 and initial temperature was approximately $22.5^{\circ} \mathrm{C}$. Sampling continued as per the previous experiments for a total of five hours. Final solution $\mathrm{pH}$ was 6.56 and final temperature was not measured, but assumed equal to initial temperature $\pm 2^{\circ}$. 
Results of experiment 11 are shown in Figure 15. Upon lamp ignition, TNT disappeared at a fast rate with no detectable concentration after 40 minutes. Both ADNT and DANT were detected as TNT degradation products, in addition to their precursor, 4-hydroxylamino-2,6-dinitrotoluene (HADNT). Two unidentified products were formed with retention times of 4.91 and 5.46 minutes. No azoxytoluenes were identified in this experiment. Both ADNT and DANT were confirmed by HPLC spectral analyses. The HADNT was confirmed by HPLC and mass spectral analysis (Figures 16 and 17).

Experiment 16 - This experiment was conducted similar to experiments 10 and 11, except with a ten-hour duration. A one-liter quantity of $100 \mathrm{ppm}$ TNT solution was treated in the photoreactor in the presence of $0.3 \mathrm{~g} \mathrm{TiO}_{2}$ and $0.4 \mathrm{mM}$ acid-form EDTA and $0.43 \mathrm{mM}$ disodium EDTA. Reactor startup and sampling was identical to the methodology outlined in the NREL Six Month Progress Report (Blake et al., 1995). Initial solution pH was 3.30 and initial temperature was approximately $16.2^{\circ} \mathrm{C}$ rising to a constant $25^{\circ} \mathrm{C}$ after one hour of treatment. Final solution $\mathrm{pH}$ was 6.92. Results of the experiment are shown in Figure 18, with an ultimate TNT destruction of greater than 95 percent.

\section{ADNT Photocatalytic Degradation Experiments}

Experiment 6 - The intent of this experiment was to observe the photodegradation of a "model" biological product of TNT degradation, 4-amino-2,6-dinitrotoluene (ADNT). A one-liter quantity of $0.44 \mathrm{mM} A D N T$ solution was treated in the photoreactor in the presence of $0.3 \mathrm{~g} \mathrm{TiO}_{2}$ and 0.72 $\mathrm{mM}$ disodium EDTA. Reactor startup and sampling was identical to the methodology outlined in the NREL Six Month Progress Report (Blake et al., 1995). Initial solution pH was 4.70 and initial temperature was approximately $25^{\circ} \mathrm{C}$. Sampling continued as per the previous experiments for a total of five hours. Final solution $\mathrm{pH}$ was 8.07 and final temperature was approximately $25^{\circ} \mathrm{C}$. Reactor contents turned to a light brown color after approximately 2 hours of reaction time.

Based on the results shown Figure 19, ADNT was degraded approximately 80 percent in five hours. Two major degradation products appeared, one of which was identified as DANT; the other was not identified. Although not positively confirmed, the suspected EDTA chromatographic peak declined throughout the experiment similar to that of ADNT, as in the previous experiments with TNT.

Experiment 7 - This experiment was a repeat of experiment 6 using similar sampling and analytical procedures. A $0.44 \mathrm{mM}$ ADNT solution was treated in the photoreactor in the presence of $0.3 \mathrm{~g} \mathrm{TiO}_{2}$ and $0.72 \mathrm{mM}$ disodium EDTA. Initial $\mathrm{pH}$ was 4.51 and final $\mathrm{pH}$ was 7.76. Initial reactor temperature was approximately $29^{\circ} \mathrm{C}$ dropping to a constant $22^{\circ} \mathrm{C}$ after one hour of reaction time. The results of this experiment are shown in Figure 20. Based on results in the figure, approximately 88 percent of the original ADNT was degraded in five hours. The unidentified degradation product (retention time of $17.04 \mathrm{~min}$ ) from experiment 6 did not appear in this experiment.

\section{Partial Anaerobic Conditions Experiment}

Experiment 17- The final experiment under this section was conducted under partial anaerobic conditions. The preparation of the initial TNT solution was not done under anaerobic conditions as in all previous experiments but rather in natural atmospheric conditions. In addition, the experiment was not conducted with a continuous nitrogen gas purge, but rather, nitrogen was purged initially into the reactor, the reactor was sealed and then the experiment was run without further attempts at keeping the contents anaerobic. This kind of scenario was thought to better imitate true treatment process conditions and would result in overall cost savings by avoiding much of the gas purge. A $0.44 \mathrm{mM}$ TNT solution was treated in the photoreactor in the presence of 0.3 $\mathrm{g} \mathrm{TiO}_{2}$ and $0.72 \mathrm{mM}$ disodium EDTA. Initial and ending solution $\mathrm{pH}$ was 3.40 and 5.59, 
respectively and the reactor contents were held at $25^{\circ} \mathrm{C}$ throughout the experiment. As can be seen in Figure 21, TNT was degraded to greater than 95 percent in 60 minutes with appearance of five photo-treatment products, two unidentified and the remaining identified as ADNT, DANT and TNAzT. The azoxytoluene did disappear with time, similar to experiment 10.

\section{PHOTOCATALYTIC DEGRADATION MECHANISM}

Three experiments in this section of experimentation were intended to elucidate the photocatalytic degradation mechanism similar to procedures of Glaze et al. (1993). Experiments 8 and 13 used tetranitromethane (TNM) and periodate, respectively, as electron scavengers. Experiment 14 used methanol as a hydroxyl radical quencher.

Experiment 8 - The intent of this experiment was to identify the mechanism of TNT degradation. Because tetranitromethane (TNM) competes in the photocatalytic reaction for electrons, it was hypothesized that its addition would effectively stop reductive TNT degradation. Once the TNM was exhausted (completely reduced), the TNT would then reductively react as in previous experiments. A one-liter quantity of $100 \mathrm{ppm}$ TNT solution was treated in the photoreactor in the presence of $0.3 \mathrm{~g} \mathrm{TiO}_{2}, 0.72 \mathrm{mM}$ disodium EDTA and $5.1 \mathrm{mM}$ TNM. Reactor startup and sampling was identical to the methodology outlined in the NREL Six Month Progress Report (Blake et al., 1995). Initial solution $\mathrm{pH}$ was 4.97 and initial temperature was approximately $19^{\circ} \mathrm{C}$. The $\mathrm{pH}$ dropped to 3.3 during the first 30 minutes of the experiment and then increased to experiment's end. Sampling continued as per the previous experiments for a total of five hours. Final solution $\mathrm{pH}$ was 4.76 and final temperature was approximately $20^{\circ} \mathrm{C}$. Reactor contents initially were green, due to the TNM, but ultimately tumed to a brown color, similar to previous anaerobic experiments.

TNT degradation was initially slowed in this experiment, presumably due to the presence of TNM (see Figure 22). Final TNT degradation amounted to only 75 percent, considerably less than the $>95$ percent as in previous experiments 10 and 11 without TNM. None of the major reduction products 4-hydroxylamino-2,6-dinitrotoluene (HADNT), 4-amino,2,6-dinitrotoluene (ADNT) nor 2,4-diamino-6-nitrotoluene (DANT) were found on the chromatograms. Neither was 2,2',6,6'tetranitro-4,4'azoxytoluene (TNAzT) found. Two unidentified products were formed with retention times of 4.91 and 5.46 minutes. While not conclusively identified in the chromatograms, TNM was thought to be one of the compounds that disappeared at 15 minutes of treatment (HPLC retention time of 18.7 or 28.5 minutes). As seen in Figure 22, TNT did not appreciably degrade until after the 15 minute sample, possibly indicating that TNM did successfully compete for electrons, effectively stopping the TNT reduction reaction. The absence of typical TNT reduction products also leads to the hypothesis that TNT did not degrade reductively.

Experiment 13 - The intent of this experiment was to help identify the mechanism of TNT degradation. Because periodate competes in the reaction for electrons, it was thought that its addition would effectively stop reductive TNT degradation. A one-liter quantity of $100 \mathrm{ppm}$ TNT solution was treated in the photoreactor in the presence of $0.3 \mathrm{~g} \mathrm{TiO}_{2}, 0.72 \mathrm{mM}$ disodium EDTA and $26.4 \mathrm{mM}$ periodate (sodium form). Reactor startup and sampling was identical to the methodology outlined in the NREL Six Month Progress Report (Blake et al., 1995). Initial solution $\mathrm{pH}$ was 4.55 and initial temperature was approximately $20^{\circ} \mathrm{C}$. Intermediate $\mathrm{pH}$ was not available due to problems with the reactor $\mathrm{pH}$ probe. Sampling continued as per the previous experiments for a total of five hours. Final solution $\mathrm{pH}$ was 8.90 and final temperature was approximately $22^{\circ} \mathrm{C}$. Reactor contents initially were clear and remained so, unlike previous anaerobic experiments without an electron scavenger that tumed a reddish-brown color during the course of the experiment. 
Surprisingly, TNT disappearance was rapid, with TNT concentration dropping to zero by the 180 minute sample (Figure 23). No reduction products, however, either monoamino-nitrotoluene, diamino-nitrotoluene or azoxy-toluenes were detected throughout the experiment.

Experiment 14. Experiment 14 was designed to quench any hydroxyl radical formation using methanol in a methanol:TNT molar ratio of 70:1. Experimental conditions were similar to experiment 11, using $0.44 \mathrm{mmol} \mathrm{TNT}, 0.4 \mathrm{mmol} \mathrm{Na} 2$ EDTA $\cdot \mathrm{H}_{2} 0$ and $0.4 \mathrm{mmol}$ acid form EDTA with the addition of $30.8 \mathrm{mmol}$ methanol. Beginning $\mathrm{pH}$ was 3.08 and ending $\mathrm{pH}$ was 6.20 . Temperature was held constant at $15.5 \pm 2.5^{\circ} \mathrm{C}$. Results are shown in Figures 24 and 25 . From the chromatogram in Figure 25, it can be seen that the results are similar to the experiment without methanol (experiment 11) with formation of ADNT and DANT and no azoxy-compounds.

\section{COMBINED PHOTOCATALYTIC AND BIOLOGICAL DEGRADATION EXPERIMENTS}

The combined photocatalytic and biological degradation experiments comprised i) three preliminary experiments to identify a likely biological treatment organism and qualitative aspects of photoreactor treatment product degradation and ii) two large quantitative experiments using ${ }^{14} \mathrm{C}$ TNT in a precendent photocatalytic degradation step with follow-on biological mineralization of the photodegradation products. The ${ }^{14} \mathrm{C}$-radiotracer experiments allowed quatitation of ultimate TNT mineralization in addition to an overall carbon balance in the system.

Biological Experiments 1 and 2. Based on the assumption that reaction intermediates from the above photocatalytic reduction degradation experiment were possibly large dimers or polymeric compounds, it was decided to use Phanerochaete chrysosporium as a likely biological agent for follow-on photoreactor product degradation. Both experiments were conducted as simply presence or absence of biological activity as seen by decoloration of the compounds.

Fresh hyphae, harvested from Phanerochaete previously grown up on a glucose/dimethyl succinic acid media (see Materials and Methods for fungal growth media and techniques descriptions), were added to varying am ounts of the leftover fluid from experiment 3 . Biological experiment 1 used a ratio of hyphae:fluid as 5:1, on a volume to volume basis. The fluid was decolored, or bleached white (the $\mathrm{TiO}_{2}$ showed white) within 3 days. The second biological experiment used a hyphae:fluid ratio of 1:5. A color change from reddish-brown to light brown was observed at 3 days with no further decoloration up to 10 days. No analyses of the Phanerochaete-amended fluid was done at this time, although it is possible that the first biological experiment was successful in degrading the polymeric materials left from anaerobic chemical photocatalysis.

Biological Experiment 3 - Phanerochaete chrysosporium was inoculated into varying concentrations of the final, unfiltered products from experiment 5 . Aliquots containing $0,20,40$, 60,70 and 83 percent photo-products were made, inoculated with fungal hyphae and allowed to react. Samples were withdrawn at three day intervals and analyzed for breakdown products from TNT degradation. Small concentrations of 4-amino-2,6-dinitrotoluene (ADNT) and 2,4-diaminonitrotoluene (DANT) were detected in time 0 samples from higher photo-product concentration aliquots with their complete disappearance three days later. Identification of possible azoxycompounds was not made during these experiments as well as inconclusive identification of other extraneous chromatographic peaks. Because the photo-products from experiment 5 were refrigerated, it was thought they may have precipitated out of solution prior to the start of this biological experiment. The fungal inoculants did, however, appear to grow, increasing in size, and were not affected by the EDTA nor the $\mathrm{TiO}_{2}$ in the reactor effluent. Peroxidase may have been expressed by the organisms, indicative of their brown color at approximately three days growth time. 
Experiment 9 - The intent of this experiment was to quantitate the carbon fractions incorporated into TNT breakdown products for use in follow-on biological experiments. A one-liter quantity of $98 \mathrm{ppm}$ TNT solution $\left({ }^{14} \mathrm{C}=28,600,00 \mathrm{dpm}\right)$ was treated in the photoreactor in the presence of 0.3 $\mathrm{g} \mathrm{TiO}_{2}$ and $0.4 \mathrm{mM}$ acid-form EDTA and $0.43 \mathrm{mM}$ disodium EDTA. Reactor startup was identical to the methodology outlined in the NREL Six Month Progress Report (Blake et al., 1995) but sampling was limited to initial and final samples only. The experiment was run for a total of 5.5 hours. Temperature and $\mathrm{pH}$ profiles were not taken to avoid undue radioactive contamination, but assumed similar to previous anaerobic experiments.

Based on differences between initial and final samples, the overall ${ }^{14} \mathrm{C}$ balance accounted for 94 percent of total radiolabeled TNT in solution (Table 3, difference between original 28,592,000 $\mathrm{dpm}$ applied and 26,882,712 dpm recovered). Table 3 shows relative minor amounts of radioactivity associated with products 1 ) adsorbed on reactor glass $(2073 \mathrm{dpm} / \mathrm{ml}$ removed in a reactor rinse); 2) presumed ${ }^{14} \mathrm{C}-\mathrm{CO}_{2}$ in carbosorb (945 dpm/ml); and 3) a nonquantitative amount (volume of sample unknown due to a simple "wipe" test) in the solids from the reactor (26677 dpm from inner tube and $21714 \mathrm{dpm}$ from outer tube). Figure 26 shows the relative amounts of radioactivity associated with each of the TNT breakdown products overlain with identified products from the chromatogram. Radioactivity was associated with TNT, ADNT and DANT in addition to two other peaks thought to be diamino-nitrotoluene isomers. It is interesing to note that no detectable amounts of azoxy- compounds were formed in this experiment, presumably due to the low $\mathrm{pH}$ arising from use of acid-form EDTA. Additional loss of radioactivity was presumably due to compounds retained by filtration as shown by information in Table 3 Fifteen to 16 percent of final reactor contents were lost on filtration depending on filter type, Teflon vs. cellulose acetate. Additionally, between 7 and 11 percent of radioactivity was lost upon filtration due to either adsorption of soluble material to the filter or adsorption of material to $\mathrm{TiO}_{2}$ and loss upon filtration, respectively.

Experiment 12. Experiment 12 used reactor contents from experiment 9, photocatalysis of ${ }^{14} \mathrm{C}$ TNT. The experiment followed protocol similar to that of 40 CFR 796.310 Aerobic Aquatic Biodegradation Shake Flask Protocol. Replicate $50 \mathrm{ml}$ quantities of mixed reactor contents from photocatalysis of ${ }^{14} \mathrm{C}$-TNT were inoculated with Phanerochaete chrysosporium on 10/9/95 and incubated on a shake table. The experiment used one control and three concentrations of an exogenous nitrogen source, $0 \mathrm{mM} \mathrm{NH}_{4}, 0.25 \mathrm{mM} \mathrm{NH}_{4}$, and $2.5 \mathrm{mM} \mathrm{NH}_{4}$. Removal and counting of the base solution contained within the flasks was done every two to three days for the 21-day experiment, to quantitate the ${ }^{14} \mathrm{C}-\mathrm{CO}_{2}$ evolved. Previous preliminary results from the experiment showed that radioactive counts occurred within the first two days, presumably due to aerobic, biodegradative attack of the photocatalysis byproducts by the Phanerochaete. Further results showed varying amounts of ultimate ${ }^{14} \mathrm{C}-\mathrm{CO}_{2}$ production (Figure 27), depending on supplemental $\mathrm{NH}_{4}$ added. Previous research has shown that addition of the exogenous nitrogen was necessary for expression of the peroxidase enzyme in Phanerochaete, although that was not the case in this study, presumably enough nitrogen was supplied by the degradation products. A mass balance on ${ }^{14} \mathrm{C}$ within the system, based on 1) evolved $\left.{ }^{14} \mathrm{C}-\mathrm{CO}_{2}, 2\right){ }^{14} \mathrm{C}$ bound to fungal hyphae and 3) $\mathrm{MeCN}$ extracted ${ }^{14} \mathrm{C}$ from the $\mathrm{TiO}_{2}$ solids showed only $60-70$ percent recovery of original added radioactivity (Table 4).

The decline in soluble radioactive compounds with time is shown in Figure 28. Presumably, the photocatalysis products contained within the reactor fluid either sorbed to the $\mathrm{TiO}_{2}$ solids within the matrix or the glass of the storage flask or a spontaneous reaction between molecular oxygen and amino- compounds occurred.

Further ${ }^{14} \mathrm{C}$ analyses of the previous reactor contents before and after degradation by Phanaerochaete is shown in Figure 29. The top graph shows photocatalytic byproducts prior to biological treatment for qualitative comparison. The first three sharp peaks represent reduction 
products, only the last of which was identified as diamino-nitrotoluene (DANT). The bottom two graphs show analysis of extracts of the fungal hyphae from experimental treatments of the fungus with $0.25 \mathrm{mM} \mathrm{NH}_{4}$ or zero $\mathrm{NH}_{4}$. The important feature of these graphs is the presence of the DANT peak with the $0.25 \mathrm{mM} \mathrm{NH}_{4}$ and the absence of the peak with no $\mathrm{NH}_{4}$ added. Exogenous $\mathrm{NH}_{4}$ was previously thought necessary for fungal metabolism of xenobiotic compounds.

Experiment 15. Experiment 15 was a repeat of the previous experiment 9, photocatalysis of ${ }^{14} \mathrm{C}$-TNT and experiment 12 , treatment of photocatalytic TNT breakdown products using Phanerochaete chrysosporium. The photocatalytic portion of the experiment was identical to previous experiment 9 . The biological portion of the experiment followed protocol similar to that of 40 CFR 796.310 Aerobic Aquatic Biodegradation Shake Flask Protocol (1992). Replicate 50 $\mathrm{ml}$ quantities of mixed reactor contents from photocatalysis of ${ }^{14} \mathrm{C}$-TNT at time $2 \mathrm{~h}$ and $6 \mathrm{~h}$ and in addition to a flask with $100 \mathrm{mg} /{ }^{14} \mathrm{C}$-TNT (no photocatalytic treatment) were inoculated with Phanerochaete chrysosporium and incubated on a shake table. An abiotic control was also run on the reactor contents. Removal and counting of the base solution contained within the flasks was done every two days for the 27 day experiment, to quantitate the ${ }^{14} \mathrm{C}-\mathrm{CO}_{2}$ evolved. Final results from the experiment showing accumulated percent ${ }^{14} \mathrm{C}_{-} \mathrm{CO}_{2}$ released are presented in Figure 30 . Ultimately more ${ }^{14} \mathrm{C}-\mathrm{CO}_{2}$ was released from the phocatalytic treatment for six hours than from that treated for two hours. This probably indicates that either longer reductive photocatalytic treatment is necessary for follow-on oxidative biological treatment or the destruction of a biologically toxic intermediate occurs after two or more hours of photocatalytic treatment. Additionally, the comparison of liquid and evolved ${ }^{14} \mathrm{C}-\mathrm{CO}_{2}$ counts for the $2 \mathrm{hr}, 6 \mathrm{hr}$ and TNT flasks is shown in Figure 31 .

The overall carbon mass balance is shown in Table 5. All recoveries of radio-tracer were good and in all cases greater than 92 percent. As can be seen in the lower portion of Table 5, almost twice as much radio-labeled material was associated with the biomass of the fungi (numbers in the $\mathrm{HCl}$ digest and tissue solubilizer rows) in the $2 \mathrm{hr}$ treatnent as with the biomass in the six hour treatment. This data agreed with the hypothesis that longer photocatalytic treatment produced more polar products with less tendency to adsorb.

Chromatograms showing TNT reduction products, before and after biological treatment, with overlain radioactive counts for the $2 \mathrm{~h}$ and $6 \mathrm{~h}$ sample are shown in Figures 32 and 33. Figure 33 also shows a chromatogram and overlain radioactive counts for the uninoculated control. Distribution of photocatalytic products in both the 2 and 6 hour treatments were similar with the exception of two peaks between 20 and 25 minute retention being at higher concentration in the 2 $\mathrm{hr}$ treatment. This was probably the toxic fraction of photoproducts that inhibited mineralization in the $2 \mathrm{hr}$ samples. Distribution of radiolabel was similar in both the 2 and $6 \mathrm{hr}$ treatnents after fungal treatment. 


\section{CONCLUSIONS AND DISCUSSION}

\section{ANALYTICAL METHODOLOGY DEVELOPMENT}

The following method for analysis of TNT and amino-nitrotoluenes on the HPLC was superior to the NREL method using a water/methanol gradient. Chromatographic peaks were better separated and quantified using the resultant method. (The method listed below is somewhat different than the method listed in Experiment 2 due to longer run time, 23 vs 18 minutes.)

\begin{tabular}{|c|c|c|c|}
\hline \multirow{2}{*}{\multicolumn{4}{|c|}{ Hewlett-Packard LC 1090}} \\
\hline Pump (DR5) & & \\
\hline \multirow{2}{*}{\multicolumn{2}{|c|}{ Stop Time }} & & \\
\hline & & \multicolumn{2}{|c|}{$0.25 \mathrm{ml} / \mathrm{min}$} \\
\hline \multicolumn{2}{|c|}{ Min. Pressure } & \multicolumn{2}{|c|}{0 bar } \\
\hline \multicolumn{2}{|c|}{ Max. Pressure } & \multicolumn{2}{|c|}{$400 \mathrm{bar}$} \\
\hline \multirow{2}{*}{\multicolumn{2}{|c|}{$\begin{array}{l}\text { Oven Temp. } \\
\text { Solvent A }\end{array}$}} & \\
\hline & & \multirow{2}{*}{\multicolumn{2}{|c|}{$\begin{array}{l}5.0 \% \text { (acetonirile) } \\
95.0 \%\left(\mathrm{PO}_{4} \text { buffer) }\right.\end{array}$}} \\
\hline \multicolumn{2}{|l|}{ Solvent B } & & \\
\hline \multicolumn{4}{|c|}{ Injector } \\
\hline \multirow{2}{*}{\multicolumn{2}{|c|}{$\begin{array}{l}\text { Injection Volume } \\
\text { Draw speed }\end{array}$}} & \multirow{2}{*}{\multicolumn{2}{|c|}{$\begin{array}{l}10.0 \mu \mathrm{l} \\
83.3 \mu \mathrm{l} / \min \end{array}$}} \\
\hline & & & \\
\hline \multicolumn{4}{|c|}{ Time Table } \\
\hline Time (min) & $\% A$ & $\% \mathrm{~B}$ & Flow (ml/min) \\
\hline 0.0 & 5 & 95 & 0.25 \\
\hline 0.5 & 5 & 95 & 0.25 \\
\hline 8.0 & 50 & 50 & 0.25 \\
\hline 9.0 & 50 & 50 & 0.25 \\
\hline 11.0 & 100 & 0 & 0.25 \\
\hline 15.0 & 100 & 0 & 0.25 \\
\hline 18.0 & 5 & 95 & 0.25 \\
\hline
\end{tabular}

Sample holding time was also found to be critical for accurate analyses. When samples were held for longer than 30 minutes or stored under reduced temperature, loss of compounds in solution occurred. This disappearance of the compounds under study was thought to be due to either adsorption onto the $\mathrm{TiO}_{2}$ particles or glass of the holding vials or spontaneous reaction and conversion to other chemical forms.

\section{PHOTOCATALYSIS OF TNT AND AMINO-DINITROTOLUENE (ADNT)}

Three major reduction products of anaerobic photocatalysis of TNT were identified in the experimentation: 1) 4-hydroxylamino-2,6-dinitrotoluene (HADNT); 2) 4-amino,2,6-dinitrotoluene (ADNT); and 3) 2,4-diamono-6-nitrotoluene (DANT). Additionally a condensation product $2,2^{\prime}, 6,6^{\prime}$-tetranitro-4,4'azoxytoluene (TNAzT) was identified in experiments where $\mathrm{pH}$ became alkaline during the course of the experiment. Other isomers of the three reduction products were suspected to have occurred along with other azoxytoluenes, based on mass spectrometry results, however positive identification was not made.

The proven reductive photocatalytic destruction of TNT in this research followed the theoretical pathway similar to that given in the Appendix of NREL's Six Month Progress Report (Blake et al., 1995): TNT ---> 4-hydroxylamino-2,6-dinitrotoluene (HADNT) ---> 4-amino,2,6-dinitrotoluene (ADNT) ---> 2,4-diamono-6-nitrotoluene (DANT). (See Figure 34) Based on this pathway, a probable biological agent, Phanerochaete chrysosporium, was deemed adequate to mineralize the resultant photodegradation products. Because HADNT is toxic to P. chrysosporium through its inhibition of the veratryl alcohol oxidase activity of lignin peroxidase (Paszczynski and Crawford, 
1995, Bumpus and Tartako, 1994, Michels and Gottschalk, 1994), it was also thought that photocatalysis of TNT had to proceed past HADNT and at least to ADNT to achieve adequate mineralization of the parent compound.

\section{COMBINED PHOTOCATALYTIC AND BIOLOGICAL DEGRADATION OF TNT}

Based on results from this section of research the following conclusions were drawn:

1. Mineralization of TNT was possible using a combined photocatalytic and biological degradation scheme, with $P$. chrysosporium as the biological agent. The maximum extent of observed mineralization of the original C-TNT was approximately 32 percent.

2. The length of photocatalysis affected the final extent of C-TNT mineralization in the combined photocatalytic and biological degradation scheme. There was evidence from the varying lengths of photocatalysis used, two and six hours, that longer treatment in the photoreactor resulted in a greater extent of biological mineralization of the initial C-TNT, 23 percent vs. 32 percent, respectively. Longer photo-treatment (six hours) also produced effluent compounds that were more polar than the original influent compounds (TNT) or than effluent compounds from shorter photo-treatment (two hours).

3. It was previously thought that preparations of $P$. chrysosporium had requirements for an exogenous nitrogen source. This phenomenon was shown to be false in our research. Fungal preparations without additional nitrogen or with low nitrogen added $(0.25 \mathrm{mM}$ $\left.\mathrm{NH}_{4}\right)$ showed greater overall mineralization than did those with higher added nitrogen (2.5 $\mathrm{mM} \mathrm{NH}_{4}$ ).

Others have investigated the sole use of $P$. chrysosporium to mineralize TNT (Fernando et al., 1990; Spiker et al., 1992; Michels and Gottschalk, 1994). While they all obtained mineralization, the ultimate extent of TNT converted to $\mathrm{CO}_{2}$ was less than in the present research. TNT was also acknowledged to be toxic to $P$. chrysosporium at concentrations above $20 \mathrm{mg} / \mathrm{l}$ in aqueous solution, further limiting ultimate mineralization using only the fungal preparations.

The greater extent of TNT mineralization in samples receiving longer photocatalysis was probably due to either absence of any toxic intermediates in the degradation pathway or greater bioavailablity of the carbon in the degradation products. Based on our results, the occurrence of HADNT, toxic to $P$. chrysosporium, was avoided by longer photocatalytic treatment. Also, longer treatment produced more polar and soluble intermediate compounds that were more bioavailable for the follow-on biological treatment, however an optimum length of photocatalytic treatment was not determined. In summary, the combined photocatalytic and biological treatment of aqueous TNT solutions appears to be a viable remediation technology if the process is properly optimized.

\section{RECOMMENDATIONS FOR FUTURE WORK}

Recommendations for future research into photocatalytic and biological destruction of pink water are the following:

1. Optimization of the combined photocatalytic and biological processes. While the combined photocatalytic and biological scheme for TNT destruction was not optimized, experimental evidence showed that better treatment could be had based on photocatalytic process length. The use of central composite experimental designs together with response surface methodologies has been successfully used to optimize response in various hazardous and non-hazardous waste treatment processes (Hess, et al., 1996; Watts et al., 
1994a). The overall combined photocatalytic and biological process should also be investigated for optimized configuration and resultant cost savings based on sequential vs. simultaneous treatment schemes.

2. Investigation of catalyst-coated solid support media. Many studies of photocatalytic treatment of waste streams are using $\mathrm{TiO}_{2}$-coated solid support media for ease of $\mathrm{TiO}_{2}$ removal in a full-scale application (Glaze et al., 1993; Hofstadler et al., 1994). Previous research has shown that aqueous suspensions of $\mathrm{TiO}_{2}$ are hard to remove, increasing the overall cost of a full-scale remediation process (Watts et al., 1994b).

3. Investigation of mixtures of explosives compounds for input into a combined photocatalytic and biological treatment scheme. It is likely that mixtures of nitroaromatic compounds will behave differently during both photocatalysis and biological degradation than does a single compound. Process optimization and resultant process cost minimization should be studied.

\section{REFERENCES}

Bauer, R. 1994. Applicability of solar irradiation for photochemical wastewater treatment. Chemosphere. 29:1225-1233.

Blake, D.M. J.E. Boulter E.J. Wolfrum, Showalter, S.K., M.R. Prairie, B.M. Stange, P.J. Rodacy, P.K. Leslie. 1995. Solar detoxification of explosives in water: six months progress report. National Renewable Energy Laboratory, Sandia National Laboratory.

Bonnarme, P. J. Perez and T.W. Jeffries. 1991. Regulation of ligninase production in white-rot fungi. in Leatham G.F. and M.E. Himmel, eds. Enzymes in Biomass Conversion. ACS, Washington, D.C.

Bumpus, J.A. and M. Tatarko. 1994. Biodegradation of 2,4,6-trinitrotoluene by Phanerochaete chrysosporium : identification of inivial degradation products and the discovery of a TNT metabolite that inhibits lignin peroxicases. Curr. Microbiol. 28:185-190.

CFR. 1992. Aerobic Aquatic Biodegradation Shake Flask Protocol. Code of Federal Regulations 40 796.310. U.S. Government Printing Office, Washington, DC.

Fernando, T., J.A. Bumpus and S.D. Aust. 1990. Biodegradation of TNT (2,4,6-trinitrotoluene) by Phanerochaete chrysosporium. Appl. Environ. Microbiol. 56:1666-1671.

Glaze, W.H. J.F. Kenneke and J.L. Ferry: 1993. Chlorinated byproducts from the TiO2-mediated photodegradation of trichloroethylene and tetrachloroethylene in water. Environ. Sci. Technol. 27:177-184.

Heertjes, P.M. 1958. Nitration with acids consisting of nitric acid and sulfur trioxide. Rec. Trav. Chim. 77:693-713.

Hess, T.F., J. Chwirka and A. Noble. 1996. Use of response surface modeling in pilot testing for design. Environ. Technol. in press.

Hofstadler, K., R. Bauèr, S. Novalic and G. Heisler. 1994. New reactor design for photocatalytic wastewater treatment with TiO2 immobilized on fused-silica glass fibers: photomineralization of 4chlorophenol. Environ. Sci. Technol. 28:670-674. 
Michels, J. and G. Gottschalk. 1994. Inhibition of the lignin peroxidase of Phanerochaete chrysosporium by hydroxylamino-dinitrotoluene, an early inntermediate in the degradation of 2,4,6-rinitrotoluene. Appl. Environ. Microbiol. 60:187-194.

Michels, J. and G. Gottschalk. 1995. Pathway of 2,4,6-trinitrotoluene (TNT) degradation by Phanerochaete chrysosporium. in Biodegradation of Nitroaromatic Compounds, ed. J. Spain. Plenum Press, NY.

Paszczynski, A. and R.L. Crawford. 1995. Potential for bioremediation of xenobiotic compounds by the white-rot fungus Phanerochaete chrysosporium. Biotechnol. Prog. 11:368-379.

Spiker, J.K. D.L. Crawford and R.L. Crawford. 1992. Influence of 2,4,6-trinitotoluene (TNT) concentration on the degradation of TNT in explosive-contaminated soils by the white rot fungus Phanerochaete chrysosporium. Appl. Environ. Microbiol. 58:3199-3202.

Stahl, J.D. and S.D. Aust. 1993. Metabolism and detoxification of TNT by Phanerochaete chrysosporium. Biochem. Biophys. Research Comm. 192:477-482.

Watts, R.J., S. Kong, M. Dippre and W.T. Bames. 1994a. Oxidation of sorbed hexachlorobenzene in soils using catalyzed hydrogen peroxide. Jour. Hazard. Mater. 39:33-47.

Watts, R.J., S. Kong, M.P. Orr and G.C. Miller. 1994b. Titanium dioxide-mediated photocatalysis of a biorefractory chloroether in secondary wastewater effluent. Environ. Technol. 15:469-475. 


\begin{tabular}{|c|c|c|c|}
\hline \multicolumn{4}{|c|}{ Hewlett-Packard LC 1090} \\
\hline \multirow{7}{*}{\multicolumn{2}{|c|}{$\begin{array}{l}\text { Pump (DR5) } \\
\text { Stop Time } \\
\text { Flow } \\
\text { Min. Pressure } \\
\text { Max. Pressure } \\
\text { Oven Temp. } \\
\text { Solvent A } \\
\text { Solvent B }\end{array}$}} & \multirow{2}{*}{\multicolumn{2}{|c|}{$35.00 \mathrm{~min}$}} \\
\hline & & & \\
\hline & & \multirow{2}{*}{\multicolumn{2}{|c|}{0 bar }} \\
\hline & & & \\
\hline & & \multirow{2}{*}{\multicolumn{2}{|c|}{$42^{\circ} \mathrm{C}$ (acetonitrile) }} \\
\hline & & & \\
\hline & & 99.0 & \\
\hline \multicolumn{4}{|c|}{ Time Table } \\
\hline Time $(\mathrm{min})$ & $\% \mathrm{~A}$ & $\% \mathrm{~B}$ & Flow $(\mathrm{ml} / \mathrm{min})$ \\
\hline 0.0 & 1 & 99 & 0.25 \\
\hline 3.0 & 1 & 99 & 0.25 \\
\hline 16.0 & 50 & 50 & 0.25 \\
\hline 20.0 & 50 & 50 & 0.25 \\
\hline 26.0 & 0 & 0 & 0.25 \\
\hline 31.0 & 0 & 0 & 0.25 \\
\hline 33.0 & 1 & 99 & 0.25 \\
\hline
\end{tabular}

Table 1. HPLC method used in experiment 1.

\begin{tabular}{|c|c|c|c|}
\hline \multicolumn{4}{|c|}{ Hewlett-Packard LC 1090} \\
\hline \multirow{2}{*}{\multicolumn{2}{|c|}{ Stop Time }} & \multicolumn{2}{|c|}{$18.00 \mathrm{~min}$} \\
\hline & & \multicolumn{2}{|c|}{$0.25 \mathrm{ml} / \mathrm{min}$} \\
\hline \multicolumn{2}{|c|}{$\begin{array}{l}\text { Flow } \\
\text { Min Pressure }\end{array}$} & \multicolumn{2}{|c|}{0 bar } \\
\hline \multicolumn{2}{|c|}{ Max. Pressure } & \multicolumn{2}{|c|}{340 bar } \\
\hline \multicolumn{2}{|c|}{ Oven Temp. } & \multirow{2}{*}{\multicolumn{2}{|c|}{$42^{\circ} \mathrm{C}$}} \\
\hline \multicolumn{2}{|c|}{$\begin{array}{l}\text { Solvent A } \\
\text { Solvent B }\end{array}$} & & \\
\hline \multirow{2}{*}{\multicolumn{4}{|c|}{$90.0 \%\left(\mathrm{LiOH} / \mathrm{PO}_{4}, \mathrm{pH} 4.0\right)$}} \\
\hline Injector & & \multirow{3}{*}{\multicolumn{2}{|c|}{$\begin{array}{l}10.0 \mu \mathrm{l} \\
83.3 \mu \mathrm{min}\end{array}$}} \\
\hline \multirow{2}{*}{\multicolumn{2}{|c|}{$\begin{array}{l}\text { Injection Volume } \\
\text { Draw speed }\end{array}$}} & & \\
\hline & & & \\
\hline \multicolumn{4}{|c|}{ Time Table } \\
\hline Time (min) & $\% \mathrm{~A}$ & $\% \mathrm{~B}$ & Flow $(\mathrm{ml} / \mathrm{min})$ \\
\hline 0.0 & 10 & 90 & 0.25 \\
\hline 1.0 & 10 & 90 & 0.25 \\
\hline 2.0 & 40 & 60 & 0.25 \\
\hline 8.0 & 60 & 40 & 0.25 \\
\hline 9.5 & 100 & 0 & 0.25 \\
\hline 10.5 & 100 & 0 & 0.25 \\
\hline & 100 & 0 & 0.25 \\
\hline 16.5 & 10 & 90 & 0.25 \\
\hline
\end{tabular}

Table 2. HPLC method used in experiment 2. 


\begin{tabular}{lr}
\multicolumn{1}{c}{${ }^{14} \mathrm{C}$ Source } & DPM \\
\hline Original ${ }^{14} \mathrm{C}$ added & $28,592,000$ \\
Reactor contents after $5.5 \mathrm{~h}$ of photocatalysis & $24,809,893$ \\
Reactor rinse & $2,072,818$ \\
Total ${ }^{14} \mathrm{C}$ recovered & $26,882,712$ \\
\hline
\end{tabular}

Total recovery

$94.02 \%$

Table $3 .{ }^{14} \mathrm{C}$ balance from photocatalysis of ${ }^{14} \mathrm{C}$-TNT in experiment 9.

\begin{tabular}{|c|c|c|c|c|c|}
\hline${ }^{14} \mathrm{C}$ Source & $\begin{array}{l}\text { Percent } \\
{ }^{14} \mathrm{C}-\mathrm{CO}_{2} \\
\text { evolved }\end{array}$ & $\begin{array}{c}\text { Percent }{ }^{14} \mathrm{C} \\
\text { in reactor } \\
\text { liquid }\end{array}$ & $\begin{array}{c}\text { Percent }{ }^{14} \mathrm{C} \\
\text { bound to } \\
\text { hyphae }\end{array}$ & $\begin{array}{c}\text { Percent }{ }^{14} \mathrm{C} \\
\text { in MeCN } \\
\text { extraction } \\
\end{array}$ & $\begin{array}{c}\text { Total } \\
\text { percent }{ }^{14} \mathrm{C} \\
\text { recovered } \\
\end{array}$ \\
\hline Control & $0.02 \pm 0$ & not done & NA & NA & $0.02 \pm 0 *$ \\
\hline $0 \mathrm{mM} \mathrm{NH}_{4}$ & $19.86 \pm 2.40$ & $24.19 \pm 3.41$ & $16.86 \pm 0.75$ & $6.63 \pm 3.38$ & $67.54 \pm 5.16$ \\
\hline $0.25 \mathrm{mM} \mathrm{NH}_{4}$ & $6.65 \pm 0.97$ & $20.60 \pm 1.69$ & $19.34 \pm 1.94$ & $16.16 \pm 1.62$ & $62.75 \pm 2.34$ \\
\hline $2.5 \mathrm{mM} \mathrm{NH}_{4}$ & $3.66 \pm 0.69$ & $21.29 \pm 0.26$ & $19.30 \pm 3.02$ & $18.03 \pm 3.87$ & $62.27 \pm 6.46$ \\
\hline
\end{tabular}

${ }^{*}$ recoverd as ${ }^{14} \mathrm{C}-\mathrm{CO}_{2}$ only

Table 4. ${ }^{14} \mathrm{C}$ balance, experiment 12 , from biological mineralization, by $P$. chrysosporium, of products from photocatalysis of ${ }^{14} \mathrm{C}$-TNT. Data are averages \pm standard error for $0,0.25$ and 2.5 $\mathrm{mM}$ additions of $\mathrm{NH}_{4}$ to the fungal/photoproduct suspensions in addition to a noninoculated control. 


\begin{tabular}{ccccc}
${ }^{14} \mathbf{C}$ source & $\begin{array}{c}\mathbf{0 ~ h} \\
\text { treatment }\end{array}$ & $\begin{array}{c}\mathbf{2} \mathbf{~ h} \\
\text { treatment }\end{array}$ & $\begin{array}{c}\mathbf{6 ~ H r} \\
\text { treament }\end{array}$ & Control \\
\hline $\mathrm{CO}_{2}$ evolved & $13.7 \pm 2.5$ & $22.7 \pm 1.3$ & $31.8 \pm 0.8$ & $2.2 \pm 0.1$ \\
Particulates in solute & $17.7 \pm 4.1$ & $2.0 \pm 0.6$ & $2.1 \pm 0.4$ & $21.4 \pm 2.1$ \\
Soluble & $17.1 \pm 6.0$ & $21.3 \pm 0.7$ & $32.7 \pm 0.8$ & $72.0 \pm 2.5$ \\
M9 Salts Wash & $1.7 \pm 0.5$ & $0.7 \pm 0.2$ & $0.9 \pm 0.4$ & $\mathrm{~N} / \mathrm{A}$ \\
$\begin{array}{c}\text { Cold TCA Wash } \\
\text { (carbohydrates) }\end{array}$ & $0.9 \pm 0.5$ & $0.2 \pm 0.0$ & $0.4 \pm 0.2$ & $\mathrm{~N} / \mathrm{A}$ \\
$\begin{array}{c}\text { Ether: Ethanol Wash } \\
\text { (lipids) }\end{array}$ & $5.3 \pm 2.4$ & $0.9 \pm 0.4$ & $1.0 \pm 0.3$ & $\mathrm{~N} / \mathrm{A}$ \\
$\begin{array}{c}\text { Hot TCA Wash } \\
\text { (nucleic acids) }\end{array}$ & $0.8 \pm 0.3$ & $0.2 \pm 0.0$ & $0.4 \pm 0.1$ & $\mathrm{~N} / \mathrm{A}$ \\
$\begin{array}{c}\text { Residue } \\
\text { HCl digest } \\
\text { (protein) }\end{array}$ & $1.1 \pm 0.1$ & $0.2 \pm 0.1$ & $0.2 \pm 0.2$ & $\mathrm{~N} / \mathrm{A}$ \\
$\begin{array}{c}\text { Tissue Solubilizer Digest } \\
\text { (strongly sorbed, bound) }\end{array}$ & $38.2 \pm 13.7$ & $39.4 \pm 2.1$ & $21.5 \pm 0.9$ & $\mathrm{~N} / \mathrm{A}$ \\
\hline Total Recovery & $100.7 \pm 11.6$ & $92.7 \pm 2.1$ & $94.6 \pm 1.6$ & N/A \\
\hline
\end{tabular}

Table 5. ${ }^{14} \mathrm{C}$ balance showing average \pm standard error of samples from biological mineralization, by $P$. chrysosporium, of products from photocatalysis of ${ }^{14} \mathrm{C}$-TNT, experiment 15. Data are from 0,2 , and 6 hours of precedent photocatalysis in addition to a noninoculated control. 


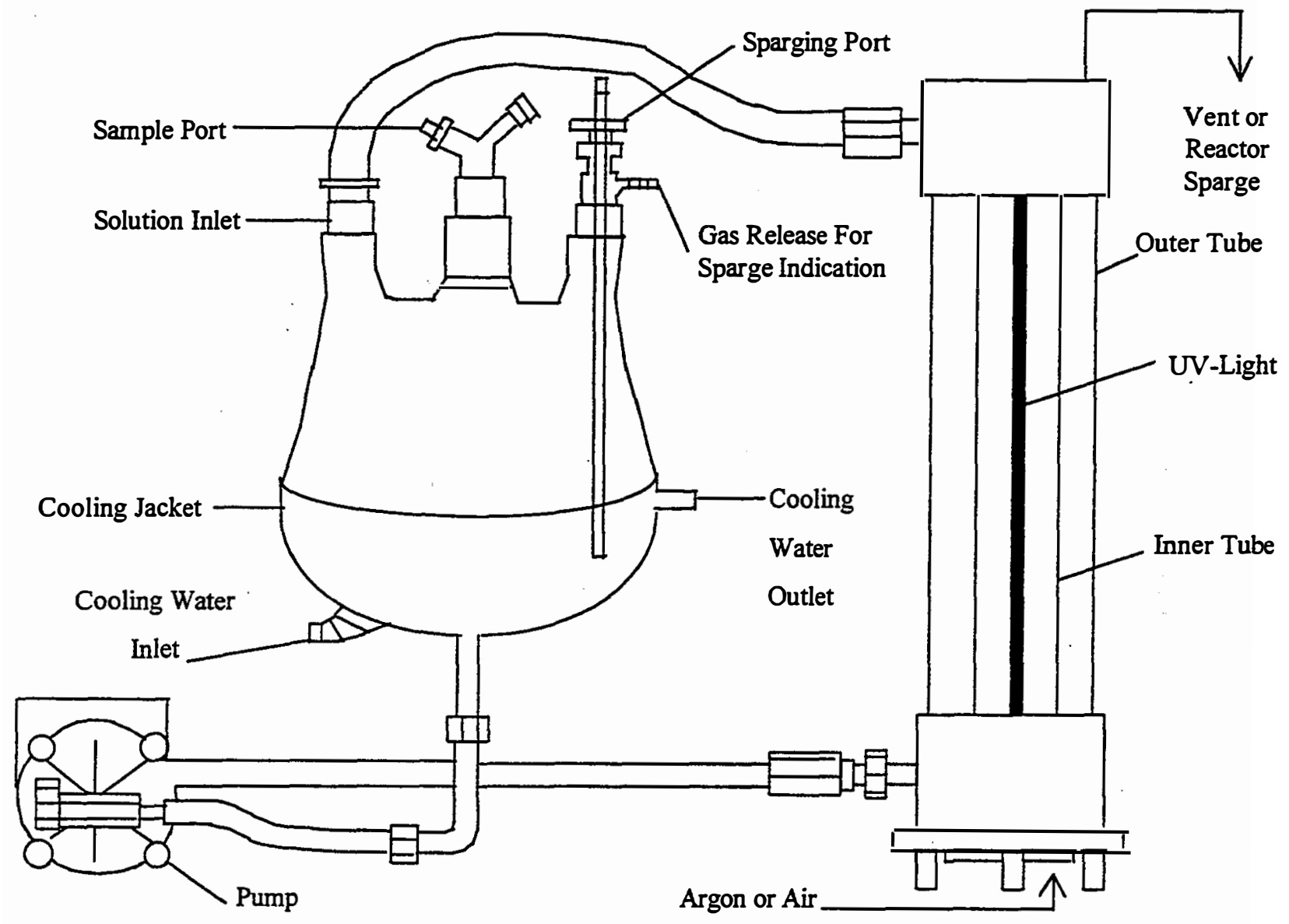

Figure 1. Schematic of annular ring, photocatalytic reactor used in all experimentation. 


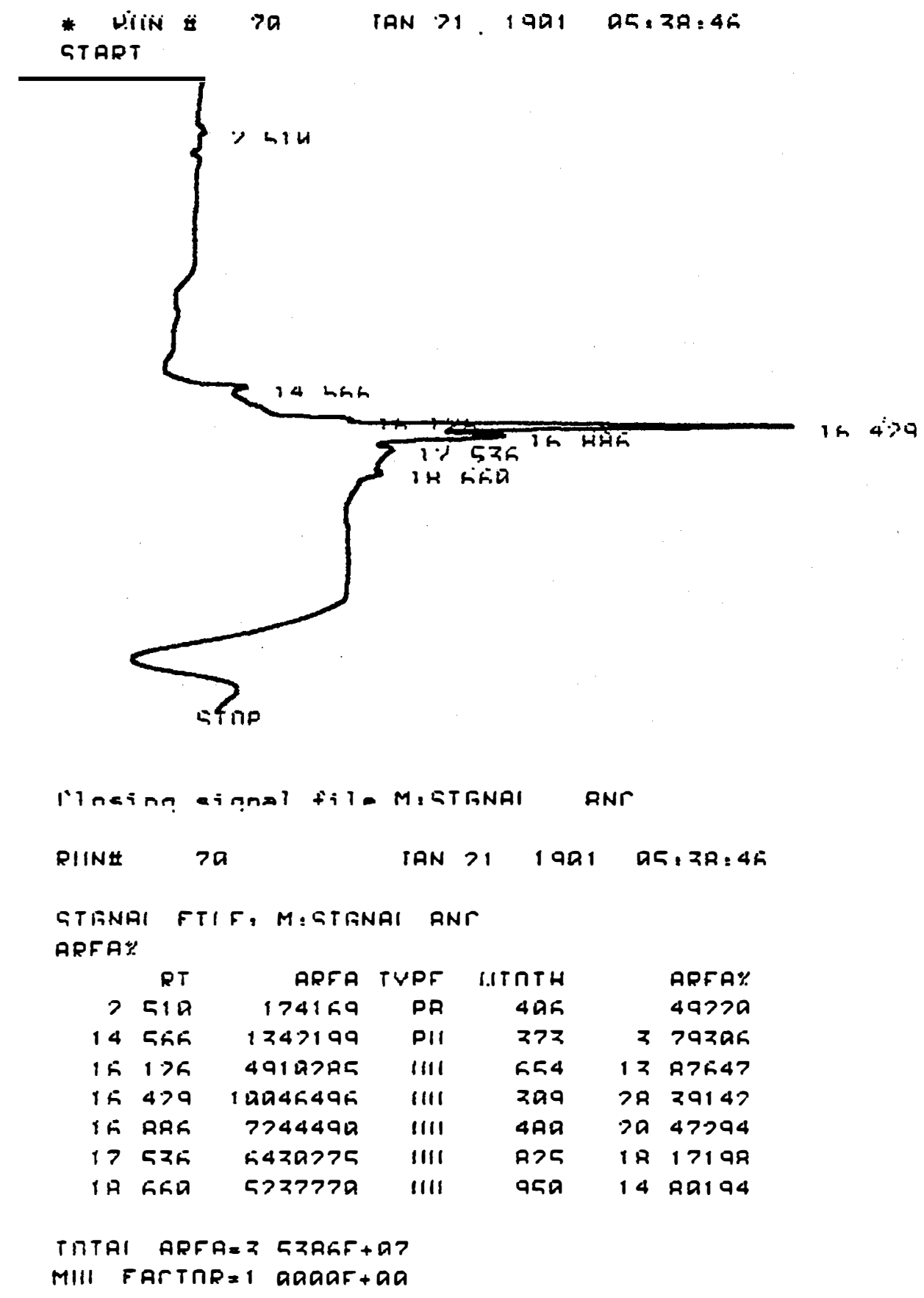

Figure 2. Chromatogram of products from photocatalytic degradation of TNT using NREL method in Experiment 1. 
TITAI DOFA=R IAEIF+AT

MIII FARTOR=I MaAaF+aด

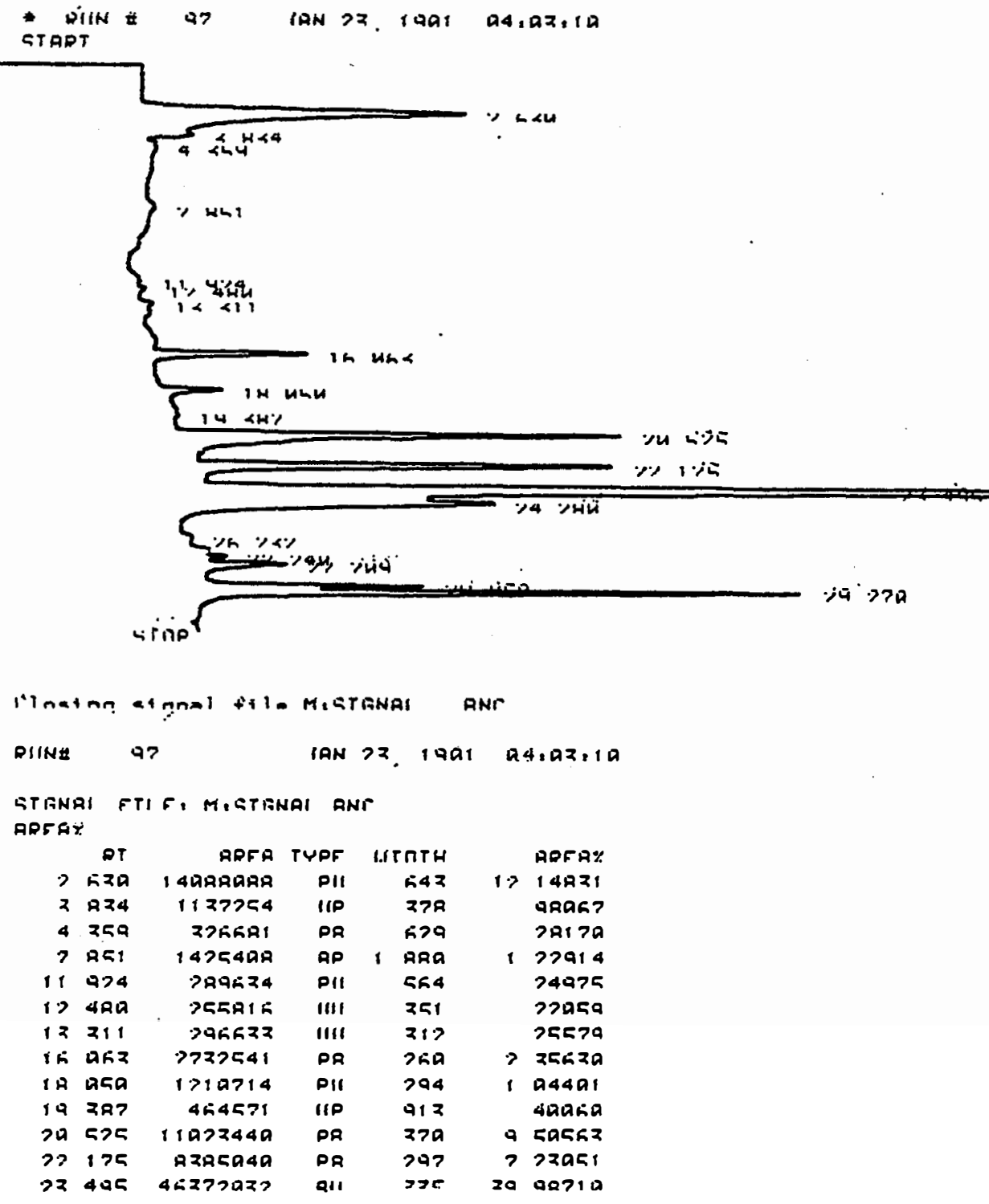

Figure 3. Chromatogram of products from photocatalytic degradation of TNT using ACN method, Experiment 1. 

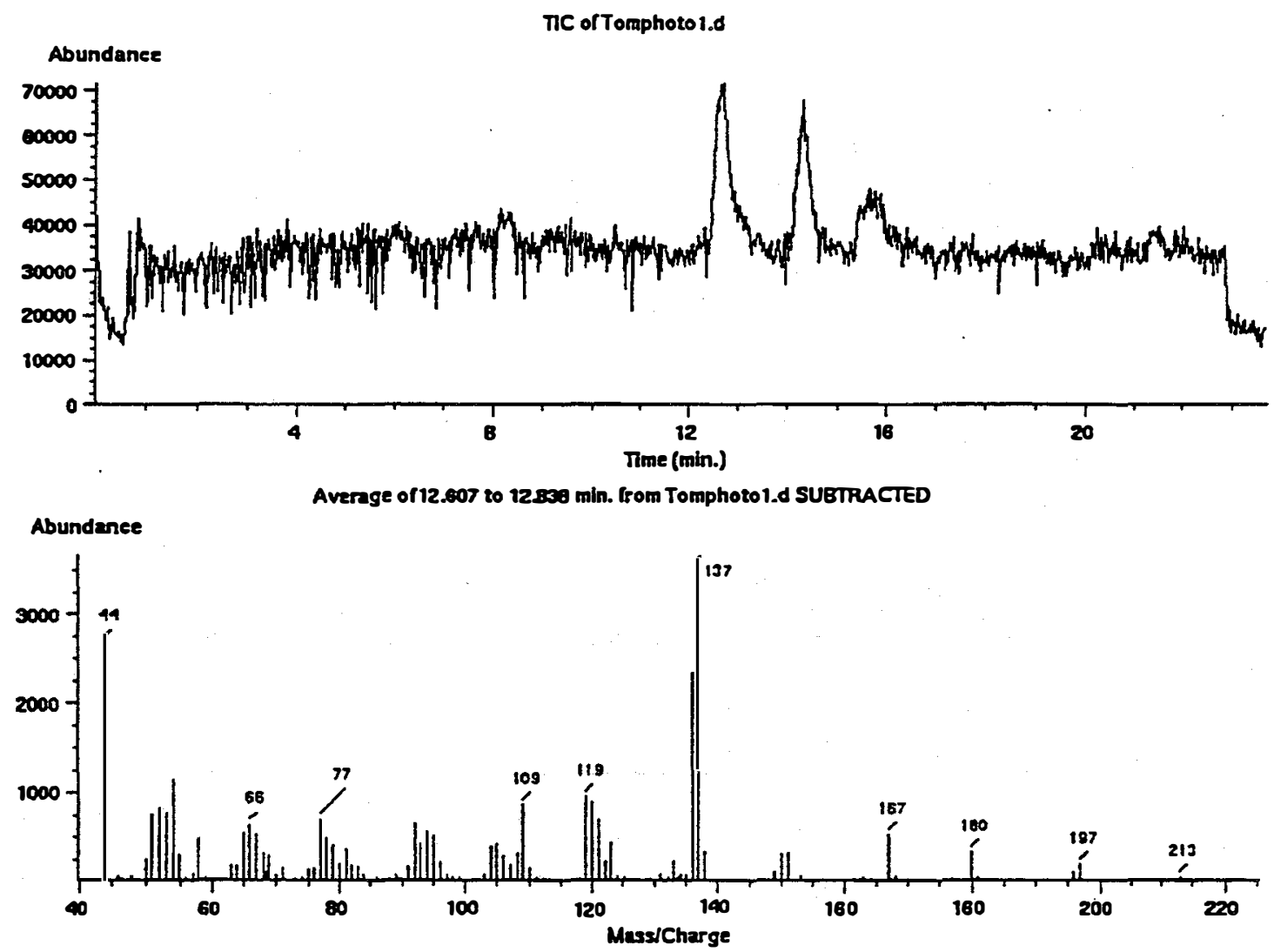

Figure 4. Chromatogram (top) and mass spectra (bottom) of an amino-nitrotoluene isomer formed during photocatalytic degradation of TNT in Experiment 1. 

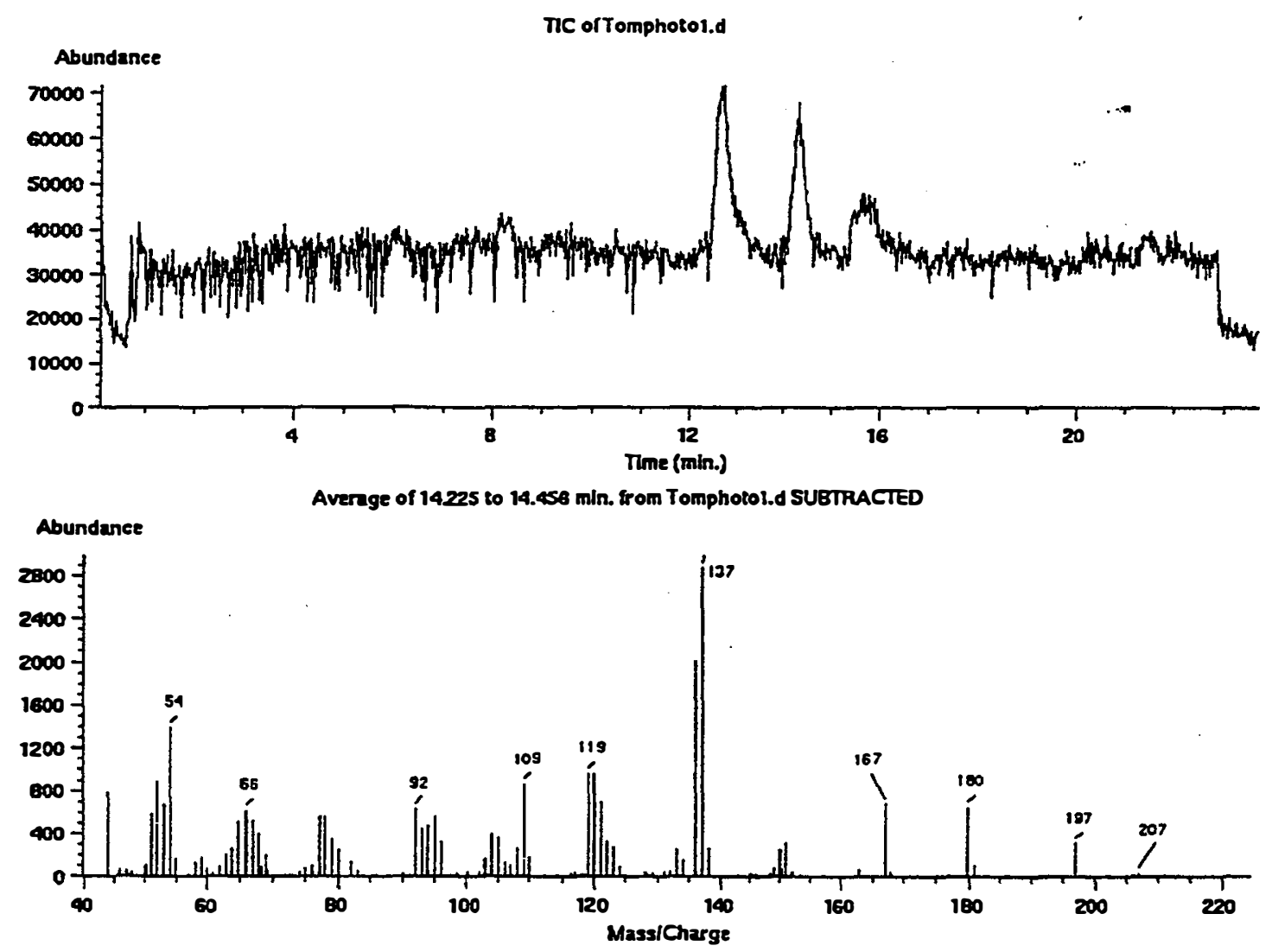

Figure 5. Chromatogram (top) and mass spectra (bottom) of an amino-nitrotoluene isomer formed during photocatalytic degradation of TNT in Experiment 1. 


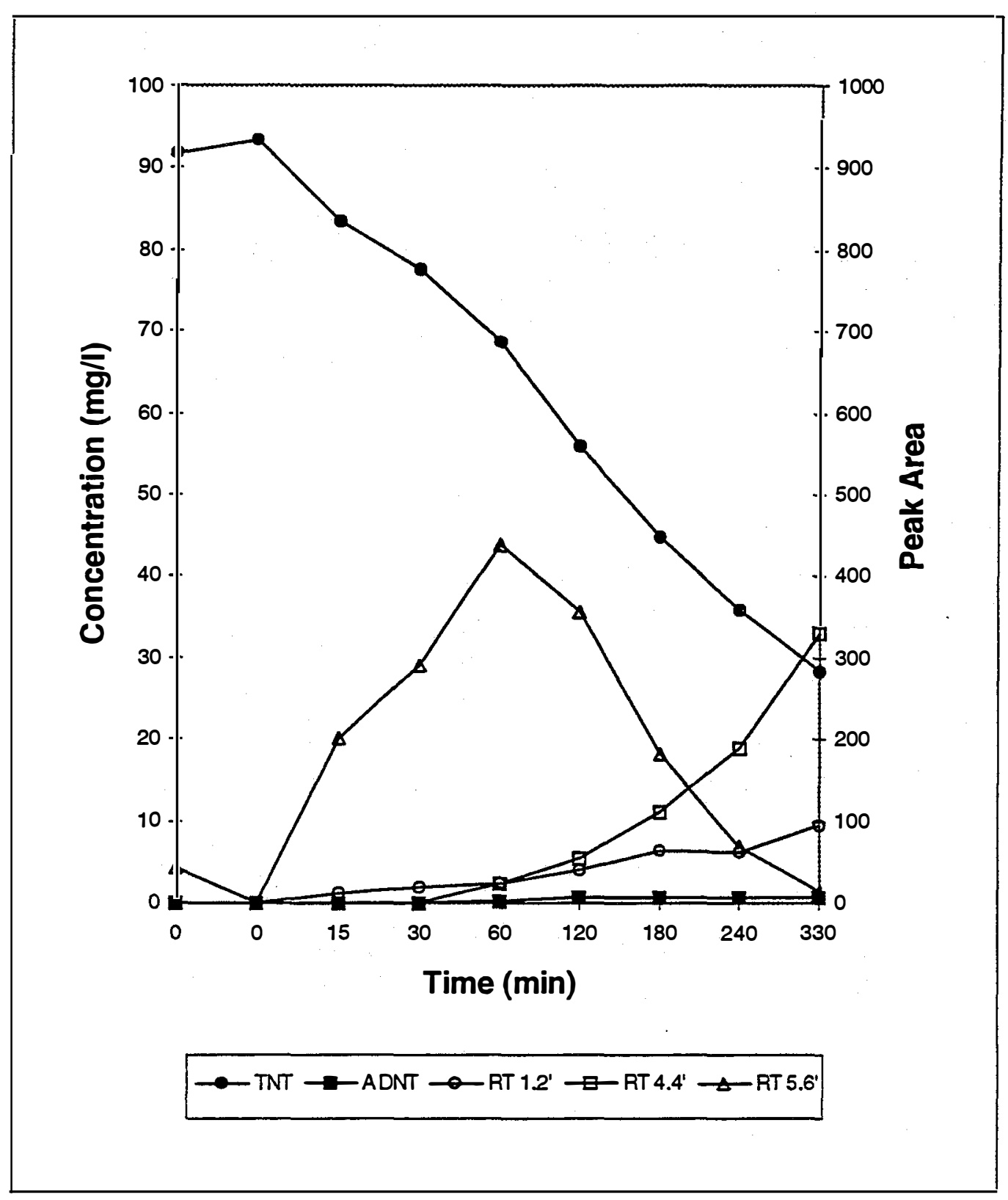

Figure 6. Anaerobic photocatalytic degradation of TNT in experiment 2. Solid symbols represent data in $\mathrm{mg} / \mathrm{l}$, open symbols show data as peak area from chromatograms. 


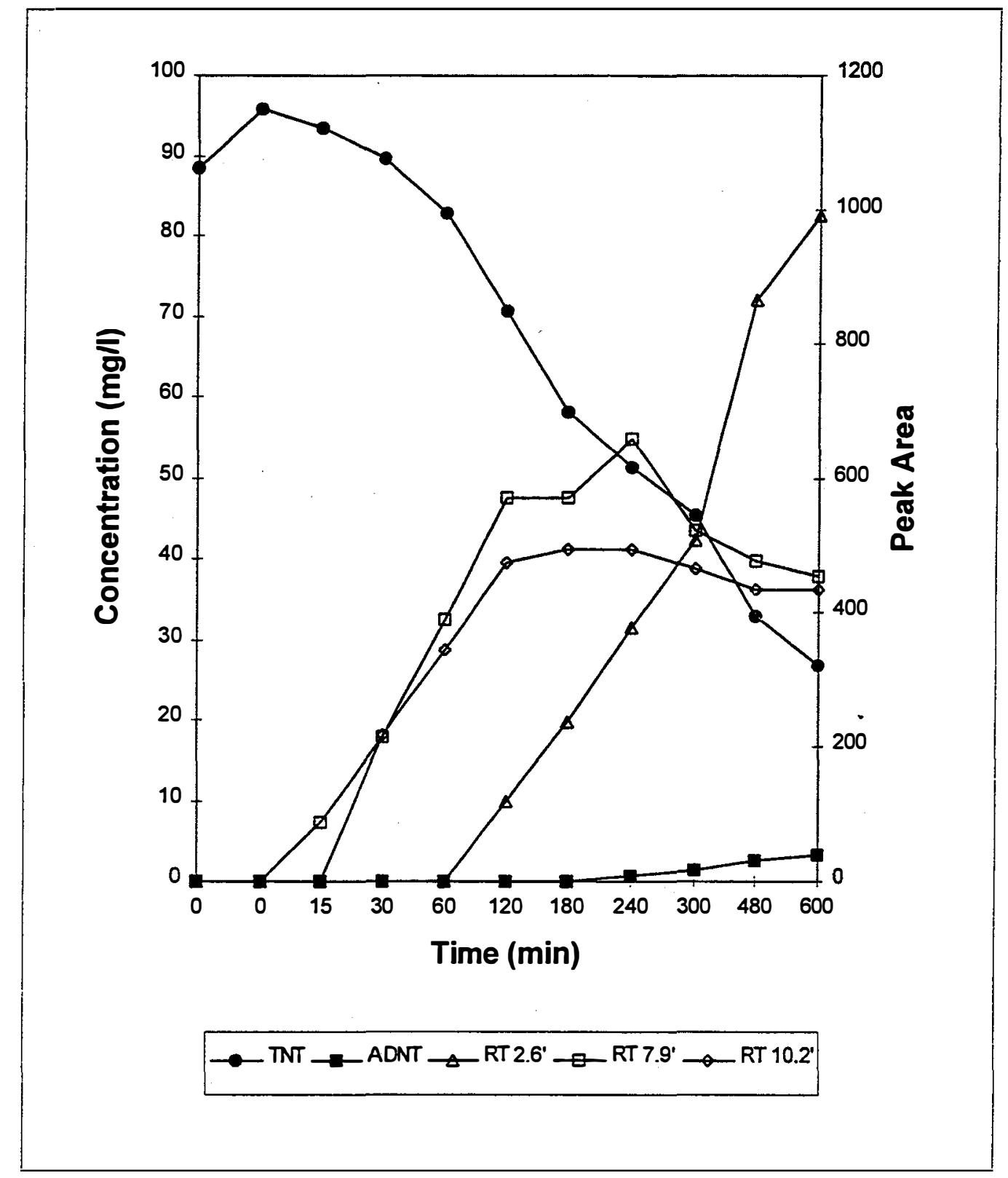

Figure 7. Anaerobic photocatalytic degradation of TNT in the presence of $\mathrm{HCO}_{3}{ }^{-}$in experiment 3. Solid symbols represent data in $\mathrm{mg} / \mathrm{l}$, open symbols show data as peak area from chromatograms. 


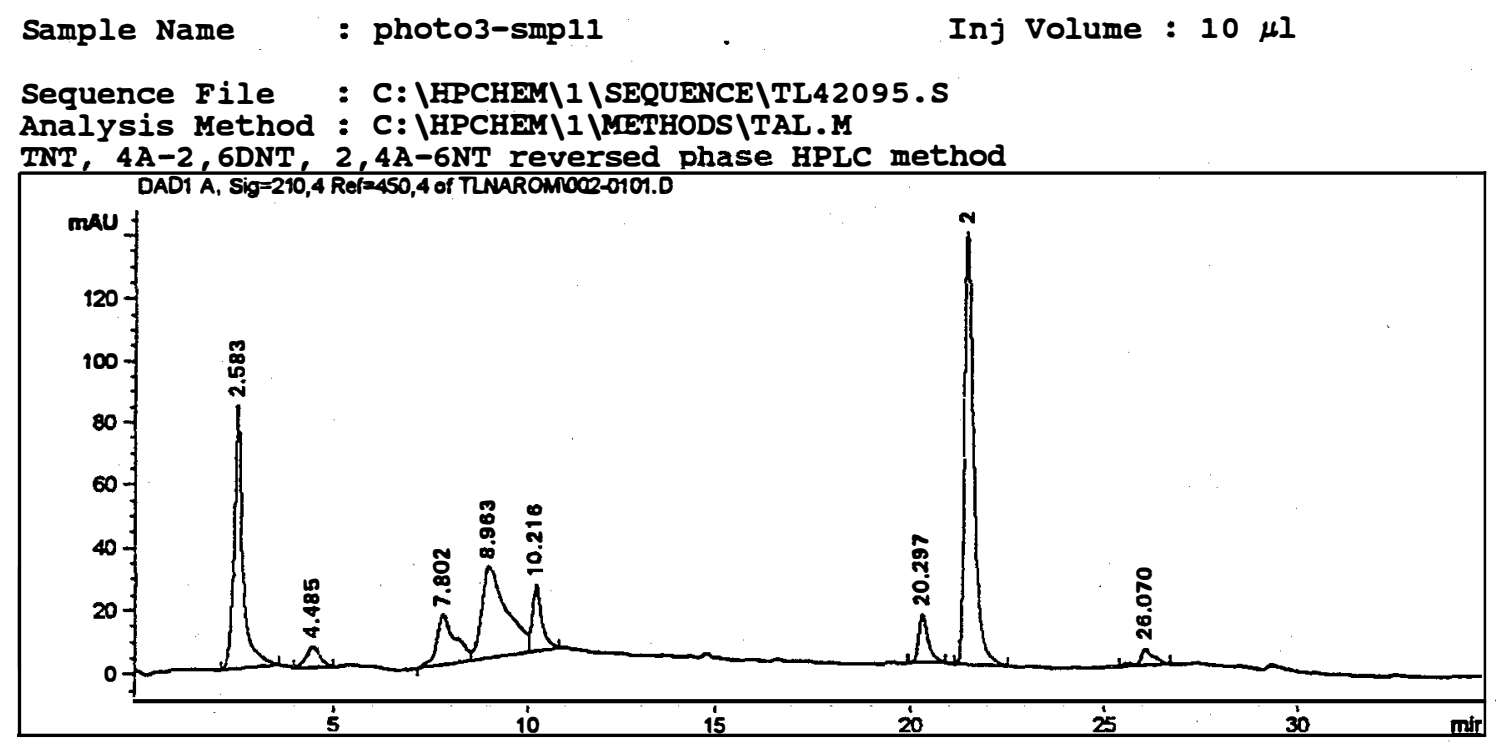

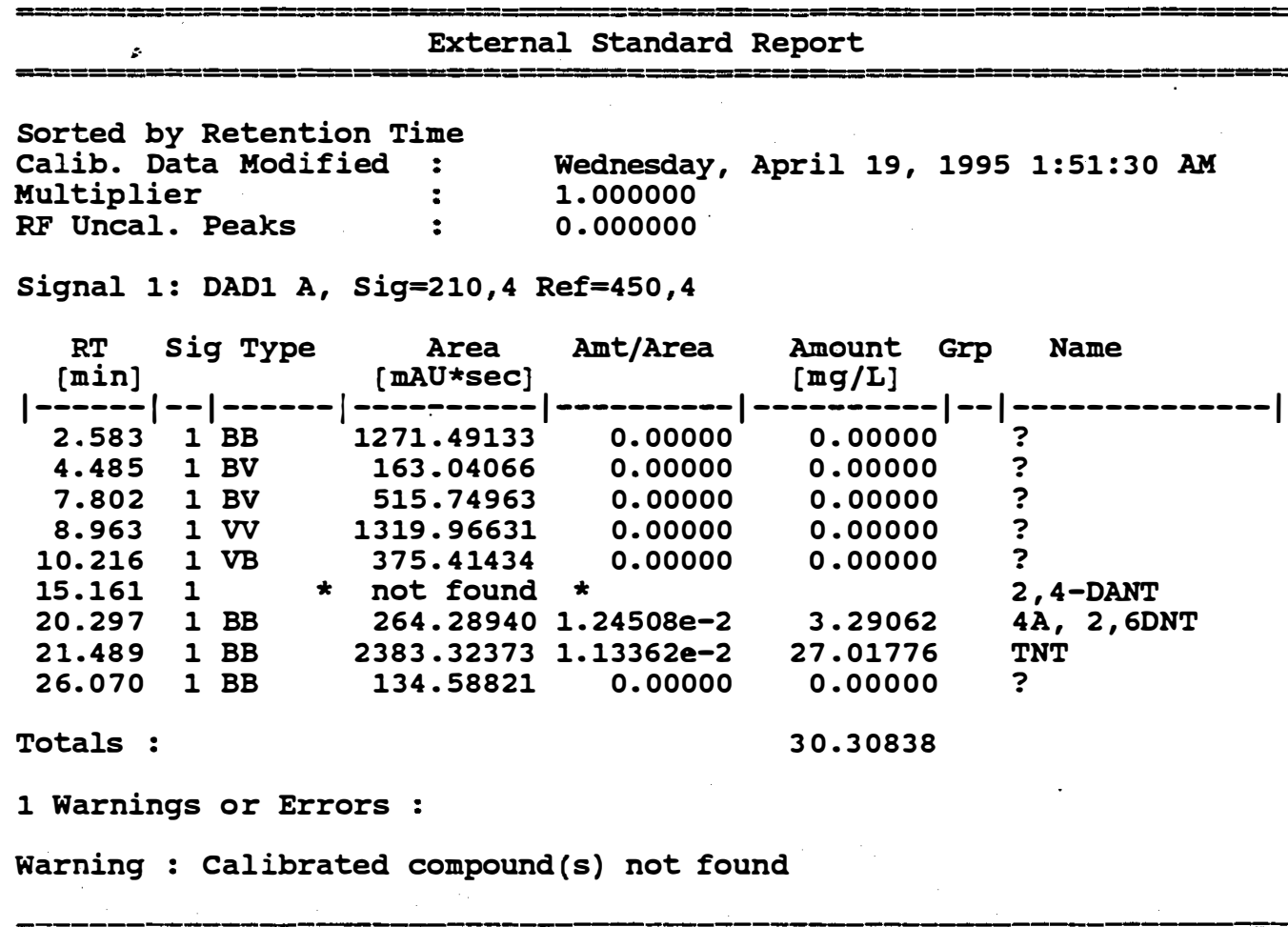

Figure 8. Chromatogram from anaerobic photocatalytic degradation of TNT in the presence of $\mathrm{HCO}_{3}{ }^{-}$during Experiment 3. 


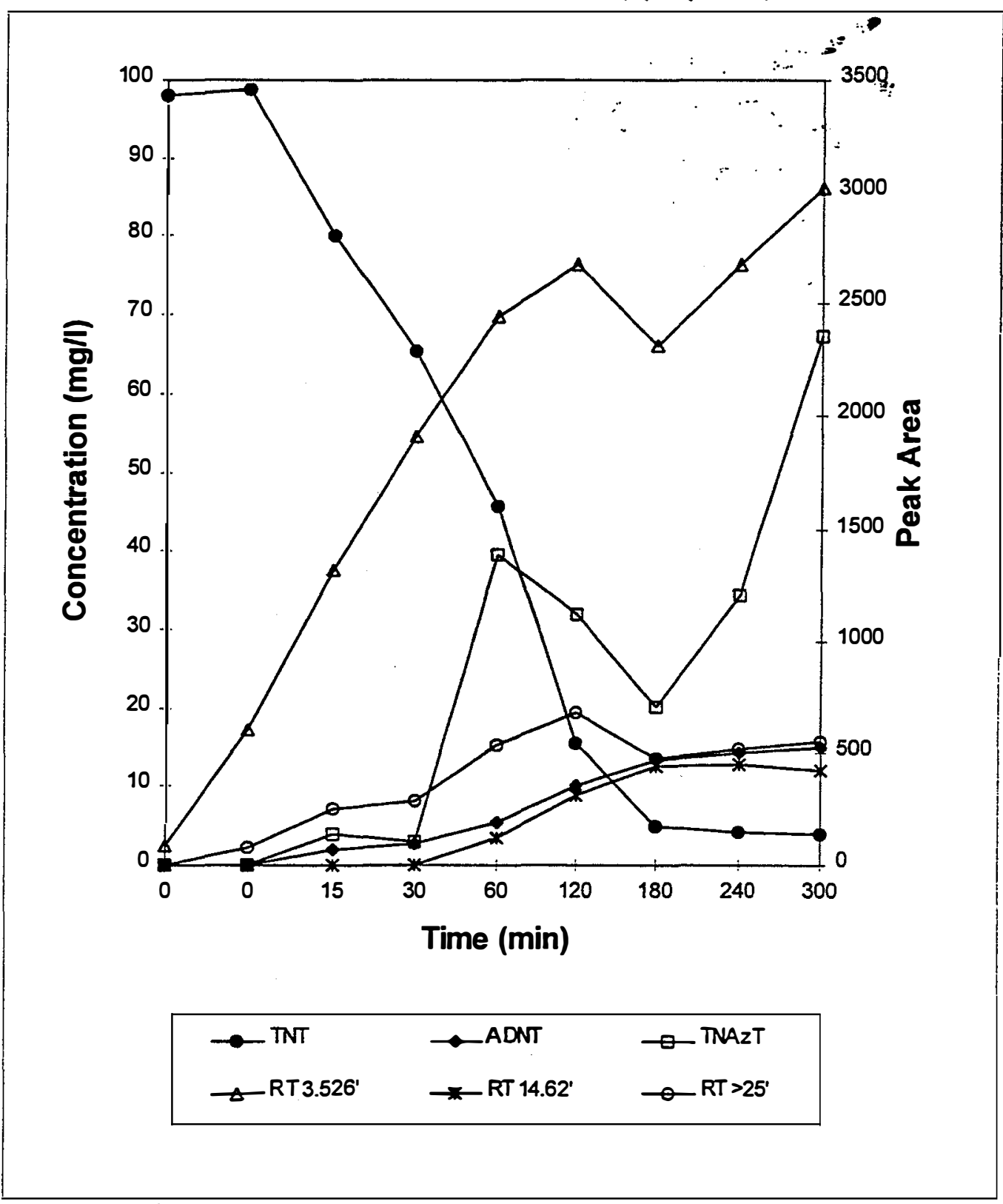

Figure 9. Anaerobic photocatalytic degradation of TNT in the presence of $\mathrm{HCO}_{3}{ }^{-}$and EDTA in experiment 4 . Solid symbols represent data in $\mathrm{mg} / \mathrm{l}$, open symbols show data as peak area from chromatograms. 


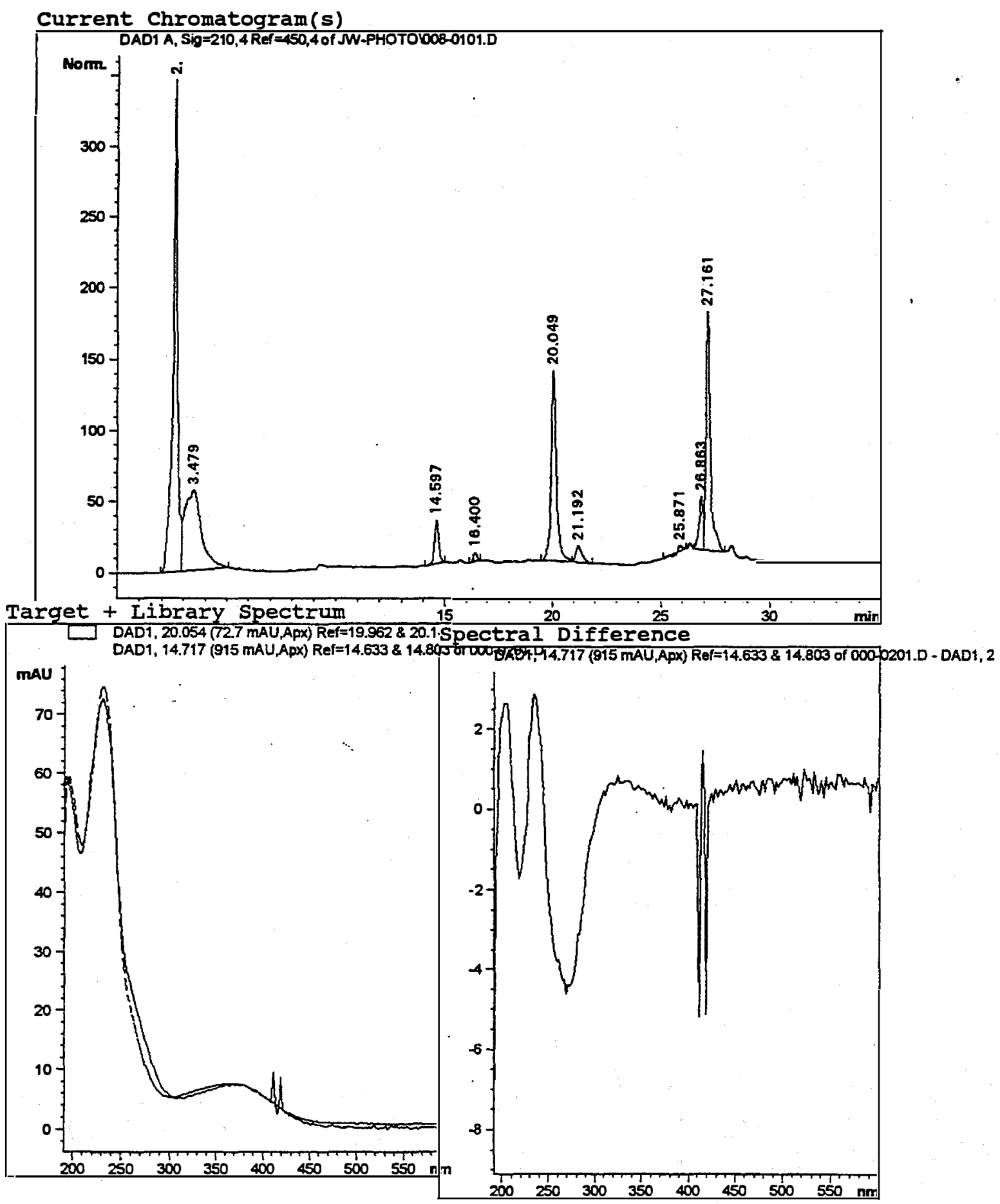

Figure 10. Chromatogram (upper) from Experiment 4 showing the spectral match (lower left) and spectral differences (lower right) for intermediate, $\mathrm{RT}=20.049 \mathrm{~min}$, identified as 4-amino-2,6-dinitrotoluene (ADNT). 


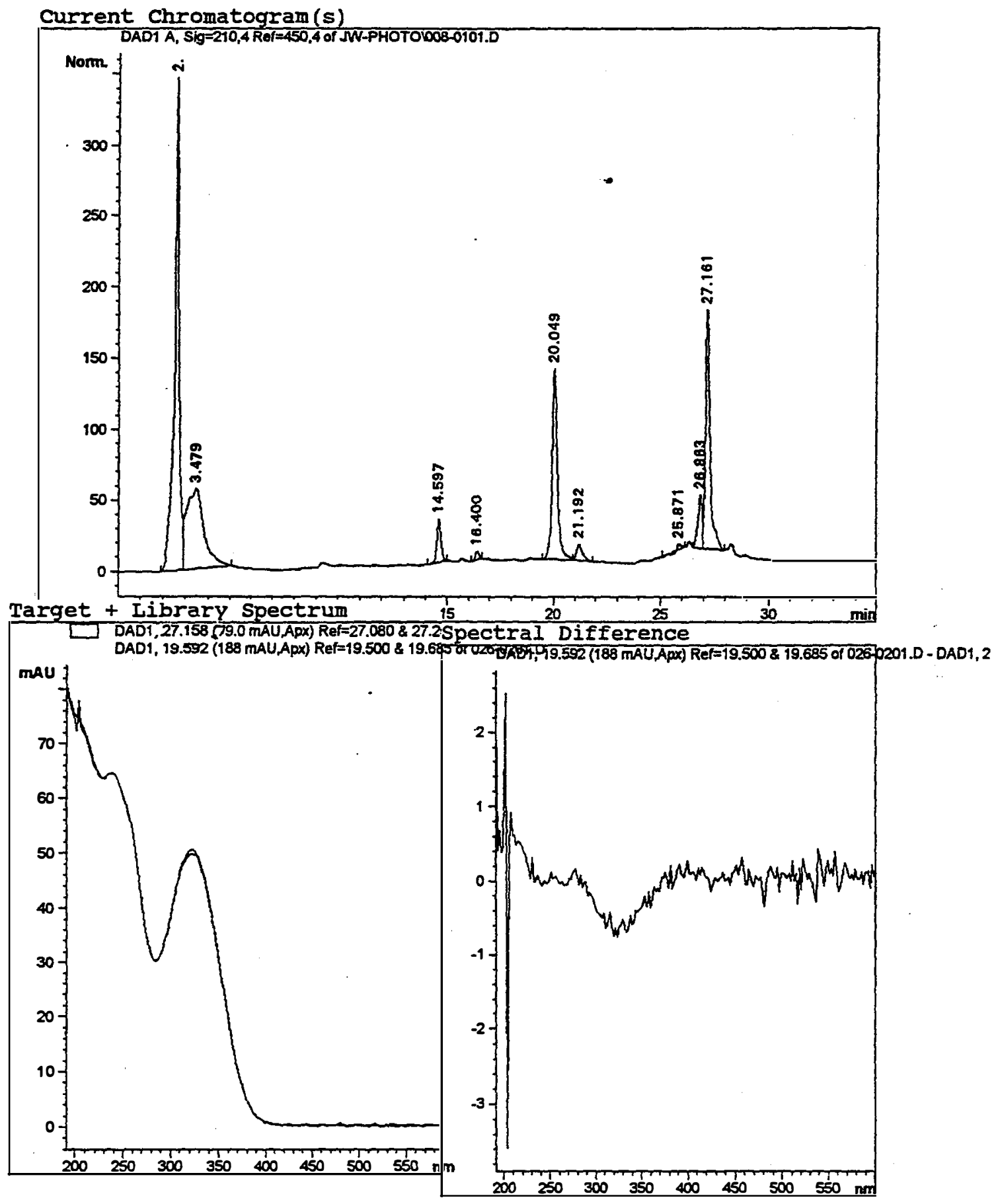

Figure 11. Chromatogram (upper) from Experiment 4 showing spectral match (lower left) and spectral difference (lower right) for intermediate, $R T=27.16 \mathrm{~min}$, identified as 2,2',6,6'-tetranitro-4,4'-azoxy toluene (TNAzT). 


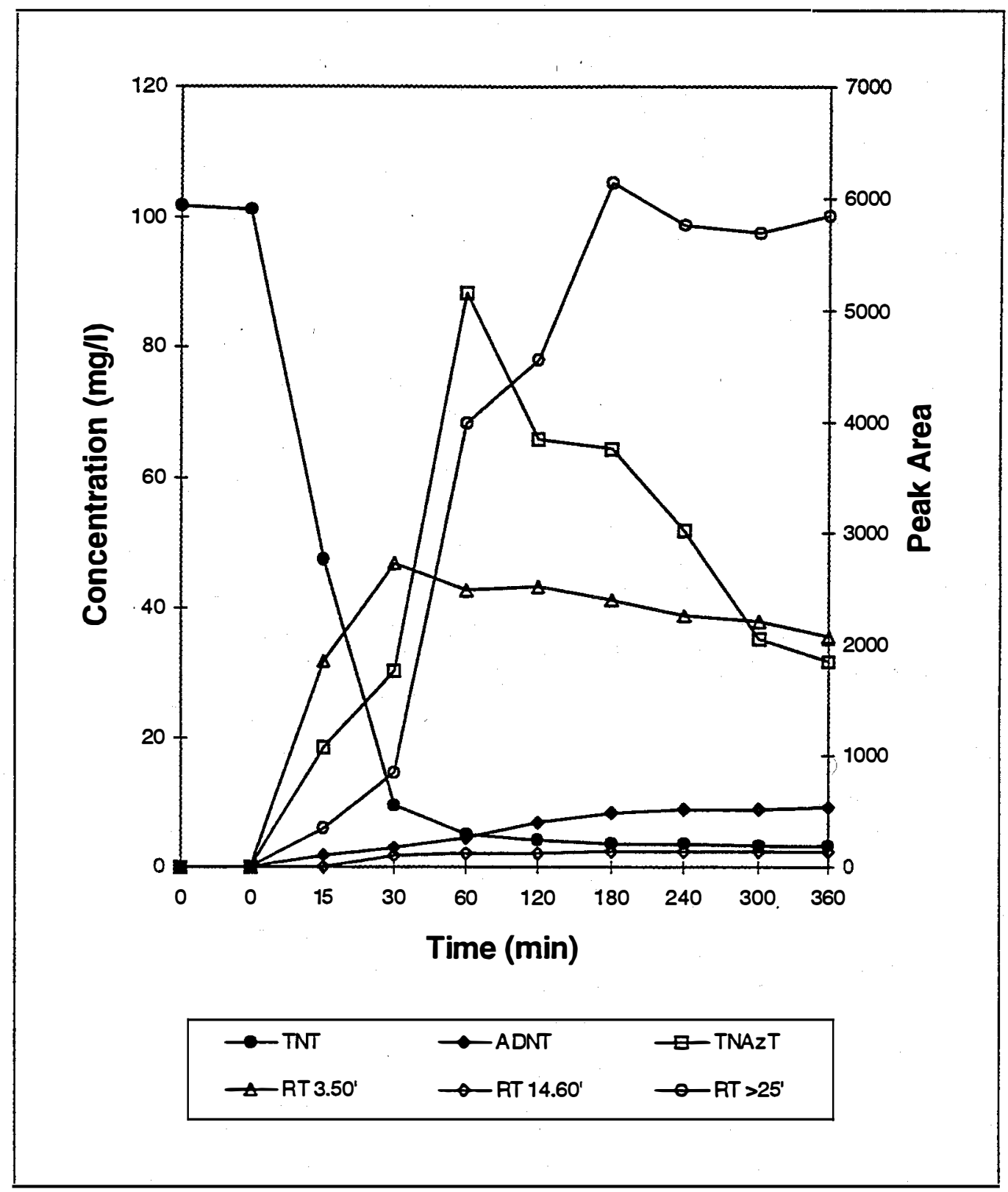

Figure 12. Anaerobic photocatalytic degradation of TNT in the presence pf EDTA in experiment 5. Solid symbols represent data in $\mathrm{mg} / \mathrm{l}$, open symbols show data as peak area from chromatograms. 


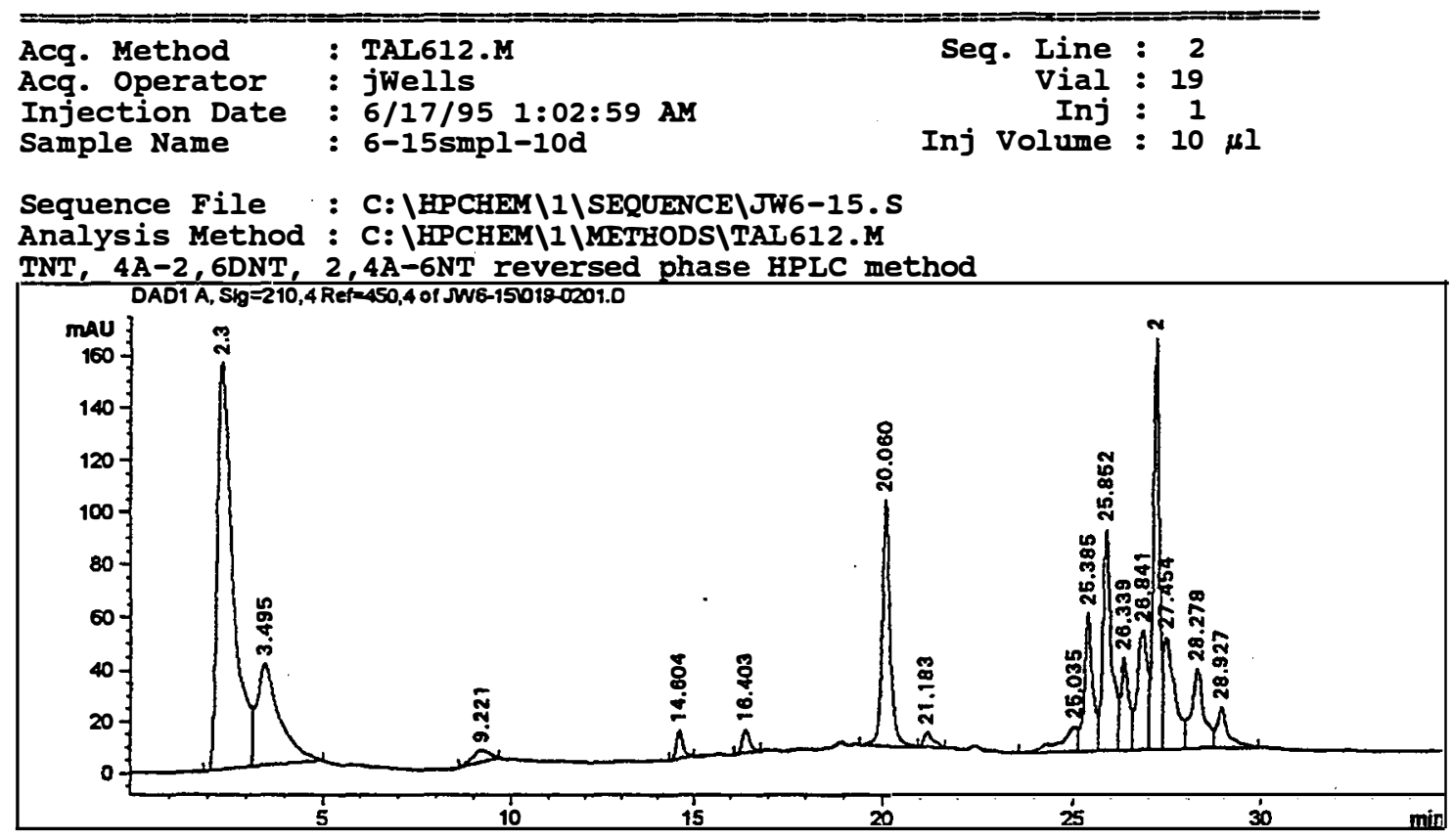

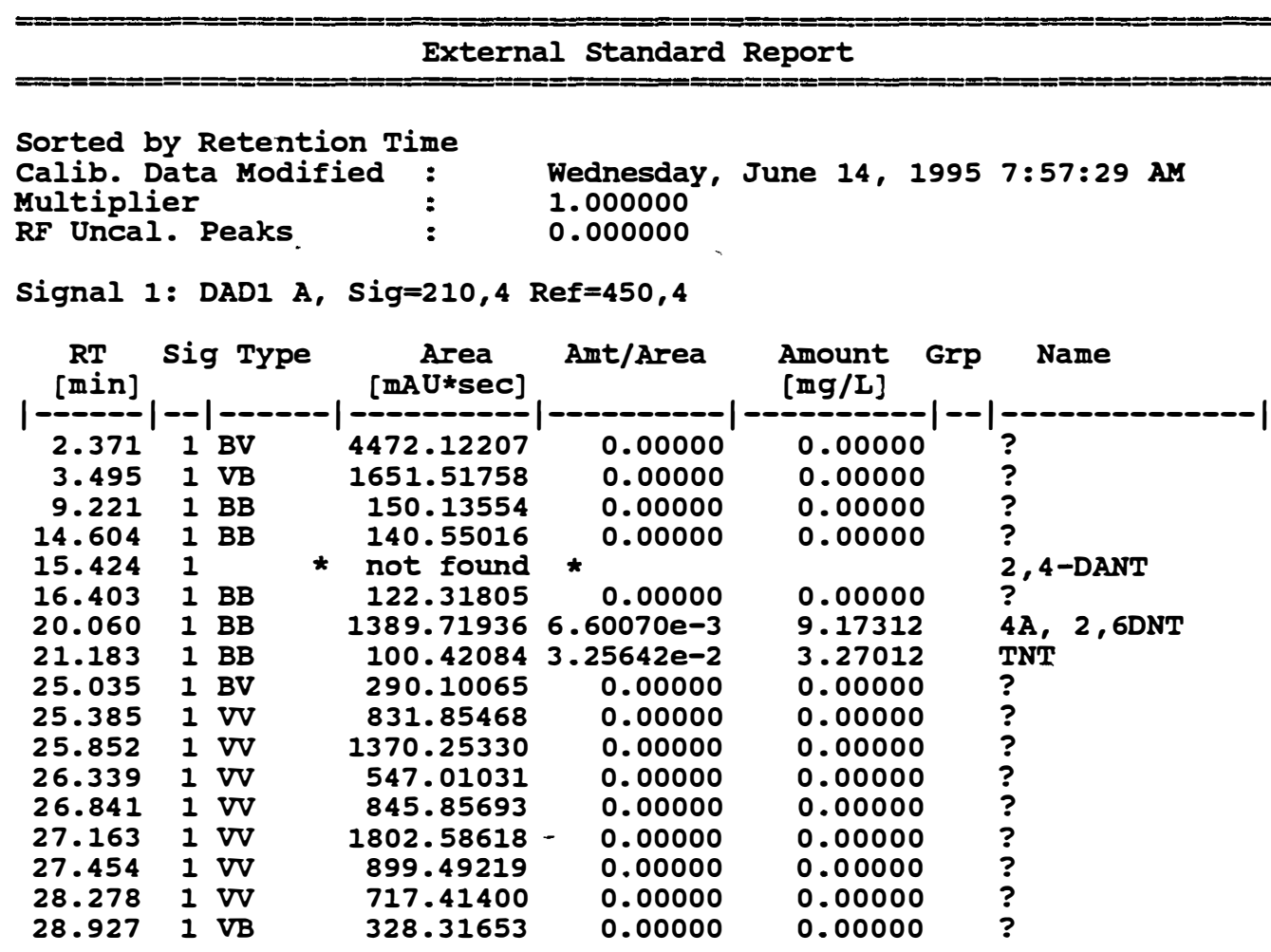

Figure 13. Chromatogram from anaerobic photocatalytic degradation of TNT in the presence of EDTA in Experiment 5. 


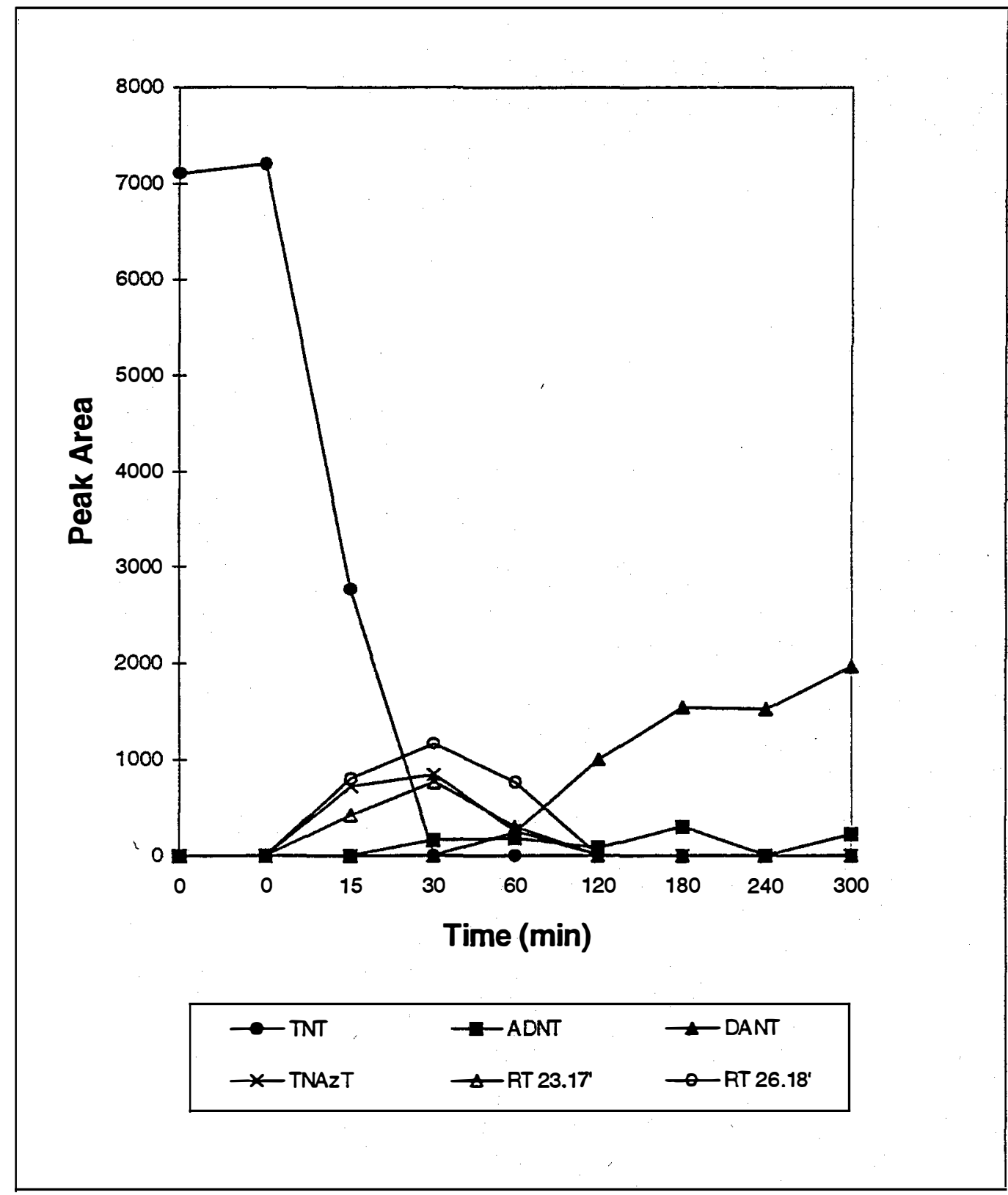

Figure 14. Anaerobic photocatalytic degradation of TNT in the presence of EDTA in experiment 10. All data are given as peak area from chromatograms. 


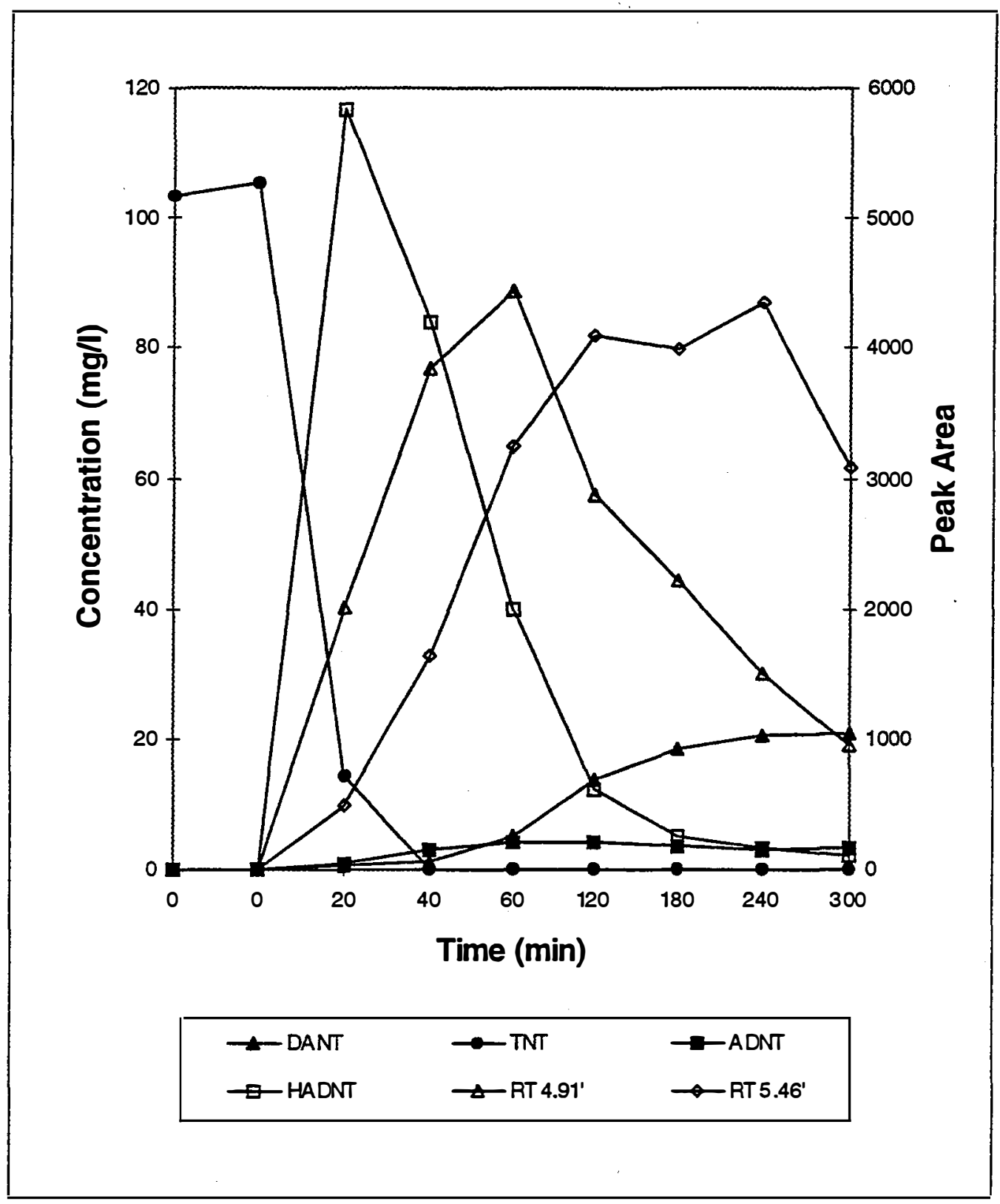

Figure 15. Anaerobic photocatalytic degradation of TNT in the presence of EDTA in experiment 11 . Solid symbols represent data in $\mathrm{mg} / \mathrm{l}$, open symbols show data as peak area from chromatograms. 
Current Chromatogram (s)

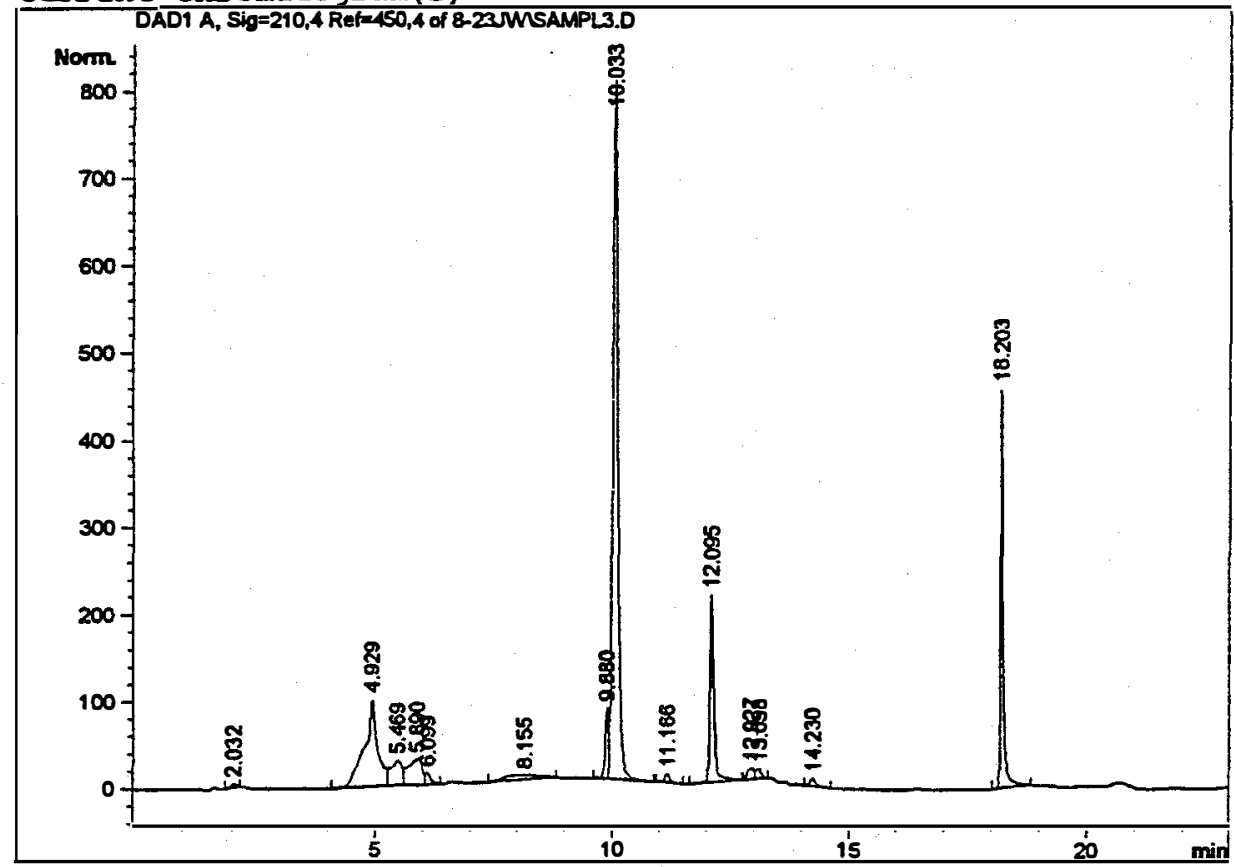

Spectral Difference

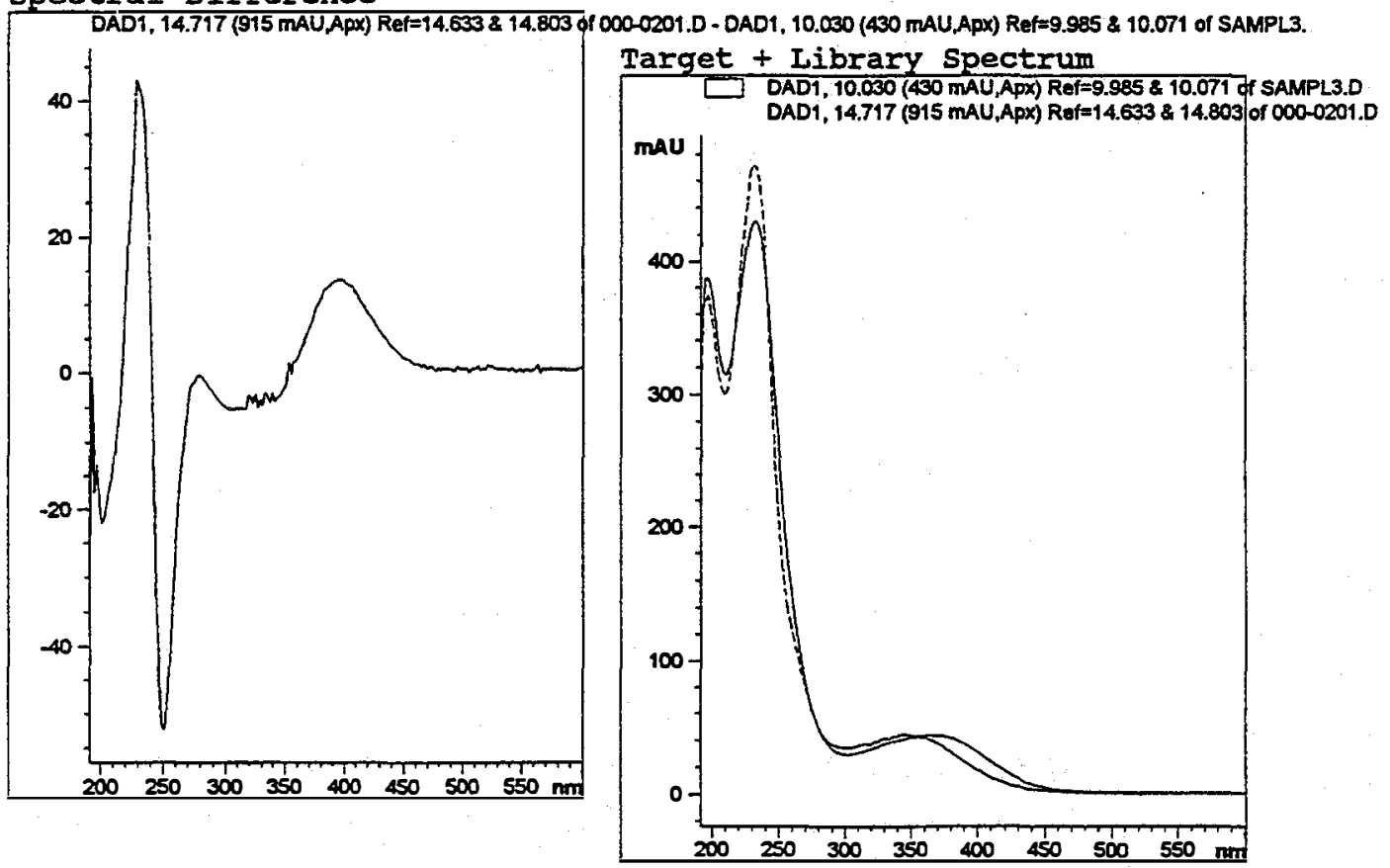

Figure 16. Chromatogram (upper) from Experiment 11 showing spectral match (lower right) and spectral difference (lower left) for intermediate, $\mathrm{RT}=10.033 \mathrm{~min}$, identified as 4-hydroxylamino-2,6-dinitrotoluene (HADNT). 

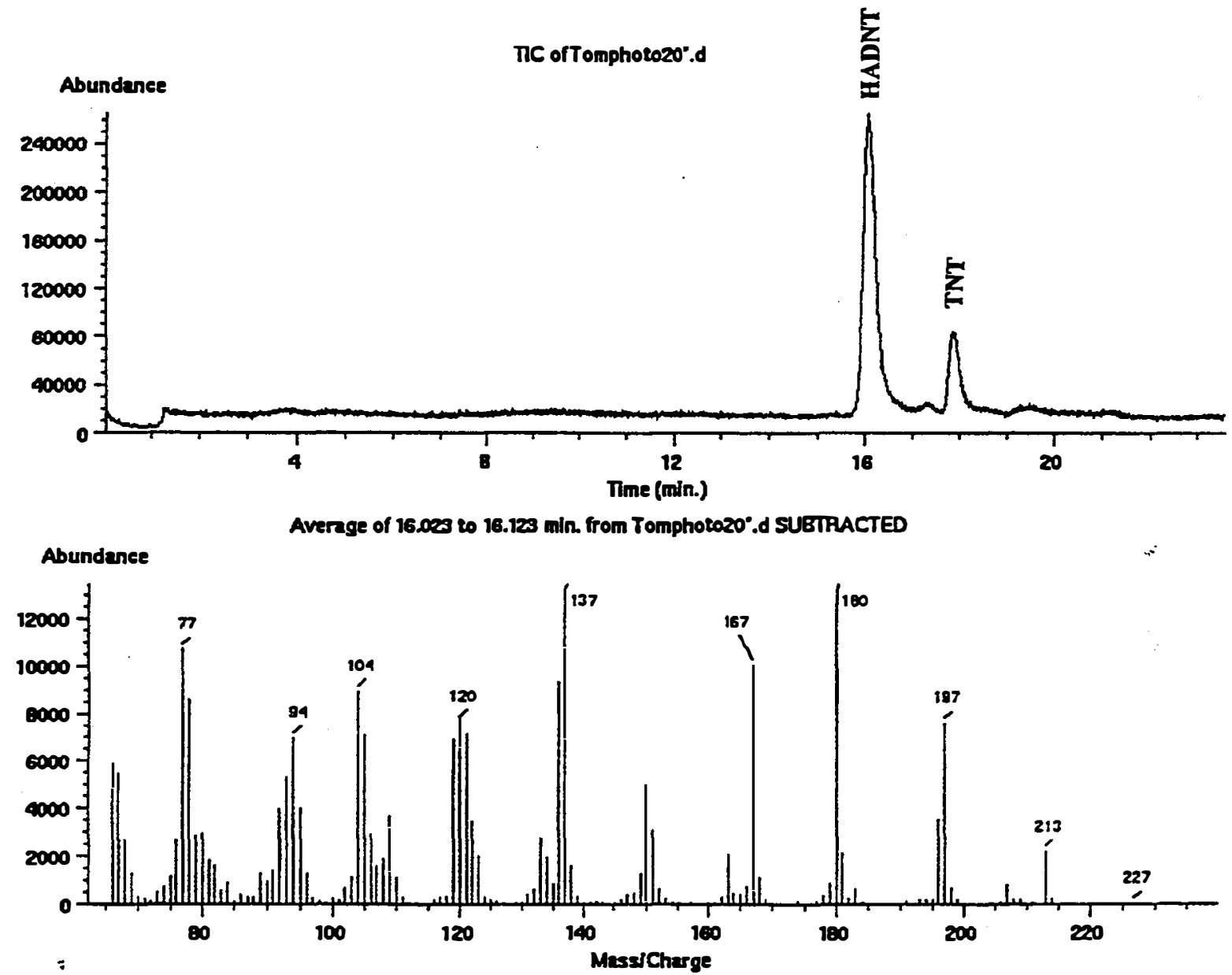

Figure 17. Chromatogram (top) and mass spectra (bottom) of 4-hydroxylamino-2,6dinitrotoluene (HADNT), an intermediate formed during anaerobic photocatalytic degradation of TNT in the presence of EDTA, in Experiment 11. 


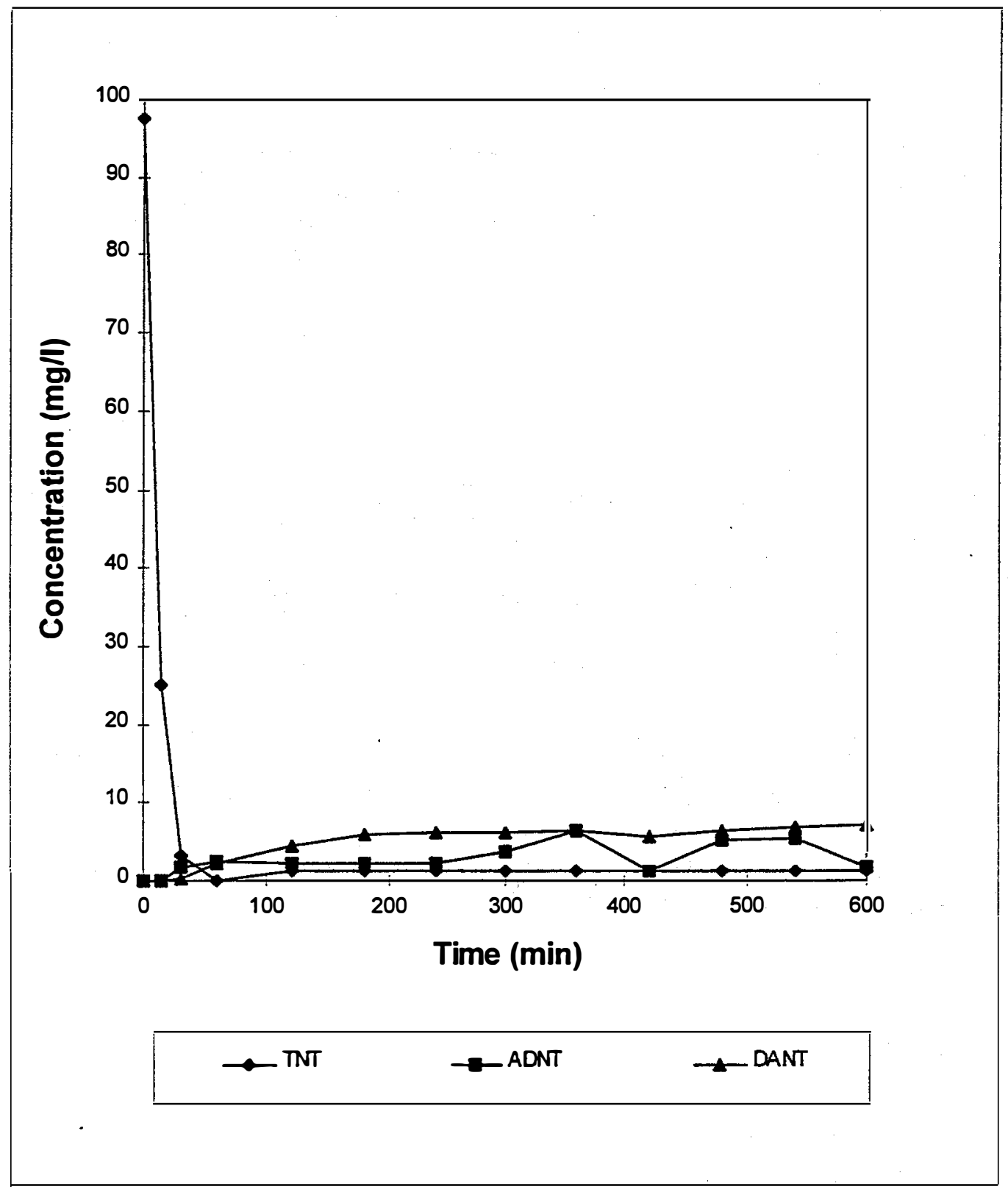

Figure 18. Anaerobic photocatalytic degradtion of TNT the presence of EDTA in experiment 16 . 


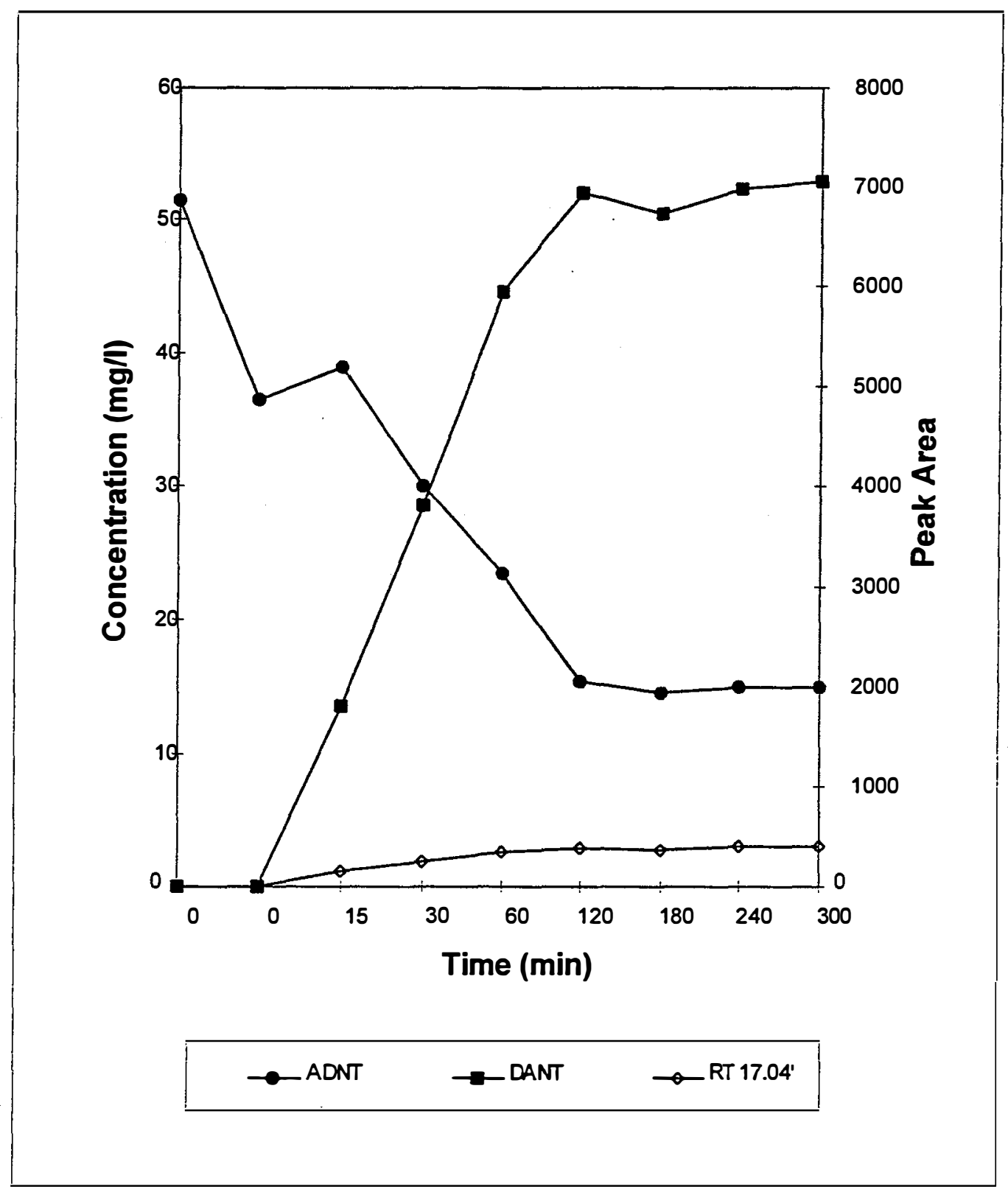

Figure 19. Anaerobic photocatalytic degradation of ADNT in the presence of EDTA in experiment 6 . Solid symbols represent data in $\mathrm{mg} / \mathrm{l}$, open symbols show data as peak area from chromatograms. 


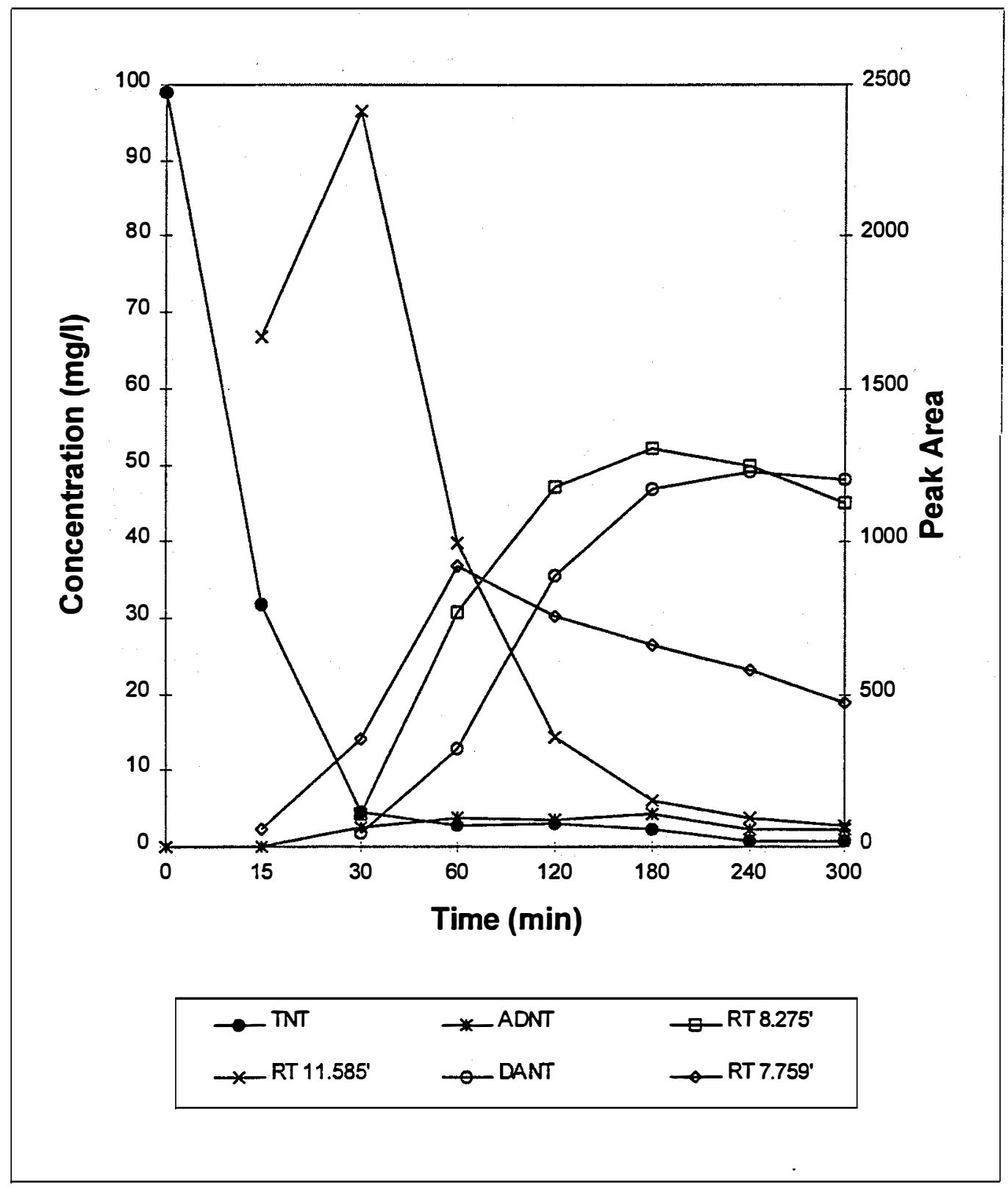

Figure 21. Partially anaerobic photocatalysis of TNT in the presence of EDTA in experiment 17 . Only an initial nitrogen purge of the reactor contents was done. 


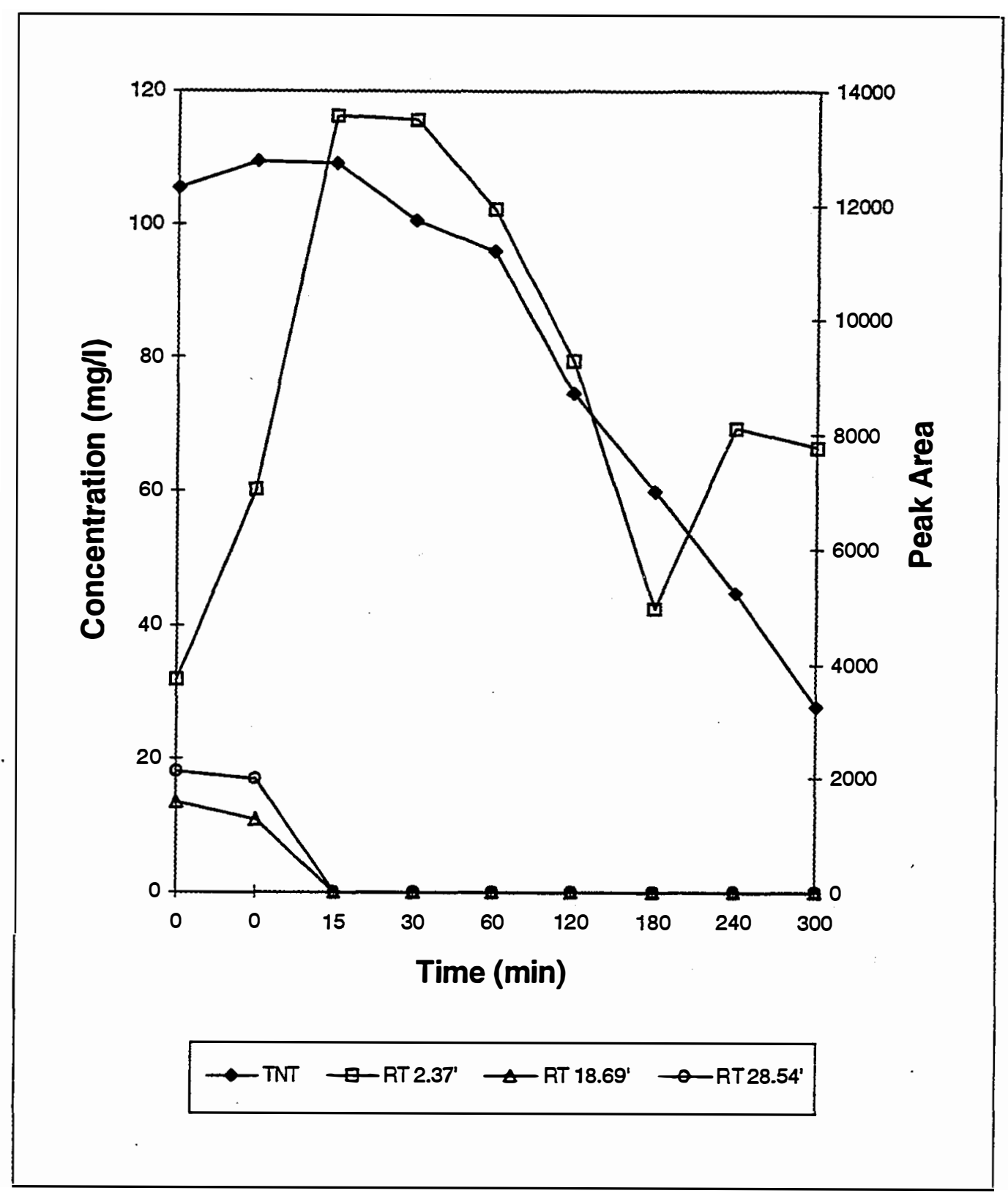

Figure 22. Anaerobic photocatalytic degradation of TNT in the presence of tetranitromethane and EDTA in experiment 8. Solid symbols represent data in $\mathrm{mg} / \mathrm{l}$, open symbols show data as peak area from chromatograms. 


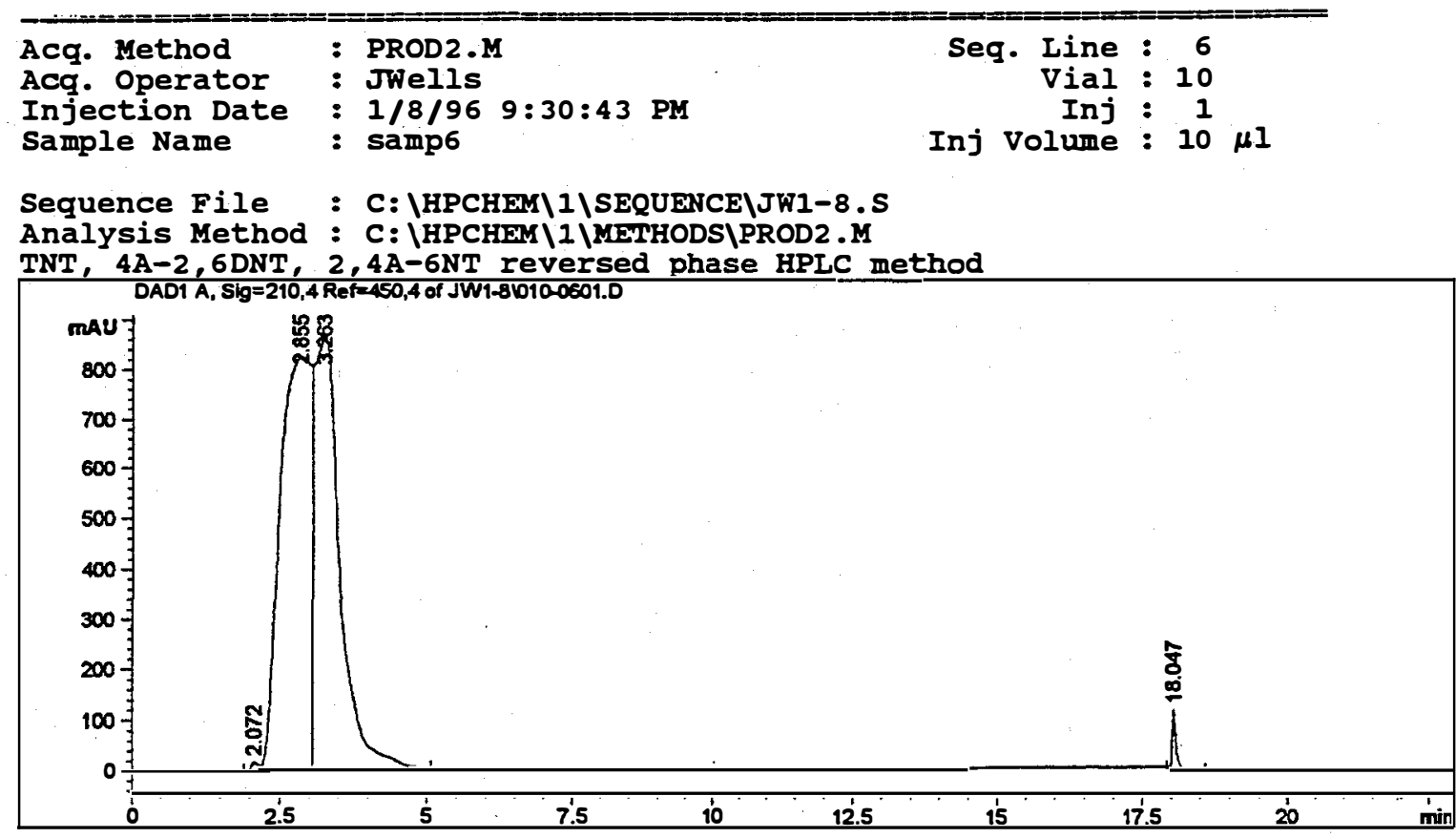

$=$ External Standard Report

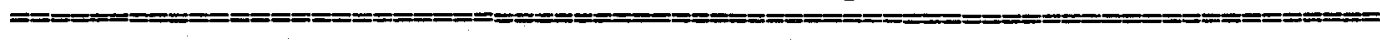

Sorted by Retention Time Calib. Data Modified : $\begin{array}{lll}\text { Multiplier } & : & 1.000000 \\ \text { Uncalibrated Peaks } & : & \text { not reported }\end{array}$ Monday, January 08, 1996 7:01:55 PM

Signal 1: DAD1 A, Sig $=210,4$ Ref $=450,4$

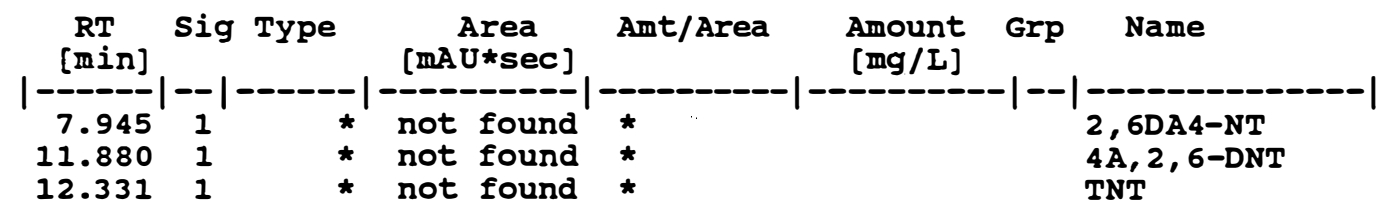

Totals :

0.00000

1 Warnings or Errors :

Warning : Calibrated compound(s) not found

Figure 23. Chromatogram from anaerobic photocatalytic degradation of TNT in the presence of periodate in Experiment 13. 


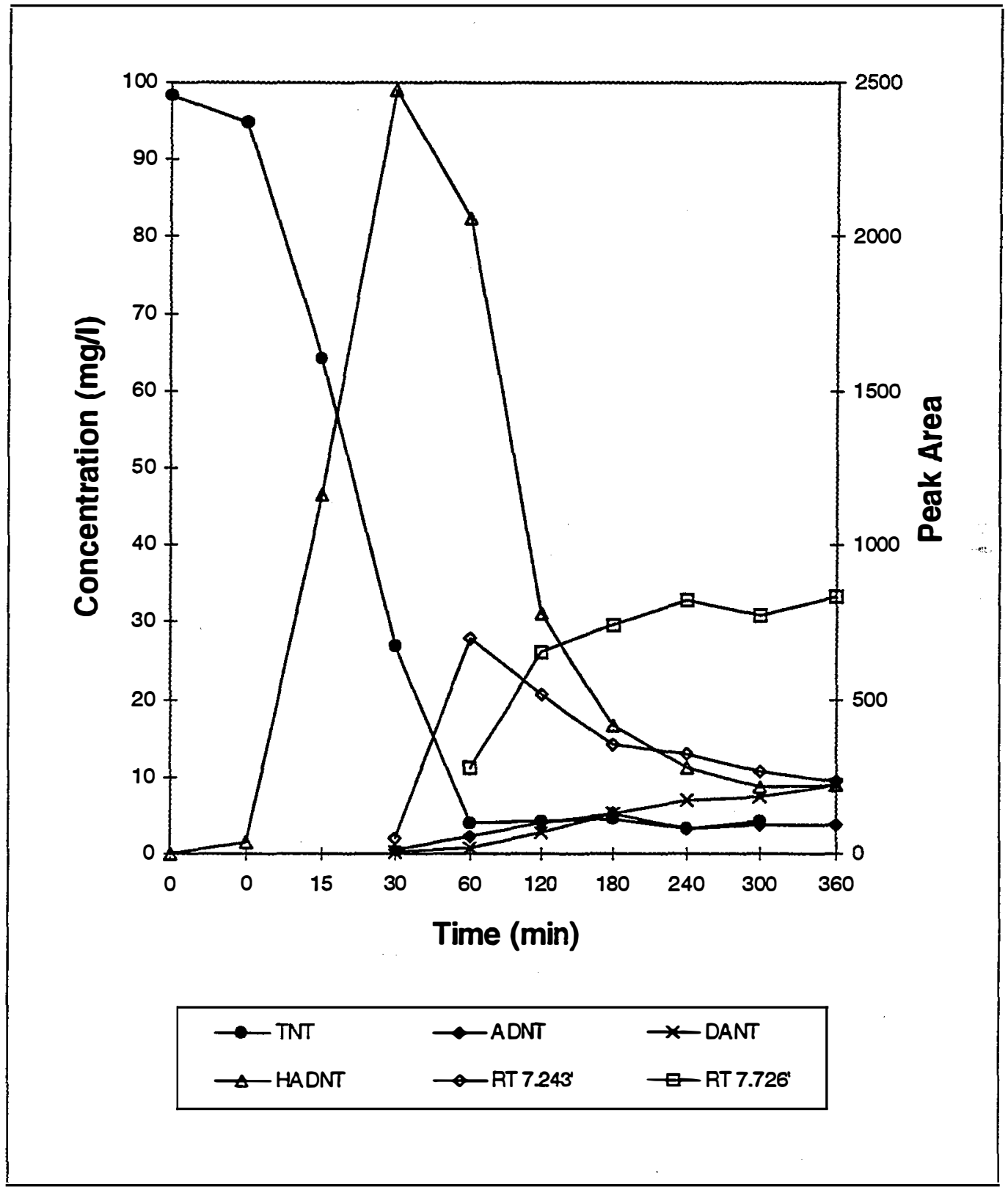

Figure 24. Anaerobic photocatalytic degradation of TNT in the presence of methanol and EDTA in experiment 14. Solid symbols represent data in $\mathrm{mg} / \mathrm{l}$, open symbols show data as peak area from chromatograms. 


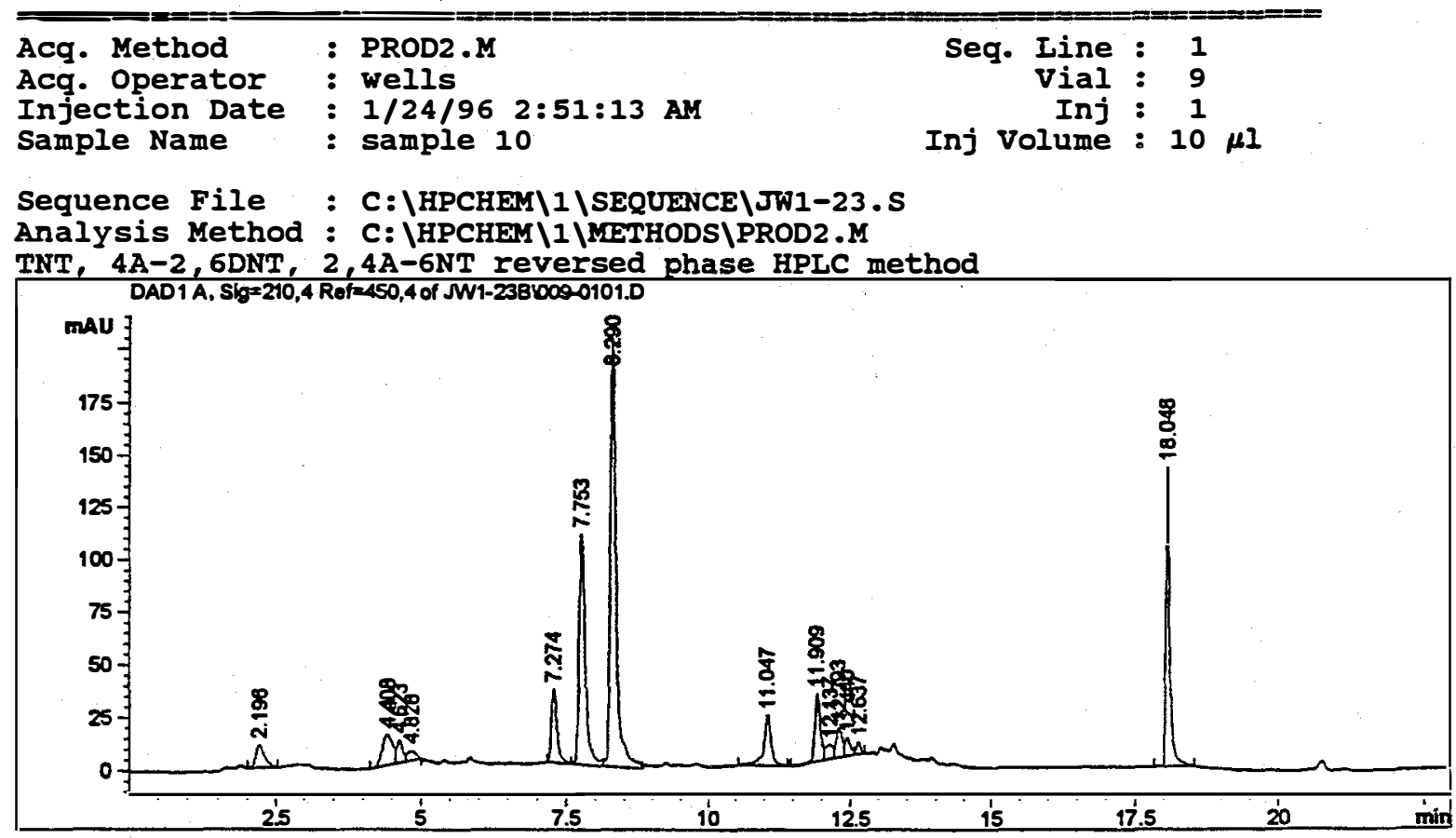

External standard Report

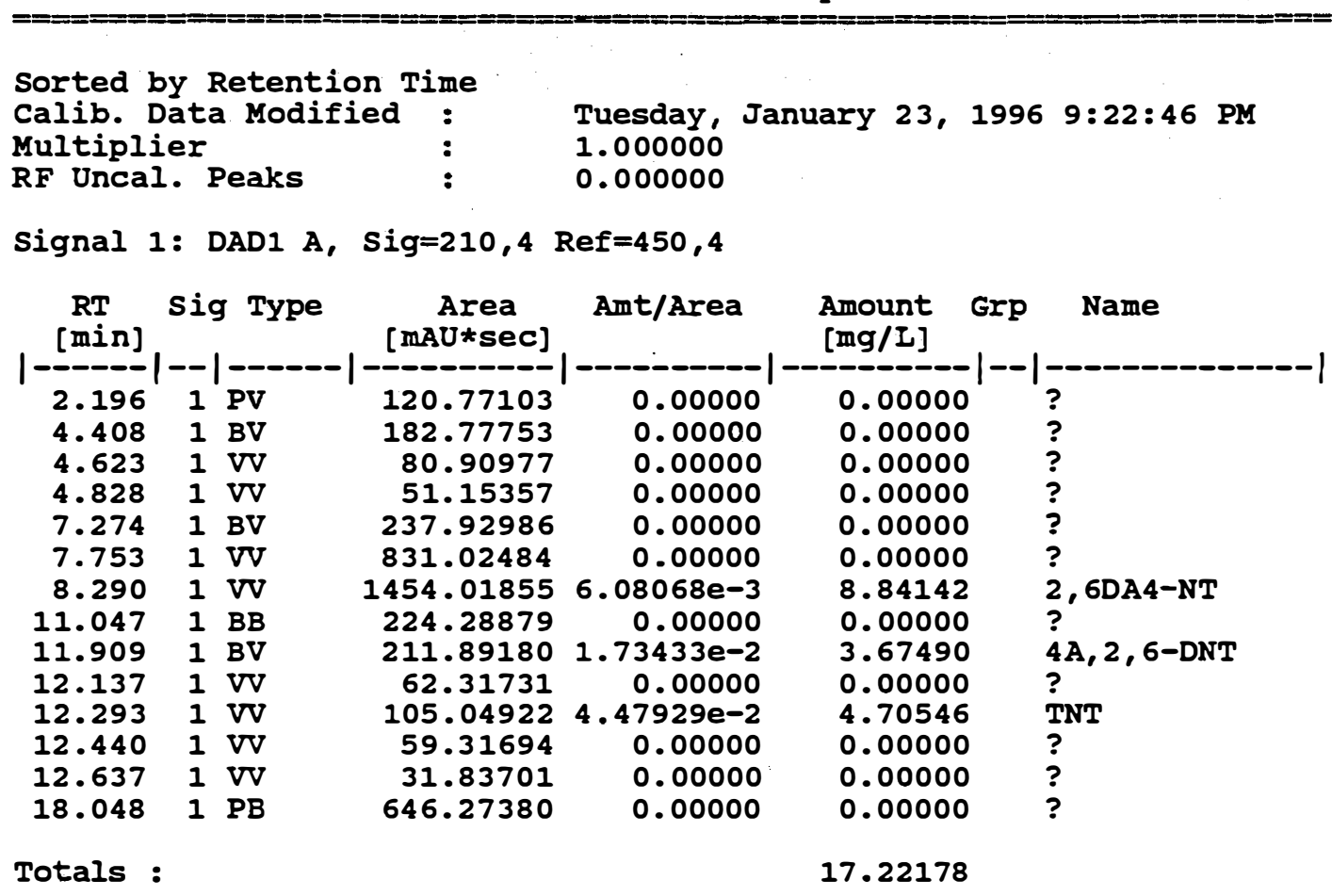

Figure 25. Chromatogram from anaerobic photocatalytic degradation of TNT in the presence of methanol in Experiment 14. 


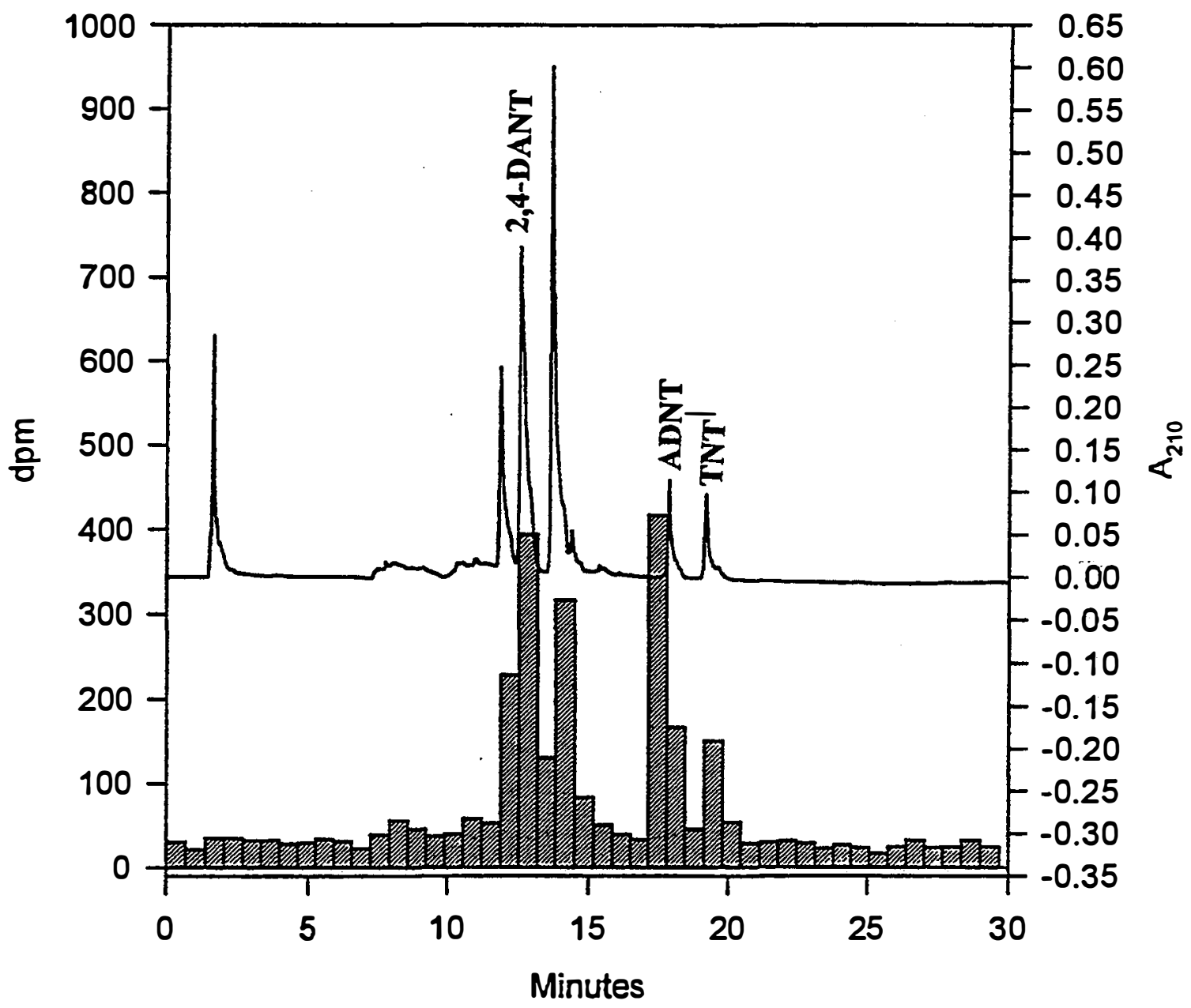

Figure 26. Chromatographic peaks $\left(\mathrm{A}_{210}\right)$ and associated ${ }^{14} \mathrm{C}$ fractionation (dpm) from photocatalytic degradation of TNT in the radiotracer study of Experiment 9. 


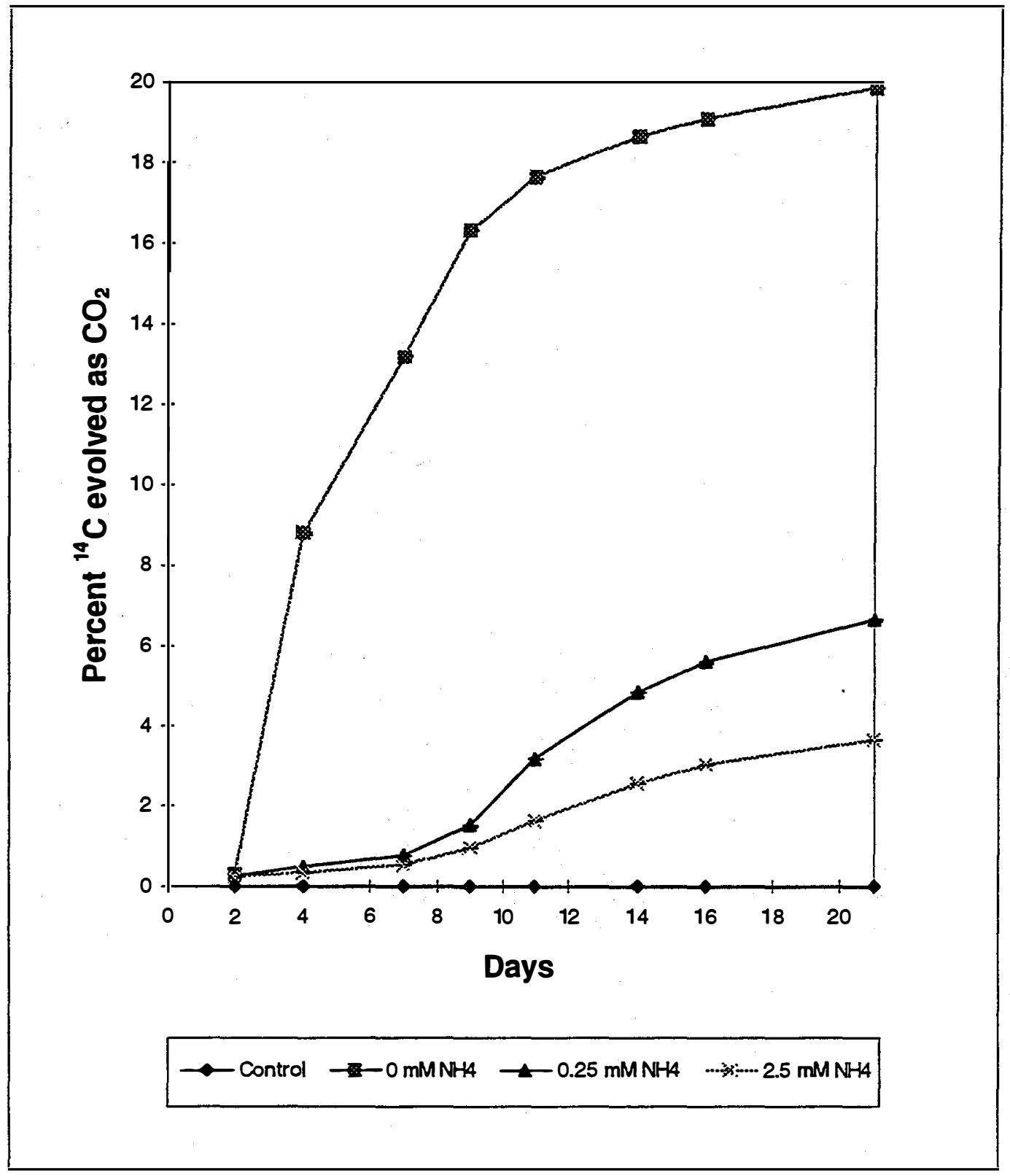

Figure 27. Evolution of ${ }^{14} \mathrm{C}-\mathrm{CO}_{2}$ over time from aerobic biological degradation of photocatalytic TNT degradation products by $P$. chrysosporium in experiment 12 . Graph shows four treatments: a non-inoculated control, and exogenous additions of $0,0.25$ and $2.5 \mathrm{mM}$ $\mathrm{NH}_{4}$. 


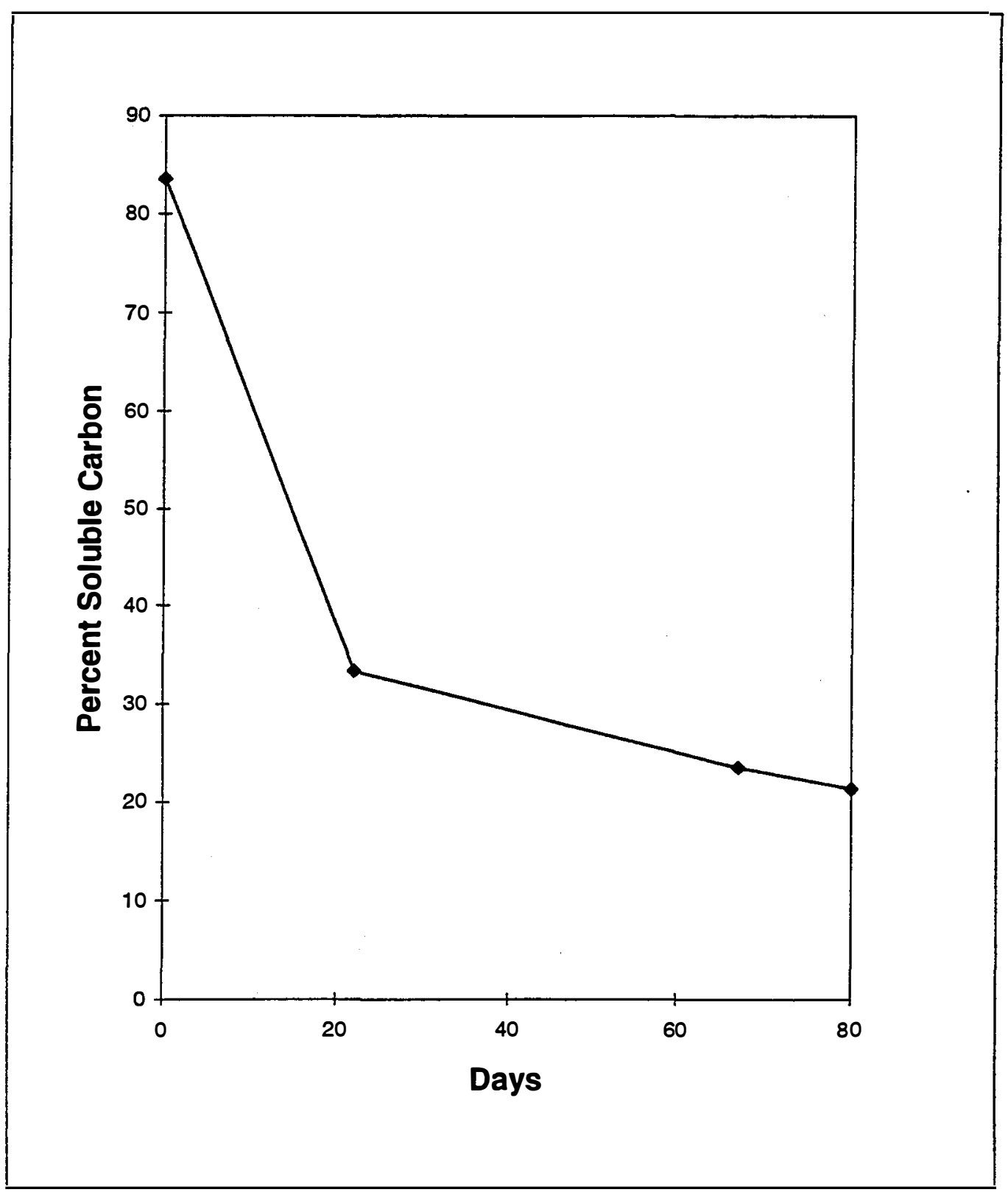

Figure 28. Loss of soluble photoproducts from solution over ime. 


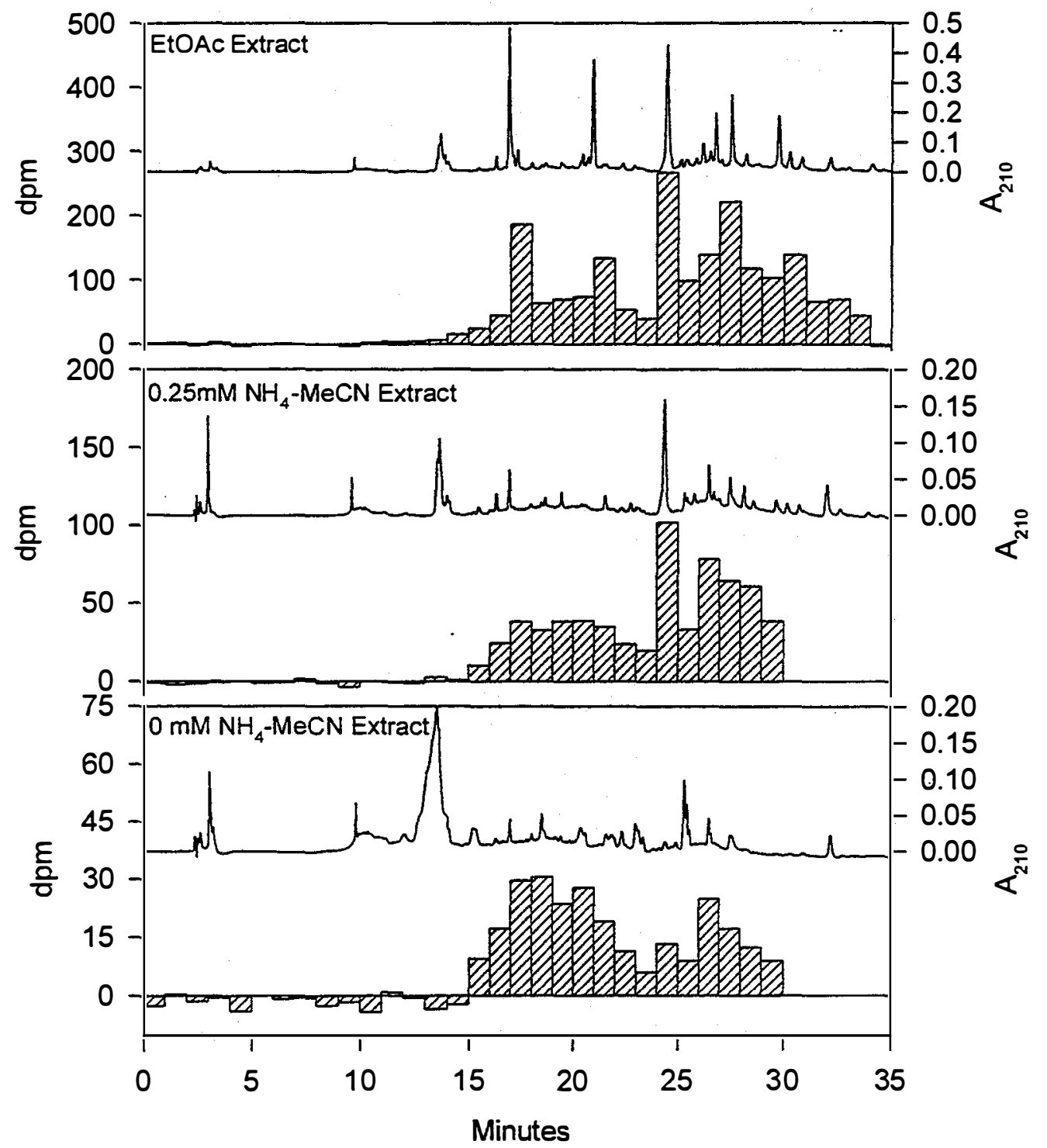

Figure 29. Chromatographic peaks $\left(\mathrm{A}_{210}\right)$ with associated ${ }^{14} \mathrm{C}$ fractionation (dpm) of photoreactor products after photocatalytic treatment of TNT prior to biological treatment (top graph) and after aerobic biological treatment by $P$.

chrysosporium in the presence of $0.25 \mathrm{mM} \mathrm{NH}_{4}$ (middle graph) and no $\mathrm{NH}_{4}$ (bottom graph), all in experiment 12. 


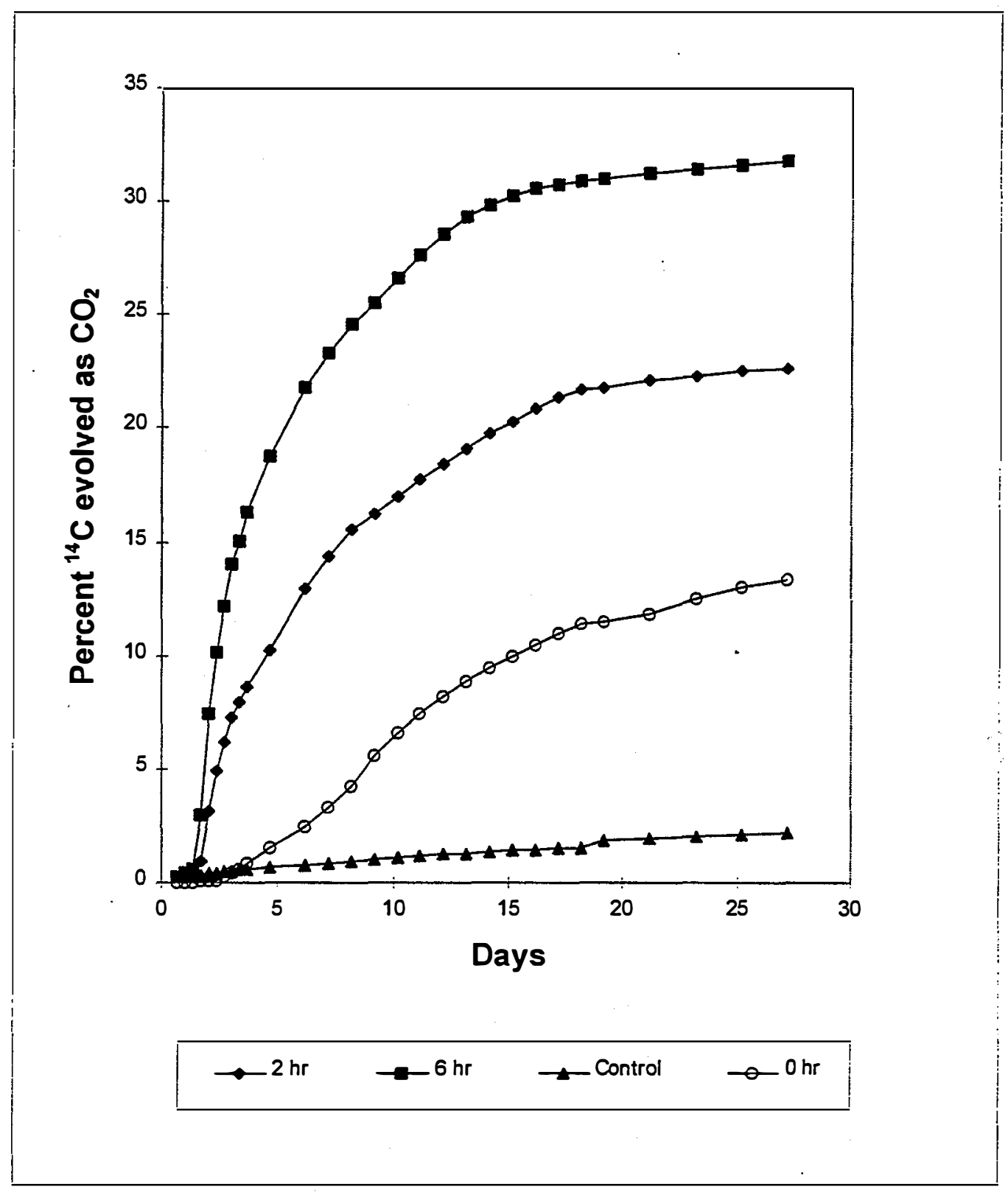

Figure 30. Evolution of ${ }^{14} \mathrm{C}-\mathrm{CO}_{2}$ over time from aerobic biological degradation of photocatalytic TNT degradation products by $P$. chrysosporium in experiment 15 . Graph shows four treatments: a non-inoculated control, no photocatalytic treatment $(0 \mathrm{hr})$ and 2 and 6 hours of photocatalysis. 


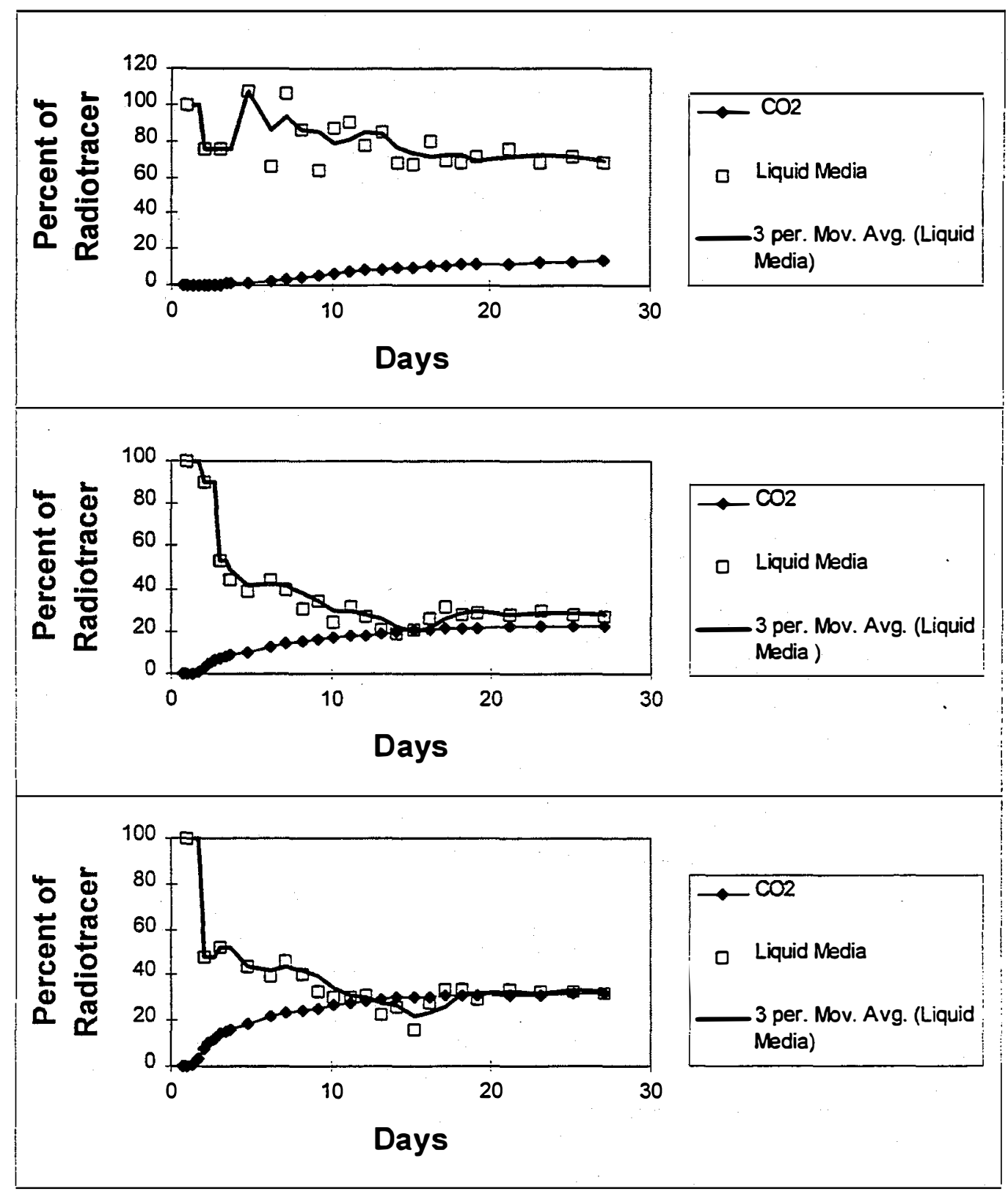

Figure 31. Distribution of ${ }^{14} \mathrm{C}$ radiotracer between evolved $\mathrm{CO}_{2}$ and that soluble in liquid media during biological treatment of photoreactor contents by $P$. chrysosporium in experiment 15. Graphs show (top to bottom): 0,2 and 6 hours of photocatalytic treatment, respectively, prior to biological treatment. 


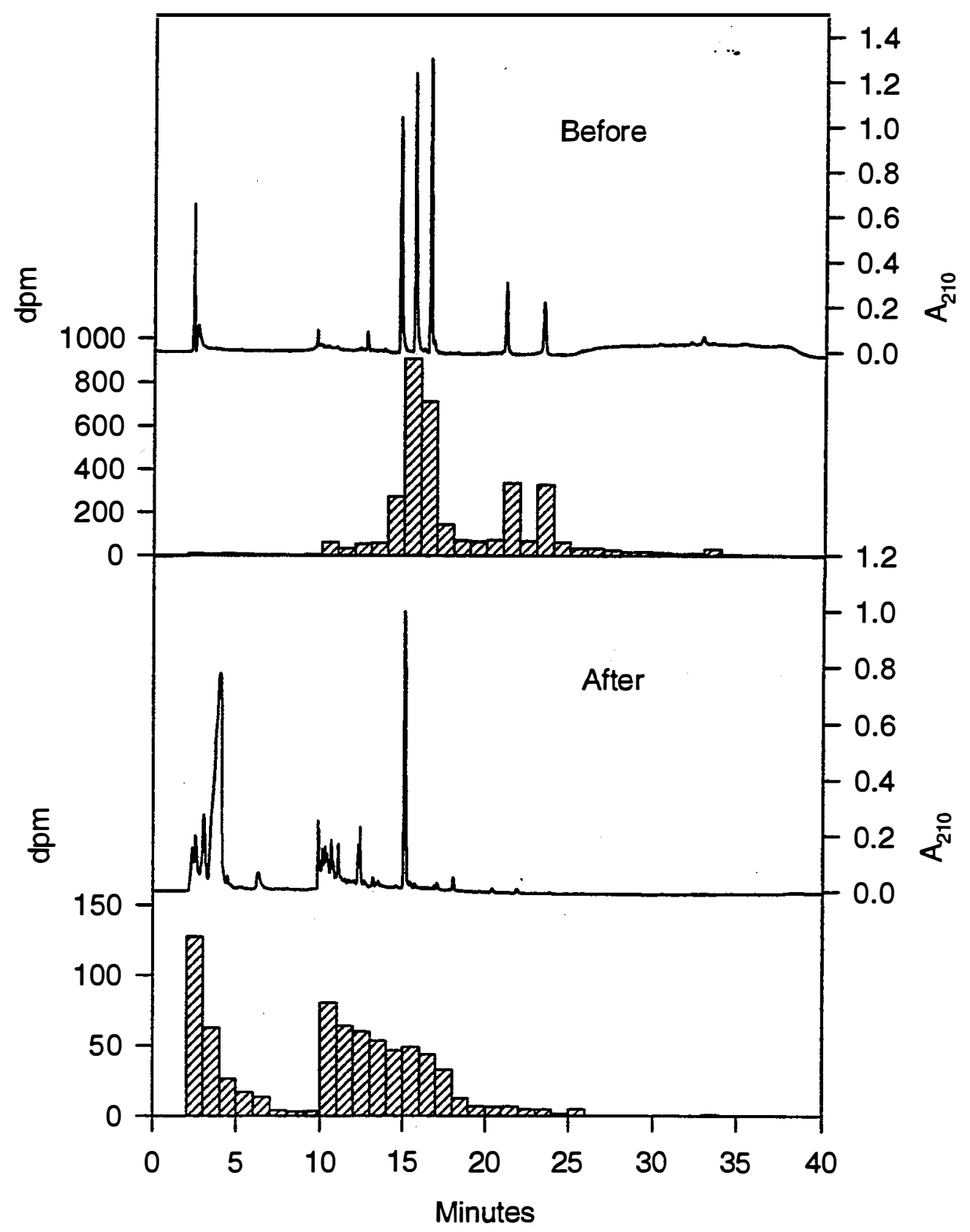

Figure 32. Chromatographic peaks $\left(\mathrm{A}_{210}\right)$ with associated ${ }^{14} \mathrm{C}$ fractionation (dpm) of photoreactor products from 2 hours of photocatalytic treatment of TNT before (top graph) and after (bottom graph) aerobic biological treatment by $P$. chrysosporium in experiment 15. 


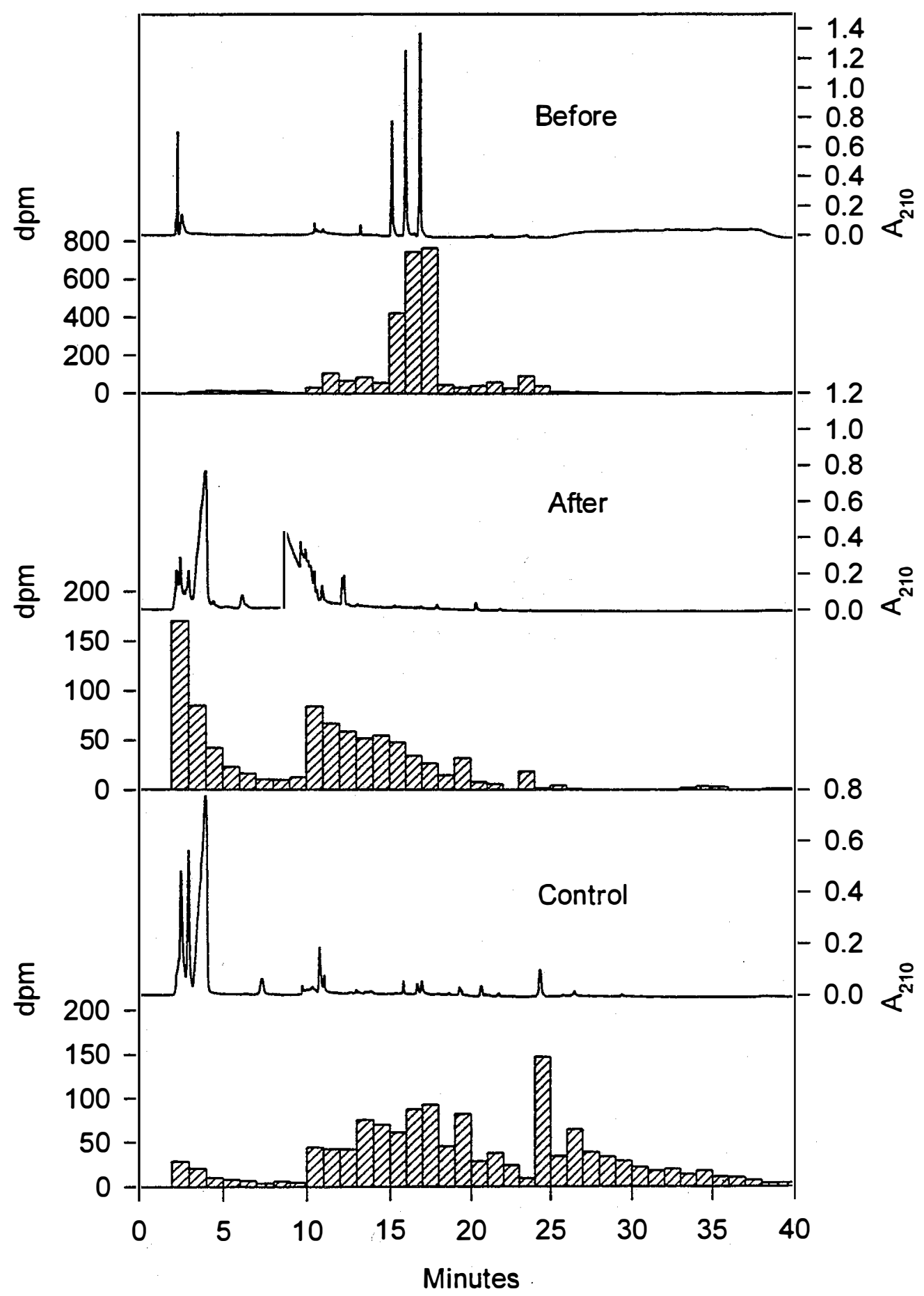

Figure 33. Chromatographic peaks $\left(\mathrm{A}_{210}\right)$ with associated ${ }^{14} \mathrm{C}$ fractionation (dpm) of photoreactor products from 6 hours of photocatalytic treatment of TNT before (top graph) and after (middle graph) aerobic biological treatment by $P$. chrysosporium in experiment 15 . An abiotic control (bottom graph) is included for comparison. 


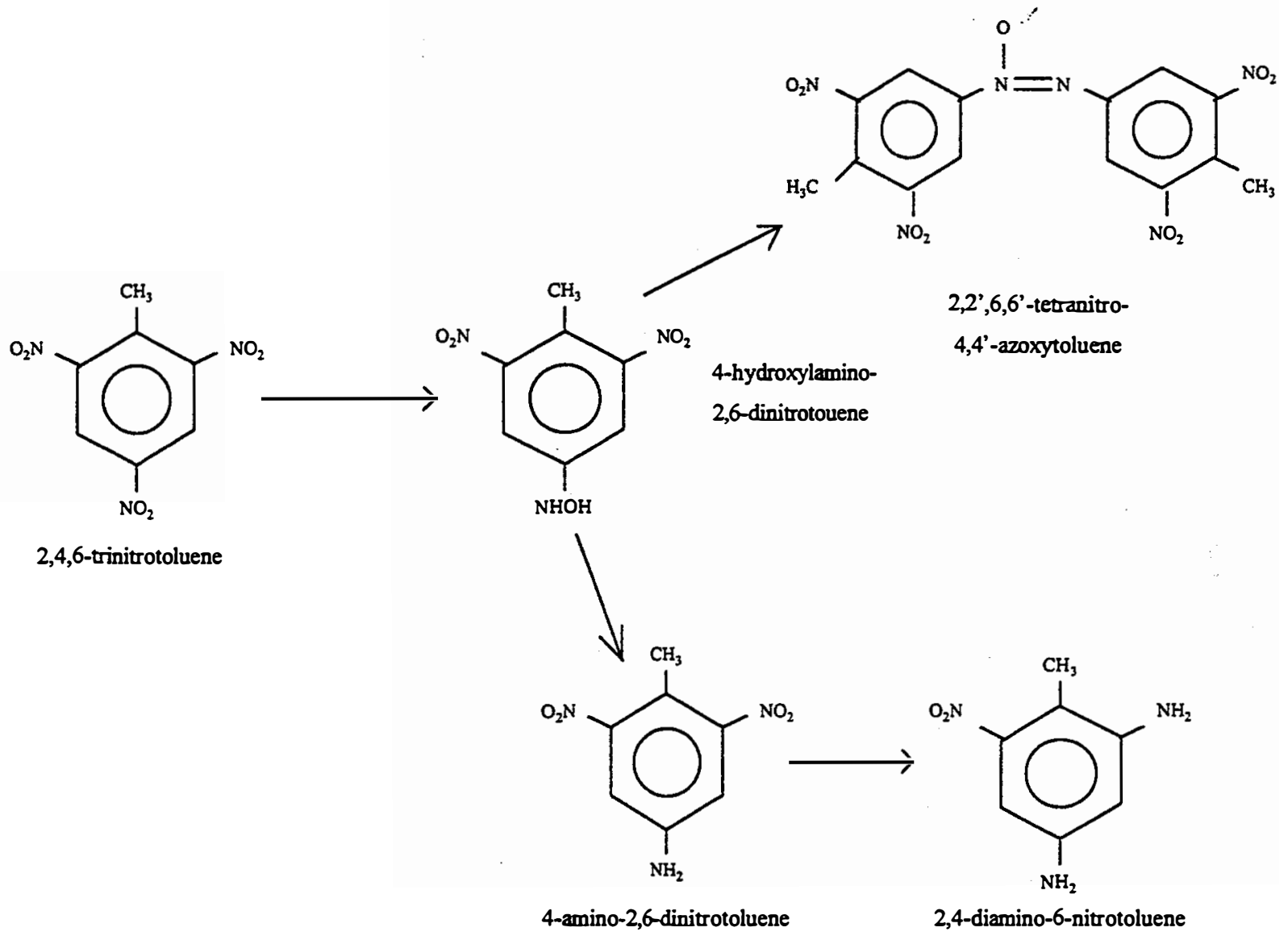

Figure 34. Proven pathway for anaerobic photocatalytic degradation of TNT. 


\section{B. Bibliography of work on treatment of pink water and related water contamination.}

Alif, Admin., and Boule Pierre. "Photochemistry and Environment Part XIV. Phototransformation of Nitrophenols Induced by Excitation of Nitrite and Nitrate Ions." J. Photochem. Photobiol. A: Chem. 59 (1991): 357-67.

Andrews, Catherine C. Photooxidative Treatment of TNT Contaminated Wastewaters, WQEC/C 80-137. Naval Weapons Support Center, Crane, IN, December 1979. ADA 084684.

Augugliaro, V., M. J. Lopez-Munoz, L. Palmisano, and J. Soria. "Influence of pH on the Degradation Kinetics of Nitrophenol Isomers in a Heterogeneous Photocatalytic System." Appl. Catal., A 101, no. 1 (1993): 7-13.

Augugliaro, Vincenzo, Leonardo Palmisano, Mario Schiavello, Antonino Sclafani, Leonardo Marchese, Gianmario Martra, and Fausto Miano. "Photocatalytic Degradation of Nitrophenols in Aqueous Titanium Dioxide Dispersion." Appl. Catal. 69, no. 2 (1991): 323-40.

Botcher, Tod R., and Charles A. Wight. "Explosive Thermal Decomposition of RDX." J. Phys. Chem. 98 (1994): 5441-4.

Bowen, Richard C., Armand A. Balasco, Michael Bryant, Kevin Cahill, and Michael Marando. Final Feasibility Study for Ground Water at Explosive Washout Lagoons (OU-3) at the Umatilla Depot Activity (UMDA), SFIM-AEC-BC-CR-93137. US Army Environmental Center, Aberdeen Proving Ground, MD 21010, 10 December 1993. USAEC.

Burlinson, N. E., M. E. Sitzmann, L. A. Kaplan, and E. Kayser. "Photochemical Generation of the 2,4,6Trinitrobenzyl Anion." J. Org. Chem. 44, no. 21 (1979): 3695-98.

Burlinson, Nicholas E., Lloyd A. Kaplan, and Charles E. Adams. Photochemistry of TNT: Investigation of the "Pink Water" Problem, NOLTR 73-172. Naval Ordnance Laboratory, White Oak, Silver Spring, MD, 3 October 1973. AD 769670.

Burrows, W. Dickinson, and Ernst E. Brueggemann. Tertiary Treatment of Effluent From Holston AAP Industrial Liquid Waste Treatment Facility V. Degradation of Nitramines in Holston AAP Wastewaters by Ultraviolet Radiation, TR8602. Fort Detrick, Frederick, MD, September 1986. AD-A176 195.

Carrazza, J., E. Pregun, C. Chandler, and W. Helbert. Treatment of Wastewater (Red Water) Resulting From TNT Purification, AD-P004 146. U. S. Army R\&D Center, Dover, NJ, 1984. AD-P004 146.

Cho, Jeong-Guk, William T. Potter, and Kerry L. Sublette. "Porphyrin-Catalyzed Reduction of Nitroaromatics for the Treatment of Pink Water." Applied Biochem. and Biotechnol. $45 / 46$ (1994): 861-70.

Ciccone, Vincent J., Richard P. Schmitt, James M. Morgan, and George A. Garrigan. Economic Evaluation of Munitions Manufacturing Pink Wastewater Treatment Alternatives Using a Present Value-Unit Cost Methodology, DRXTH-TE-CR-82126. USATHAMA, Aberdeen Proving Ground, MD, February 1982. AD A115218. 
Davis-Hoover, Wendy. J. R. Simplot Ex-Situ Bioremediation Technology for Treatment of TNTContaminated Soils, EPA/540/R-95/529. U.S. Environmental Protection Agency, Cincinnati, OH, September 1995.

DeBerry, David W., Alfred Viehbeck, and Dean Meldrum. A Literature Survey: Basic Mechanisms of Explosive Compounds in Wastewater, DRXTH-TE-CR-84279. USATHAMA, Aberdeen Proving Ground, MD, May 1984. AD-A141 703.

Dieckmann, M. S., K. A. Gray, and P. V. Kamat. "Photocatalyzed Degradation of Adsorbed Nitrophenolic Compounds on Semiconductor Surfaces." Water Sci. Technol 25, no. 3 (1992): 277-9.

Diller, Ralf, Matthias Brandt, Iris Fornefett, Ulrike Siebers, and Detlef Bahnemann. "Photocatalytic Degradation of Trinitrotoluene and Other Nitroaromatic Compounds." Chemosphere 30, no. 12 (1995): 2333-41.

Doyle, Richard C., and Judith F. Kitchens. Composting of Soils/Sediments and Sludges Containing Toxic Organics Including High Energy Explosives, DOE/CH-9208. Argonne National Laboratory, Argonne, IL, July, 1993. Argonne National Laboratory, Argonne, IL 60439.

Dunnivant, Frank M., Rene P. Schwarzenbach, and Donald L. Macalady. "Reduction of Substituted Nitrobenzenes in Aqueous Solutions Containing Natural Organic Matter." Environ. Sci. Technol. 26, no. 11 (1992): 2133-41.

Freeman, Donald J., and Olin A. Colitti. Removal of Explosives From LAP Wastewater (Pink Water) Using Surfactant Technology, 820526050. ARRADCOM, TSD, Dover, NJ, May 1982. AD A115086.

Funk, Stephen B., Deborah J. Roberts, Don L. Crawford, and Ronald L. Crawford. "Initial-Phase Optiminzation for Bioremediation of Munition Compound-Contaminated Soils." Appl. and Environ. Microbiol. 59, no. 7 (1993): 2171-77.

Gray, K. A., U. Stafford, M. S. Dieckmann, and P. Kamat. "Mechanistic Studies in Titanium Dioxide Systems: Photocatalytic Degradation of Chloro- and Nitrophenols." Trace Met. Environ 3, no. Photocatalytic Purification and Treatment of Water and Air (1993): 455-72.

Haderlein, Stefan B., Kenneth W. Weissmahr, and Rene P. Schwarzenbach. "Specific Adsorption of Nitroaromatic Explosives and Pesticides to Clay Minerals." Environ. Sci. Technol. 30, no. 2 (1996): 61222.

Heijman, Comelis G., Erwin Grieder, Shristof Holliger, and Rene P. Schwarzenbach. "Reduction of Nitroaromatic Compounds Coupled to Microbial Iron Reduction in Laboratory Aquifer Columns." Enivron. Sci. Technol. 29, no. 3 (1995): 775-83.

Heilmann, Harro M., Udo Wiesmann, and Michael K. Stenstrom. "Kinetics of the Alkaline Hydrolysis of High Explosives RDX and HMX in Aqueous Solution and Adsorbed on Activated Carbon." Environ. Sci. Technol. 30, no. 5 (1996): 1485-92.

Higdem, Dane. Demonstration of the J. R. Simplot Ex Situ Bioremediation Technology for Treatment of Nitroaromatic Contaminants at the Weldon Spring Ordnance Works Site in Weldon Spring, MO, U.S. Environmental Protection Agency, Cincinnati, OH, March 1994. USEPA. 
Hinshaw, Gary D., Cindy B. Fanska, Douglas E. Fiscus, and Scot A. Sorensen. Granular Activated Carbon (GAC) System Performance Capabilities and Optimization, AMXTH-TE-CR87111. Midwest Research Institute, Kansas City, MO, 27 February 1987. MRI.

Hoffsommer, J. C., L. A. Kaplan, D. J. Glover, D. A. Kubose, C. Dickinson, H Goya, E. G. Kayser, C. L. Groves, and M. E. Sitzmann. Biodegradability of TNT: A Three-Year Pilot Plant Study, NSWC/WOL TR 77-136. Naval Surface Weapons Center, Silver Spring, MD, 13 February 1978. AD A061 144.

Jain, Kamlesh K., and Armond J. Bryce. "Feasibility of Munitions Wastewater Treatment by AdsorptionOxidation." Carbon Adsorption Handbook, Editors Chesemisinoff, and Ellerbush, 661-85.

Jenkins, T. F., Philip G. Thome, and Marianne E. Walsh. Field Screening Method for TNT and RDX in Groundwater, SR94-14. U. S. Army CRREL, Hanover, NH, May 1994. U. S. Army, CRREL.

Jenkins, Thomas F., Richard P. Murnmann, and Daniel C. Leggett. "Mass Spectra of Isomers of Trinitrotoluene." J. Chem. and Eng. Data 18, no. 4 (1973): 438.

Kaake, R. H., D. L. Crawford, and R. L. Crawford. "Optimization of an Anaerobic Bioremediation Process for Soil Contaminated With the Nitroaromatic Herbicide Dinoseb (2-Sec-Butyl-4,6-Dinitrophenol)." Applied Biotechnology for Site Remediation, Editors Robert E. Hinchee, Daniel B. Anderson, and Gregory D. Sayles, 337-41. Boca Raton, FL: Lewis Publishers, 1994.

Kaplan, D. L., and A. M. Kaplan. "Thermophilic Biotransformations of 2,4,6-Trinitrotoluene Under Simulated Composting Conditions." Applied and Environmental Microbiology 44, no. 3 (1982): 757-60.

Kaplan, Lloyd A., Nicholas E. Burlinson, and M. E. Sitzmann. Photochemistry of TNT: Investigation of the Pink Water Problem, Part II, NSWC/WOL/TR 75-152. Naval Surface Weapons Center, Silver Spring, MD, 21 November 1975.

Klausen, Jorg, Serge P. Trober, Stefan B. Haderlein, and Rene P. Schwarzenbach. "Reduction of Substituted Nitrobenzenes by Fe(II) in Aqueous Mineral Suspensions." Environ. Sci. Technol. 29, no. 9 (1995): 2396-404.

Kulkami, Ramchandra K. Pollutant Adsorbent Systems for TNT, RDX, and HMX in Wastewater, TR 8605. US Army Medical Research and Development Command, Frederick, MD, October 1986. AD-A188 407.

Lamson, Davis W., Peter Ulrich, and Robert O. Hutchins. "Aromatic Denitration With Borohydride. Nucleophilic Displacement of Nitrite by Hydride." J. Org. Chem. 38, no. 17 (1973): 2928-30.

Larson, Richard A., Miller Penney L., and Thomas O. Crowley. "Borohydride Photoreduction of Nitroaromatic Compounds Related to Military Ordnance Constituents." Environ. Sci. Technol. 30, no. 4 (1996): 1192-7.

Layne, William S., Richard A. Nicholson, Richard M. Wahl, and Patrick M. O'Brian. Ultraviolet-Ozone Treatment of Pink Water - A Pilot Plant Study, 322. Mason \& Hanger - Silas Mason Co., Inc., Middletown, Iowa, 15 September 1980. Mason \& Hanger - Silas Mason Co., Inc. 
Lichin, Norman N., Junchang Dong, and K. M. Vijayakumar. "Photopromoted Titanium Oxide-Catalyzed Oxidative Decomposition of Organic Pollutants in Water and in the Vapor Phase." Water Pollut. Res. J. Can 27, no. 1 (1992): 203-10.

Lipczynska-Kochany, Eva. "Novel Method for a Photocatalytic Degradation of 4-Nitrophenol in Homogeneous Aqueous Solution." Environmental Technology 12 (1991): 87-92.

Low, G. K. C., S. R. McEvoy, and R. W. Matthews. "Formation of Nitrate and Ammonium Ions in Titanium Dioxide Mediated Photocatalytic Degredation of Organic Compounds Containing Nitrogen Atoms." Environ. Sci. Tech. 25 (1991): 460-467.

Low, Gary K. C., Stephen R. McEvoy, and R. W. Matthews. "Formation of Ammonium and Nitrate Ions From Photocatalytic Oxidation of Ring Nitrogenous Compounds Over Titanium Dioxide." Chemosphere 19, no. 10-11 (1989): 1611-21.

Low, Gary K. C., Stephen R. McEvoy, and Ralph W. Matthews. "Formation of Nitrate and Ammonium Ions in Titanium Dioxide Mediated Photocatalytic Degradation of Organic Compounds Containing Nitrogen Atoms." Environ. Sci. Technol 25, no. 3 (1991): 460-7.

Mabey, W. R., D. Tse, A. Baraze, and T. Mill. "Photolysis of Nitroaromatics in Aquatic Systems. I. 2,4,6Trinitrotoluene." Chemosphere 12, no. 1 (1983): 3-16.

Mahannah, J. L. Survey of Generation and Management of Explosive-Laden Spent Carbon, CETHA-TSCR-92024. Arthur D. Little, Inc., Cambridge, MA, November 1992. AD Little, Inc.

Matthews, R. W., and M. Abdullah. "Safeguarding the Environment: Organic Carbon Analysis in Water." Chem. Australia (1990): 85-89.

Matthews, R. W., M. Abdullah, and G. K. C. Low. "Photocatalytic Oxidation for Total Organic Carbon Analysis." Anal. Chim. Acta 233 (1990): 171-79.

Matthews, Ralph W. "Kinetics of Photocatalytic Oxidation of Organic Solutes Over Titanium Dioxide." J.Catal. 111 (1988): 264-72.

McCormick, N. G., J. H. Cornell, and A. M. Kaplan. "Biodegradation of Hexahydro-1,3,5-Trinitro-1,3,5Triazine." Applied and Environmental Microbiology 42, no. 5 (1981): 817-23.

McCormick, N. G., T. D. Peltonen, and A. M. Kaplan. Development of Design Parameters for an Explosive Contaminated Wastewater Treatment System, WQEC/C 85-297. Naval Weapons Support Center, Crane, IN, June 1985. AD-A159 416.

McCormick, Neil G., Florence E. Feeherry, and Hillel S. Levinson. "Microbial Transformation of 2,4,6Trinitrotoluene and Other Nitroaromatic Compounds." Applied and Environmental Microbiology 31, no. 6 (1976): 949-58.

Miyares, Paul H., and Thomas F. Jenkins. Improved Salting Out Extraction-Preconcentration Method for the Determination of Nitroaromatics and Nitramines in Water, SR91-18. U. S. Army, CRREL, Hanover, NH, October 1991. U. S. Army, CRREL. 
Mondecar, M., J. Bender, J. Ross, W. George, and J. Preslan. "Removal of 2,4,6-Trinitrotoluene From Contaminated Water With Microbial Mats." Applied Biotechnology for Site Remediation, Editors Robert E. Hinchee, Daniel B. Anderson, and Gregory D. Sayles, 342-. Boca Raton, FL: Lewis Publishers, 1994.

Moza, P. N., K. Hustert, S. Pal, and P. Sukul. "Photocatalytic Decomposition of Pendimethalin and Alachlor." Chemosphere 25, no. 11 (1992): 1675-82.

Mueller, Wolfgang R., Glenn W. Bedell, Brian Baker, Saeed Shojaee, and Paul J. Jackson. Bioremediation of TNT Wastes by Higher Plants.

Nay, Marshall W.Jr., Clifford W. Randall, and Paul H. King. "Biological Treatability of Trinitrotoluene Manufacturing Wastewater." Water Pollution Control 46, no. 3 (March 1974): 485-97.

Noss, Charles I., and Ralph H. Chyrek. Tertiary Treatment of Effluent From Holsten AAP Industrial Liquid Waste Treatment Facility IV. Ultraviolet Radiation and Hydrogen Peroxide Studies: TNT, RDX, HMX, TAX, and SEX, TR 8308. Fort Detrick, Frederick, MD, March 1984. AD-A141 135.

Okamoto, Yoshiyuki, and S. T. Attarwala. "Reactions of Trinitrotoluenes With Sodium Borohydride in a Phase Transfer Catalytic System." J. Org. Chem. 44, no. 18 (1979): 3269-71.

Pal, Bimal C., and Michael G. Ryon. Database Assessment of Pollution Control in the Military Explosives and Propellants Production Industry, ORNL-6202. Oak Ridge National Laboratory, Oak Ridge, TN, February 1986. AD-A165 853.

Palmisano, L., V. Augugliaro, M. Schiavello, and A. Sclafani. "Influence of Acid-Base Properties on Photocatalytic and Photochemical Processes." J. Mol. Catalysis 56 (1989): 284-95.

Patil, Sampatrao S., and Vijay M. Shinde. "Biodegradation Studies of Aniline and Nitrobenzene in Aniline Plant Waste Water by Gas Chromatography." ES \& T 22, no. 10 (1988): 1160-1165.

Pelizzetti, E., C. Minero, P. Piccinini, and M. Vincenti. "Phototransformations of Nitrogen Containing Organic Compounds Over Irradiated Semiconductor Metal Oxides. Nitrobenzene and Atrazine Over Titania and Zinc Oxide." Coord. Chem. Rev 125, no. 1-2 (1993): 183-93.

Pereira, W. E., D. L. Short, D. B. Manigold, and P. K. Roscio. "Isolation and Characterization of TNT and Its Metabolites in Groundwater by Gas Chromatograph-Mass Spectrometer-Computer Techniques." Bull. Envrironm. Contam. Toxicol. 21 (1979): 554-62.

Prairie, M. R., L. R. Evans, B. M. Stange, and S. L. Martinez. "An Investigation of TiO2 Photocatalysis for the Treatment of Water Contaminated With Metals and Organic Chemicals." Envir. Sci. Technol. 27, no. 9 (1993): 1776-82.

Roberts, D. J., R. H. Kaake, S. B. Funk, D. L. Crawford, and R. L. Crawford. "Anaerobic Remediation of Dinoseb From Contaminated Soil. An On-Site Demonstration." Applied Biochemistry and Biotechnology 39/40 (1993): 781-89.

Roberts, Deborah J., Farrukh Ahmad, and Suhasini Pendharkar. "Optimization of an Aerobic Polishing Stage to Complete the Anaerobic Treatment of Munitions-Contaminated Soils." Environ. Sci. Technol. 30, no. 6 (1996): 2021-26. 
Ronning, Mathew A., Ronald L. Atkins, and Carl A. Heller. "TNT Photolysis Quantum Yield." J. Photochem. 9 (1973): 403-5.

Roth, Milton, and Joseph M. MurphyJr. Ultraviolet-Ozone and Ultraviolet-Oxidant Treatment of Pink Water, ARLCD-TR-78057. US Army Armament Research and Development Command, Large Caliber Weapon Systems Laboratory, Dover, NJ, Dover, NJ, November, 1978. AD-E400 263.

Schmelling, D. C., and K. A Gray. "Feasibility of Photocatalytic Degradation of TNT As a Single or Integrated Treatment Process." Trace Met. Environ 3, no. Photocatalytic Punification and Treatment of Water and Air (1993): 625-31.

Schmelling, D. C., and K. A. Gray. "Feasibility of Photocatalytic Degradation of TNT As a Single or Integrated Treatment Process ." Photocatalytic Purification and Treatment of Water, Eds. D. Ollis, and H. Al-Ekabi, 625pages. Holland: Elsevier Science Publishers.

Schmelling, Daniel C., and Kimberly A. Gray. "Photocatalytic Transformation and Mineralization of 2,4,6Trinitrotoluene (TNT) in TiO2 Slurries." Water Res. 29, no. 12 (1995): 2651-62.

Schmelling, Daniel C., and Kimberly A. Gray. "Photocatalytic Transformations and Degradation of 2,4,6Trinitrotoluene (TNT) in TiO2 Slurries." Crit. Issues Water Wastewater Treat., Proc. Natl. Conf. Environ. Eng.Joseph N. Ryan, and Marc Edwards, 751-5, New York, NY: American Society of Civil Engineers, 1994.

Schwarzenbach, Rene P., Ruth Stierli, Klaus Lanz, and J. Zeyer. "Quinone and Iron Porphyrin Mediated Reduction of Nitroaromatic Compounds in Homogeneous Aqueous Solution." Environ. Sci. Technol. 24, no. 10 (1990): 1566-74.

Schwarzenbach, Rene P., Ruth Stierli, Klaus Lanz, and Josef Zeyer. "Quinone and Iron Porphyrin Mediated Reduction of Nitroaromatic Compounds in Homogeneous Aqueous Solution." Environ. Sci. Technol. 24, no. 10 (1990): 1566-74.

Sierka, Raymond A. An Ultrasound Catalyzed Ozone Oxidation Process Feasibility Study for the Destruction of TNT and Other Explosives in Aqueous Solution, DRXTH-TE-CR-82175. USATHAMA, Aberdeen Proving Ground, MD, October 1982. AD A124 989.

Simmons, Milagros S., and Richard G. Zepp. "Influence of Humic Substances on Photolysis of Nitroaromatic Compounds in Aqueous Systems." Wat. Res. 20, no. 7 (1986): 899-904.

Smith, John G. Water Quality Criteria for Nitroglycerin, DE86 013971. Oak Ridge National Laboratory, Oak Ridge, TN, July 1986. ORNL.

Smith, L. L., J. Carrazza, and K. Wong. "Biological Treatment for Waste Streams From Propellants and Explosives." J. Hazardous Materials 5 (1982): 277-96.

Smith, L. L., J. Carrazza, and K. Wong. "Treatment of Wastewaters Containing Propellants and Explosives." J. Hazardous Materials 7 (1983): 303-16.

Stahl, J. D., and S. D. Aust. "Metabolism and Detoxification of TNT by Phanerochaete Chrysosporium." Biochem. and Biophys. Res. Comm. 192, no. 2 (1993): 477-82. 
Stevens, Todd O., Ronald L. Crawford, and Donald L. Crawford. "Selection and Isolation of Bacteria Capable of Degrading Dinoseb (2-Sec-Butyl-4,6-Dinitrophenol)." Biodegradation 2 (1991): 1-13.

Suhnel, J., and K. Gustav. "Theory of Proton-Transfer Reactions. On the Solvent Dependence of the Kinetic Isotope Effect." Chem. Phys. 33 (1984): 391-97.

T-Raissi, A., and N. Z. Muradov. "Flow Reactor Studies of Titanium Dioxide Photocatalytic Treatment of Airborne Nitroglycerin." Trace Met. Environ 3, no. Photocatalytic Purification and Treatment of Water and Air (1993): 435-54.

Triegel, Elly K., Joseph R. Kolmer, and Douglas W. Ouanian. Solidification and Thermal Degradation of TNT Waste Sludges Using Asphalt Encapsulation, EPA/6007D-86/195. US Environmental Protection Agency, Cincinnati, OH, August 1986. NTIS.

Tsang, Wing, and John T. Herron. "Chemical Kinetic Data Base for Propellant Combustion. 1. Reactions Involving NO, $\mathrm{NO}_{2}, \mathrm{HNO}_{2}, \mathrm{HCN}$, and $\mathrm{N}_{2} \mathrm{O}$." J. Phys. Chem. Ref. Data 20, no. 4 (1991): 609.

Wade, Robert C. "Catalyzed Reductions of Organofunctional Groups With Sodium Borohydride." J. Mol. Catal. 18 (1983): 273-97.

Walker, John E., and David L. Kaplan. "Biological Degradation of Explosives and Chemical Agents." Biodegradation 3 (1992): 369-85.

Walsh, Marianne E. Environmental Transformation and Products of Nitroaromatics and Nitramines. Literature Review and Recommendations for Analytical Method Development, SR90-2. U. S. Army Cold Regions Research and Engineering Laboratory, Hanover, NH, February, 1990. U. S. Army, CRREL.

Wang, Zhikai, and Charles Kutal. "Photocatalytic Mineralization of 2,4,6-Trinitrotoluene in Aqueous Suspensions of Titanium Dioxide." Chemosphere 30, no. 6 (1995): 1125-36.

Wentz, John A., John E. Spessard, Judy Hessling, and Mike Mahannah Janet Resch. Technology Evaluation for Treatment of Red Water, 92-01435. USATHAMA, Aberdeen Proving Ground, MD, April 1990. ADA244 873.

Wirth, Peter K. Explosives Waste Disposal Sites: A DOD-Wide Problem. Case Study: Milan Army Ammunition Plant O-Line Settling Ponds, USATHAMA, Aberdeen Proving Ground, MD, August 1984. AD-P004 854.

Woodward, Richard E. Evaluation of Composting Implementation: A Literature Review, TCN 89363. USATHAMA, Aberdeen Proving Ground, MD, July 1990. AD-A243 908.

Yinon, Jehuda, and Shmuel Zitrin. Modern Methods and Applications in Analysis of Explosives. New York, NY: John Wiley \& Sons, 1993. 


\section{REPORT DOCUMENTATION PAGE}

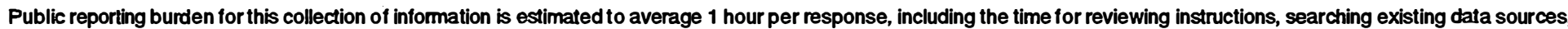

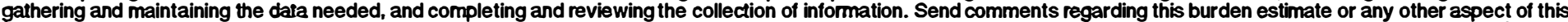

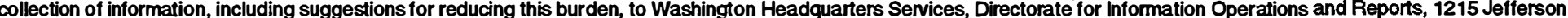

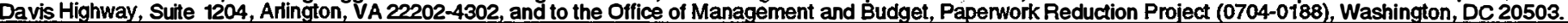

\begin{tabular}{|l|l|l}
\hline $\begin{array}{l}\text { 1. AGENCY USE ONLY (Leave } \\
\text { blank) }\end{array}$ & $\begin{array}{c}\text { 2. REPORT DATE } \\
\text { October 1996 }\end{array}$ & $\begin{array}{l}\text { 3. REPORT TYPE AND DATES COVERED } \\
\text { Technical Report }\end{array}$ \\
\hline
\end{tabular}

4. TITLE AND SUBTITLE

Photocatalytic Oxidation and Reduction Chemistry and a New Process for Treatment of Pink Water and Related Contaminated Water

5. FUNDING NUMBERS

task \# SI61.3610

6. AUTHOR(S)

Daniel M. Blake, Edward Wolfrum, and James Boulter, NREL

Michael Prairie, Steven Showalter, Philip Rodacy, Pam Leslie, and Bertha Stange. Sandia

7. PERFORMING ORGANIZATION NAME(S) AND ADDRESS(ES)

National Renewable Energy Laboratory, 1617 Cole. Boulevard, Golden, Colorado 80401

Sandia National Laboratories, Albuquerque, New Mexico

8. PERFORMING

ORGANIZATION REPORT

NUMBER DE96013073

9. SPONSORING/MONITORING AGENCY NAME(S) AND ADDRESS(ES)

10.

SPONSORING/MONITORING

AGENCY REPORT NUMBER

1617 Cole Boulevard

Golden, Colorado 80401

NREUTP-430-21580

\section{SUPPLEMENTARY NOTES}

\section{2a. DISTRIBUTION/AVAILABILITY STATEMENT}

National Technical Information Service

U.S. Department of Commerce

5285 Port Royal Road

Springfield, VA 22161 12b. DISTRIBUTION CODE

UC Category: 1414

13. ABSTRACT (Maximum 200 words) Photocatalytic treatment of pink water under oxidative conditions can mineralize TNT, HMX, and RDX but requires long residence times and a large power consumption. Photocatalytic treatment under reducing conditions, using EDTA, citric acid, glucose, and sodium formate, converts TNT to other substances. Power costs are significantly less than for the oxidative process. Biological treatment using Phanerochaete crysosporium following EDTA reduction of pink water partially mineralized TNT. The degree of conversion of carbon to $\mathrm{CO}_{2}$ depended on the duration of the photocatalytic pretreatment. Six hours of pretreatment produced $32 \%$ mineralization. This innovative new process for treating pink water is an effective method for reducing the level of TNT below the detection limit of $20 \mathrm{ppb}$. HMX and RDX are removed at a somewhat lower rate. Parties interested in learning more about this process may contact the authors of this report at NREL. Annual operating costs are estimated at $\$ 179,000$ for a $150 \mathrm{gpm}$ flow of pink water. The currently used carbon adsorption process costs $\$ 323,500$. Capital costs are believed to be similar for both processes.

\section{SUBJECT TERMS}

Pink water TNT HMX RDX Phanerochaete crysosporium Photocatalytic reduction
18. SECURITY CLASSIFICATION

OF THIS PAGE
19. SECURITY CLASSIFICATION OF ABSTRACT
15. NUMBER OF PAGES

16. PRICE CODE

20. LIMITATION OF ABSTRACT 